Portland State University

PDXScholar

Summer 8-6-2019

\title{
The Fate of Atmospherically Deposited Mercury in Mountain Lake Food Webs, and Implications for Fisheries Management
}

Ariana Martos Chiapella

Portland State University

Follow this and additional works at: https://pdxscholar.library.pdx.edu/open_access_etds

Part of the Environmental Sciences Commons, and the Terrestrial and Aquatic Ecology Commons Let us know how access to this document benefits you.

\section{Recommended Citation}

Chiapella, Ariana Martos, "The Fate of Atmospherically Deposited Mercury in Mountain Lake Food Webs, and Implications for Fisheries Management" (2019). Dissertations and Theses. Paper 5091.

https://doi.org/10.15760/etd.6967

This Dissertation is brought to you for free and open access. It has been accepted for inclusion in Dissertations and Theses by an authorized administrator of PDXScholar. Please contact us if we can make this document more accessible: pdxscholar@pdx.edu. 
The Fate of Atmospherically Deposited Mercury in Mountain Lake Food Webs, and Implications for Fisheries Management

\author{
by \\ Ariana Martos Chiapella \\ requirements for the degree of \\ Doctor of Philosophy \\ in \\ Earth, Environment and Society \\ Dissertation Committee: \\ Angela L. Strecker, Chair \\ Jennifer Allen \\ Collin Eagles-Smith \\ Elise Granek \\ Max Nielsen-Pincus \\ Yangdong Pan
}

A dissertation submitted in partial fulfillment of the

Portland State University

2019 


\begin{abstract}
Mountain lakes are an iconic feature of the landscape in the Mountain West. They hold significant ecological and cultural value, and are important sentinels of environmental change. Despite their pristine image, these remote waterbodies are subjected to numerous anthropogenic stressors. Mountain lakes are naturally fishless systems, but historical fish stocking has led to major changes in mountain lake food web structure, including declines of resident amphibians, large-bodied zooplankton, and emergent insect populations. Atmospherically deposited contaminants, such as mercury, can accumulate in mountain lake food webs, leading to relatively high levels in the fish relative to the water. Managing for these stressors is difficult, because although fish stocking causes ecological problems, and mercury bioaccumulation poses human health risks, the cultural value of angling remains important.

The goal of this dissertation was to better understand the issues of fish stocking and mercury bioaccumulation in a socioecological context: from the importance of trophic dynamics for mercury bioaccumulation in mountain lake fish, to the implications fish stocking and mercury bioaccumulation for mountain lake management. In Chapter 2, I identified the ecological, limnological, and landscape-level indicators of mercury bioaccumulation in mountain lake food webs in order to inform better ecosystem management. In Chapter 3, I conducted an experiment to test if fatty acid stable isotopes can partition benthic and terrestrial prey sources in fish in a simplified mountain lake food web, in hopes of providing a more informative tool for future food web studies. In Chapter 4, I used intercept surveys to determine the public perceptions of mountain lake
\end{abstract}


fisheries management in two national parks, and assess the risk mercury may pose to mountain lake anglers by determining fish consumption habits.

I determined that nearshore forest cover and fish diet were the best predictors of mercury concentrations in mountain lake fish, but that our understanding of the role of terrestrial prey subsidies for fish is constrained by limitations in current diet tracing methods. My experiment demonstrates that using stable isotopes of fatty acids is a promising approach to distinguishing between benthic and terrestrial diet sources, but that doing so effectively requires an in-depth understanding of physiological context specific to the ecosystem of interest. Lastly, through my surveys, I found that thousands of anglers regularly consume fish from mountain lakes, and that while most visitors have concerns about the ecological impacts of fish stocking, anglers support a conservationbased approach that balances ecological health with the cultural value of fish stocking.

This dissertation provides a unique set of tools that advance our understanding of food web dynamics and mercury bioaccumulation in mountain lakes, as well as the social value of these ecosystems. My results suggest that the most effective way to protect the health of mountain lakes and their visitors will be for managing agencies to collaborate with scientists and angling groups when making fisheries management decisions, and to invest in outreach about both the ecological and toxicological implications of fish stocking and mercury bioaccumulation in mountain lakes. The use of such socioecological research approaches is becoming progressively more important, as the threats of climate change and unstable regulatory protections for mountain ecosystems increase. 


\section{Acknowledgements}

This work would not have been possible without incredible amounts of support from my academic community, family, and friends. I would first like to thank my advisor, Dr. Angela Strecker, for her ongoing support and mentorship, and contributions to the development, funding, implementation, writing, and publishing of my research. Thank you to my committee: Dr. Max Nielsen Pincus for his contributions and support in publishing my first manuscript; Dr. Collin Eagles-Smith for providing generous research and analysis support, mentorship, and valuable advice and contributions to the preparation of my second manuscript; and to Dr. Yangdong Pan, Dr. Elise Granek, and Dr. Jennifer Allen for their ongoing support and feedback. I would also like to thank Dr. Martin Kainz, who has essentially been an honorary committee member and has been very generous with his time, mentorship, and collaboration.

I would like to thank many others who have supported this research in a variety of ways. Thank you to my former and current lab mates, and fellow PSU students who have provided helpful conversation and insight, both with research and with the emotional demands of graduate school: Meredith Holgerson, Tim Elder, Zbigniew Grabowski, Amelia Johnson, Joey Peters, Sam Cimino, Meredith Jordan, Jeff Brittain, Crysta Gantz, Brian McGann, Lara Jansen, and Taylor Dodrill. Thanks also to Mary Ann Rozance, Ashlie Denton, and Manar Alattar for interdisciplinary engagement. Thank you to my field assistants Elyse Cogburn and Alec Trusty for their excellent attitudes and willingness to hike incredible distances with absurd amounts of weight on their backs, and to lab support from Kendra Lynn and the students from Camas High School. Thanks to Regina Rochefort, Ashley Rawhouser, Carmen Welch, Hugh Anthony, Rebecca 
Lofgren, Shannon Hagen, Steve Fradkin, and Adam Pfleeger at the National Parks Service who provided advice, field assistance, and data that made my fieldwork possible, and to the North Cascades field and trail crews for data collection and backcountry support. Thank you to James Willacker, John Pierce, Colleen Emery, Caitlin Rumrill, and Erica Johnson at USGS for their lab support. My work in Austria would not have been possible without research support and a welcoming community from Kathi Winter, Steffi Danner, Marina Jecmenica, Masumi Stadler, Fen Guo, Serena Rasconi, Mirjiam Jehele, Hannes Hagler, and Mike Meyer. I would also like to thank Gene Foster, Elena Nilsen, Jules Blais, and Joe Rasmussen for their advice and insight during the early stages of my project development, and to Jake Vander Zanden for sharing his code for the lake primary productivity models.

My friends and family near and far provided invaluable emotional support throughout my degree. Thank you to my mom, Jennifer Chiapella, and my dad, Chris Chiapella, for sharing their love of the outdoors with me from a young age and inspiring me to pursue this path, and for the support that made it possible to make it this far. Thank you to the strong and resilient female role models in my family: my mom, my grandmothers Linda Rogers and Jacqueline Chiapella, and my aunts Julia Chiapella, Marie Chavis, and Delia Windwalker. Thank you to my in-laws, Kathy and Mark Blanchard, for their support. And thank you to my grandfather, Steven Chiapella, whom I wish I could share this work with. Thanks to my Portland community for helping me maintain balance and always lending an ear, especially John Perkins, Robyn Wardell, Carly and Leah Harrison, Vanessa and Alex Dolle, Sara Miller, and Meredith McEntee. Thank you to Lyndsay 
Brown, Kylie DiLiberto, Dana Johnson, and Shauna Landrey for providing support from afar.

Perhaps most profoundly, thank you to my husband, Patrick Blanchard, for his support, patience, encouragement, flexibility, unwavering positive attitude, and love throughout my time in this program. I could not imagine doing any of this without you.

Research funding for this dissertation was provided by the NSF GRPF (grant \# 1638278), NSF IGERT (grant \#0966376: "Sustaining Ecosystem Services to Support Rapidly Urbanizing Regions), the North Coast and Cascades Science Learning Network, NSF GROW and the Austrian Science Fund (FWF), IGERT comparative funding, the Edward and Olive Bushby Scholarship Fund, Mazamas, and Sigma Xi. Any opinions, findings, and conclusions or recommendations expressed in this material are those of the authors and do not necessarily reflect the views of the National Science Foundation. 


\section{Table of Contents}

Abstract i

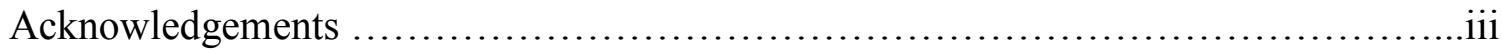

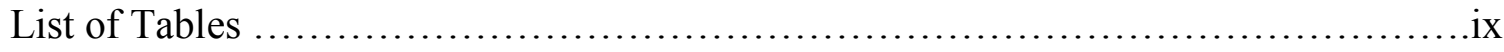

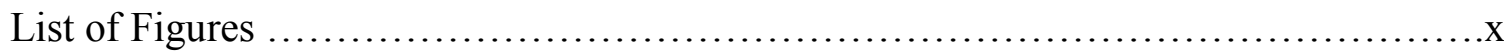

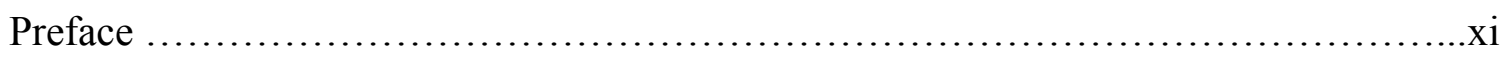

Chapter 1:

Fish stocking and mercury bioaccumulation in mountain lakes .......................

1.1 Mountain lakes ..................................................................

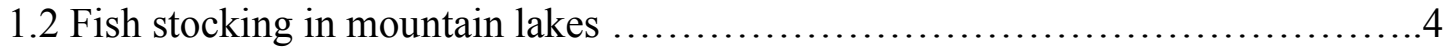

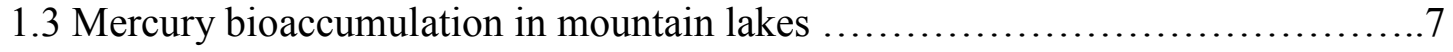

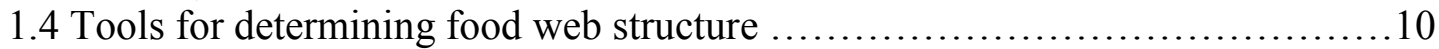

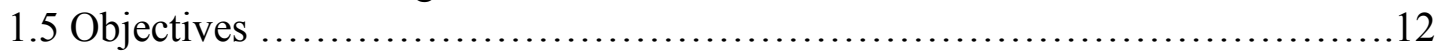

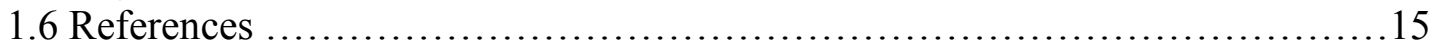

Chapter 2:

From forests to fish: Mercury in mountain lake food webs influenced by factors at

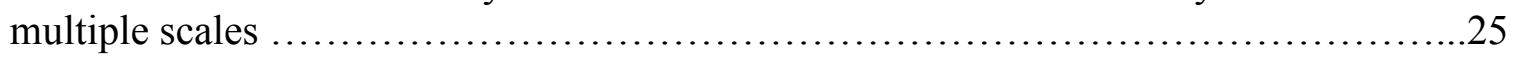

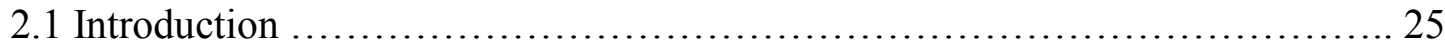

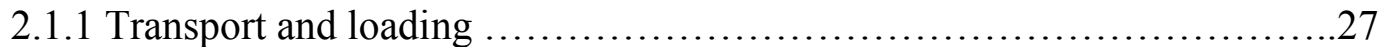

2.1.2 Biogeochemistry and morphometry ................................27

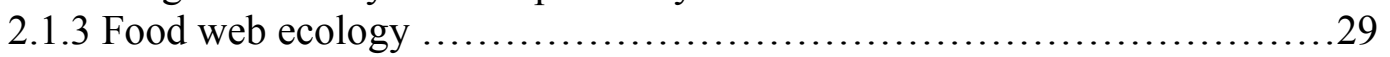

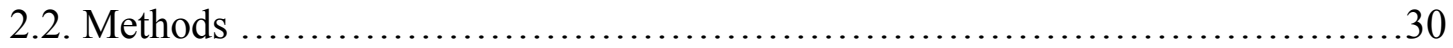

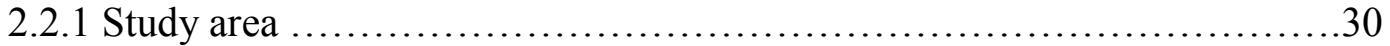

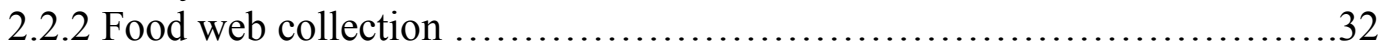

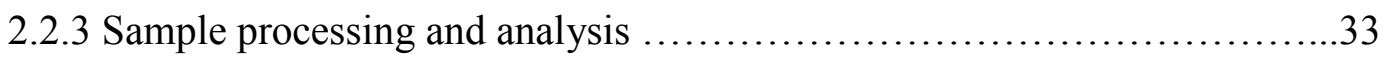

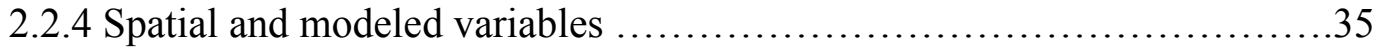

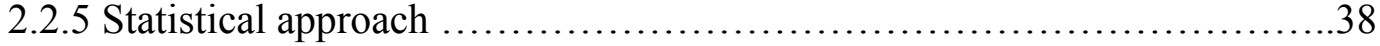

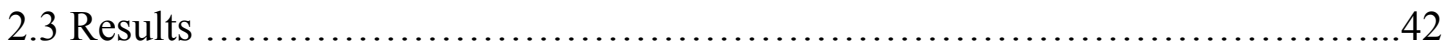

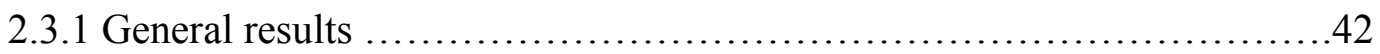

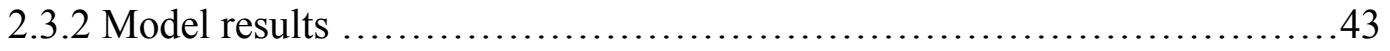

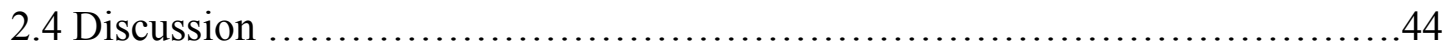

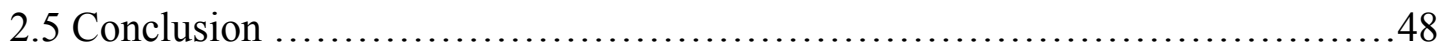

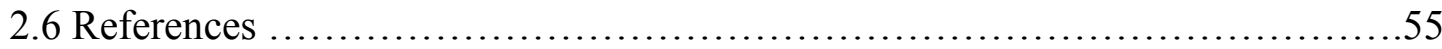


Chapter 3

Can fatty acid stable isotopes overcome the diet-tracing challenges of bulk stable isotope

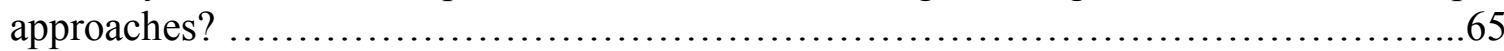

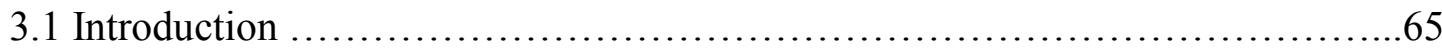

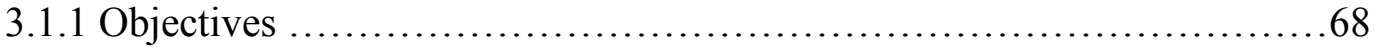

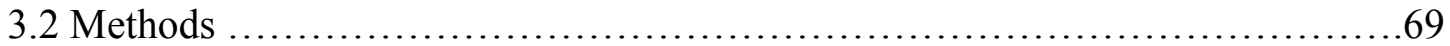

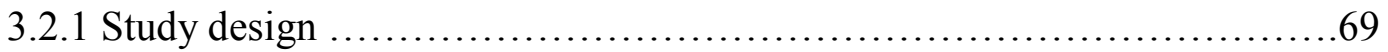

3.2.2 Sample processing and analysis .................................... 71

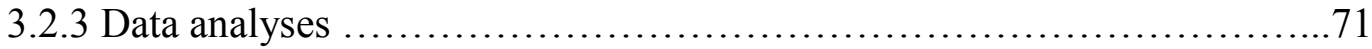

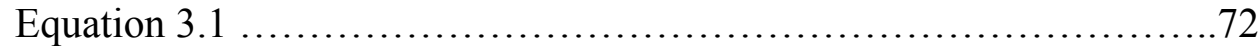

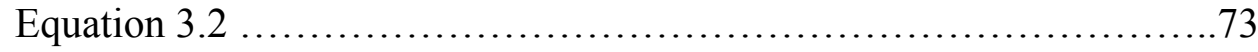

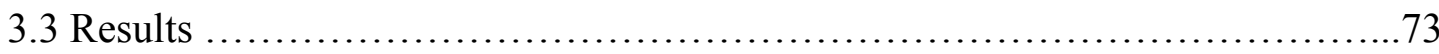

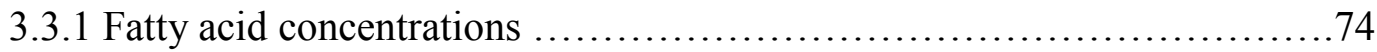

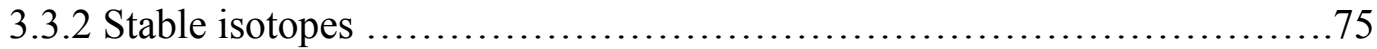

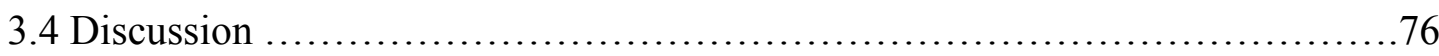

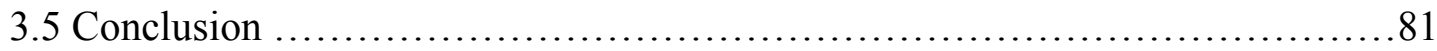

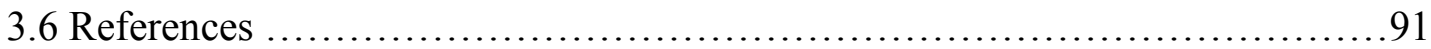

Chapter 4

Public perceptions of mountain lake fisheries management in national parks ...........96

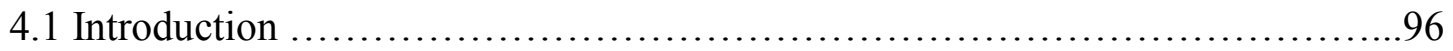

4.1 .1 Objectives ..................................................... 100

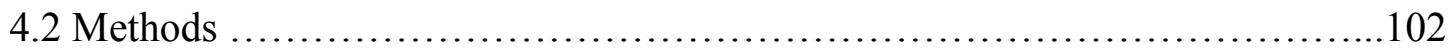

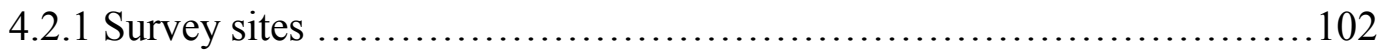

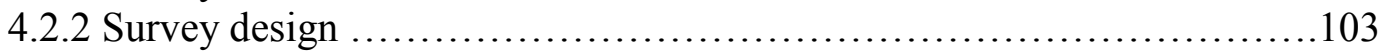

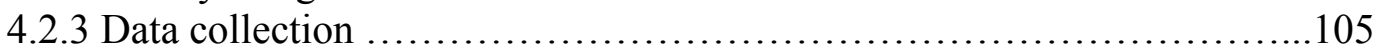

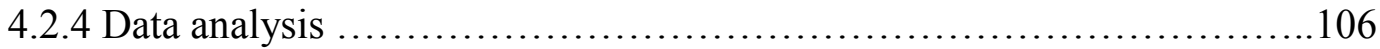

4.2.5 Visitor attitudes toward fisheries management ..........................107

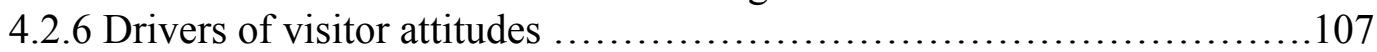

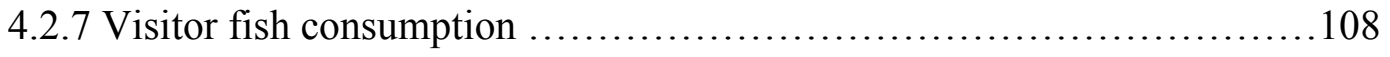

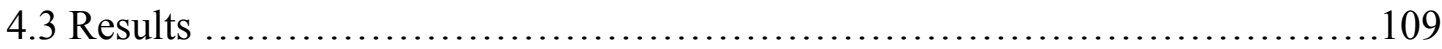

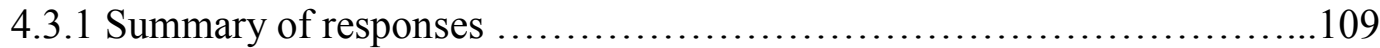

4.3.2 Visitor attitudes toward fisheries management approaches ................109

4.3.3 Drivers of visitor attitudes ............................................ 110

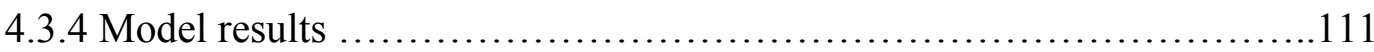

4.3.5 Visitor fish consumption ......................................... 114

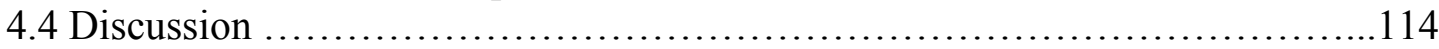


4.4.1 Visitor attitudes toward fisheries management approaches .............. 115

4.4.2 Drivers of management attitudes .....................................116

4.4.3 Contaminant precautions ........................................... 118

4.4.4 A balanced participatory approach ................................. 119

4.4.5 Bias and caveats ................................................... 121

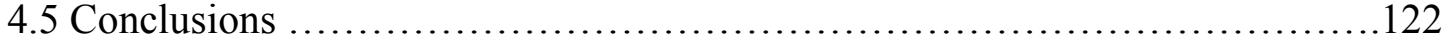

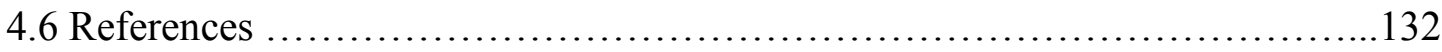

Chapter 5

Conclusions

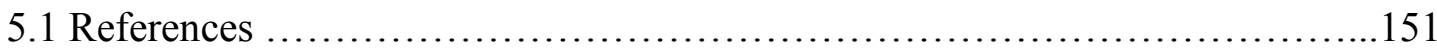

Appendix A

Supporting tables and figures for Chapter 2

Appendix B

Supporting tables and figures for Chapter 3

Appendix C

Supporting tables and figures for Chapter 4

\section{Appendix D}

Institutional Review Board approval

Appendix E

Institutional Animal Care and Use Committee (IACUC) permit 


\section{List of Tables}

\section{Chapter 2}

Table 2.1 Summary of measured and modeled environmental variables for all lakes

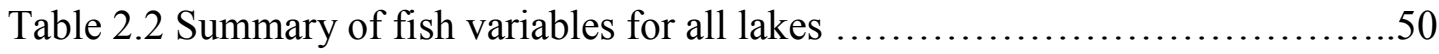

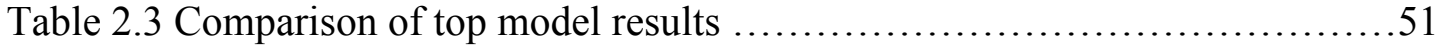

\section{Chapter 3}

Table $3.1 t$-statistics from the post-hoc test for LSM differences in fatty acid concentrations between treatments in fish muscle and liver ......................82

Table 3.2 Concentration factors of each EFA for fish muscle and liver ..............83

Table 3.3 EFA $\Delta \delta^{13} \mathrm{C}$ for each diet treatment in fish muscle and fish liver ...........84

Table $3.4 t$-statistics from the post-hoc test for LSM differences in fatty acid and bulk $\delta^{13} \mathrm{C}$ between treatments in fish muscle and liver

\section{Chapter 4}

Table 4.1 Sections from Part 2 of the survey, including the questions asked, list of rankings, and scale used

Table 4.2 Demographic, group membership, stocking knowledge, and angling participation data for survey respondents

Table 4.3 Factors and factor loadings of mountain lakes fisheries management attitude statements

Table 4.4 Factors and factor loadings for beliefs related to NP waterbody importance

Table 4.5 Logistic regression model results for predicting positive attitudes toward three mountain lake fisheries management approaches 


\section{List of Figures}

Chapter 1

Figure 1.1 Contrasting simplified mountain lake food webs with and without fish ....3

Figure 1.2 Conceptual diagram depicting how each of the three research chapters

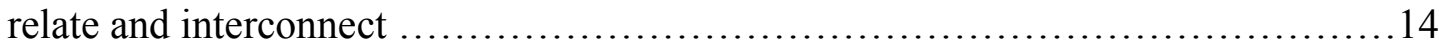

\section{Chapter 2}

Figure 2.1. Wet weight $\mathrm{Hg}$ in fish, by park and by species, compared to consumption

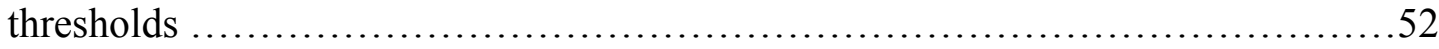

Figure 2.2. Boxplot of average invertebrate $\mathrm{MeHg}$ concentrations (DW ng/g) in each

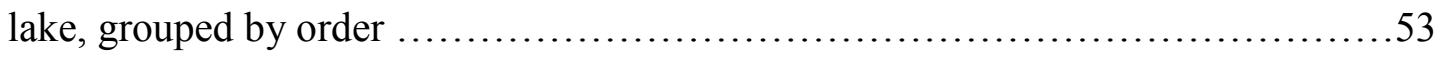

Figure 2.3. 3-D scatterplot of top model variables ..........................54

\section{Chapter 3}

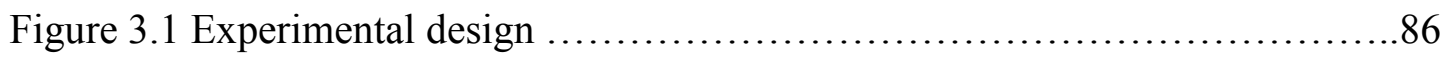

Figure 3.2 Profiles of major fatty acid groups and EFAs in diets and respective treatments in fish liver and muscle, as illustrated by PCA ......................87

Figure 3.3 Mean EFA- $\delta^{13} \mathrm{C}$ in fish liver and muscle and diets .....................88

Figure 3.4 Box and whisker plots of mean bulk $\delta^{13} \mathrm{C}$ in diets and diet treatments ...90

Figure 3.5 Illustration of bioconversion of EPA in diets to DHA in fish tissues ......89

\section{Chapter 4}

Figure 4.1 Survey responses for each mountain lake fish management statement ...130

Figure 4.2 Annual fish consumption frequency of angler respondents 


\section{Preface}

Chapter 4 has been published in the Journal of Environmental Management (DOI: https://doi.org/10.1016/j.jenvman.2018.08.040), and Chapters 2 and 3 will also be submitted for publication as individual manuscripts. Therefore, some repetition of introductory information exists. References are cited at the end of each chapter. 


\section{Chapter 1}

\section{Fish stocking and mercury bioaccumulation in mountain lakes}

Aquatic food web structure and the flow of energy through and across trophic levels are concepts ecologists have been striving to comprehend for decades, and are important measures of ecosystem function (Lindeman 1942, Schindler et al. 2004). Since the seminal work by Lindeman (1942), tracing food web dynamics and species interactions is an effort that is central to the field of ecology. The processes that regulate energy transfer through food webs are complex, but untangling these processes has important implications for the advancement of ecological theory (e.g., Paine 1980). Understanding energy flow and trophic interactions is also important for determining how ecosystems are affected by anthropogenic stressors, such as species introductions, climate change, and atmospheric deposition of contaminants (Vander Zanden et al. 1999, Kallenborn 2006, Schindler 2009). By evaluating how anthropogenic stressors affect aquatic systems, the fate of both ecosystem health and human health may be determined. The interactions of trophic dynamics and anthropogenic stressors and the resulting implications for ecosystem management are central themes in this dissertation, and I explore them in the context of mountain lakes.

\subsection{Mountain lakes}

I define mountain lakes as typically oligotrophic waterbodies situated in high forest, subalpine, or alpine mountain ecosystems with geologic barriers to upstream fish passage and hydrological dependence primarily on atmospheric precipitation and/or glaciers. 
Mountain lakes are an excellent template for studying trophic dynamics; their food webs are less complex relative to lakes in downstream ecosystems, and therefore their response to stressors can be easier to quantify. Additionally, the response of mountain lake food webs to stressors can be an early indicator of how more complex systems may be affected (Catalan et al. 2013, Moser et al. 2019). A lake's response to stress often manifests in its food web, and understanding this stress response is important for informing management of mountain lake ecosystems - namely whether or not to remove stocked fish.

The simple food web structure of mountain lakes (Figure 1.1) provides for an optimal study system, often with fewer confounding variables than their downstream counterparts. These ecosystems are the lifelines of ecosystems downstream. Mountain lakes are an important headwater resource, because their relatively undeveloped watersheds serve as important protection for water quality and crucial climate refugia for cold water organisms (Isaak et al. 2016). Mountain lakes and their surrounding ecosystems are also valuable recreation destinations; many are situated in protected natural areas, and are thus actively managed by public agencies.

Two common stressors of mountain lake ecosystems include stocking trout and atmospheric contaminant deposition. These two stressors interact because stocked trout accumulate atmospherically deposited contaminants. However, the mechanisms influencing how much of a contaminant accumulates in fish are not well understood, and likely pose risks both to lake ecology, as well as humans and wildlife who consume fish from these systems. Although there has been a large effort to characterize the levels of contaminants in mountain ecosystems (Schindler et al. 1995, Blais et al. 2006, Moran et 
al. 2007, Ackerman et al. 2008, Landers et al. 2008, Bizzotto et al. 2009), there remain many questions about how persistent contaminants are taken up into and move through the food web.

(a)

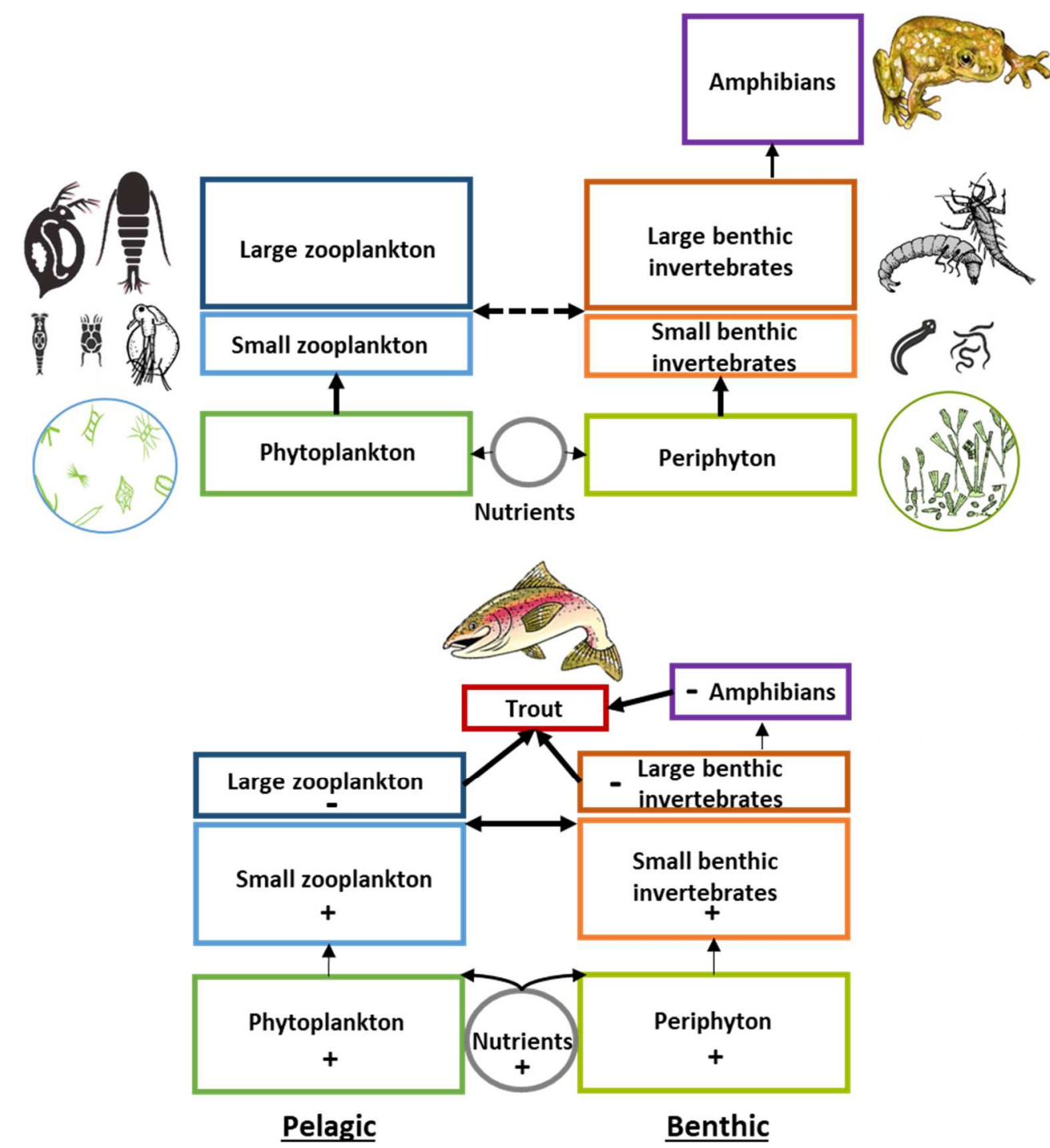

Figure 1.1 Contrasting simplified mountain lake food webs: without fish (a) and with fish (b). Size of each box represents biomass, and thickness of arrows represents strength of interaction. In the fishless food web (a), primary producer biomass is low due to low 
nutrient concentrations; dominant invertebrates include large zooplankton that effectively graze algae (e.g., Daphnia, Hesperodiaptomus) and large conspicuous benthic invertebrates (e.g., caddisflies, mayflies, chironomids).There is distinct segregation between pelagic and benthic habitats; the dotted horizontal line between pelagic (open water) and benthic (lake bottom) food webs indicates low habitat coupling. Emergent insects supply food to amphibians. In the fish-stocked food web (b), there is substantial loss of large-bodied invertebrate prey biomass: macroscopic invertebrates are prey targets for fish. Trout both prey upon and compete with amphibians for their food. Primary productivity increases, and habitat coupling strengthens due to P-cycling by fish, indicated by the solid horizontal line between pelagic and benthic food webs. Small, disturbance-resistant invertebrate taxa that are less effective grazers become the dominant food web constituents.

\subsection{Fish stocking in mountain lakes}

Stocking fishless mountain lakes has been practiced for well over a century as a means of drawing people to natural areas, and to foster a conservation ethic among the public (Knapp et al. 2001a). However, recent research has shown that there can be severe ecological consequences of stocking these historically fishless lakes (usually with different species of trout) (Knapp et al. 2001b, Larson and Hoffman 2002, Sarnelle and Knapp 2004, Finlay and Vredenburg 2007, Epanchin et al. 2010; Figure 1.1). For example, mountain lakes with reproducing populations of fish often experience a loss of large-bodied zooplankton and benthic invertebrates due to predation, resulting in a 
notable increase in small zooplankton and benthic invertebrates and higher algal biomass due to reduced grazing pressure (Knapp et al. 2001b, Schindler et al. 2001). Additionally, fish change the cycling of nutrients, which can lead to increased primary production in mountain lakes (Schindler et al. 2001). Another notable effect of fish stocking is decreased populations, or even extirpation, of amphibians, such as the mountain yellowlegged frog (Rana muscosa) in the Sierra Nevada Mountains, CA (Knapp et al. 2000), and the Northwestern salamander (Ambystoma gracile) in the Cascade Mountains, WA (Larson and Hoffman 2002).

While the effects of trout introductions on native ecosystems have become increasingly clear, the cultural importance of fish in mountain lakes has made their management a complex issue. Many fish-stocked mountain lakes are located in federally protected wilderness areas, but vague policy language in the Wilderness Act has led to differences in mountain lake fisheries management practices across US federal land management and regulatory agencies (e.g., US Forest Service, Bureau of Land Management, National Parks Service, and US Fish and Wildlife Service) (Landres et al., 2001). For example, trout stocking is still common in many mountain lakes managed by the US Forest Service and Bureau of Land Management, but the practice is at odds with National Park Service policies in the western US (Landres et al., 2001; Pister, 2001). At present, the National Parks Service has largely terminated mountain lake stocking programs in the western US (Landres et al., 2001)

Thus, stocking programs on public lands with strict protections (e.g., national parks, wilderness areas) have generally been stopped, and in some cases, management 
has refocused on fish removal. However, individual national parks approach fisheries management differently. For example, Mount Rainier National Park has mainly used manual methods to remove fish (e.g., gill nets), and only experimentally from a few lakes, while other parks in the western US have used, or are considering, chemical removal techniques. North Cascades National Park has used the plant-based piscicide rotenone, in conjunction with gill nets, to remove stocked fish from some mountain lakes. In response, fishing groups lobbied against this decision, and in 2016, the Washington Department of Fish and Wildlife began re-stocking select mountain lakes in North Cascades National Park with species native to downstream waters as a result of the North Cascades National Park Service Complex Fish Stocking Act of 2014. In California's Sierra Nevada Mountains, fish eradication efforts have been kept confidential by management agencies, as to avoid gill net vandalism and re-stocking of lakes by anglers (Halverson 2011). Controversies like these leave park managers with difficult decisions, which require weighing the social benefits of stocking with the ecological consequences (e.g., National Parks Service 2007).

Decisions around how to manage mountain lake fisheries are made more complicated as there is also increasing evidence of contaminant accumulation in fish from mountain lakes (e.g., Landers et al. 2008). If recreational fishing poses a threat to human health, this may also affect if and where agencies decide to stock or remove fish. Successful management of mountain lake fisheries will thus depend on a better understanding of how visitors to mountain lakes perceive the issue of fish stocking, how 
they value mountain lakes, and what the level of contaminant exposure risk to anglers might be.

\subsection{Mercury bioaccumulation in mountain lakes}

Mercury is abundant and persistent in the environment. Although it is naturally released in small amounts from geologic deposits (such as in cinnabar and coal ore), atmospheric concentrations of mercury have increased substantially since the industrial revolution (Mason 1994, Driscoll et al. 2013). Coal combustion for electricity production and industrial activity is the most prominent source of anthropogenic mercury to the atmosphere (Eagles-Smith et al. 2016a). Releases from active and historical cinnabar and gold mining also contribute mercury directly to ecosystems locally (Boening 2000, Alpers et al. 2005). Anthropogenic mercury is typically released into the environment in its gaseous elemental form $\left(\mathrm{Hg}_{0}\right)$, however, mercury cycles between different chemical species, depending on its environment (atmospheric, oceanic, freshwater) (Morel et al. 1998). The ability of mercury to form different chemical species means that it can be transported globally and accumulate in aquatic ecosystems (Mason et al. 1994, Morel et al. 1998, Boening 2000).

Mercury is deposited onto high-elevation landscapes as a result of the cold condensation effect (Fitzgerald et al. 1998). It then accumulates in sediments, snowpack, and glacial ice, resulting in a springtime pulse to lakes (Landers et al. 2008, Schartup et al. 2015). Once in the lake, mercury can be methylated $\left(\mathrm{Hg} \rightarrow \mathrm{CH}_{3} \mathrm{Hg}\right)$ to its bioavailable form, methylmercury (MeHg); $\mathrm{MeHg}$ can then dissolve in the water column or bind to 
organic carbon (Ullrich et al. 2001). Because of the organic methyl group, MeHg has lipophilic and protein-binding properties, which means it easily accumulates in the tissues of organisms - i.e., bioaccumulates (Ullrich et al. 2001). MeHg accumulates in the base of the lake food web via absorption from the water column, as well as interaction with its particulate form (Driscoll et al. 1995). MeHg then biomagnifies up the food web, resulting in concentrations in fish that can be more than $10^{7}$ times higher than concentrations in the water (Wiener et al. 2003). Methylmercury (MeHg) bioaccumulation in aquatic ecosystems is a concern because it is a neurotoxin and can have immunosuppressive effects on humans and wildlife (e.g., Clarkson and Magos 2006, Scheuhammer and Sandheinrich 2008).

Mercury methylation and bioaccumulation are complex processes driven by many different abiotic and biotic factors. In mountain lakes, catchment vegetation, water chemistry, catchment morphometry, and food web processes are likely important in determining the extent of mercury bioaccumulation in the food web. There is an increasing body of evidence that forest cover, and specifically conifer density, can be an important predictor of mercury bioaccumulation in mountain lakes, possibly because of conifers' ability to adsorb mercury from the atmosphere and how litter fall might affect water chemistry (Graydon et al. 2008, Drenner et al. 2013, Eagles-Smith et al. 2016b). Dissolved organic carbon (DOC) is an important, yet complex variable that can bind to Hg so that it doesn't methylate, or bind to MeHg and render it unavailable for biotic uptake. Conversely, it can also inhibit photodemethylation by decreasing water clarity (Ravichandran 2004, Klapstein and O'Driscoll 2018). Mercury methylation also tends to 
be closely related to redox conditions, with high methylation often occurring in low $\mathrm{pH}$ and low oxygen environments (e.g., Gilmour and Henry 1991, Clayden et al. 2013). However, it is likely rare that mountain lakes experience the conditions necessary to promote high rates of methylation because productivity and water temperature are relatively low, dissolved oxygen is usually relatively high, and many lakes may not even stratify because they are shallow. Morphometry may be an especially important factor in determining mercury bioaccumulation potential because wetlands - which are known to promote mercury methylation in their anaerobic surface sediments - are a common lowslope feature in mountain lake catchments (St. Louis 1994, Winn et al. 2009). Additionally, lakes with smaller surface areas tend to have higher mercury bioaccumulation (Eagles-Smith et al. 2016b), so lake size is likely also important. Lastly, food web processes are important in determining mercury bioaccumulation. It is well established that fish trophic position and food chain length are positively correlated with mercury bioaccumulation, but prey availability and habitat-specific foraging may also be important factors (Eagles-Smith et al. 2008, Willacker et al. 2013, Karimi et al. 2016, Arcagni et al. 2018), although their importance in mountain lake food webs is unknown.

The factors that influence mercury bioaccumulation potential are complex and occur at widely different scales. Additionally, mountain lakes have strong environmental gradients, which makes it difficult to predict mercury bioaccumulation in mountain lake food webs. However, mercury bioaccumulation, especially in lakes with fish, is important to quantify, because mercury can pose ecological and human health risks. Because many mountain lakes reside on publicly managed land, determining indicators of mercury 
bioaccumulation is an important objective for management and the protection of human and ecological health.

\subsection{Tools for determining food web structure}

Food web structure is an important determinant of mercury bioaccumulation in mountain lakes. Therefore, delineating food web structure and energy pathways in mountain lakes is an important goal of my dissertation. A number of tools exist for tracing energy flow, but each with their own limitations. Gut content analysis can provide insight into an organism's most recent meal, but is limited to large organisms and does not provide time-integrated dietary data. Stable isotope analysis largely overcomes these challenges, albeit with slightly less precision.

In aquatic systems, the analysis of stable carbon and nitrogen isotopes can determine an organism's relative diet and trophic position, respectively. Carbon stable isotope signatures - the ratio of ${ }^{12} \mathrm{C}:{ }^{13} \mathrm{C}\left(\right.$ i.e., $\left.\delta^{13} \mathrm{C}\right)$ - in primary producers is distinctive between littoral and pelagic habitats in lakes due to differences in carbon fractionation during photosynthesis (France 1995). Littoral algae tend to be enriched in ${ }^{13} \mathrm{C}$ relative to pelagic phytoplankton, which are relatively depleted in ${ }^{13} \mathrm{C}$. These carbon isotope signatures get passed from prey to consumer with relatively little fractionation, and thus provide a basis for tracing energy sources in lake consumers (Peterson and Fry 1987). On the other hand, nitrogen stable isotope signatures - the ratio of ${ }^{14} \mathrm{~N}:{ }^{15} \mathrm{~N}\left(\right.$ i.e., $\left.\delta^{15} \mathrm{~N}\right)-$ shows relatively predictable fractionation when passed from prey to consumer, resulting in a 3-4\% enrichment of $\delta^{15} \mathrm{~N}$ with increasing trophic position (Peterson and Fry 1987, 
Post 2002). Thus, $\delta^{15} \mathrm{~N}$ can be used to estimate trophic position of a consumer. When used together, it becomes possible to create a general map of food web structure in a lake ecosystem.

Stable isotope analysis is time-integrated, but susceptible to shifts in baseline (primary producer) isotope signatures, sometimes making it difficult to accurately estimate trophic position and dietary contributions in a consumer. Additionally, while carbon isotopes are useful in distinguishing between energy sources within a lake, they are not very effective in determining contributions from external energy subsidies. For instance, littoral and terrestrial carbon isotope signatures often overlap, making it difficult to determine the extent an aquatic food web or aquatic consumer is subsidized by terrestrial energy sources (France 1995, Pace et al. 2004). The overlap of terrestrial and littoral energy sources makes it especially difficult to determine food web structure in mountain lakes, which often have substantial terrestrial subsidies (Vander Zanden and Gratton 2011, Rola et al. 2018). This overlap has important implications for understanding how food web structure affects mercury bioaccumulation.

Compound-specific stable isotope analysis - the analysis of carbon or nitrogen isotopes of a specific molecular compound, like amino acids or fatty acids - is a relatively new approach that can likely overcome many of the limitations of traditional stable isotopes. Preliminary evidence suggests stable carbon isotopes of fatty acids may be more accurate tracers of carbon energy pathways than "bulk" stable carbon isotopes. The five common essential fatty acids- linoleic acid (LIN; 18:2n-6), arachidonic acid (ARA; 20:4n-6), alpha-linoleic acid (ALA; 18:3n-3), eicosapentaenoic acid (EPA; 20:5n- 
3), and docosahexaenoic acid (DHA; 22:6n-3) - may be especially useful in tracing dietary sources. Essential fatty acids serve critical physiological functions, but vertebrates lack the enzymes necessary to synthesize ALA and LIN, which are precursors that can be used to make small amounts of ARA (via LIN), EPA (via ALA), and DHA (via ALA and/or EPA) (Parrish et al. 2009). Therefore, essential fatty acids can only be obtained from a fish's diet, so the $\delta^{13} \mathrm{C}$ signature of each essential fatty acid in the fish should be similar to the $\delta^{13} \mathrm{C}$ signatures of the respective essential fatty acid in their diets (Bec et al. 2011). Early studies suggest fatty acid stable isotopes may therefore be able to overcome many of the challenges of bulk stable isotopes (Evershed et al. 2007, Budge et al. 2008; Bec et al. 2011), but experimental studies testing its effectiveness are limited, especially in freshwater food webs.

\subsection{Objectives}

The overarching objective of my dissertation was to better understand the issues associated with fish stocking and mercury accumulation in a socioecological context, from the importance of trophic dynamics for mercury bioaccumulation in mountain lake fish, to the implications fish stocking and mercury bioaccumulation for mountain lake management. The primary goals of my research were to:

- Identify ecological, limnological, and landscape-level indicators of mercury bioaccumulation in mountain lake food webs in order to inform better ecosystem management (Chapter 2), 
- Test if fatty acid stable isotopes can partition littoral and terrestrial prey sources in fish in a simplified mountain lake food web (Chapter 3), and

- Determine public perceptions of mountain lake fisheries management, and assess the risk mercury poses to mountain lake anglers (Chapter 4).

In Chapter 2, I conducted a field study to determine how factors at multiple scales can affect mercury bioaccumulation in mountain lake fish (Figure 1.2). Chapter 3 outlines a diet manipulation experiment I conducted with mesocosms at WasserCluster Lunz, in Lunz am see, Austria, to determine how diet availability and distinctive diet pathways affect contaminant burdens in fish (Figure 1.2). Lastly, in Chapter 4, I surveyed visitors in North Cascades and Mount Rainier National Parks, to understand their recreational interests and fishing habits, knowledge of lake ecology, and opinions about management of mountain lakes in an effort to inform mountain lake fisheries management decisions (Figure 1.2). In Chapter 5, I synthesize how my findings can advance our understanding of trophic dynamics and mountain lake ecology, and inform management of mountain lake fisheries to protect human and ecological health. 
Ch. 2: How do food web + lake + landscape variables affect $[\mathrm{Hg}]$ in mountain lake fish, and which are most prominent?

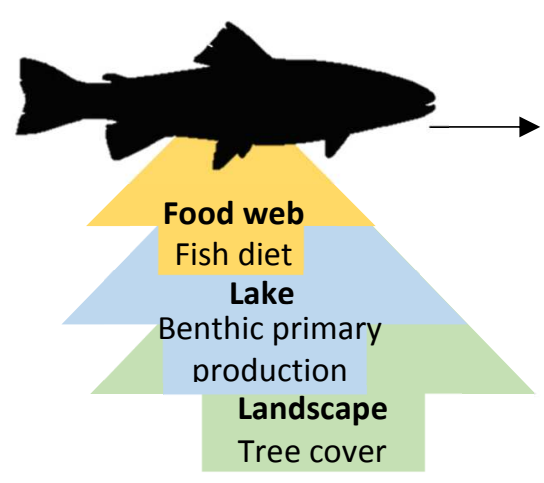

Ch. 3: Is it possible to distinguish between benthic and terrestrial diet sources in mountain lake fish using $\delta^{13} C_{\text {of fatty acids? What are the implications }}$ for bioaccumulation?

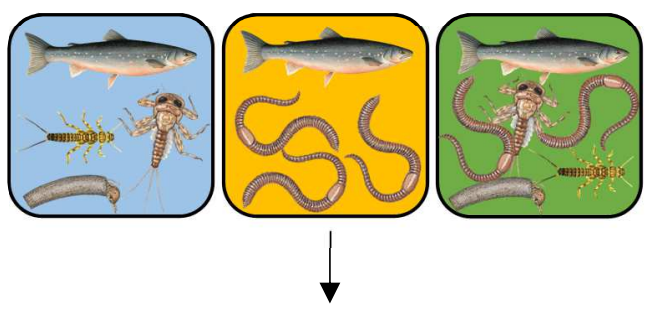

Ch. 4: How do national park visitors perceive fish stocking and fisheries management in mountain lakes, and what are their angling habits? How can social and ecological data be leveraged to optimize management for the health of humans and mountain lake ecosystems?
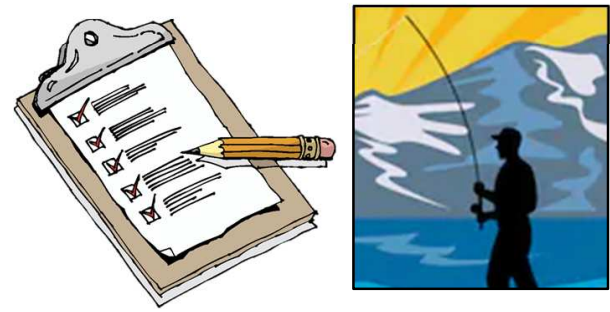

Figure 1.2. Conceptual diagram depicting how each of the three research chapters relate and interconnect. Chapter 2 investigates the effectiveness of indicator variables at the food web, lake, and landscape scale in modeling mercury concentrations $([\mathrm{Hg}])$ in mountain lake fish. Chapter 3 simulates a mountain lake food web to determine if stable carbon isotopes of fatty acids can effectively distinguish benthic and terrestrial diets which are difficult to distinguish using traditional stable isotopes - in Arctic Char (Salvelinus alpinus). Chapter 4 determines public perceptions of mountain lake fisheries management and visitor angling habits in national parks to provide insight for how managers can balance social and ecological values while protecting human and ecological health. 


\subsection{References}

Ackerman, L.K., Schwindt, A.R., Simonich, S.L.M., Koch, D.C., Blett, T.F., Schreck, C.B., Kent, M.L., Landers, D.H., 2008. Atmospherically deposited PBDEs, pesticides, PCBs, and PAHs in western U.S. National Park fish: concentrations and consumption guidelines. Environ. Sci. Technol. 42, 2334-41. https://doi.org/10.1021/es702348j

Alpers, C.N., Hunerlach, M.P., May, J.T., Hothem, R.L., 2005. Mercury Contamination From Historical Gold Mining in California. U.S. Geological Survey, p. 6.

Arcagni, M., Juncos, R., Rizzo, A., Pavlin, M., Fajon, V., Arribére, M.A., Horvat, M., Ribeiro Guevara, S., 2018. Species- and habitat-specific bioaccumulation of total mercury and methylmercury in the food web of a deep oligotrophic lake. Sci. Total Environ. 612, 1311-1319. https://doi.org/10.1016/j.scitotenv.2017.08.260

Bec, A., Perga, M.E., Koussoroplis, A., Bardoux, G., Desvilettes, C., Bourdier, G., Mariotti, A., 2011. Assessing the reliability of fatty acid-specific stable isotope analysis for trophic studies. Methods Ecol. Evol. 2, 651-659. https://doi.org/10.1111/j.2041-210X.2011.00111.x

Bizzotto, E.C., Villa, S., Vighi, M., 2009. POP bioaccumulation in macroinvertebrates of alpine freshwater systems. Environ. Pollut. 157, 3192-8. https://doi.org/10.1016/j.envpol.2009.06.001

Blais, J.M., Charpentié, S., Pick, F., Kimpe, L.E., St Amand, A., Regnault-Roger, C., 2006. Mercury, polybrominated diphenyl ether, organochlorine pesticide, and 
polychlorinated biphenyl concentrations in fish from lakes along an elevation transect in the French Pyrénées. Ecotoxicol. Environ. Saf. 63, 91-9.

https://doi.org/10.1016/j.ecoenv.2005.08.008

Boening, D.W., 2000. Ecological effects, transport, and fate of mercury: A general review. Chemosphere 40, 1335-1351. https://doi.org/10.1016/S0045-6535(99)002830

Budge, S.M., Wooller, M.J., Springer, A.M., Iverson, S.J., McRoy, C.P., Divoky, G.J., 2008. Tracing carbon flow in an arctic marine food web using fatty acid-stable isotope analysis. Oecologia 157, 117-129. https://doi.org/10.1007/s00442-008-10537

Catalan, J., Bartrons, M., Camarero, L., Grimalt, J.O., 2013. Mountain waters as witnesses of global pollution, in: Pechan, P., de Vries, G.E. (Eds.), Living with Water: Targeting Quality in a Dynamic World. Springer New York, pp. 31-67.

Clarkson, T.W., Magos, L., 2006. The toxicology of mercury and its chemical compounds. Crit. Rev. Toxicol. 36, 609-62. https://doi.org/10.1080/10408440600845619

Clayden, M.G., Kidd, K. a., Wyn, B., Kirk, J.L., Muir, D.C.G., O’Driscoll, N.J., 2013. Mercury biomagnification through food webs is affected by physical and chemical characteristics of lakes. Environ. Sci. Technol. 47, 12047-12053.

https://doi.org/10.1021/es4022975 
Drenner, R.W., Chumchal, M.M., Jones, C.M., Lehmann, C.M.B., Gay, D. a, Donato, D.I., 2013. Effects of mercury deposition and coniferous forests on the mercury contamination of fish in the south central United States. Environ. Sci. Technol. 47, S:1-7. https://doi.org/10.1021/es303734n

Driscoll, C.T., Mason, R.P., Chan, H.M., Jacob, D.J., Pirrone, N., 2013. Mercury as a global pollutant: Sources, pathways, and effects. Environ. Sci. Technol. 47, 49674983. https://doi.org/10.1021/es305071v

Eagles-Smith, C.A., Herring, G., Johnson, B., Graw, R., 2016a. Conifer density within lake catchments predicts fish mercury concentrations in remote subalpine lakes. Environ. Pollut. 212, 279-289. https://doi.org/10.1016/j.envpol.2016.01.049

Eagles-Smith, C.A., Suchanek, T.H., Colwell, A.E., Anderson, N.L., 2008. Mercury trophic transfer in a eutrophic lake: The importance of habitat-specific foraging. Ecol. Appl. 18, 196-212. https://doi.org/10.1890/06-1476.1

Eagles-Smith, C.A., Wiener, J.G., Eckley, C.S., Willacker, J.J., Evers, D.C., MarvinDiPasquale, M., Obrist, D., Fleck, J.A., Aiken, G.R., Lepak, J.M., Jackson, A.K., Webster, J.P., Stewart, A.R., Davis, J.A., Alpers, C.N., Ackerman, J.T., $2016 b$. Mercury in western North America: A synthesis of environmental contamination, fluxes, bioaccumulation, and risk to fish and wildlife. Sci. Total Environ. 568, $1213-$ 1226. https://doi.org/10.1016/j.scitotenv.2016.05.094 
Epanchin, P.N., Knapp, R. a, Lawler, S.P., 2010. Nonnative trout impact an alpinenesting bird by altering aquatic-insect subsidies. Ecology 91, 2406-15. https://doi.org/https://doi.org/10.1890/09-1974.1

Evershed, R.., Bull, I.D., Corr, L.., Crossman, Z.., Van Dongen, B.E., Evans, C.J., Jim, S., Mottram, H.R., Mukherjee, A.J., Pancost, R.D., 2007. Compound-specific stable isotope analysis in ecology and paleoecology, in: Michener, R., Lajtha, K. (Eds.), Stable Isotopes in Ecology and Environmental Science. Blackwell Publishing, pp. $480-540$

Finlay, J.C., Vredenburg, V.T., 2007. Introduced trout sever trophic connections in watersheds: consequences for a declining amphibian. Ecology 88, 2187-98. https://doi.org/https://doi.org/10.1890/06-0344.1

Fitzgerald, W.F., Engstrom, D.R., Mason, R.P., Nater, E. a., 1998. The Case for Atmospheric Mercury Contamination in Remote Areas. Environ. Sci. Technol. 32, 17. https://doi.org/10.1021/es970284w

France, R.L., 1995. Carbon-13 enrichment in benthic compared to planktonic algae: food web implications. Mar. Ecol. Prog. Ser.

Gilmour, C.C., Henry, E. a, 1991. Mercury methylation in aquatic systems affected by acid deposition. Environ. Pollut. 71, 131-169. https://doi.org/10.1016/02697491(91)90031-Q

Graydon, J.A., Louis, V.L.S., Hintelmann, H., Lindberg, S.E., Sandilands, A., Rudd, J.W.M., Kelly, C.A., Hall, B.D., Mowat, L.D., 2008. Long-Term Wet and Dry 
Deposition of Total and Methyl Mercury in the Remote Boreal Ecoregion of Canada Long-Term Wet and Dry Deposition of Total and Methyl Mercury in the Remote Boreal Ecoregion of Canada 8345-8351. https://doi.org/10.1021/es801056j

Halverson, A., 2011. Chasing Rainbows. Conserv. Mag.

Isaak, D.J., Young, M.K., Luce, C.H., Hostetler, S.W., Wenger, S.J., Peterson, E.E., Ver Hoef, J.M., Groce, M.C., Horan, D.L., Nagel, D.E., 2016. Slow climate velocities of mountain streams portend their role as refugia for cold-water biodiversity. Proc. Natl. Acad. Sci. 113, 4374-4379. https://doi.org/10.1073/pnas.1522429113

Kallenborn, R., 2006. Persistent organic pollutants (POPs) as environmental risk factors in remote high-altitude ecosystems. Ecotoxicol. Environ. Saf. 63, 100-7. https://doi.org/10.1016/j.ecoenv.2005.02.016

Karimi, R., Chen, C.Y., Folt, C.L., 2016. Comparing nearshore benthic and pelagic prey as mercury sources to lake fish: The importance of prey quality and mercury content. Sci. Total Environ. 565, 211-221. https://doi.org/10.1016/j.scitotenv.2016.04.162

Klapstein, S.J., O’Driscoll, N.J., 2018. Methylmercury Biogeochemistry in Freshwater Ecosystems: A Review Focusing on DOM and Photodemethylation. Bull. Environ. Contam. Toxicol. 100, 14-25. https://doi.org/10.1007/s00128-017-2236-X

Knapp, R.A., Corn, P.S., Schindler, D.E., 2001a. The Introduction of Nonnative Fish into Wilderness Lakes : Good Intentions, Conflicting Mandates, and Unintended Consequences. Ecosystems 4, 275-278. https://doi.org/10.1007/s10021 
Knapp, R., Matthews, K., \& Sarnelle, O., 2001b. Resistance and Resilience of Alpine Lake Fauna to Fish Introductions. Ecol. Monogr. 71, 401-421.

Knapp, R.A., Matthews, K.R., 2000. Non-Native Fish Introductions and the Decline of the Mountain Yellow-Legged Frog from within Protected Areas. Conserv. Biol. 14, $428-438$.

Landers, D.H., Simonich, S.M., Jaffe, D., Geiser, L., Campbell, D.H., Schwindt, A., Schreck, C., Kent, M., Hafner, W., Taylor, H.E., Hageman, K., Usenko, S., Ackerman, L., Schrlau, J., Rose, N., Blett, T., Erway, M.M., 2008. The Fate , Transport, and Ecological Impacts of Airborne Contaminants in Western National Parks (USA), EPA/600/R-07/138. U.S. Environmental Protection Agency, Office of Research and Development, NHEERL, Western Ecology Division, Corvallis, Oregon.

Landres, P., Meyer, S., Matthews, S., 2001. The Wilderness Act and Fish Stocking: An Overview of Legislation, Judicial Interpretation, and Agency Implementation. Ecosystems 4, 287-295. https://doi.org/10.1007/s10021

Larson, G.L., Hoffman, R.L., 2002. Abundances of northwestern salamander larvae in montane lakes with and without fish, Mount Rainier National Park, Washington. Northwest Sci. 76, 35-40.

Lindeman, R.L., 1942. The Trophic-Dynamic Aspect of Ecology 23, 399-417.

Mason, R., Fitzgerald, W., Morel, F., 1994. The biogeochemical cycling of elemental

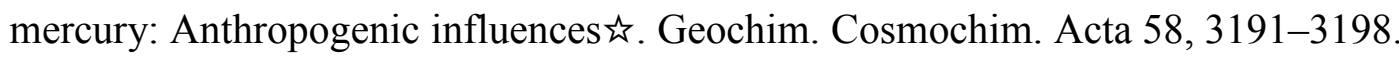
https://doi.org/10.1016/0016-7037(94)90046-9 
Moran, P.W., Aluru, N., Black, R.W., Vijayan, M.M., 2007. Tissue contaminants and associated transcriptional response in trout liver from high elevation lakes of Washington. Environ. Sci. Technol. 41, 6591-7.

Morel, F.M.M., Kraepiel, A.M.L., Amyot, M., 1998. The Chemical Cycle and Bioaccumulation of Mercury. Annu. Rev. Ecol. Syst. 29, 543-566. https://doi.org/10.1146/annurev.ecolsys.29.1.543

Moser, K.A., Baron, J.S., Brahney, J., Oleksy, I.A., Saros, J.E., Hundey, E.J., Sadro, S.A., Kopáček, J., Sommaruga, R., Kainz, M.J., Strecker, A.L., Chandra, S., Walters, D.M., Preston, D.L., Michelutti, N., Lepori, F., Spaulding, S.A., Christianson, K.R., Melack, J.M., Smol, J.P., 2019. Mountain lakes: Eyes on global environmental change. Glob. Planet. Change. https://doi.org/10.1016/j.gloplacha.2019.04.001

National Parks Service, 2007. Mountain Lakes Fishery Management Plan Environmental Impact Statement.

Pace, M.L., 2004. Whole lake carbon-13 additions reveal terrestrial support of aquatic food webs. Nature 427, 240-243. https://doi.org/10.1038/nature02215.1.

Paine, R.T., 1980. Food Webs : Linkage , Interaction Strength and Community Infrastructure. J. Anim. Ecol. 49, 666-685. https://doi.org/10.2307/4220

Parrish, C.C., 2009. Essential fatty acids in aquatic food webs, in: Kainz, M., Brett, M., Arts, M. (Eds.), Lipids in Aquatic Ecosystems. Springer, New York, NY, pp. 309326. 
Peterson, B.J., Fry, B., 1987. Stable isotopes in ecosystem studies. Annu. Rev. Ecol. Syst. 18, 293-320. https://doi.org/10.1146/annurev.es.18.110187.001453

Pister, E.P., 2001. Wilderness Fish Stocking: History and Perspective. Ecosystems 4, 279-286. https://doi.org/10.1007/s10021

Post, D.M., 2002. Using stable isotopes to estimate trophic position: models, methods, and assumptions. Ecology 83, 703-718. https://doi.org/Doi 10.2307/3071875

Ravichandran, M., 2004. Interactions between mercury and dissolved organic matter - A review. Chemosphere 55, 319-331. https://doi.org/10.1016/j.chemosphere.2003.11.011

Rola, M., Biffoni, G., Brighenti, S., Iacobuzio, R., Liautaud, K., Pasquaretta, C., Tiberti, R., 2018. Predation by introduced fish can magnify the terrestrial arthropod subsidies in mountain lakes. Can. J. Fish. Aquat. Sci. 1-25.

Sarnelle, O., Knapp, R.A., 2004. Zooplankton recovery after fish removal : Limitations of the egg bank. Limnol. Oceanogr. 49, 1382-1392. https://doi.org/https://doi.org/10.4319/1o.2004.49.4_part_2.1382

Schartup, A.T., Balcom, P.H., Soerensen, A.L., Gosnell, K.J., Calder, R.S.D., 2015. Freshwater discharges drive high levels of methylmercury in Arctic marine biota. Proc. Natl. Acad. Sci. 112, 11789-11794. https://doi.org/10.1073/pnas.1505541112 
Scheuhammer, A.M., Sandheinrich, M.B., 2008. Recent advances in the toxicology of methylmercury in wildlife. Ecotoxicology 17, 67-68. https://doi.org/10.1007/s10646007-0186-5

Schindler, D.E., Knapp, R.A., Leavitt, P.R., 2001. Alteration of Nutrient Cycles and Algal Production Resulting from Fish Introductions into Mountain Lakes. Ecosystems 4, 308-321. https://doi.org/10.1007/s10021

Schindler, D.W., 2009. Lakes as sentinels and integrators for the effects of climate change on watersheds, airsheds, and landscapes. Limnol. Oceanogr. 54, 2349-2358. https://doi.org/10.4319/1o.2009.54.6_part_2.2349

Schindler, D.W., Kidd, K.A., Muir, D.C.G., Lockhart, W.L., 1995. The effects of ecosystem characteristics on contaminant distribution in northern freshwater lakes. Sci. Total Environ. 160, 1-17.

Schindler, D.E., Lubetkin, S.C., Polis, G.A., Power, M.A. and Huxel, G.R., 2004. Using stable isotopes to quantify material transport in food webs. Food webs at the landscape level. University of Chicago Press, Chicago, Illinois, USA, pp.25-42.

St. Louis, V.L., Rudd, J.W.M., Kelly, C. a., Beaty, K.G., Bloom, N.S., Flett, R.J., 1994. Importance of Wetlands as Sources of Methyl Mercury to Boreal Forest Ecosystems. Can. J. Fish. Aquat. Sci. 51, 1065-1076. https://doi.org/10.1139/f94-106

Ullrich, S.M., Tanton, T.W., Abdrashitova, S. a., 2001. Mercury in the aquatic environment: a review of factors affecting methylation. Crit. Rev. Environ. Sci. Technol. 31, 241-293. https://doi.org/10.1080/20016491089226 
Vander Zanden, M.J., Casselman, J.M., Rasmussen, J.B., 1999. Stable isotope evidence for the food web consequences of species invasions in lakes. Lett. to Nat. 401, 19972000.

Vander Zanden, M.J., Gratton, C., 2011. Blowin' in the wind: reciprocal airborne carbon fluxes between lakes and land. Can. J. Fish. Aquat. Sci. 68, 170-182. https://doi.org/10.1139/F10-157

Wiener, J.G., Krabbenhoft, D.P., Heinz, G.H., Scheuhammer, A., 2003. Ecotoxicology of mercury. In: Hoffman, D., Burton, G.A.J., Cairns, J.J. (Eds.), Handbook of ecotoxicology, 2nd edition CRC Press, Boca Raton, FL, pp. 409-463

Willacker, J.J., von Hippel, F.A., Ackerly, K.L., O’Hara, T.M., 2013. Habitat-specific foraging and sex determine mercury concentrations in sympatric benthic and limnetic ecotypes of threespine stickleback. Environ. Toxicol. Chem. 32, 1623-1630. https://doi.org/10.1002/etc.2213

Winn, N., Williamson, C.E., Abbitt, R., Rose, K., Renwick, W., Henry, M., Saros, J., 2009. Modeling dissolved organic carbon in subalpine and alpine lakes with GIS and remote sensing. Landsc. Ecol. 24, 807-816. https://doi.org/10.1007/s10980-0099359-3 
Chapter 2

\section{From forests to fish: Mercury in mountain lake food webs influenced by factors at multiple scales}

Co-authors: Collin Eagles-Smith; Angela Strecker

\subsection{Introduction}

Remote montane lakes are important habitats in temperate regions because they help preserve aquatic biodiversity and water quality in the face of downstream urbanization and development. Substantial fish stocking efforts in the $19^{\text {th }}$ and $20^{\text {th }}$ centuries have also made mountain lakes a popular destination for anglers because of the cultural value placed on these ecosystems (Chiapella et al. 2018) and the perceived opportunity to catch fish free from industrial pollution common in more developed watersheds. Despite their isolation from many direct anthropogenic impacts, environmental contaminants still can be found in mountain lakes through atmospheric deposition to their watersheds (Fitzgerald et al. 1998, Kallenborn 2006, Landers et al. 2008). Mercury ( $\mathrm{Hg})$ is of particular concern because it is globally prevalent, and when converted to the more toxic and bioavailable form, methylmercury $(\mathrm{MeHg})$, it biomagnifies through food webs to concentrations that can pose health risks to wildlife and humans. Importantly, the amount of inorganic $\mathrm{Hg}$ transported to ecosystems is a generally poor predictor of $\mathrm{MeHg}$ concentrations and risk (e.g., Heim et al. 2007) because of the complex factors driving $\mathrm{MeHg}$ biogeochemical cycling and accumulation through food webs (Eagles-Smith et al. 2016a). Thus, understanding the relative 
importance of various drivers controlling $\mathrm{MeHg}$ risk is an important goal for managing human and ecological health. This objective has sparked substantial research efforts to understand the factors that influence $\mathrm{MeHg}$ accumulation in aquatic food webs (e.g., McIntyre and Beauchamp 2007, Lavoie et al. 2013, Eagles-Smith 2016a). However, much less is known about which factors predict fish mercury concentrations in mountain lakes. The goal of this study is to determine if there are single, measurable variables that are representative of the processes influencing $\mathrm{MeHg}$ at the landscape, lake, and food web scale.

Methylmercury bioaccumulation is controlled by a complex and hierarchical suite of factors that can be characterized in three broad categories at each of these scales: 1) factors influencing inorganic Hg transport and loading (Jaffe and Strode 2008, Sackett et al. 2010); 2) biogeochemical and morphological factors influencing MeHg production (Kainz and Lucotte 2006, Clayden et al. 2013, Klapstein and O’Driscoll 2018); and 3) ecological factors influencing $\mathrm{MeHg}$ bioaccumulation and biomagnification through aquatic food webs (Eagles-Smith et al. 2016a). However, the relative importance of these categories and the factors comprising them can vary across different habitat types (Eagles-Smith et al. 2016a), especially in mountain lakes, which have strong environmental gradients (Loewen et al. 2018). While previous studies typically focus on individual factors that influence mercury bioaccumulation, few have tried to identify representative variables at each scale that are relatively easy to measure, and could serve as indicators of mercury bioaccumulation. 


\subsubsection{Transport and loading}

Mercury reaches mountain lake watersheds primarily by long-range transport, although local point sources such as power plants or cinnabar mines can contribute substantial amounts of mercury when present. Although total mercury deposition to a watershed is difficult to measure, precipitation and forest cover may be useful indicators. Precipitation patterns influence mercury deposition, as higher precipitation leads to higher wet deposition of mercury (Eagles-Smith et al. 2016a). Forest cover can also serve as an indicator of localized mercury deposition. Specifically, conifer cover can increase the loading of mercury in a lake via adsorption of $\mathrm{Hg}$ from the atmosphere and consequent litterfall and throughfall (Graydon et al. 2008, Drenner et al. 2013). In fact, conifer density in subalpine lake catchments explained $75 \%$ of the variability in average fish $\mathrm{Hg}$ concentrations within lakes in the Pacific Northwest region of the United States (Eagles-Smith et al. 2016b).

\subsubsection{Biogeochemistry and morphometry}

Forest cover may also be an important factor influencing mercury bioaccumulation because of its effects on aquatic biogeochemistry. More watershed vegetation leads to higher inputs of allochthonous organic matter to lakes, ultimately affecting dissolved organic carbon (DOC) concentrations - which can be important for mercury bioavailability (Jardine et al. 2012). In oligotrophic systems, labile DOC can increase the bioavailability of methylmercury by fueling methylating bacteria. Recalcitrant DOC can bind to both $\mathrm{Hg}$ and $\mathrm{MeHg}$, which decreases methylation and 
bioavailability, respectively, but can also prevent photodemethylation (Ravichandran 2004, Klapstein and O'Driscoll 2018). Wetlands are also known to be an important driver of $\mathrm{MeHg}$ concentrations in lakes because they often contain low redox potential and contribute labile DOC to lakes (St. Louis et al. 1994).

Evidence for the importance of low-slope areas - like wetlands - for DOC production is strong in mountain lakes (Winn et al. 2009), meaning morphometry could be an especially important driver of mercury methylation in these systems. Lake depth can also influence methylation potential. Depth can determine if a lake stratifies; if it does, anoxia at the sediment-water boundary is more likely to occur, which promotes methylation (Ullrich et al. 2001), while shallow lakes with full light penetration have higher rates of benthic primary production, which can lead to algal dilution of $\mathrm{MeHg}$ (e.g., Pickhardt et al. 2002) and photodemethylation (Klapstein and O'Driscoll 2018).

Recently, there has been increased focus and greater understanding of the importance of benthic production in lake food webs (Hecky and Hesslein 1995, Vadeboncoeur et al. 2002, Vander Zanden 2006, Sadro et al. 2011). The contribution of the benthos to total lake production seems to be particularly important in oligotrophic systems, such as mountain lakes (Sadro et al. 2011). Many of the factors that influence mercury methylation and bioavailability are also important in determining rates of primary production. For example, modeled benthic primary production in lakes relies on measures of lake morphometry (mean and maximum lake depth, surface area) and productivity (water clarity, phosphorus, chlorophyll a) (Vadeboncoeur et al. 2008). Additionally, differences in the relative importance of pelagic and benthic primary 
production could contribute to rates of secondary production, which may in turn prey availability to fish, and MeHg exposure may be different between benthic and pelagic prey. Thus, benthic primary production should be considered when determining drivers of $\mathrm{MeHg}$ bioaccumulation in mountain lakes.

\subsubsection{Food web ecology}

Higher order food web processes, such as trophic interactions, are also important for understanding mercury bioaccumulation. Evidence suggests foraging habitat is an important factor that influences mercury exposure (Cabana and Rasmussen 1994, Wong

et al. 1997, Eagles-Smith et al. 2008a). For example, the benthic pathway has been shown to be the most important mercury exposure route in eutrophic or heavily contaminated lakes (Eagles-Smith et al. 2008b, Parkman and Meili 1993) because of the high redox potential associated with benthic habitats in these systems. Conversely, the pelagic pathway seems to be more important for mercury exposure in oligotrophic systems (Power et al. 2002, Gorski et al. 2003, Karimi et al. 2016). Therefore, a pelagic diet may be indicative of higher mercury concentrations in mountain lake fish, but the effect of diet on mercury bioaccumulation is not well understood in these systems.

Remote mountain lakes provide a unique setting to examine how these factors influence $\mathrm{Hg}$ concentration in fish because, despite being similar in many ways, they often exhibit gradients in many of the factors described above. In this study, we assessed mercury bioaccumulation in 19 mountain lakes in the Olympic and Cascade Mountains, Washington, USA. Study sites ranged from alpine (no tree cover), subalpine (sparse tree 
cover), and high elevation forest (high tree cover), with a wide range of morphometric attributes (Table 2.1). Our goals were to determine the overarching patterns of mercury concentrations in mountain lake food webs, and elucidate the relative importance of landscape, limnological, and ecological drivers of these patterns. We hypothesize that: (1) tree cover will be the most important landscape-level predictor of fish mercury, due to its relationship to DOC production and the promotion of mercury throughfall by conifers; (2) benthic primary production will be negatively correlated with fish mercury, because of reduced methylation potential from low redox (high oxygen) conditions; (3) habitatspecific foraging will be an important food web factor because zooplankton typically have higher MeHg than benthic invertebrates in oligotrophic lakes (Power et al. 2002, Karimi et al. 2016). Using an information-theoretic approach, we examined the relative importance of tree cover, benthic primary production, and benthic reliance on fish mercury concentrations, while also accounting for other potential confounding variables.

\subsection{Methods}

\subsubsection{Study area}

The Cascade and Olympic Mountain ranges extend through the state of Washington, USA. The Olympic Mountains are coastal, and occupy the Olympic Peninsula, whereas the Cascade Range is inland, and stretches from southern Oregon to the US-Canada border. Much of the land area in the Olympic and Cascade Mountains is comprised of national forest, national park, and designated wilderness areas. Study sites included lakes in North Cascades National Park (2014-2015), Mt. Baker-Snoqualmie National Forest (2014-2015), Mount Rainier National Park (2015), and Olympic National 
Park (2015) (Table 2.1). Data from North Cascades National Park and Mt. BakerSnoqualmie National Forest were pooled for later analyses because of the close proximity of sites. Our sites, while all mountainous, encompass a heterogeneous landscape with lake basins that have a wide range in size and include a mix of high forest, subalpine and alpine scrub vegetation, and variable annual temperatures. Although historically fishless, all sample lakes were at one point stocked with fish, and now retain reproducing populations of either Cutthroat Trout (Oncorhynchus clarkii), Rainbow Trout (Oncorhynchus mykiss), or Eastern Brook Trout (Salvelinus fontinalis). We sampled nineteen lakes from 2014 and 2015 from late July - September to ensure complete iceoff. We selected lakes based on elevation, vegetation zone (high forest, subalpine, alpine), and surface area to ensure we captured a wide environmental gradient.

We measured water temperature $\left({ }^{\circ} \mathrm{C}\right)$, conductivity $(\mu \mathrm{S} / \mathrm{cm})$, and dissolved oxygen $(\mathrm{mg} / \mathrm{L})$ using a YSI ProPlus (Yellow Springs, $\mathrm{OH})$ at 1-m intervals at a deep area of each lake. pH was measured in situ using an Extech EC500 (Extech, Nashua, NH). Water samples for total phosphorus and nitrogen were collected as an integrated epilimnetic sample using a 2.5-cm diameter Tygon tube, kept on snow or ice, and frozen until analysis. We did not include nitrogen in our analyses, because the benthic primary production model only required total phosphorus as a nutrient input. Clarity was determined by measuring Secchi depth, then calculating the proportion of maximum depth that was represented by Secchi depth. 


\subsubsection{Food web collection}

At each lake, zooplankton were collected with a 30-cm diameter $80-\mu \mathrm{m}$ mesh conical net via horizontal tows in order to aggregate enough biomass for chemical analyses. Benthic macroinvertebrates were collected from the littoral area of the lake using a D-net with 500- $\mu \mathrm{m}$ mesh until enough biomass was collected for analyses ( $\sim 500 \mathrm{mg}$ of biomass per taxon). All invertebrates were coarsely sorted to taxonomic order in the field and placed into respective amber glass jars with a Teflon lid and stored in either a final concentration of 70\% HPLC-grade ethanol (2014) or kept cold until frozen in the lab (2015). To ensure methodological differences did not confound our results, we collected and preserved zooplankton at varying time intervals to test whether ethanol preservation influenced mercury concentrations compared to frozen samples. We found that although preservation led to an average of $17 \mathrm{ng} / \mathrm{g}$ dry weight $( \pm 6.37 \mathrm{SD})$ higher $\mathrm{MeHg}$ than frozen samples between 3 and 90 days of preservation, long-term storage of 180 days resulted in mean MeHg concentrations that were not significantly higher than frozen samples (Tukey's HSD: $p=0.99$; Figure A1). All of our invertebrate samples were stored for $>180$ days.

Fish were collected via a monofilament gill net at each site $(36 \mathrm{~m}$ long X $1.8 \mathrm{~m}$ wide; mesh sizes: $12.5 \mathrm{~mm}, 18.5 \mathrm{~mm}, 25 \mathrm{~mm}, 33 \mathrm{~mm}$; Lundgrens Fiskredskap AB, Sweden). Nets were deployed perpendicular to shoreline, with the small mesh sizes closer to shore. Nets were checked and cleared of any captures approximately every 30-60 minutes, and nets were generally retrieved after 5-6 fish were caught. Captured fish were removed and immediately euthanized via stunning force to the head followed by pithing 
of the brain (IACUC protocol \#36, Portland State University). We identified fish to species, recorded for weight and length, and then wrapped in solvent-washed aluminum foil and kept cool on snow or ice until frozen in the lab, where they were stored at $-20^{\circ} \mathrm{C}$ until processing.

Total chlorophyll $a$ was sampled by collecting $1 \mathrm{~L}$ of water from the epilimnion with a $2.5-\mathrm{cm}$ diameter tube sampler and concentrating it directly onto the collection filter, while a second liter was first passed through a $35-\mu \mathrm{m}$ filter to represent the highly edible algal fraction (Cyr and Curtis 1999). Each fraction was filtered onto a 1.2- $\mu$ m pore size glass fiber filter. At each lake, periphyton samples for stable isotope analyses were collected by placing 3-4 cobbles in a bin with water, scrubbing them with a brush, and then filtering the water through a $1.2-\mu \mathrm{m}$ pore size glass fiber filter. All filters were wrapped in aluminum foil, then kept on ice or snow until frozen in the lab.

\subsubsection{Sample processing and analysis}

Chlorophyll $a$ samples were analyzed using acetone to extract chlorophyll from filters, and concentrations were determined using US Environmental Protection Agency (EPA) Method 445 (Arar and Collins 1997) with a TD-7200 fluorometer using the Trilogy Chl $a$ NA Module (Turner Designs, Sunnyvale, CA). Total phosphorus was analyzed at the University of Washington's Marine Chemistry Laboratory, using methods from Valderrama (1981). For some lakes, water samples were lost due to adverse weather conditions or transportation complications. In an attempt to fill gaps in data, chlorophyll $a$ and phosphorus values, which were required for the benthic primary production 
models, were gathered from Williams \& Labou's (2017) database. In some cases, only total dissolved phosphorus (TDP) data were available from the database for our lakes with missing total phosphorus (TP) values. In most cases, TDP and TP concentrations were similar for the subset of lakes that had both values: using a paired $t$-test, we found no significant difference between TDP and TP $(\mathrm{t}=-1.20, \mathrm{p}=0.26, \mathrm{n}=12)$ across published and measured concentrations. Thus we used whatever concentration was available for a given lake (TP or TDP). Unless otherwise stated, all total and dissolved phosphorus values are henceforth referred to as phosphorus.

Fish samples were thawed to room temperature, and dorsal muscle tissue plugs were excised from each fish. Fish tissue, zooplankton, and macroinvertebrates were freeze-dried then homogenized using a mortar and pestle. Small subsets of each sample were placed into tin capsules for stable isotope analysis. Periphyton filters were ovendried at $60^{\circ} \mathrm{C}$ for $12-24$ hours, and then periphyton was scraped off filters and placed into tin capsules for stable isotope analysis. Capsules were analyzed for stable carbon $\left(\delta^{13} \mathrm{C}\right)$ and nitrogen $\left(\delta^{15} \mathrm{~N}\right)$ isotopes at the Yale University Isotope Lab (2014) and UC Davis Stable Isotope Facility (2015) on a PDZ Europa ANCA-GSL elemental analyzer interfaced to a PDZ Europa 20-20 isotope ratio mass spectrometer (Sercon Ltd., Cheshire, UK) with reference material Vienna PeeDee Belemnite and air for carbon and nitrogen, respectively.

We analyzed total mercury in the remaining fish tissue homogenate for mercury via combustion on a DMA 80 tri-cell $\mathrm{Hg}$ analyzer (Milestone) following EPA Method 7473 (1998), and in macroinvertebrate and zooplankton homogenate, $\mathrm{MeHg}$ was 
analyzed via cold-vapor atomic fluorescence following EPA Method 1631 (2002) at the US Geological Survey Contaminant Ecology Research Lab in Corvallis, OR. We analyzed total mercury (THg) in fish because most (90-95\%) mercury in fish muscle is in the form of methylmercury (MeHg) (Bloom 1992). Invertebrates were analyzed for methylmercury because ratios of $\mathrm{MeHg}$ : $\mathrm{THg}$ in invertebrates are less consistent than in fish (Tremblay et al. 1996). All mercury values are reported on a dry weight basis (unless stated otherwise), and quality assurance protocols including matrix blanks, duplicates, and spikes were used. Recoveries for calibration verification standards were $102.7 \%$ $(n=12)$ for $\mathrm{THg}$ and $104.4 \%(n=16)$ for MeHg. Certified reference material recoveries were $101.73 \%(n=12)$ for $\mathrm{THg}$ and $98.8 \%(\mathrm{n}=10)$ for $\mathrm{MeHg}($ standard deviation $=6.48)$. Relative percent difference averaged $1.26 \%$ for all $\mathrm{THg}$ duplicates and $4.52 \%$ for $\mathrm{MeHg}$. Matrix spike recoveries for $\mathrm{MeHg}$ averaged $111 \%$.

\subsubsection{Spatial and modeled variables}

We determined lake elevation, surface area, bathymetry, and watershed size and slope using ArcMap 10 (ESRI, Redlands, CA, USA). Each lake perimeter was outlined using 1:24,000 USGS topographic maps and satellite photography. Using the National Hydrologic Dataset (US Geological Survey 2017), we delineated watersheds by identifying flow direction, water accumulation, and catchment pour points within 10-m digital elevation models (US Geological Survey 2017). We created 25\% (of lake area) buffers around each lake, and calculated mean slope and mean elevation change within 
each buffer (Heathcote et al. 2015, Messager et al. 2016). These parameters were then used to model volume and mean depth for each lake.

For the subset of lakes of which there were no existing bathymetries, we used a Lowrance Fishfinder sonar device to obtain GPS-tagged depth measurements in a concentric pattern. We created bathymetric maps using these data points in ArcMap 10, and then calculated lake volume from the bathymetric polygons. We obtained preexisting bathymetric maps from the National Parks Service for the remainder of lakes. We used the volume calculated from pre-existing maps and our sonar bathymetry calculations to compare with estimates modeled using methods from Heathcote et al. (2015) and Messager et al. (2016). The models had varying accuracy, depending on the lake, and for many lakes the sonar data were not high enough quality to adequately compare between modeled, measured, and pre-existing estimates of mean lake depth. Therefore, measured or pre-existing values of mean depth and volume were selected for use when available, while maximum depth and observational knowledge of basin morphometry were used to select which modeled value to use in lakes that did not have measured values available (Table A1).

Because lakes could only be sampled once per season and water temperature is dynamic, especially in shallow lakes, we used data from PRISM models (PRISM Climate Group 2018) to determine the mean annual air temperature in each catchment in lieu of using water temperature. There exists sufficient evidence to assume that changes in surface water temperature are concurrent with changes in air temperature during ice-out, which we expected to correlate to average annual air temperature (e.g., O'Reilly et al. 
2015). Additionally, we obtained mean annual precipitation values for each lake catchment (PRISM Climate Group 2018). We used five-year averages (2011-2015) of both annual precipitation and mean annual temperature to account for any uncharacteristically hot/cold or wet/dry years.

We estimated benthic primary production (as a proportion of whole-lake production) using the model from Vadeboncoeur et al. (2008), following modifications by Vander Zanden et al. (2011). The model uses established relationships between light (Secchi depth), morphometry (lake area, mean depth, maximum depth), nutrients (total phosphorus), and primary algal production for benthic and pelagic habitats. While the model does not explicitly include macrophytes in its estimation of primary production, most of our sites had negligible or no macrophyte production. The model uses pelagic chlorophyll $a$ to estimate pelagic primary production, and sums this value over the depth of the photic zone ( $>1 \%$ incident light) to yield total pelagic primary production per square meter of lake surface area. The model estimates benthic primary production at discrete depth intervals, as a function of light availability at depth. As in Vander Zanden et al. (2011), we set the maximum, light-saturated rate of primary productivity to $30 \mathrm{mg}$ $\mathrm{C} / \mathrm{m}^{2} / \mathrm{h}$ because it represents a value typical of oligotrophic to moderately productive lakes (Table 2.1). The model then scaled relative contributions of benthic and primary production to the whole-lake level using lake area, mean depth, and maximum depth (Vadeboncoeur et al. 2008).

We determined percent tree cover within a buffer of each lake (buffer scaled to $25 \%$ of lake area to compensate for large differences in lake size). Estimates of percent 
tree cover were calculated by hand from Landsat 8 satellite imagery in ArcMap

(TerraColor 2013-2018). Within the 25\% lake buffers, polygons were drawn around tree stands and then cut away from the buffer. The area of the clipped buffer was then divided by the area of the original buffer to determine what percent of the buffer area was occupied by trees.

\subsubsection{Statistical approach}

In order to account for the multiple interacting factors that influence mercury bioaccumulation in fish, we used a tiered approach, which we outline below, followed by a more detailed description. We first characterized the overarching patterns of mercury concentrations in mountain lake food webs by comparing mean mercury concentrations between each park, and between different invertebrate and fish taxonomic groups. We then used stable isotopes of nitrogen to determine fish trophic positions, and used stable isotopes of carbon in mixing models to determine fish foraging habitat. We standardized fish mercury concentrations by trophic position using a least squares mean (LSM) approach. Lastly, we determined how watershed precipitation and temperature, catchment tree cover, benthic primary production, and mean benthic reliance influenced LSM mercury in fish using multiple linear regression models with $\mathrm{AIC}_{\mathrm{c}}$ selection.

First, we investigated overarching trends to determine the general distribution of wet weight mercury concentrations in fish among species and across study sites relative to EPA consumption guidelines (Borum et al. 2001). To understand whether mercury concentrations differed across our three study regions, we used analysis of variance 
(ANOVA) followed by a Tukey's Honest Significant Difference (HSD) test to determine if mean mercury concentrations were significantly different between North Cascades, Mount Rainier, and Olympic National Park lakes. We simultaneously tested whether THg concentrations differed among fish species. The goal of these models was to determine the level of exposure an angler might expect based on the species they catch, and the region in which they are fishing; therefore, we did not correct mercury concentrations for fish trophic position for these tests.

We then compared MeHg concentrations across invertebrate taxonomic groups, and between pooled pelagic zooplankton and littoral macroinvertebrate groups, to investigate variation in MeHg concentrations in fish prey. Macroinvertebrates included amphipods (Amphipoda), beetles (Coleoptera), dipteran flies (Diptera), mayflies (Ephemeroptera), dragonflies (Odonata), and caddisflies (Trichoptera). We used a mixedeffects ANOVA with lake as a random factor to calculate lake-adjusted LSM for each taxonomic group, then calculated Tukey's-adjusted differences of MeHg between the groups to determine if there were significant differences in MeHg concentrations. We also tested for a relationship between fish LSM Hg and pelagic resources (i.e., pooled zooplankton), and fish LSM Hg and benthic resources (i.e., pooled macroinvertebrates) using linear regression models. Zooplankton MeHg values for each lake were from an integrated water column sample, and were thus representative of the range of zooplankton $\mathrm{MeHg}$ concentrations in each lake. Mean lake benthic invertebrate $\mathrm{MeHg}$ values included all taxa in order to capture a representative average of $\mathrm{MeHg}$ (which does assume fish do not discriminate between taxa). 
We used nitrogen stable isotopes $\left(\delta^{15} \mathrm{~N}\right)$ to calculate invertebrate and fish trophic position, and stable carbon isotopes $\left(\delta^{13} \mathrm{C}\right)$ to estimate percent benthic reliance of fish. We calculated trophic position using the $\delta^{15} \mathrm{~N}$ of fish and either a primary consumer (typically chironomid larvae) or primary producer (periphyton) using the equation from Post (2002). We calculated fish littoral reliance using a two end-member mixing model (adapted from Vander Zanden et al. 2011). We used the $\delta^{13} \mathrm{C}$ of composite zooplankton samples as the pelagic end-member of the model for each lake, and we used the most enriched $\delta^{13} \mathrm{C}$ value of all macroinvertebrates within a lake as the littoral-benthic endmember. We used this averaging technique for the littoral end-member because the littoral community composition of each lake was variable, and no single taxon was represented across all lakes. Therefore, we felt averaging the $\delta^{13} \mathrm{C}$ of all primary consumers was the best way to represent the littoral reliance of fish. For some fish $(9.6 \%)$, the mixing model produced values greater than 1 or less than 0 , in which case the values were set to either 1 or 0, respectively (Vander Zanden et al. 2011).

Next, we normalized mean fish $\mathrm{THg}$ concentrations for each lake to trophic position, because trophic position is known to influence mercury (Kidd et al. 1995). We used an analysis of covariance to determine the effect of trophic position on fish mercury concentrations across lakes, then calculated the trophic position-corrected LSM of fish mercury concentrations in each lake. We used this approach because the number of fish we caught in each lake was variable, most lakes only had one fish species present, and our variables were at very different scales, so we would have had issues with 
convergence with mixed effects models. Unless otherwise stated, all fish mercury data are presented as the ln-transformed LSM from the model output.

We then used multiple linear regression models in an information theoretic framework (i.e. Akaike's Information Criterion; Burnham and Anderson 2002) to determine whether and how percent tree cover, mean benthic reliance, benthic primary production, average annual air temperature (five-year mean), average annual precipitation (five-year mean), and sampling date influenced LSM fish mercury concentrations. By using LSM fish mercury as our response variable, we are able to account for the individual-level factors (such as trophic position) that influence fish $\mathrm{Hg}$ concentrations, and use more comparable estimates of $\mathrm{Hg}$ exposure across lakes. Due to the autocorrelation between precipitation and tree cover, we ran a linear model regressing precipitation (five-year mean) against percent tree cover, and used the residuals as our precipitation variable in our fish LSM mercury models (Figure A2).

Because we only caught one fish in some lakes, we ran two sets of models. The first model included all 19 lakes, while the second model included the 13 lakes where we caught $>1$ fish. We used the Akaike Information Criterion model selection for small sample sizes $\left(\mathrm{AIC}_{\mathrm{c}}\right)$ to calculate model Akaike weights $\left(\omega_{\mathrm{i}}\right)$ and variable weights $(\omega \beta)$ for model selection, and variance inflation factors (VIF, cutoff 3 ) to identify if variables had high multicollinearity. To ensure a balanced design for allowing interpretation of variable weights, we included all possible combinations of variables in our candidate model set. However, to accommodate the low sample sizes of lakes, we only allowed a maximum of four variables to appear in any given model. All analyses were completed using R version 
3.2.1 (R Core Team, 2016). Statistical analyses were conducted with packages MASS (Ripley et al. 2019), MuMIn (Bartoń 2019), and lsmeans (Lenth 2018).

\subsection{Results}

\subsubsection{General results}

Lakes had a wide range of morphometry, tree cover, benthic primary production, and annual precipitation (five-year mean) (Table 2.1). Water quality also varied, with relatively large ranges in hypolimnetic dissolved oxygen, water clarity, conductance, and chlorophyll $a$, while phosphorus concentrations were consistently low across sites (Table 2.1). We collected 100 fish from 19 lakes across the three study areas. Fish ranged from juvenile to adult, and the most common species caught was Rainbow Trout (46\%), followed by Eastern Brook Trout (38\%) and Cutthroat Trout (16\%) (Table 2.2). The geometric mean fish mercury concentration across all lakes, fish sizes, and species was $243.20 \mathrm{ng} / \mathrm{g} \mathrm{dw}$ ( $\pm 186.06 \mathrm{SD}$ ), and ranged more than three-fold across lakes (Table 2.2). All fish were well below the EPA fish tissue methylmercury criterion value of $300 \mathrm{ng} / \mathrm{g}$ ww for the protection of human health, but generally above the EPA recommendation for subsistence consumption (50 ng/g ww) (Borum et al. 2001; Figure 2.1). Across all sample lakes, we did not find significant differences in mean fish mercury concentrations among parks (ANOVA: $\mathrm{F}_{2,16}=1.40, \mathrm{p}=0.28$ ), although mean concentrations were about $10 \mathrm{ng} / \mathrm{g}$ lower in North Cascades lakes relative to Olympic and Mount Rainier lakes. THg concentrations differed among species (ANOVA: $\mathrm{F}_{2,97}=7.6, \mathrm{p}<0.01$ ), with Rainbow 
Trout having significantly lower mercury than Cutthroat (Tukey’s HSD: $p=0.01$ ) and Eastern Brook Trout (Tukey's HSD: $p<0.01$; Figure 2.1).

Mean invertebrate $\mathrm{MeHg}$ concentrations ranged widely among taxonomic groups (Mixed-effects ANOVA: $\mathrm{F}_{6,47}=4.38, \mathrm{p}<0.01$ ). Zooplankton and amphipods had significantly higher lake-adjusted LSM MeHg than aquatic beetles, dipteran flies, mayflies, dragonflies, and caddisflies (Tukey's-adjusted LSM differences: $\mathrm{p}<0.05$ ), but no other significant differences existed between other taxa (Figure 2.2). We did not observe a relationship between fish LSM Hg and lake-specific zooplankton $\mathrm{MeHg}\left(\mathrm{R}^{2}=\right.$ $0.05, \mathrm{p}=0.53, \mathrm{df}=8)$ or macroinvertebrate $\mathrm{MeHg}$ concentrations $\left(\mathrm{R}^{2}=0.05, \mathrm{p}=0.44, \mathrm{df}=\right.$ 12), and therefore did not consider these variables in subsequent models.

\subsubsection{Model results}

We examined the factors influencing fish $\mathrm{THg}$ concentrations across lakes with multiple linear regression using two datasets: one that included all lakes $(n=19)$, and one that included only lakes where $>1$ fish was caught $(n=13)$. For both datasets, percent tree cover and mean benthic reliance were included in our top models $\left(\Delta \mathrm{AIC}_{\mathrm{c}}<2\right.$; Table 2.3$)$. For our models including lakes with $>1$ fish, percent tree cover was included in both of our top models, while benthic reliance was included in only one model $\left(\Delta \mathrm{AIC}_{\mathrm{c}}<2\right.$; Table 2.3). Percent tree cover and mean benthic reliance were both positively related to fish LSM mercury concentrations (Figure 2.3). When we summed the $\mathrm{AIC}_{\mathrm{c}}$ weights for each variable (Burnham and Anderson 2002), tree cover (0.93 for all lakes; 0.87 for lakes with $>1$ fish) was more important than benthic reliance ( 0.69 for all lakes; 0.61 for lakes with 
$>1$ fish), but both were strongly supported model variables. In contrast, there was little support for all other model variables $\left(\mathrm{AIC}_{\mathrm{c}}\right.$ weights $\left.<0.1\right)$.

\subsection{Discussion}

We observed a wide range of mercury bioaccumulation in invertebrates and fish both within lakes and across the landscape. As we anticipated, our models suggested that both landscape-scale and ecological processes were important for explaining differences in mercury bioaccumulation across our sample lakes. However, benthic primary production, which we used as an indicator variable for limnological and morphometric drivers of mercury bioaccumulation, was not an important predictor of fish mercury. Wet weight concentrations of mercury in mountain lake fish from all of our study lakes were below the EPA fish tissue methylmercury criterion value, indicating relatively low risk of health effects from $\mathrm{Hg}$ in comparison to top predator fish in more impacted ecosystems (Eagles-Smith et al. 2016a).

Although there were no significant differences in mean mercury between parks, we observed significantly lower mercury concentrations in Rainbow Trout compared to Cutthroat and Brook Trout, even though trophic position was not different between species (ANOVA: $F_{2,70}=0.94, p=0.40$ ). This could be the result of more voracious predation - and thus greater bioaccumulation potential - which has been observed by Brook Trout in mountain lakes (Bull and Marx 2002, Murphy 2002). Therefore, species identity may be an important factor to consider in the management of mountain lake fisheries and potential mercury exposure to anglers. 
As we hypothesized, tree cover was an important landscape-level driver of fish mercury concentrations. The importance of tree cover in our models is in line with previous studies that found relationships between conifer cover and fish mercury (Drenner et al. 2013, Eagles-Smith et al. 2016b), as the forests in our study lakes were all conifer dominated. However, contrary to past studies, our calculations of tree cover were within a buffer around each lake, instead of at the catchment scale. We chose this approach because the mechanisms by which tree cover leads to higher mercury bioaccumulation - throughfall and litterfall (Graydon et al. 2008, Drenner et al. 2013) are likely most pronounced at the lake edge. Additionally, strong elevation gradients exist within a single lake catchment in these regions, leading to large differences in nearshore versus catchment-scale tree density. As a result, climate change may have important implications for fish mercury bioaccumulation because a warming climate may facilitate the expansion of tree cover to higher elevations (Theurillat and Guisan 2001). For example, using estimates from our more conservative model (lakes with $>1$ fish), an increase in tree cover from $70 \%$ to $75 \%$ would result in an increase of fish LSM from 320 $\mathrm{ng} / \mathrm{g}$ to $340 \mathrm{ng} / \mathrm{g}$, or $6.3 \%$.

Because diet is the primary route of $\mathrm{MeHg}$ exposure in fishes (Hall et al. 1997), variation in prey items is often a key determinant influencing fish $\mathrm{Hg}$ concentration, particularly if there are differences in prey $\mathrm{MeHg}$ concentrations. Zooplankton $\mathrm{MeHg}$ concentrations were generally higher than those of benthic invertebrates, thus it is surprising that benthic reliance was positively correlated with fish $\mathrm{Hg}$ concentrations across our sample lakes. Because mountain lakes are typically resource limited, fish diet 
is likely dictated by prey availability, meaning lakes containing fish with high benthic reliance probably have macroinvertebrate-dominated food webs. Additionally, prey quality may be a factor influencing this result. Fish with a benthic diet in New England lakes had less mercury than fish with a pelagic diet because benthic prey were higher quality, and fish need to consume fewer benthic invertebrates relative to zooplankton to meet their caloric demands (Karimi et al. 2016). Perhaps the opposite is true in mountain lakes: benthic prey may be of lower quality, and thus fish need to eat more - and consequently accumulate more mercury - to meet their caloric demands. Many of the common benthic invertebrates in the New England lakes were soft bodied, including amphipods, dragonfly larvae, and chironomids, whereas the more common benthic invertebrates found in our lakes included beetle larvae, adult aquatic beetles, and caddisflies, whose bodies contain more recalcitrant material. It could also be possible that more effort is expended by fish to find and consume enough calories of benthic prey to meet their energy demands, which could lead to poorer body condition. Interestingly, terrestrial prey may be an important prey subsidy to fish in mountain lakes (Vander Zanden and Gratton 2011, Rola et al. 2018), but the stable carbon isotope signatures of benthic and terrestrial organisms can often overlap, due to the contribution of terrestrial carbon to the littoral zone (Pace et al. 2004). This overlap could be contributing to inflated estimates of benthic reliance of our fish, especially considering that mountain lake consumers are highly omnivorous (Sánchez-Hernández et al. 2015). These overestimates could in turn be overshadowing biodilution of mercury in fish who rely on terrestrial prey as a significant part of their diet, because terrestrial insects have lower 
mercury than within-lake prey (Bartrons et al. 2015). Further investigation into the role of fish diet, and especially terrestrial prey subsidies, will be important for gaining a better understanding of how food web structure and foraging habitat influence mercury bioaccumulation in mountain lakes.

Contrary to our hypotheses, benthic primary production was not an important predictor of fish $\mathrm{Hg}$. However, our ability to discern any relationship was likely constrained by a limited sample size of lakes with a narrow gradient in benthic productivity. Moreover, we used modeled estimates of benthic primary production in our analyses, which included morphometry variables that were also modeled, likely resulting in greater error in our estimates than actual measured rates. In situ measurements are likely to provide a more accurate estimate of benthic production, and may be more informative to use in future studies. However, there is likely more to understand about how this variable interacts with mercury bioavailability and bioaccumulation. For example, we hypothesized that higher benthic production would lead to conditions antagonistic to $\mathrm{MeHg}$ production, and thus less bioavailability at the base of the food web. However, lakes with high benthic primary production also tend to have lower catchment slopes than lakes with lower benthic primary production (Vadeboncoeur et al. 2008). Therefore, lakes with high benthic production probably also produce more labile DOC than lakes with lower benthic production (Winn et al. 2009), and this higher labile DOC production may lead to increased rates of methylation, while contributions of recalcitrant DOC may inhibit photodemethylation (Ravichandran 2004, Klapstein and O’Driscoll 2018). Thus, the role of benthic primary production in mercury 
bioaccumulation is likely more complicated than we originally hypothesized, but still important to consider, because it can comprise a substantial portion of lake primary production, and affect fish diet availability via secondary production (Vander Zanden et al. 2006, 2011).

\subsection{Conclusion}

Our results indicate that both landscape and food web factors are important determinants of mercury bioaccumulation in mountain lake food webs. Together, tree cover and benthic reliance (a function of prey availability) explained much of the variability in mean fish mercury concentrations in mountain lakes across Washington. Therefore, it may be possible to identify lakes with the potential for higher mercury bioaccumulation in fish by surveying nearshore tree cover and invertebrate communities. The importance of tree cover in our models also implies that climate change could lead to higher mercury bioaccumulation in the future, as tree cover and DOC are likely to increase in high elevation lakes. Our findings have important implications for the management of mountain lake fisheries, and may help inform the decision-making process of management agencies who are responsible for fish stocking and/or fish removal. 
Table 2.1 Summary of measured and modeled environmental variables for all lakes. Hypolimnetic temperature and oxygen were only measured in lakes with maximum depth $<30 \mathrm{~m}(\mathrm{n}=17)$.

\begin{tabular}{|c|c|c|c|}
\hline Variable & Median & Min & Max \\
\hline Mean depth (m) & 4.90 & 1.40 & 17.70 \\
\hline Max depth (m) & 8.90 & 2.80 & 79.00 \\
\hline Surface area (ha) & 4.0 & 0.5 & 25.0 \\
\hline Slope $(\%, 100 \mathrm{~m}$ buffer $)$ & 46.88 & 12.90 & 86.89 \\
\hline Slope $(\%, 25 \mathrm{~m}$ buffer $)$ & 22.59 & 5.13 & 99.80 \\
\hline Elevation $(\mathrm{m})$ & 1387 & 1250 & 1747 \\
\hline Elevation change units ( $\mathrm{m}, 25 \%$ buffer) & 1406.5 & 1254.6 & 1780.3 \\
\hline Clarity (\%max depth) & 75.8 & 15.1 & 100.0 \\
\hline Hypolimnetic temperature $\left({ }^{\circ} \mathrm{C}\right)$ & 9.80 & 5.04 & 16.50 \\
\hline Mean annual air temperature $\left(5\right.$-year; $\left.{ }^{\circ} \mathrm{C}\right) \dagger$ & 5.42 & 2.03 & 6.09 \\
\hline Mean annual watershed precipitation $(5$-year; $\mathrm{mm}) \dagger$ & 3114.6 & 1820.8 & 4326.4 \\
\hline Hypolimnetic dissolved oxygen saturation (\%) & 87.11 & 16.40 & 124.40 \\
\hline Specific conductance $(\mu \mathrm{S} / \mathrm{cm})$ & 41.6 & 8.8 & 138.8 \\
\hline $\mathrm{pH}$ & 6.80 & 6.18 & 7.83 \\
\hline Phosphorus $(\mu \mathrm{g} / \mathrm{L})^{*}$ & 5 & 2 & 22 \\
\hline Edible chlorophyll $a(\mu \mathrm{g} / \mathrm{L})^{*}$ & 0.37 & 0.03 & 2.77 \\
\hline Benthic primary production $(\%) \dagger$ & 39 & 19 & 57 \\
\hline Nearshore tree over (\%) & 26.1 & 2.2 & 93.0 \\
\hline
\end{tabular}


Table 2.2 Summary of fish variables for all lakes.

\begin{tabular}{llll}
\hline Variable & Median & Min & Max \\
\hline $\begin{array}{l}\text { Geometric mean Hg }(\mathrm{dw} ; \\
\mathrm{ng} / \mathrm{g})\end{array}$ & 271.85 & 109.44 & 549.27 \\
Average $\mathrm{Hg}(\mathrm{dw} ; \mathrm{ng} / \mathrm{g})$ & 317.50 & 114.17 & 612.25 \\
$\mathrm{LSM} \mathrm{Hg} \mathrm{(dw;} \mathrm{ng} / \mathrm{g}) \dagger$ & 329 & 0 & 626.67 \\
Weight $(\mathrm{g})$ & 118 & 12 & 360 \\
Length $(\mathrm{mm})$ & 177 & 20 & 339 \\
Trophic position $\dagger$ & 2.9 & 2.3 & 3.5 \\
Benthic reliance $(\%) \dagger$ & 67.16 & 0.00 & 100.00 \\
\hline$\dagger$ Modeled values & & & \\
dw $=$ dry weight & & &
\end{tabular}




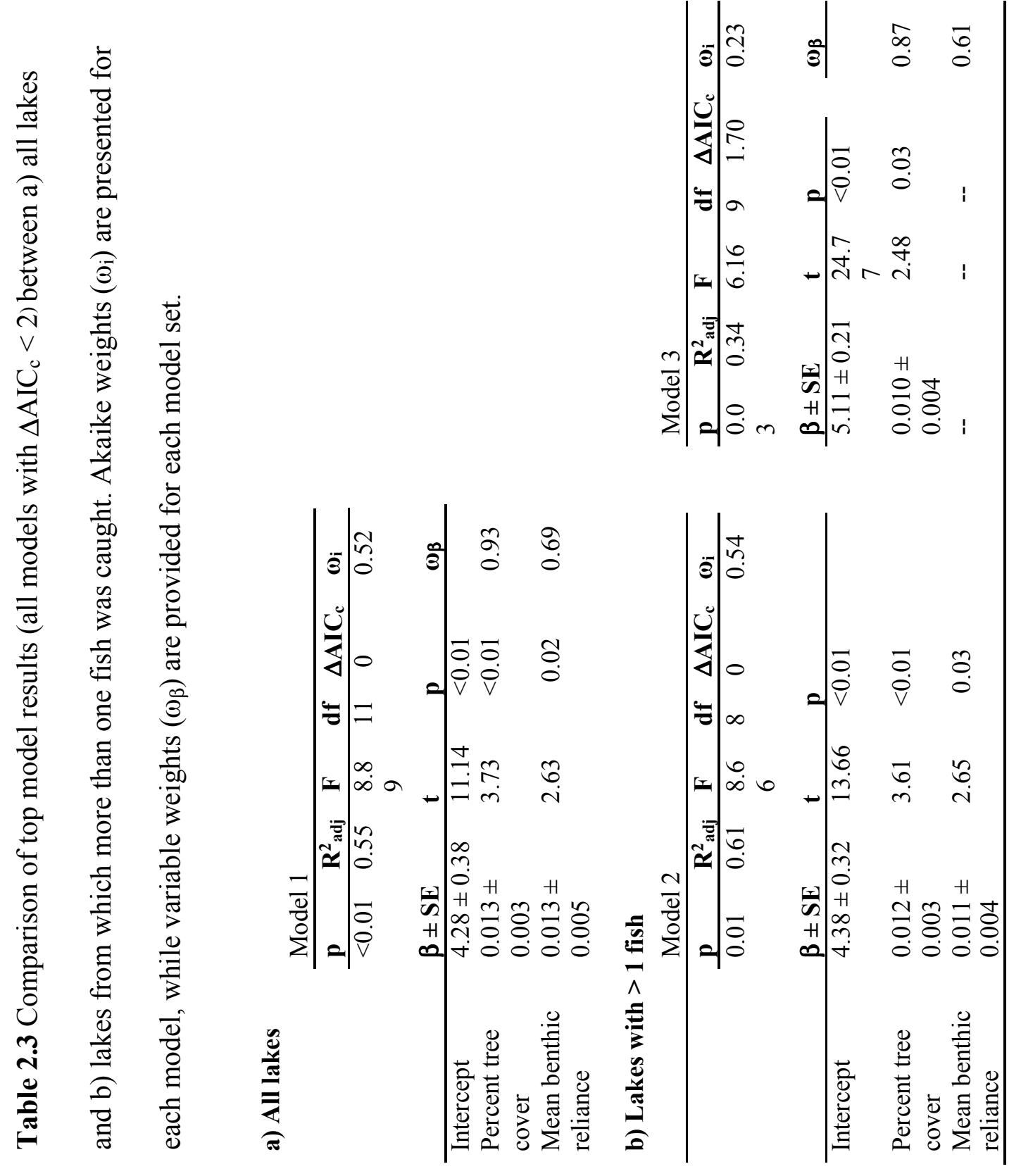



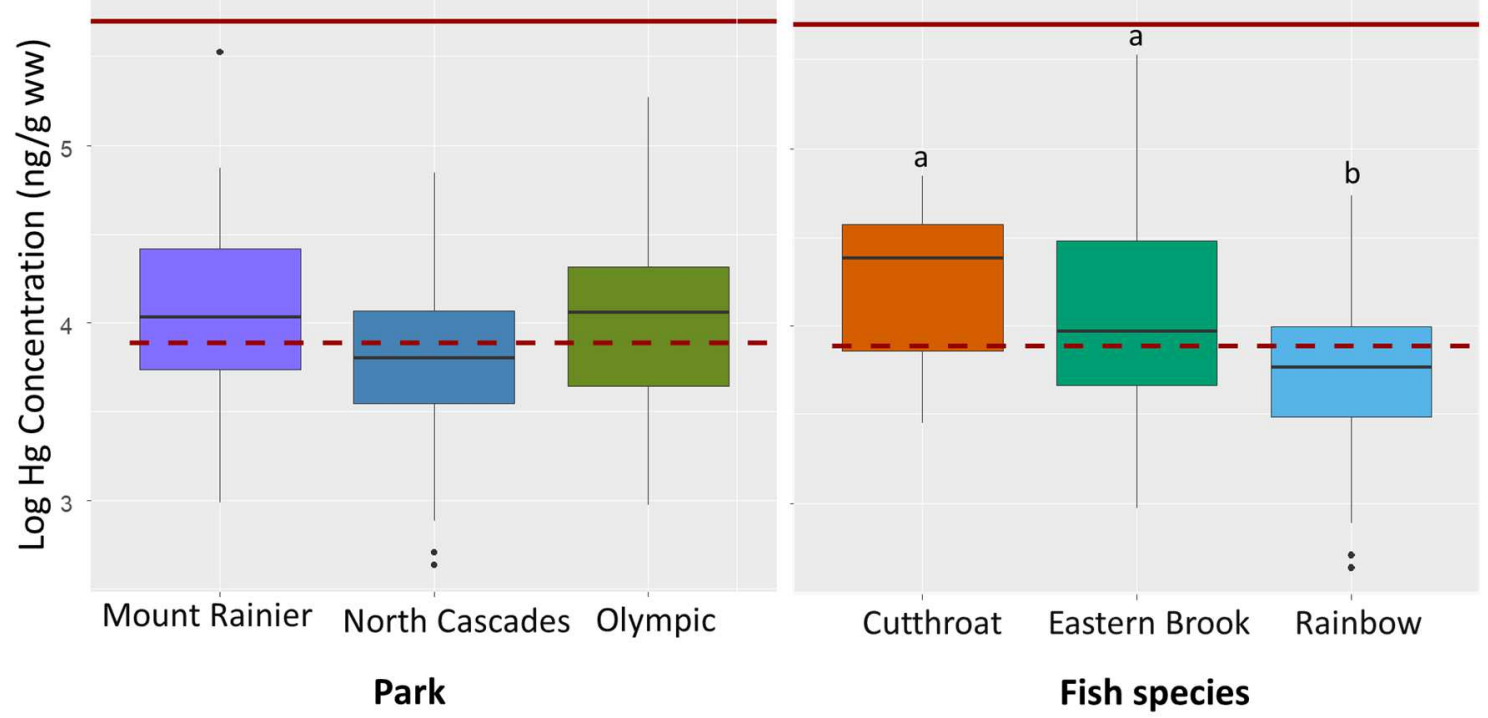

Figure 2.1 Differences in wet weight $\mathrm{Hg}$ (ln-transformed) in fish $(\mathrm{n}=100)$, between Mount Rainier $(n=6)$, North Cascades $(n=7)$, and Olympic National Park $(n=6)($ left $)$ and between Cutthroat $(n=16)$, Eastern Brook $(n=38)$, and Rainbow Trout $(n=46)$ (right), compared to consumption thresholds (which are listed in wet weight). The solid red line indicates the EPA fish tissue methylmercury criterion value $(300 \mathrm{ng} / \mathrm{g})$ while the dotted red line indicates the EPA recommendation for subsistence intake (50 ng/g). Letters denote significant differences (Tukey's HSD $\mathrm{p}<0.05$ ) in fish mercury concentrations between species. 


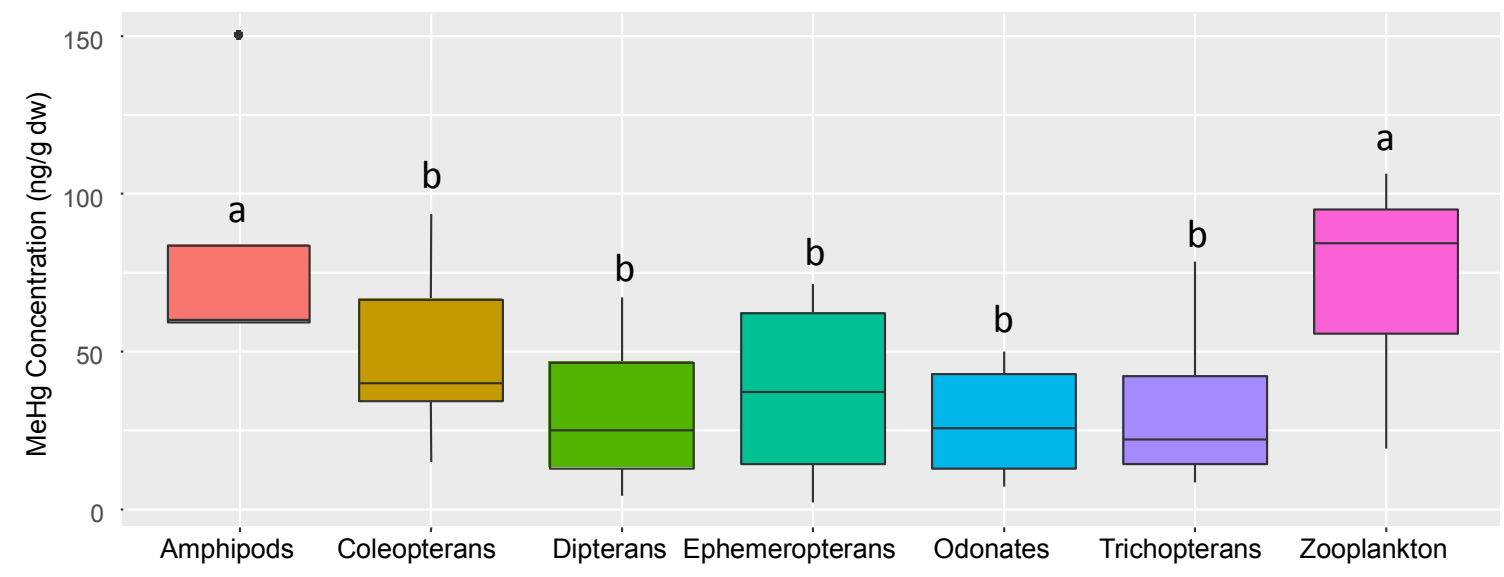

Figure 2.2 Boxplot of average invertebrate $\mathrm{MeHg}$ concentrations (DW ng/g) in each lake, grouped by order (with the exception of zooplankton, which are a composite sample). Letters denote significant differences (Tukey's-adjusted LSM difference $\mathrm{p}<0.05)$ in invertebrate $\mathrm{MeHg}$ between taxa. 

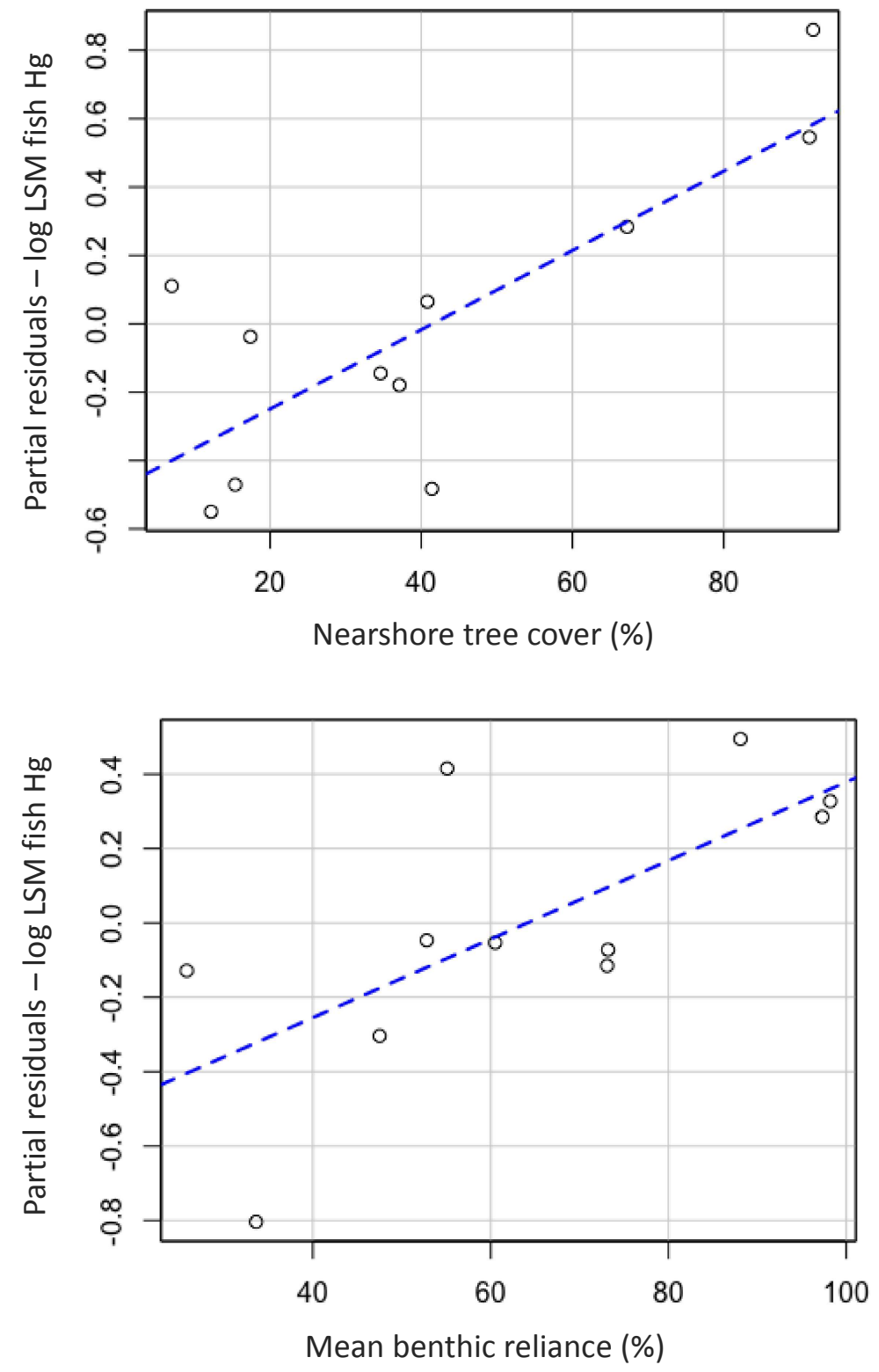

Figure 2.3 Partial residual plots of top model variables of percent nearshore tree cover (above) and mean benthic reliance (below) for lakes with $>1$ fish. Model variables are on the x-axes, and component-specific partial residuals of ln LSM fish mercury are on the yaxes. Pink lines represent Fish mercury concentrations increase with greater nearshore tree cover and a higher degree of benthic reliance. 


\subsection{References}

Arar, E.., Collins, G.., 1997. Method 445.0: In vitro determination of chlorophyll a and pheophytin a in marine and freshwater algae by fluorescence.

Bartoń, K., 2019. MuMIn: Multi-Model Inference.

Bartrons, M., Gratton, C., Spiesman, B.J., Vander Zanden, M.J., 2015. Taking the trophic bypass : aquatic-terrestrial linkage reduces methylmercury in a terrestrial food web. Ecol. Appl. 25, 151-159.

Bloom, N.S., 1992. On the Chemical Form of Mercury in Edible Fish and Marine Invertebrate Tissue. 1Canadian J. Fish. Aquat. Sci. 49, 1010-1017.

Bull, E.L., Marx, D.B., 2002. Influence of fish and habitat on amphibian communities in high elevation lakes in northeastern Oregon. Northwest Sci. 76, 240-248.

Burnham, K.P., Anderson, D.R., 2002. Model Selection and Multimodel Inference: a Practical Information-theoretic Approach, second ed. Springer-Verlag, New York.

Cabana, Gilbert; Rasmussen, J.B., 1994. Modelling food chain structure and contaminant bioaccumulation using stable isotopes. Lett. to Nat. 372, 255-257.

Chiapella, A.M., Nielsen-Pincus, M., Strecker, A.L., 2018. Public perceptions of mountain lake fisheries management in national parks. J. Environ. Manage. 226, 169-179. https://doi.org/10.1016/j.jenvman.2018.08.040

Clayden, M.G., Kidd, K. a., Wyn, B., Kirk, J.L., Muir, D.C.G., O’Driscoll, N.J., 2013. Mercury biomagnification through food webs is affected by physical and chemical characteristics of lakes. Environ. Sci. Technol. 47, 12047-12053. 
https://doi.org/10.1021/es4022975

Cyr, H., Curtis, J.., 1999. Zooplankton community size structure and taxonomic composition affects size-selective grazing in natural communities. Oecologia 118, 306-315.

Drenner, R.W., Chumchal, M.M., Jones, C.M., Lehmann, C.M.B., Gay, D. a, Donato, D.I., 2013. Effects of mercury deposition and coniferous forests on the mercury contamination of fish in the south central United States. Environ. Sci. Technol. 47, S:1-7. https://doi.org/10.1021/es303734n

Eagles-Smith, C.A., Ackerman, J.T., Willacker, J.J., Tate, M.T., Lutz, M.A., Fleck, J.A., Stewart, A.R., Wiener, J.G., Evers, D.C., Lepak, J.M., Davis, J.A., Pritz, C.F., 2016a. Spatial and temporal patterns of mercury concentrations in freshwater fish across the Western United States and Canada. Sci. Total Environ. 568, 1171-1184. https://doi.org/10.1016/j.scitotenv.2016.03.229

Eagles-Smith, C.A., Herring, G., Johnson, B., Graw, R., 2016b. Conifer density within lake catchments predicts fish mercury concentrations in remote subalpine lakes. Environ. Pollut. 212, 279-289. https://doi.org/10.1016/j.envpol.2016.01.049

Eagles-Smith, C.A., Suchanek, T.H., Colwell, A.E., Anderson, N.L., 2008a. Mercury trophic transfer in a eutrophic lake: The importance of habitat-specific foraging. Ecol. Appl. 18, 196-212. https://doi.org/10.1890/06-1476.1

Eagles-Smith, C.A., Suchanek, T.H., Colwell, A.E., Anderson, N.L., Moyle, P.B., $2008 b$. Changes in fish diets and food web mercury bioaccumulation induced by an invasive planktivorous fish. Ecol. Appl. 18, 213-226. https://doi.org/10.1890/06-1415.1 
Eagles-Smith, C.A., Wiener, J.G., Eckley, C.S., Willacker, J.J., Evers, D.C., MarvinDiPasquale, M., Obrist, D., Fleck, J.A., Aiken, G.R., Lepak, J.M., Jackson, A.K., Webster, J.P., Stewart, A.R., Davis, J.A., Alpers, C.N., Ackerman, J.T., 2016c. Mercury in western North America: A synthesis of environmental contamination, fluxes, bioaccumulation, and risk to fish and wildlife. Sci. Total Environ. 568, 12131226. https://doi.org/10.1016/j.scitotenv.2016.05.094

Fitzgerald, W.F., Engstrom, D.R., Mason, R.P., Nater, E. a., 1998. The Case for Atmospheric Mercury Contamination in Remote Areas. Environ. Sci. Technol. 32, 1-7. https://doi.org/10.1021/es970284w

Gorski, P.R., Cleckner, L.B., Hurley, J.P., Sierszen, M.E., Armstrong, D.E., 2003. Factors affecting enhanced mercury bioaccumulation in inland lakes of Isle Royale National Park, USA. Sci. Total Environ. 304, 327-348. https://doi.org/10.1016/S0048-9697(02)00579-X

Graydon, J.A., Louis, V.L.S., Hintelmann, H., Lindberg, S.E., Sandilands, A., Rudd, J.W.M., Kelly, C.A., Hall, B.D., Mowat, L.D., 2008. Long-Term Wet and Dry Deposition of Total and Methyl Mercury in the Remote Boreal Ecoregion of Canada Long-Term Wet and Dry Deposition of Total and Methyl Mercury in the Remote Boreal Ecoregion of Canada 8345-8351. https://doi.org/10.1021/es801056j

Hall, B.D., Bodaly, R.A., Fudge, R.J.P., Rudd, J.W.M., Rosenberg, D.M., 1997. Food as the dominant pathway of methylmercury uptake by fish. Water 100, 13-24.

Heathcote, A.J., del Giorgio, P. a., Prairie, Y.T., Brickman, D., 2015. Predicting bathymetric features of lakes from the topography of their surrounding landscape. 
Can. J. Fish. Aquat. Sci. 72, 643-650. https://doi.org/10.1139/cjfas-2014-0392

Hecky, R.E., Hesslein, R.H., 1995. Contributions of benthic algae to lake food webs as revealed by stable isotope analysis. J. North Am. Benthol. Soc. 14, 631. https://doi.org/10.2307/1467546

Heim, W.A., Coale, K.H., Stephenson, M., Choe, K.Y., Gill, G.A., Foe, C., 2007. Spatial and habitat-rased variations in total and methyl mercury concentrations in surficial sediments in the San Francisco Bay-Delta. Environ. Sci. Technol. 41, 3501-3507. https://doi.org/10.1021/es0626483

Jaffe, D., Strode, S., 2008. Sources, fate and transport of atmospheric mercury from Asia. Environ. Chem. 5, 121-126.

Jardine, T.D., Kidd, K.A., Rasmussen, J.B., 2012. Aquatic and terrestrial organic matter in the diet of stream consumers : implications for mercury bioaccumulation. Ecol. Appl. 22, 843-855.

Kainz, M., Lucotte, M., 2006. Mercury concentrations in lake sediments - Revisiting the predictive power of catchment morphometry and organic matter composition. Water. Air. Soil Pollut. 170, 173-189. https://doi.org/10.1007/s11270-006-3009-z

Kallenborn, R., 2006. Persistent organic pollutants (POPs) as environmental risk factors in remote high-altitude ecosystems. Ecotoxicol. Environ. Saf. 63, 100-7. https://doi.org/10.1016/j.ecoenv.2005.02.016

Karimi, R., Chen, C.Y., Folt, C.L., 2016. Comparing nearshore benthic and pelagic prey as mercury sources to lake fish: The importance of prey quality and mercury 
content. Sci. Total Environ. 565, 211-221.

https://doi.org/10.1016/j.scitotenv.2016.04.162

Klapstein, S.J., O’Driscoll, N.J., 2018. Methylmercury Biogeochemistry in Freshwater Ecosystems: A Review Focusing on DOM and Photodemethylation. Bull. Environ. Contam. Toxicol. 100, 14-25. https://doi.org/10.1007/s00128-017-2236-x

Landers, D.H., Simonich, S.M., Jaffe, D., Geiser, L., Campbell, D.H., Schwindt, A., Schreck, C., Kent, M., Hafner, W., Taylor, H.E., Hageman, K., Usenko, S., Ackerman, L., Schrlau, J., Rose, N., Blett, T., Erway, M.M., 2008. The Fate , Transport, and Ecological Impacts of Airborne Contaminants in Western National Parks (USA), EPA/600/R-07/138. U.S. Environmental Protection Agency, Office of Research and Development, NHEERL, Western Ecology Division, Corvallis, OR.

Lavoie, R. a, Jardine, T.D., Chumchal, M.M., Kidd, K. a, Campbell, L.M., 2013. Biomagnification of Mercury in Aquatic Food Webs: A Worldwide Meta-Analysis. Environ. Sci. Technol. 47, 13385-13394. https://doi.org/10.1021/es403103t

Lenth, R., 2018. 1smeans: Least-Square Means.

Loewen, C.J.G., Strecker, A.L., Larson, G.L., Vogel, A., Fischer, J.M., Vinebrooke, R.D., 2018. Macroecological drivers of zooplankton communities across the mountains of western North America. Ecography (Cop.). 1-13. https://doi.org/10.1111/ecog.03817

McIntyre, J.K., Beauchamp, D. a, 2007. Age and trophic position dominate bioaccumulation of mercury and organochlorines in the food web of Lake Washington. Sci. Total Environ. 372, 571-84. 
https://doi.org/10.1016/j.scitotenv.2006.10.035

Messager, M.L., Lehner, B., Grill, G., Nedeva, I., Schmitt, O., 2016. Estimating the volume and age of water stored in global lakes using a geo-statistical approach. Nat. Commun. 7, 1-11. https://doi.org/10.1038/ncomms13603

Morel, F.M.M., Kraepiel, A.M.L., Amyot, M., 1998. The Chemical Cycle and Bioaccumulation of Mercury. Annu. Rev. Ecol. Syst. 29, 543-566. https://doi.org/10.1146/annurev.ecolsys.29.1.543

Murphy, P.D., 2002. The effects of different species of introduced salmonids on amphibians in headwater lakes of north-central Idaho. Idaho State University, Pocatello.

O’Reilly, C.M., Rowley, R.J., Schneider, P., Lenters, J.D., Mcintyre, P.B., Kraemer, B.M., 2015. Rapid and highly variable warming of lake surface waters around the globe. Geophys. Res. Lett. 1-9. https://doi.org/10.1002/2015GL066235.Received

Pace, M.L., 2004. Whole lake carbon-13 additions reveal terrestrial support of aquatic food webs. Nature 427, 240-243. https://doi.org/10.1038/nature02215.1.

Parkman, H., Meili, M., 1993. Mercury in Macroinvertebrates from Swedish Forest Lakes: Influence of Lake Type, Habitat, Life Cycle, and Food Quality. Can. J. Fish. Aquat. Sci. 50, 521-534.

Pickhardt, P.C., Folt, C.L., Chen, C.Y., Klaue, B., Blum, J.D., 2002. Algal blooms reduce the uptake of toxic methylmercury in freshwater food webs. Proc. Natl. Acad. Sci. U. S. A. 99, 4419-4423. https://doi.org/10.1073/pnas.072531099 
Power, M., Klein, G.M., Guiguer, K.R.R.A., Kwan, M.K.H., 2002. Mercury accumulation in the fish community of a sub-Arctic lake in relation to trophic position and carbon sources. J. Appl. Ecol. 39, 819-830. https://doi.org/10.1046/j.1365-2664.2002.00758.x

PRISM Climate Group, Oregon State University [WWW Document], n.d. URL http://www.prism.oregonstate.edu

Ravichandran, M., 2004. Interactions between mercury and dissolved organic matter - A review. Chemosphere 55, 319-331. https://doi.org/10.1016/j.chemosphere.2003.11.011

Ripley, B., Venables, B., Bates, D.M., Hornik, K., Gebhardt, A., Firth, D., 2019. MASS: Modern applied statistics.

Rola, M., Biffoni, G., Brighenti, S., Iacobuzio, R., Liautaud, K., Pasquaretta, C., Tiberti, R., 2018. Predation by introduced fish can magnify the terrestrial arthropod subsidies in mountain lakes. Can. J. Fish. Aquat. Sci. 1-25.

Sackett, D.K., Aday, D.D., Rice, J.A., Cope, W.G., Buchwalter, D., 2010. Does proximity to coal-fired power plants influence fish tissue mercury? Ecotoxicology 19, 1601-1611. https://doi.org/10.1007/s10646-010-0545-5

Sadro, S., Melack, J.M., MacIntyre, S., 2011. Spatial and Temporal Variability in the Ecosystem Metabolism of a High-elevation Lake: Integrating Benthic and Pelagic Habitats. Ecosystems 14, 1123-1140. https://doi.org/10.1007/s10021-011-9471-5

Sánchez-Hernández, J., Cobo, F., Amundsen, P.-A., 2015. Food Web Topology in High 
Mountain Lakes. PLoS One 10, e0143016.

https://doi.org/10.1371/journal.pone.0143016

St. Louis, V.L., Rudd, J.W.M., Kelly, C. a., Beaty, K.G., Bloom, N.S., Flett, R.J., 1994. Importance of Wetlands as Sources of Methyl Mercury to Boreal Forest Ecosystems. Can. J. Fish. Aquat. Sci. 51, 1065-1076. https://doi.org/10.1139/f94-106

TerraColor, n.d. TerraColor $15 \mathrm{~m}$ imagery.

Theurillat, J.P., Guisan, A., 2001. Potential impact of climate change on vegetation in the European alps: A review. Clim. Change 50, 77-109. https://doi.org/10.1023/A:1010632015572

Tremblay, A., Lucotte, M., Rheault, I., 1996. Methylmercury in a benthic food web of two hydroelectric reservoirs and a natural lake of northern Quebec (Canada). Water Air Soil Pollut. 91:255-269. http://dx.doi.org/10.1007/BF00666262.

Ullrich, S.M., Tanton, T.W., Abdrashitova, S. a., 2001. Mercury in the aquatic environment: a review of factors affecting methylation. Crit. Rev. Environ. Sci. Technol. 31, 241-293. https://doi.org/10.1080/20016491089226

U.S. EPA (U.S. Environmental Protection Agency). 2000. Methodology for Deriving Ambient Water Quality Criteria for the Protection of Human Health (2000). Office of Science and Technology, Office of Water. Washington, D.C. EPA-822-B-00-004.

Vadeboncoeur, Y., Peterson, G., Vander Zanden, M.J., Kalff, J., 2008. Benthic Algal Production across Lake Size Gradients : Interactions among Morphometry. Ecology $89,2542-2552$. 
Vadeboncoeur, Y., Vander Zanden, M.J., Lodge, D.M., 2002. Putting the Lake Back Together: Reintegrating Benthic Pathways into Lake Food Web Models. BioScience 52, 44-54. https://doi.org/10.1641/0006-3568(2002)052[0044:PTLBTR]2.0.CO;2

Valderrama (1981). The simultaneous analysis of total nitrogen and total phosphorus on natural waters. Mar.Chem (10), 109-122

Vander Zanden, M.J., Chandra, S., Park, S.-K., Vadeboncoeur, Y., Goldman, C.R., 2006. Efficiencies of benthic and pelagic trophic pathways in a subalpine lake. Can. J. Fish. Aquat. Sci. 63, 2608-2620. https://doi.org/10.1139/f06-148

Vander Zanden, M.J., Gratton, C., 2011. Blowin' in the wind: reciprocal airborne carbon fluxes between lakes and land This paper is based on the J.C. Stevenson Memorial Lecture presented at the Canadian Conference for Fisheries Research (CCFFR) in Ottawa, Ontario, 9-11 January 2009. Can. J. Fish. Aquat. Sci. 68, 170-182. https://doi.org/10.1139/F10-157

Vander Zanden, M.J., Vadeboncoeur, Y., Chandra, S., 2011. Fish Reliance on LittoralBenthic Resources and the Distribution of Primary Production in Lakes. Ecosystems 14, 894-903. https://doi.org/10.1007/s10021-011-9454-6

Williams, J., Labou, S.G., 2017. A database of georeferenced nutrient chemistry data for mountain lakes of the Western United States. Sci. Data 4, 170069. https://doi.org/10.1038/sdata.2017.69

Winn, N., Williamson, C.E., Abbitt, R., Rose, K., Renwick, W., Henry, M., Saros, J., 2009. Modeling dissolved organic carbon in subalpine and alpine lakes with GIS and remote sensing. Landsc. Ecol. 24, 807-816. https://doi.org/10.1007/s10980-009- 
9359-3

Wong, A.H.K., McQueen, D.J., Williams, D.D., Demers, E., 1997. Transfer of mercury from benthic invertebrates to fishes in lakes with contrasting fish community structures. Can. J. Fish. Aquat. Sci. 54, 1320-1330. https://doi.org/10.1139/f97-035 
Chapter 3

\title{
Can fatty acid stable isotopes overcome the diet-tracing challenges of bulk stable isotope approaches?
}

\author{
Co-authors: Martin Kainz, Angela Strecker
}

\subsection{Introduction}

A central goal in the field of ecology is to understand the flow of energy in ecosystems. By advancing this effort, it is possible to help evolve theories related to energy flow, trophic dynamics, and cross-ecosystem interactions. Lakes are an especially important context in which to study these concepts, as they are sentinels of environmental change (Schindler 2009), exist in many different ecotones across the world, and have distinct ecosystem boundaries. Although lake food webs are often simplified into two linear food chains (benthic and pelagic), there is now a wealth of evidence supporting strong habitat coupling, as well as significant allochthonous subsidies, especially in smaller lakes (e.g., Vander Zanden \& Vadeboncoeur 2002, Pace et al. 2004, Carpenter et al. 2005, Milardi et al. 2015). These phenomena are observed both at the base of the food web (via carbon and nutrient cycling; e.g., Pace et al. 2004, Solomon et al. 2011), as well as with top predators like fish (via cross-habitat foraging and terrestrial insect subsidies; e.g., Vander Zanden \& Vadeboncoeur 2002, Milardi et al. 2015). Because large fish are often omnivorous and can migrate across habitat boundaries within lakes, it is difficult to accurately trace and quantify their energy sources. However, being able to partition energy sources is critical for understanding energy flow and the role of subsidies in lakes. Compound-specific isotopes may present a new solution to this persistent challenge. 
Traditional research methods on energy flow, such as gut content analysis and bulk stable isotope analysis, can provide insight into energy pathways, but have many assumptions and limitations. For instance, gut content analyses provide dietary information for just a snapshot in time, and identification is biased toward organisms that are not easily digested (e.g., Grey 2006). Bulk stable isotope analysis is subject to seasonal variability (Grey et al. 2004), discrepancies in turnover time between food web items, and significant error without a strong isotopic baseline (Post 2002, Grey 2006). In addition, bulk stable isotopes have low taxonomic resolution (Peterson and Fry 1987), making it nearly impossible to trace energy along specific pathways with precision, especially if energy sources have overlapping isotope signatures, as is common with benthic and terrestrial sources (France 1995). Without employing other methods, bulk stable isotope analysis alone may fail to provide enough information to extract specific details about energy flow in lake food webs (Grey 2006).

Fatty acid profiles of diet items can differ between both prey species (Lau et al. 2012) and lake habitats (Napolitano 1999, Brett et al. 2009), but the accuracy of this method for dietary tracing lacks consistency. Preliminary evidence suggests that the $\delta^{13} \mathrm{C}$ signature of fatty acids $\left(\delta^{13} \mathrm{C}_{\mathrm{FA}}\right)$ can discriminate between diet sources at a finer resolution than traditional bulk stable isotope analysis (Evershed et al. 2007), and this method has shown promise, especially when used in conjunction with fatty acid profiles. The combined use of fatty acid biomarkers and stable isotope signatures of fatty acids show increasing utility in their ability to trace consumer diet sources in aquatic food webs (Evershed et al. 2007, Budge et al. 2008, Bec et al. 2011, Taipale et al. 2015). 
The five common essential fatty acids (EFAs) - linoleic acid (LIN; 18:2n-6), arachidonic acid (ARA; 20:4n-6), alpha-linoleic acid (ALA; 18:3n-3), eicosapentaenoic acid (EPA; 20:5n-3), and docosahexaenoic acid (DHA; 22:6n-3) - may be especially useful in tracing dietary sources. Vertebrates lack the enzymes necessary to synthesize ALA and LIN, which are precursors that can be used to make small amounts of ARA (via LIN), EPA (via ALA), and DHA (via ALA and/or EPA). Therefore, EFAs can only be obtained via a fish's diet, yet serve critical physiological functions. EPA, DHA and ARA are particularly important for fish somatic growth, neural and ocular development, reproduction, and survival (Parrish et al. 2009).

Assuming a fish's diet has a sufficient amount of each EFA - which can be assessed by quantifying fatty acid concentrations - the $\delta^{13} \mathrm{C}$ signature of each EFA in the fish should be similar to the $\delta^{13} \mathrm{C}$ signatures of the respective EFA in their diets (Bec et al. 2011). Deviation of essential fatty acid $\delta^{13} \mathrm{C}$ between a fish and its diet can be expected when fractionation occurs as a result of bioconversion of precursor fatty acids (e.g., ALA, LIN), which is necessary when there are insufficient concentrations of dietary EFAs to support the needs of the fish. This scenario can be identified by calculating the concentration factors for each EFA - which we define as the proportion of a fatty acid in a consumer divided by the proportion of that fatty acid in its diet. Fish with high concentration factors for a given EFA are likely not getting enough of that EFA from their diet, and have to elongate and/or desaturate a precursor fatty acid in order to meet its physiological demands. Therefore, the $\delta^{13} \mathrm{C}$ value of that $\mathrm{EFA}$ will be enriched relative to its diet due to preferential use of the lighter isotope during bioconversion. For example, if sufficient amounts of DHA are not present in a fish's diet, then fish must then elongate 
and desaturate the precursors ALA and/or EPA. These transformations would result in the fractionation of ALA, EPA, and DHA $\delta^{13} \mathrm{C}$ in fish tissues, leading to depleted $\delta^{13} C_{\text {DHA }}$ values in the fish relative to its diet.

Using $\delta^{13} \mathrm{C}$ of EFAs may be particularly useful for distinguishing between terrestrial and benthic aquatic diet sources in fish. DHA and EPA tend to primarily be found in aquatic environments, because these EFAs are synthesized by algae, while ALA and LIN are typically considered to have more terrestrial origins (Sayanova and Napier 2004, Galloway and Winder 2015, Hixson et al. 2015). However, contrary to what one would expect based on these observations, there is little evidence that fatty acid profiles alone can distinguish aquatic- versus terrestrially-derived diet sources for omnivorous

freshwater consumers (Hixson et al. 2015), likely due to issues around bioconversion and biosynthesis (Bec et al. 2003, Brett et al. 2009). However, preliminary evidence shows that carbon isotope signatures of certain EFAs may be different between terrestrial and aquatic diet sources (Evershed et al. 2007, Budge et al. 2008; Bec et al. 2011). By employing the current knowledge of fatty acid biomarkers and stable isotope research, the use of fatty acid stable isotopes could be a very powerful diet-tracing tool. However, this method is in its infancy, and it is important to first test its effectiveness in a controlled setting.

\subsubsection{Objectives}

In order to experimentally test the ability of fatty acid stable isotopes to discriminate between terrestrial and benthic dietary sources, we conducted a laboratory study. We reared juvenile Arctic Char (Salvelinus alpinus) in mesocosms to investigate 
the following. (1) How do the fatty acid profiles and $\delta^{13} \mathrm{C}$ of EFAs between $S$. alpinus fed benthic invertebrates versus those fed terrestrial invertebrates differ, and how do the differences compare to bulk $\delta^{13} \mathrm{C}$ ? (2) Can $\delta^{13} \mathrm{C}$ of EFAs be used to partition dietary ratios from a mixed benthic and terrestrial diet? We tested these objectives by feeding fish a diet of either benthic stream invertebrates, terrestrial earthworms, a mix of both, or pellets. We then analyzed the fatty acid profiles, fatty acid $\delta^{13} \mathrm{C}$, and bulk $\delta^{13} \mathrm{C}$ of each fish after four weeks and compared them to their diets. Based on preliminary evidence suggesting that precursor EFAs can be useful dietary tracers (Evershed et al. 2007, Budge et al. 2008, Bec et al. 2011), we anticipated that we would see significant differences in $\delta^{13} \mathrm{C}$ of ALA, LIN, and possibly EPA between fish with benthic and terrestrial diets. We also anticipated that there would not be distinguishable differences in fatty acid profiles and bulk $\delta^{13} \mathrm{C}$ between fish with different diet treatments.

\subsection{Methods}

\subsubsection{Study design}

We used 1- $\mathrm{m}^{3}$ aquaculture tanks to simulate one of four diet scenarios: benthic, terrestrial, mixed, and control (Figure 3.1). Tanks were made of a fiberglass polyester mix, and had a flow-through system with a continuous supply of gravel-filtered spring water. Waste water was drained using a sink hole covered by a 5-mm mesh screen. Prior to the experiment, we reared S. alpinus in a hatchery at WasserCluster Lunz Biological Station, Austria. During hatchery rearing, fish were fed an isocaloric pellet diet daily (Table B1). We then randomly selected 45 juvenile fish (mean weight: $82 \mathrm{~g} \pm 17 \mathrm{SD}$ ) to add to the treatment tanks. Five fish were added to each of nine treatment tanks, which 
were randomly assigned a diet treatment: benthic (2), terrestrial (2), mixed (4), or control (continued pellet feed) (1). We assigned a higher number of mixed-diet treatments relative to single-diet treatments because one of our main objectives was to partition energy sources in a mixed diet scenario and we were constrained in the number of tanks available. The experiment was run for four weeks, which was likely enough time for the new diet to be reflected in tissues (Vander Zanden et al. 2015), though may not have allowed for whole-body tissue turnover. This time frame more realistically mimics how dietary shifts would be detected in nature.

All treatment fish received approximately $1.5 \%$ of their body weight in food daily (as in Murray et al. 2014). For the benthic invertebrate treatment, a mix of mayflies, stoneflies, and caddisflies were collected from a neighboring stream on a daily basis (Table B2). For the terrestrial treatment, earthworms were collected from riparian soil daily. All fresh invertebrates were weighed and portioned out for each treatment tank. All tanks received the same biomass daily. Mixed tanks received an approximate 50:50 mix of benthic invertebrates:earthworms, by mass. After weighing the samples, the invertebrates were placed in their respective tanks as fish feed. Each week, extra samples of each invertebrate were collected for analysis, as a means of tracking the baseline fatty acid ratios and $\delta^{13} \mathrm{C}_{\mathrm{FA}}$ values throughout the course of the experiment. After four weeks, fish were euthanized, dissected for muscle and liver tissues, and then frozen at $-80^{\circ} \mathrm{C}$. Fish were rendered unconscious (blow on the head) and then killed by cardiac incision following the Federal Act on the Protection of Animals, Austria (http://www.ris.bka.gv.at). 


\subsubsection{Sample processing and analysis}

A more thorough account of processing and analytical methods can be found in Taipale et al. (2011), but a brief overview is provided here. All sample analyses were completed at WasserCluster Lunz. Fish muscle and liver, benthic invertebrates, earthworms, and pellets were lyophilized then homogenized with a mortar and pestle. Lipids were extracted from each sample using a 4:2:1 chloroform:methanol:water mixture (Parrish 1999) and subsequent sonicating and vortexing. Fatty acid methyl esters (FAME) were formed by adding toluene and a sulfuric acid-methanol solution to the lipid extracts. Samples were then kept at $50^{\circ} \mathrm{C}$ for $16 \mathrm{~h}$. Final extractions for FAME were completed with hexane and centrifugation to release $\mathrm{CO}_{2}$, followed by drying with $\mathrm{N}_{2}$ and dissolving in hexane. The final FAME extracts were analyzed with a gas chromatograph (GC) equipped with a temperature-programmable injector and autosampler, and separated using a Supelco SP-2560 GC-column (100 m x $0.2 \mu \mathrm{m}$ x 0.25 $\mathrm{mm}$ ). Fatty acid mass fractions (i.e., mg fatty acid per g dry weight) were calculated using calibration curves based on standard concentrations. Samples were then analyzed for $\delta^{13} \mathrm{C}$ of individual fatty acids using a GC-isotope ratio mass spectrometer (IRMS) equipped with a Supelco SP-2560 GC-column (100 m x $0.2 \mu \mathrm{m}$ x $0.25 \mathrm{~mm}$ ), and quantified using internal fatty acid standards.

\subsubsection{Data analyses}

We compared concentrations and $\delta^{13} \mathrm{C}$ of essential fatty acids and bulk $\delta^{13} \mathrm{C}$ between diet items (i.e., earthworms, macroinvertebrates, pellets) and across treatments (i.e., terrestrial, benthic, mixed) in S. alpinus muscle and liver using Analysis of Variance 
(ANOVAs) linear mixed effects models, to account for the unbalanced effect of tank. In the mixed effects models for the diets, we used weekly subsamples as the sample unit, treatment as the fixed factor, and time as a random effect. In the mixed effects models for the fish, we used fish as the sample unit, treatment as a fixed factor, and tank as a random factor. We then conducted a post-hoc analysis by calculating the Tukey's-adjusted differences between least-squares means (LSM) of fatty acid concentrations for each treatment to determine if concentrations were distinctive across treatments. Calculating the least-squares means of each fatty acid group from the mixed effects models allowed us to control for the effect of time and tank, respectively, when comparing differences between treatments.

We used principal components analysis (PCA) to examine differences in fatty acid compositions between diets and between treatments in S. alpinus muscle and fish liver. We calculated concentration factors (also called calibration coefficients; Iverson et al. 2004, Budge et al. 2012) for each EFA by determining the ratio of each EFA concentration $(\mathrm{mg} / \mathrm{g})$ between fish $(f)$ and their respective diets $(d)$ :

\section{Equation 3.1 $\quad \mathrm{EFA}_{\mathrm{CF}}=\mathrm{EFA}_{\mathrm{f}} / \mathrm{EFA}_{\mathrm{d}}$}

If an EFA had a high concentration factor $(>2)$, this indicated that the dietary supply of that EFA was insufficient to meet the physiological demands of the fish. In this case, the fish would need to obtain the EFA by either mobilization from fat stores, or elongation and desaturation of a dietary precursor FA. This would mean the EFA $\delta^{13} \mathrm{C}$ value in the consumer would be more similar to the $\delta^{13} \mathrm{C}$ of the precursor in its diet (but also 
fractionated by more than $4 \%$ as a result of the modification; Budge et al. 2011).

Therefore, a high concentration factor would lead us to expect significant differences in fatty acid $\delta^{13} \mathrm{C}$ between a fish and its diet. We then determined the reliability of each essential fatty acid $\delta^{13} \mathrm{C}$ as a dietary tracer by calculating the difference in $\delta^{13} \mathrm{C}$ of each fatty acid $\left(\delta^{13} \mathrm{C}_{\mathrm{FA}}\right)$ between each fish $(f)$ and its respective $\operatorname{diet}(d)$ :

Equation 3.2 $\Delta \delta^{13} \mathrm{C}_{\mathrm{FA}}=\delta^{13} \mathrm{C}_{f}-\delta^{13} \mathrm{C}_{d}$

Due to high levels of variance in fatty acid $\delta^{13} \mathrm{C}$, we were unable to use isotope mixing models to partition differences in fatty acid $\delta^{13} \mathrm{C}$ in fish muscle and liver. All statistical methods were completed using packages MASS (Ripley et al. 2019), lme4 (Bates et al. 2019), lmerTest (Kuznetsova et al. 2019), lsmeans (Lenth 2018), and MuMIn (Bartoń 2019) in R Studio version 1.1.463 (R Studio Team 2016).

\subsection{Results}

Two fish experienced mortality after approximately 10 days, seemingly due to gas bubble disease (a common phenomenon in hatchery experiments due to oxygen supersaturation from water inflow), resulting in a 5\% mortality rate. All other fish did not show symptoms of this disease; however many fish lost weight during the experiment due to competition. In most tanks, 2-3 of the fish seemed to monopolize the diet additions, despite efforts to distribute the invertebrates evenly throughout the tank. Although all fish were observed feeding at some point, we only included fish who gained weight over the course of the experiment in our analyses $(n=23)$. 


\subsubsection{Fatty acid concentrations}

Concentrations of fatty acids in diets and fish varied widely, especially for essential fatty acids (Table B3). Differences in fatty acid profiles between diets were largely driven by differences in ALA and ARA concentrations between diets, with some differences in LIN, EPA, and DHA (Table 3.1, Figure 3.2). ALA concentrations were significantly different between diets: benthic invertebrates had significantly higher ALA than pellets (ANOVA: $F_{2,13}=12.99, p=0.05$ ). ARA concentrations were significantly different between diets ARA was higher in benthic invertebrates and earthworms relative to pellets (ANOVA: $\left.\mathrm{F}_{2,12}=8.72, \mathrm{p}<0.01\right)$. Benthic invertebrates did have somewhat higher LIN relative to earthworms, but concentrations were not significantly different between diets (ANOVA: $F_{2,11}=3.46, p=0.07$ ), but. EPA was somewhat higher in benthic invertebrates relative to pellets, but EPA concentrations were not significantly different between diets (ANOVA: $\left.F_{2,13}=2.95, p=0.09\right)$. DHA was somewhat higher in pellets relative to earthworms, but overall was not significantly different between diets (ANOVA: $\left.\mathrm{F}_{2,13}=3.54, \mathrm{p}=0.06\right)$.

Differences in fatty acid concentrations were not as pronounced in the respective treatments in fish muscle and liver (Table 3.1). Mean concentrations of the fatty acids did not differ significantly between treatments in fish muscle (ANOVA: $p>0.01$ for all models). There was a small random effect of tank for each of the treatments (Table B4).Concentration factors were low for most EFA, with the exception of DHA (Table 3.2). DHA concentration factors were high for all diet treatments, but most pronounced for fish with terrestrial and mixed diets. 


\subsubsection{Stable isotopes}

Although there was substantial variability in the $\delta^{13} \mathrm{C}$ of essential fatty acids, there were some significant differences observed in $\delta^{13} \mathrm{C}$ for certain fatty acids in the fish diets (Table 3.4, Figure 3.3). $\delta^{13} \mathrm{C}$ was significantly different between treatments for ALA (ANOVA: $\mathrm{F}_{2,10}=10.66, \mathrm{p}<0.01$ ), ARA (ANOVA: $\mathrm{F}_{2,10}=19.74, \mathrm{p}<0.01$ ), and EPA (ANOVA: $F_{2,8}=22.02, p<0.01$ ), but not LIN (ANOVA: $F_{2,10}=0.32 ; p=0.73$ ) or DHA (no values for benthic invertebrates). Earthworms were significantly more enriched in $\delta^{13} \mathrm{C}_{\mathrm{ALA}}, \delta^{13} \mathrm{C}_{\mathrm{ARA}}$, and $\delta^{13} \mathrm{C}_{\mathrm{EPA}}$ relative to benthic invertebrates. Earthworms were about 5\%o more enriched in $\delta^{13} \mathrm{C}_{\mathrm{ALA}}$, about 6\%o more enriched in $\delta^{13} \mathrm{C}_{\mathrm{ARA}}$, and about 3\%o more enriched in $\delta^{13} \mathrm{C}_{\mathrm{EPA}}$ relative to benthic invertebrates. We were unable to obtain $\delta^{13} \mathrm{C}_{\mathrm{DHA}}$ values in benthic invertebrates, possibly because concentrations were too low. Additionally, earthworm $\delta^{13} \mathrm{C}_{\mathrm{DHA}}$ was highly variable. Pellets had significantly more depleted $\delta^{13} \mathrm{C}_{\mathrm{ARA}}$ than earthworms, and significantly more enriched $\delta^{13} \mathrm{C}_{\mathrm{EPA}}$ than earthworms and benthic invertebrates, and significantly more enriched $\delta^{13} \mathrm{C}_{\mathrm{DHA}}$ than earthworms, but there were otherwise no significant differences between treatment and control diets.

The differences observed between $\delta^{13} \mathrm{C}_{\mathrm{ALA}}, \delta^{13} \mathrm{C}_{\mathrm{ARA}}$, and $\delta^{13} \mathrm{C}_{\mathrm{EPA}}$ in diets were not well reflected in S. alpinus tissues (Table 3.4; Figure 3.3). There were no significant differences in fatty acid $\delta^{13} \mathrm{C}$ between treatments in fish muscle and fish liver, with the exception of LIN in liver (ANOVA: $\mathrm{p}>0.01$ for all models). The patterns exhibited in fish liver $\delta^{13} \mathrm{C}_{\mathrm{ALA}}$ and $\delta^{13} \mathrm{C}_{\mathrm{EPA}}$ were similar to, but a much smaller magnitude than those seen in their treatment diets (Figure 3.3), were not significant at $\alpha=0.05$, and had high $\Delta \delta^{13} \mathrm{C}$ values (Table 3.3). In fact, no significant differences in $\delta^{13} \mathrm{C}_{\mathrm{ALA}}$ and $\delta^{13} \mathrm{C}_{\mathrm{EPA}}$ were 
observed between treatments in liver or muscle (Table 3.4). In some cases, for example with $\delta^{13} \mathrm{C}_{\mathrm{ARA}}$, patterns exhibited by fish muscle and fish liver were opposite those seen in diets, with the benthic treatment having the same or more depleted $\delta^{13} \mathrm{C}_{\mathrm{ARA}}$ relative to the terrestrial treatment (Figure 3.3). In fish liver, $\delta^{13} \mathrm{C}_{\mathrm{LIN}}$ in terrestrial-based diets was significantly higher than in fish with mixed and control diet treatments (ANOVA: $\mathrm{F}_{3,19}=$ 5.01, $\mathrm{p}=0.01$ ), even though there were no differences in dietary $\delta^{13} \mathrm{C}_{\mathrm{LIN}}$ (Table 3.4). The random effect of tank explained a lot of variability between treatments for $\delta^{13} \mathrm{C}_{\mathrm{ALA}}$ and $\delta^{13} \mathrm{C}_{\mathrm{DHA}}$, but was otherwise small or nonexistent for the other EFAs (Table B5).

There were significant differences in bulk $\delta^{13} \mathrm{C}$ between diets (ANOVA: $\mathrm{F}_{2,6}=$ 9.87, $\mathrm{p}=0.01$; Figure 3.4a). Pellets were significantly more enriched in $\delta^{13} \mathrm{C}$ than benthic invertebrates as were earthworms (Table 3.4). The differences in $\delta^{13} \mathrm{C}$ between pellets and benthic invertebrates were not reflected in fish muscle. In fact, the relationship of bulk $\delta^{13} \mathrm{C}$ between benthic and terrestrial treatments in fish was opposite to that seen between the diets (Table 3.4; Figure 3.4a-b). Fish with the control diet treatment had more depleted bulk $\delta^{13} \mathrm{C}$ relative to fish with benthic or terrestrial diet treatments. No significant differences in bulk $\delta^{13} \mathrm{C}$ existed between diet treatments in S. alpinus liver, although similar to diets, benthic treatments were more depleted in bulk $\delta^{13} \mathrm{C}$ relative to terrestrial treatments (Table 3.4; Figure 3.4c).

\subsection{Discussion}

This was the first study to investigate the effectiveness of fatty acid stable isotopes in tracing mixed dietary sources in fish in a simulated freshwater food web. We sought to determine if $\delta^{13} \mathrm{C}$ of essential fatty acids could differentiate benthic and 
terrestrial prey sources in S. alpinus more effectively than fatty acid concentrations or bulk $\delta^{13} \mathrm{C}$. We found that the use of fatty acid concentrations and bulk $\delta^{13} \mathrm{C}$ was indeed insufficient in partitioning benthic and terrestrial dietary sources in this scenario. Our data also suggest that using $\delta^{13} \mathrm{C}$ of EFAs may be an effective diet tracing approach, but only when used with a deep understanding of fish physiology, and, ideally, after more robust laboratory studies have been conducted.

We observed differences of fatty acid profiles between the different diets. Interestingly, earthworm fatty acid profiles were distinguished by higher concentrations of polyunsaturated fatty acids, which is not typically the case with terrestrial invertebrates. Additionally, the variation in benthic invertebrate fatty acid profiles suggests that there were differences between the functional groups we collected. Luckily, this did not seem to affect the fatty acid stable isotope values of benthic invertebrates, which still had lower error than the hatchery pellets (Figure 3.3). Although there were some differences in fatty acid profiles between earthworms and terrestrial invertebrates, these differences were not well reflected in the fatty acid profiles of the respective treatments in fish muscle and liver tissues (Figure 3.2). This result is similar to what past studies with other aquatic consumers have found (Bec et al. 2003, Brett et al. 2009, Heissenberger et al. 2010), and further justifies the need for more precise diet tracing methods like compound-specific isotopes. However, similar to bulk $\delta^{13} \mathrm{C}$, the differences in $\delta^{13} \mathrm{C}$ of EFAs in diets were also not well reflected by the $\delta^{13} \mathrm{C}$ of EFAs in diet treatments in fish liver and muscle. While diets had significantly different $\delta^{13} \mathrm{C}$ for some EFAs, these same differences were not seen in the respective treatment groups in fish muscle and liver. 
Surprisingly, $\delta^{13} \mathrm{C}$ of essential fatty acids in benthic invertebrates and earthworms had low variability, with the exception of $\delta^{13} \mathrm{C}_{\mathrm{DHA}}$ (Figure 3.3). In fact, the variability of essential fatty acid $\delta^{13} \mathrm{C}$ in the treatment diets was often less than in the control diet (i.e., pellets). This result is encouraging for field studies because it suggests that $\delta^{13} \mathrm{C}_{\mathrm{FA}}$ in invertebrates from a given system is relatively consistent for most EFAs, even when coarse functional groups are used (e.g., earthworms). Although the differences in $\delta^{13} \mathrm{C}_{\mathrm{FA}}$ between treatments in fish tissues were not significant, the patterns of $\delta^{13} \mathrm{C}_{\mathrm{ALA}}$ we observed in fish liver, and of $\delta^{13} \mathrm{C}_{\mathrm{EPA}}$ in fish liver and muscle suggest that a longer experimental period that allows for greater tissue turnover may yield more pronounced results in future studies. Because tissue turnover is faster in fish liver than in fish muscle (Boecklen et al. 2011), we also suggest that future studies prioritize measuring $\delta^{13} \mathrm{C}_{\mathrm{FA}}$ in the liver, and secondarily, muscle tissue (Mohan et al. 2016).

Our use of concentration factors to identify which EFAs could be reliable tracers worked well. For example, the somewhat high concentration factor for LIN in fish with terrestrial diets (Table 3.2) may explain why we saw significantly more enriched $\delta^{13} \mathrm{C}_{\text {LIN }}$ in liver of fish with the terrestrial diet treatment compared to fish with mixed and control diet treatments (Figure 3.3). Fish with terrestrial diets were not getting enough LIN in their diets, and therefore likely had to obtain LIN from their lipid stores in order to meet their physiological demand for LIN. Mobilizing LIN from lipid stores would lead to fractionation of $\delta^{13} \mathrm{C}_{\mathrm{LIN}}$, and could thus explain why differences were seen in fish with terrestrial diets, even though there were no differences in $\delta^{13} \mathrm{C}_{\mathrm{LIN}}$ between diet treatments. Additionally, DHA had a high concentration factor, and as expected, it was not a reliable EFA for tracing $\delta^{13} \mathrm{C}$. In fact, likely because of the low concentrations of DHA in benthic 
invertebrates, we were not able to obtain a $\delta^{13} \mathrm{C}_{\mathrm{DHA}}$ value during sample analysis. In addition, the $\delta^{13} \mathrm{C}_{\mathrm{DHA}}$ in earthworms was highly variable. Because dietary concentrations of DHA were so low in both benthic invertebrates and earthworms (Table B3), it is likely that fish were desaturating and elongating EPA during the experiment in order to meet their physiological demand for DHA (Heissenberger et al. 2010).

We do see evidence that the fish were elongating and desaturating EPA to make DHA when comparing the $\delta^{13} \mathrm{C}_{\mathrm{DHA}}$ values in fish tissues to the $\delta^{13} \mathrm{C}_{\mathrm{EPA}}$ values seen in benthic invertebrates and earthworms (Figure 3.5). The mean $\delta^{13} \mathrm{C}_{\mathrm{DHA}}$ in the terrestrial treatments was enriched by about $2.5 \%$ relative to the mean $\delta^{13} \mathrm{C}_{\mathrm{DHA}}$ in benthic treatments in fish liver and muscle; the difference in mean $\delta^{13} \mathrm{C}_{\mathrm{EPA}}$ between earthworms and benthic invertebrates was a similar magnitude (about $3 \%$ ). Additionally, the $\Delta \delta^{13} \mathrm{C}$ between fish tissue DHA and the dietary EPA of each respective treatment was between 6-7\%. Other studies have observed a $\delta^{13} \mathrm{C}$ enrichment of 1-4\% in fatty acids of a consumer relative to its diet (Budge et al. 2011), and so the enrichment in $\delta^{13} \mathrm{C}_{\mathrm{DHA}}$ relative to dietary $\delta^{13} \mathrm{C}_{\mathrm{EPA}}$ seems to indicate a much larger amount of fractionation - a magnitude we might expect due to bioconversion. These patterns seen between dietary $\delta^{13} \mathrm{C}_{\mathrm{EPA}}$ and fish $\delta^{13} \mathrm{C}_{\mathrm{DHA}}$ suggest that understanding the physiological context of a system - including dietary availability of EFA and concentration factors - will be crucial to successfully using fatty acid stable isotopes in diet-tracing studies. Our study simulates the trends that might be expected in oligotrophic, diet-limited freshwater systems like northern temperate, arctic, or alpine waterbodies. Therefore, similar patterns of fractionation and variability with EPA and DHA can likely be expected in these systems. 
It is not clear why the patterns of $\delta^{13} \mathrm{C}_{\mathrm{ARA}}$ we observed in fish tissues were opposite to those in diets. We suspect that this may be due in part to variability introduced by low sample size, constraints in the number of treatment tanks, and competition among fish, as well as the limited duration of the experiment. These challenges may also explain why significant differences between treatments were not seen in fish muscle and liver. Only 2/10 fish from the benthic treatment, 6/10 fish from the terrestrial treatment, and 10/20 fish from the mixed treatment gained weight during the experiment, which we attribute to competition between fish. The competition was likely in part due to the challenge of collecting enough biomass of each of the diets in a single day. Therefore, we would expect the differences we observed between fish tissue treatments would be much more pronounced with a larger sample size and in fish with more substantial weight gain in future experiments.

Although the challenges with experimental design and complexity of fish physiology could not lead to a straightforward test of the reliability of dietary tracing with fatty acid stable isotopes, the trends we observed suggest that this method could be effective in the field if carried out with proper consideration of physiological context and adequate sample size. Similar findings among other food web components, such as algae, zooplankton, and birds, have led others to a similar conclusion that fatty acid stable isotopes could be used in the field conservatively, but that more laboratory studies are needed (Budge et al. 2008, Bec et al. 2011, Budge et al. 2011). Our use of concentration factors illustrates the importance of dietary availability of EFAs when choosing tracers. We suggest that precursor fatty acids such as ALA, LIN, and possibly EPA would be the best candidates in future tracing studies - assuming differences in their $\delta^{13} \mathrm{C}$ are 
distinctive in the consumer's diet. Because DHA is rarely available to consumers in terrestrial and benthic freshwater prey (Tocher 2003), we suggest excluding this EFA as a possible $\delta^{13} \mathrm{C}_{\mathrm{FA}}$ candidate for dietary tracing. However, ideally, more rigorous laboratory studies should be conducted prior to implementation of this method in the field. Although our experiment would have benefitted from a longer timeframe and conditions that reduced competition, the conditions we simulated are likely realistic, especially for coldwater species like Arctic Char who experience periods of food limitation.

\subsection{Conclusion}

Our study is the first to examine whether fatty acid stable isotopes can partition between benthic and terrestrial diet sources in freshwater fish in an experimental setting. Although our results suggest more investigation is needed to test the reliability of this method, we illustrate that $\delta^{13} \mathrm{C}$ of essential fatty acids, such as ALA, ARA, and EPA, could be a promising and potentially powerful tool to trace energy flow in aquatic systems. If the supply of these fatty acids is high enough in diets to meet the consumer's physiological demand, fatty acid $\delta^{13} \mathrm{C}$ could increase the number of sources in, and therefore the reliability and accuracy, of isotope mixing models. Our findings provide an important baseline for future studies to use fatty acid stable isotopes as a new way to trace energy flow in food webs. 
Table 3.1 $t$-statistics from the post-hoc test for LSM differences in fatty acid concentrations between treatments in fish muscle and liver. Bold indicates significant difference at $\mathrm{p}=0.05$.

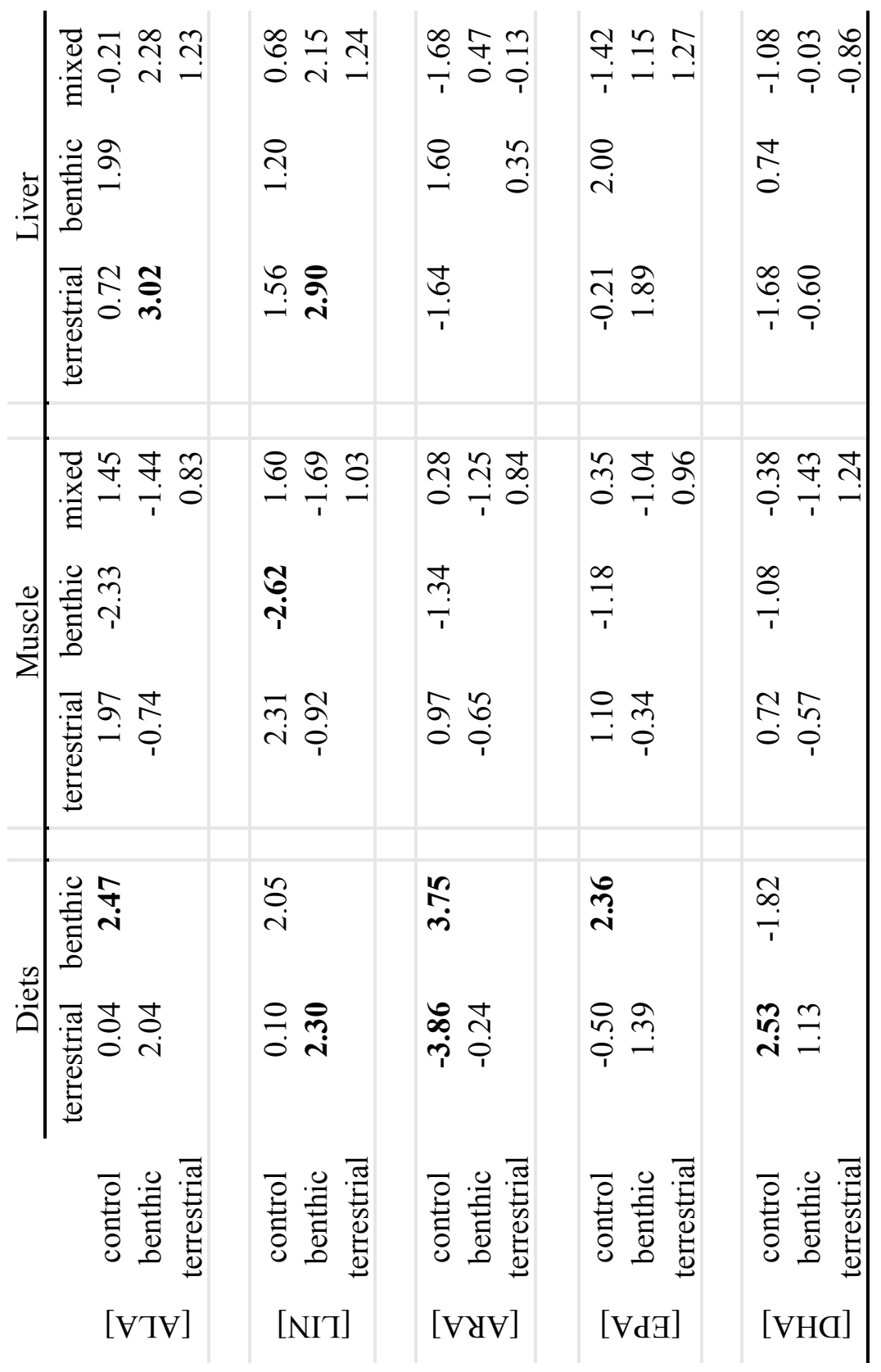


Table 3.2 Concentration factors of each EFA for fish liver and muscle, calculated using Equation 1. Fatty acids with large $(>2)$ concentration factors are bolded.

\begin{tabular}{lllllll} 
& \multicolumn{7}{c}{ Concentration factor } \\
Diet treatment & Tissue & LIN & ALA & ARA & EPA & DHA \\
\hline benthic & liver & 0.87 & 0.06 & 0.96 & 0.11 & $\mathbf{1 5 . 8 1}$ \\
& muscle & 0.29 & 0.02 & 0.20 & 0.04 & $\mathbf{8 . 9 7}$ \\
terrestrial & liver & $\mathbf{3 . 2 2}$ & 1.23 & 0.59 & 0.24 & $\mathbf{9 9 . 7 1}$ \\
& muscle & $\mathbf{4 . 1 6}$ & 1.66 & 0.15 & 0.15 & $\mathbf{5 7 . 8 1}$ \\
control & liver & 1.60 & 1.36 & $\mathbf{3 . 7 1}$ & 1.69 & $\mathbf{5 . 5 1}$ \\
& muscle & 1.60 & 1.36 & $\mathbf{3 . 7 1}$ & 1.69 & $\mathbf{5 . 5 1}$ \\
mixed & liver & 0.90 & 0.07 & 0.70 & 0.13 & $\mathbf{2 7 . 2 2}$ \\
& muscle & 1.10 & 0.08 & 0.20 & 0.09 & $\mathbf{2 0 . 3 3}$ \\
\hline
\end{tabular}


Table 3.3 EFA $\Delta \delta^{13} \mathrm{C}$ for each diet treatment in fish muscle and fish liver. A positive number indicates the fish tissue is more enriched in $\delta^{13} \mathrm{C}_{\mathrm{FA}}$ than its diet; the larger the number, the larger the isotopic fractionation. Blue shading indicates enrichment of $\delta^{13} \mathrm{C}_{\mathrm{FA}}$ in tissue relative to diet, while red shading indicates depletion of $\delta^{13} \mathrm{C}_{\mathrm{FA}}$ in tissue relative to diet; darker shading indicates a larger departure from zero. We did not calculate concentrations factors for mixed treatments because we could not assume that fish were getting an exact 50:50 benthic:terrestrial mix due to selective feeding and competition between fish.

\section{Diet}

\begin{tabular}{|c|c|c|c|c|c|c|}
\hline treatment & Tissue & $\Delta \delta^{13} C_{\text {LIN }}$ & $\Delta \delta^{13} C_{\text {ALA }}$ & $\Delta \delta^{13} C_{\text {ARA }}$ & $\Delta \delta^{13} C_{\text {EPA }}$ & $\Delta \delta^{13} C_{\text {DHA }}$ \\
\hline \multirow[t]{2}{*}{ benthic } & liver & 1.4 & 5.4 & 6.2 & 5.5 & -- \\
\hline & muscle & 1.1 & 5.2 & 5.4 & 6.0 & -- \\
\hline \multirow[t]{2}{*}{ terrestrial } & liver & 1.0 & -0.2 & -0.6 & 4.3 & 14.7 \\
\hline & muscle & 0.8 & 1.1 & -0.6 & 3.9 & 13.4 \\
\hline \multirow[t]{2}{*}{ control } & liver & 2.4 & 0.4 & 5.6 & 1.4 & 0.5 \\
\hline & muscle & 0.4 & 2.7 & 2.4 & 0.3 & -2.0 \\
\hline
\end{tabular}


Table 3.4 $t$-statistics from the post-hoc test for LSM differences in fatty acid and bulk $\delta^{13} \mathrm{C}$ between treatments in fish muscle and liver. Bold indicates significant difference at $\mathrm{p}=0.05$.

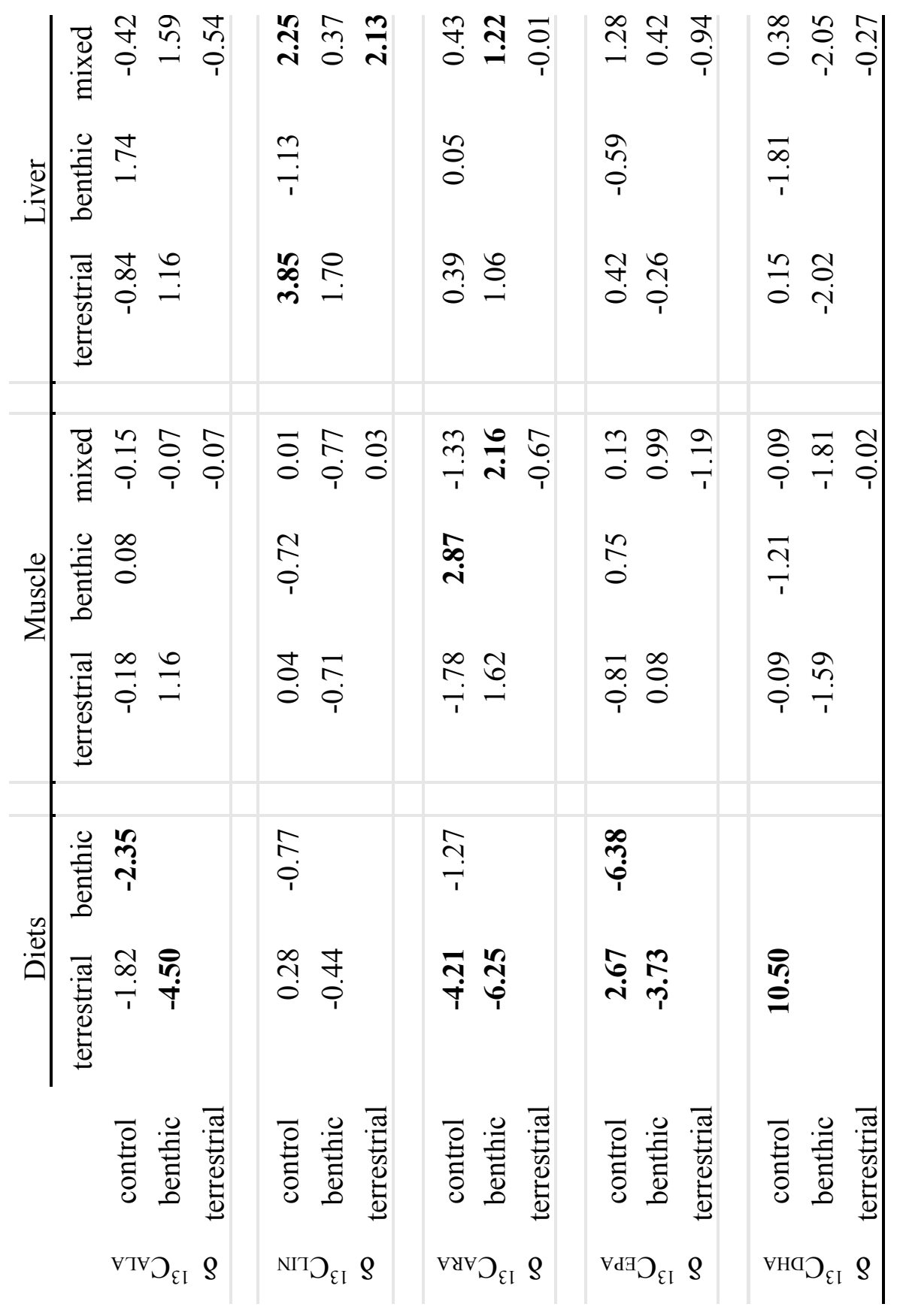




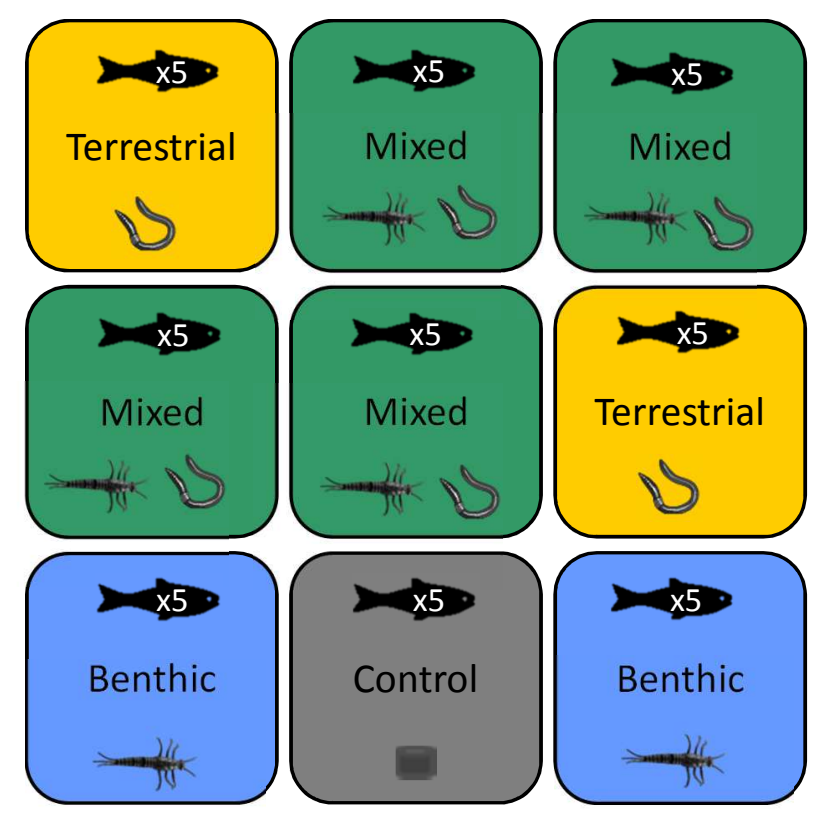

Figure 3.1 The study included two benthic diet treatments, two terrestrial diet treatments, four mixed diet treatments, and one control treatment, which were randomly applied to nine aquaculture tanks, each containing five S. alpinus. 

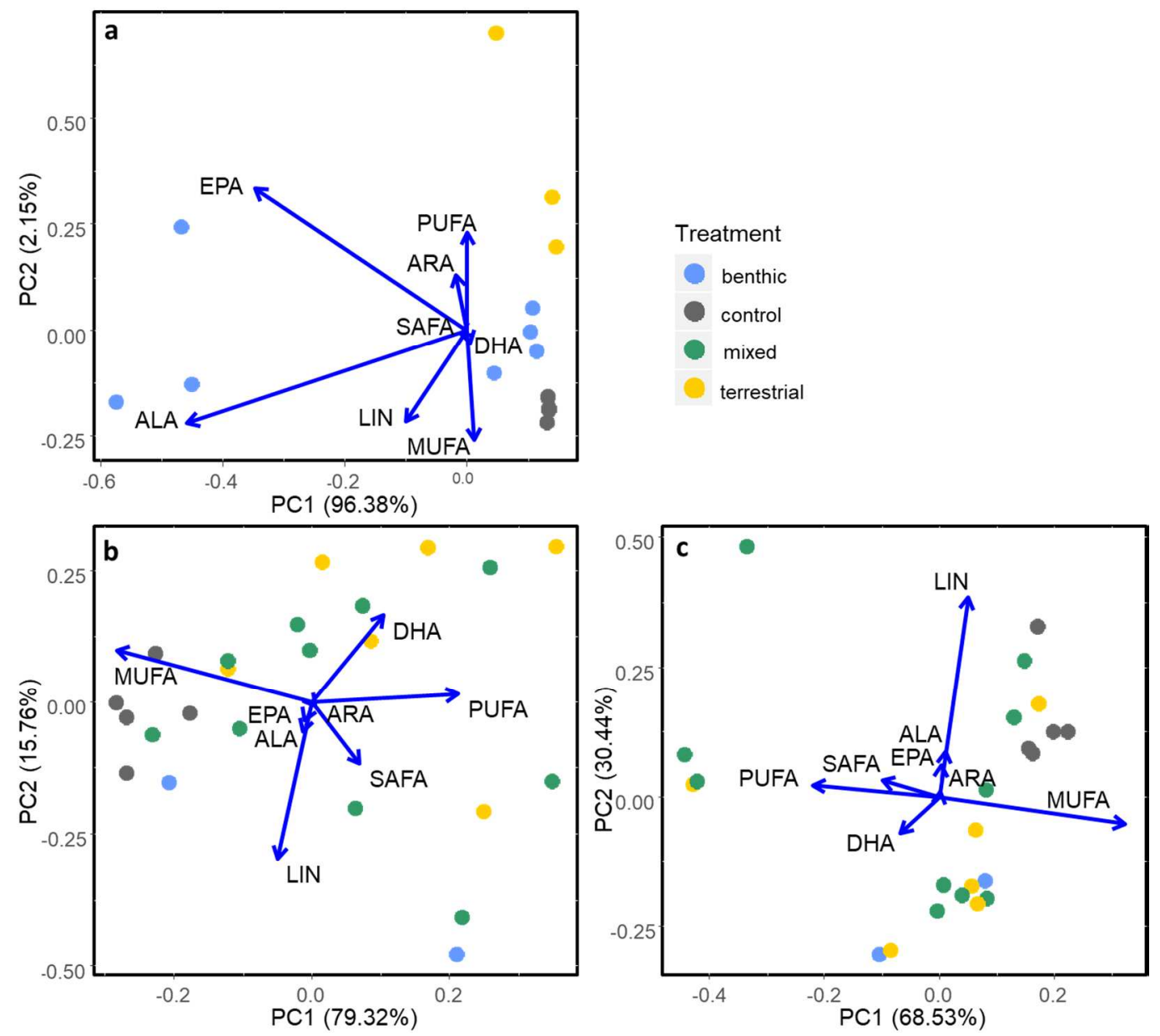

Figure 3.2 Profiles of major fatty acid groups and EFAs in (a) diets, and respective treatments in fish (b) liver and (c) muscle, as illustrated by PCA. Major fatty acid groups include saturated fatty acids (SAFA), monounsaturated fatty acids (MUFA), and polyunsaturated fatty acids (MUFA). Arrows show which fatty acid groups or EFAs are driving differences in fatty acid profiles between each point. In panel (a), the blue dots represent benthic invertebrates, the yellow dots represent earthworms, and the grey dots represent pellets. In panels (b) and (c), the dots represent individual fish, with colors for diet treatments. 


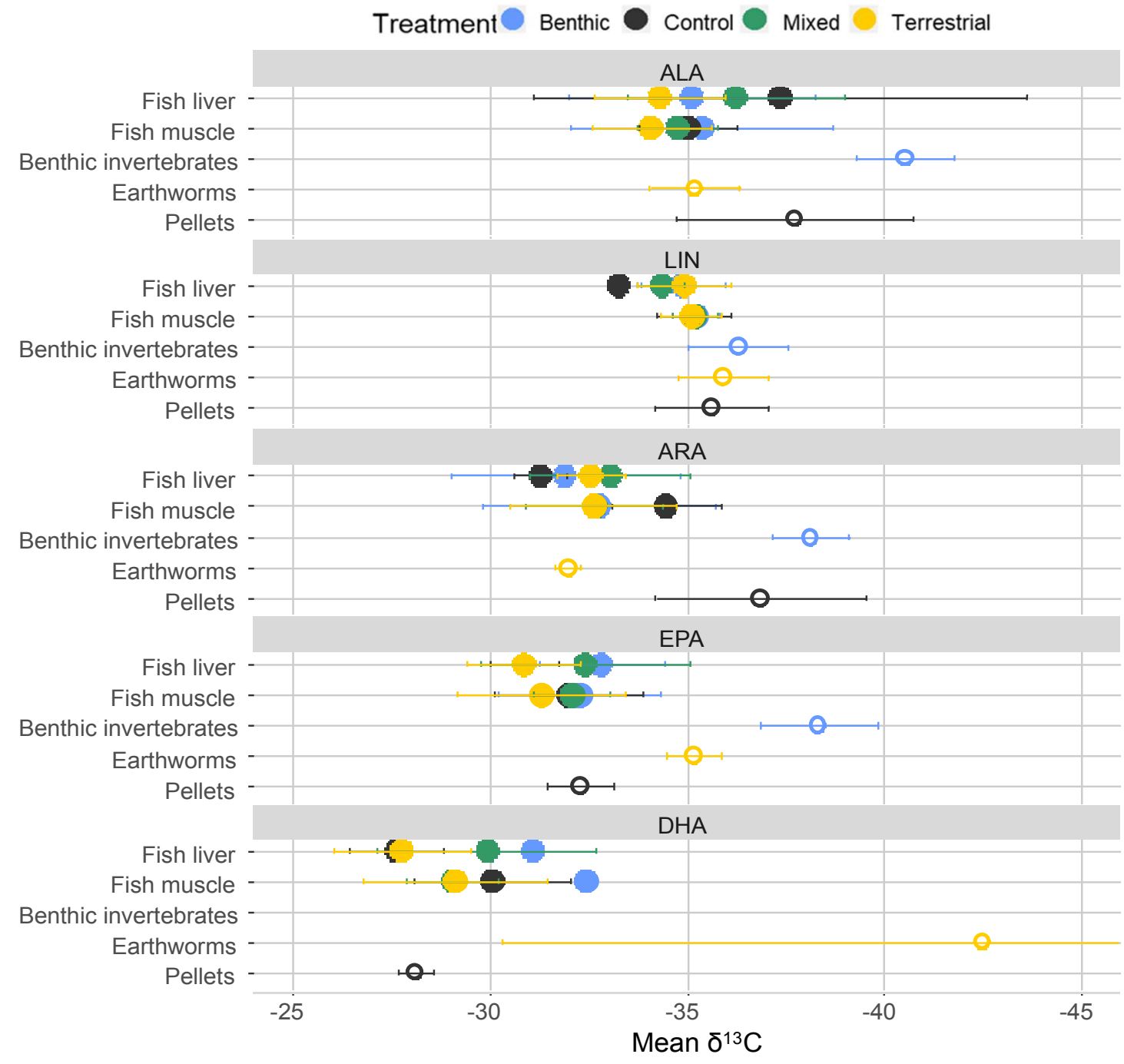

Figure 3.3 Mean EFA- $\delta^{13} \mathrm{C}$ in fish liver and muscle (closed circles), and diets (open circles: benthic invertebrates $(n=6)$, earthworms $(n=3)$, and pellets $(n=6))$. Error bars represent standard deviations. 


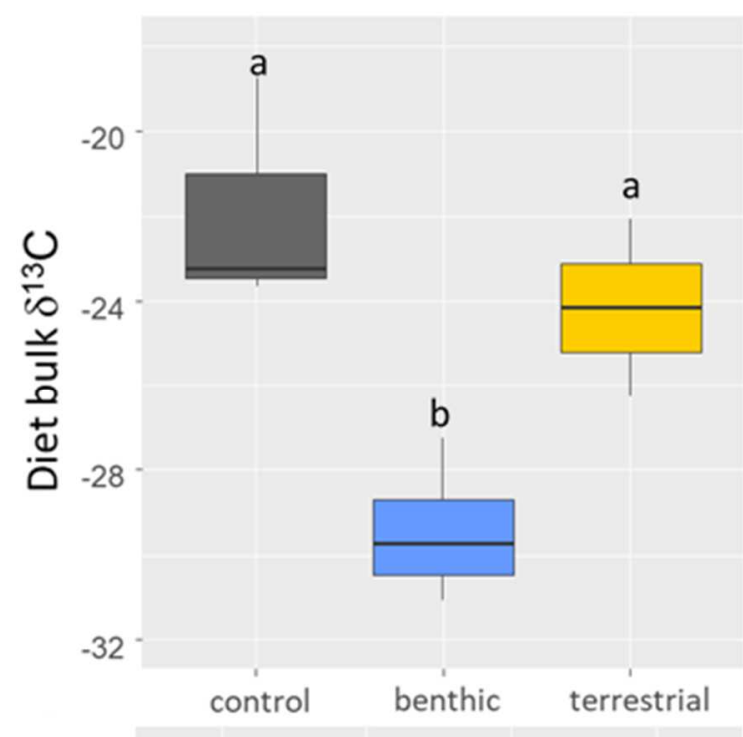

\section{Treatment}

良 benthic

control

mixed

追 terrestrial

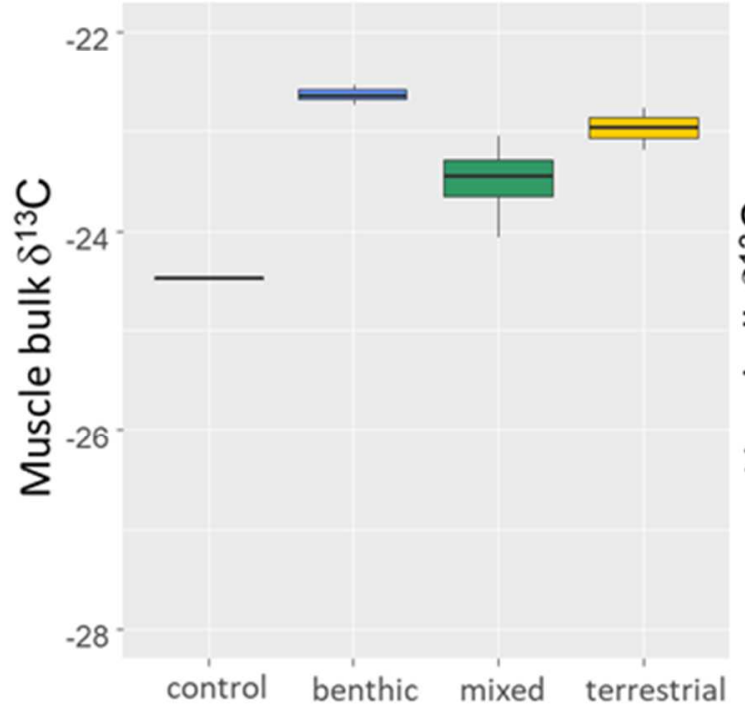

$-22$

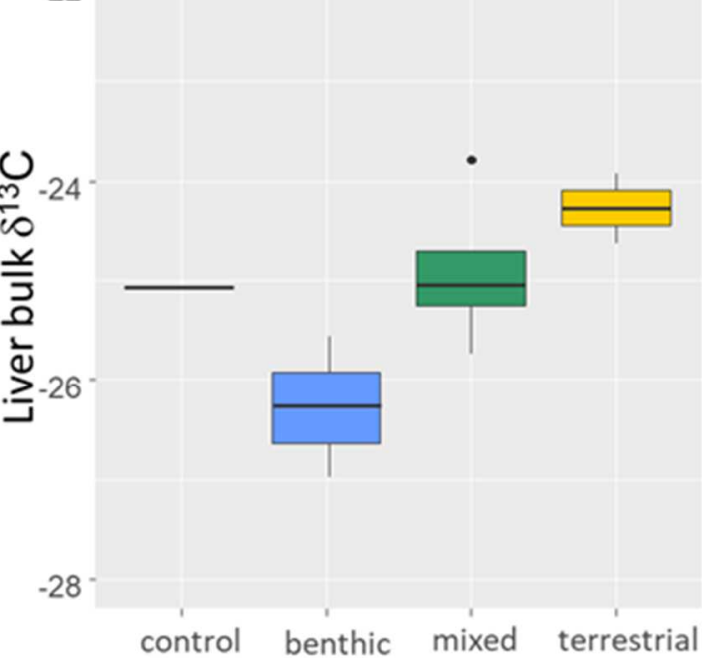

Treatment

Figure 3.4 Box and whisker plots of mean bulk $\delta^{13} \mathrm{C}$ in (a) diets and diet treatments in (b) muscle and (c) liver. The boxes represent the interquartile range, lines represent the group median, whiskers represent 1.5 times the interquartile range, and dots represent outliers. Letters denote significant difference at $\mathrm{p}<0.05$ (determined using Tukey-adjusted differences in least-square means). 


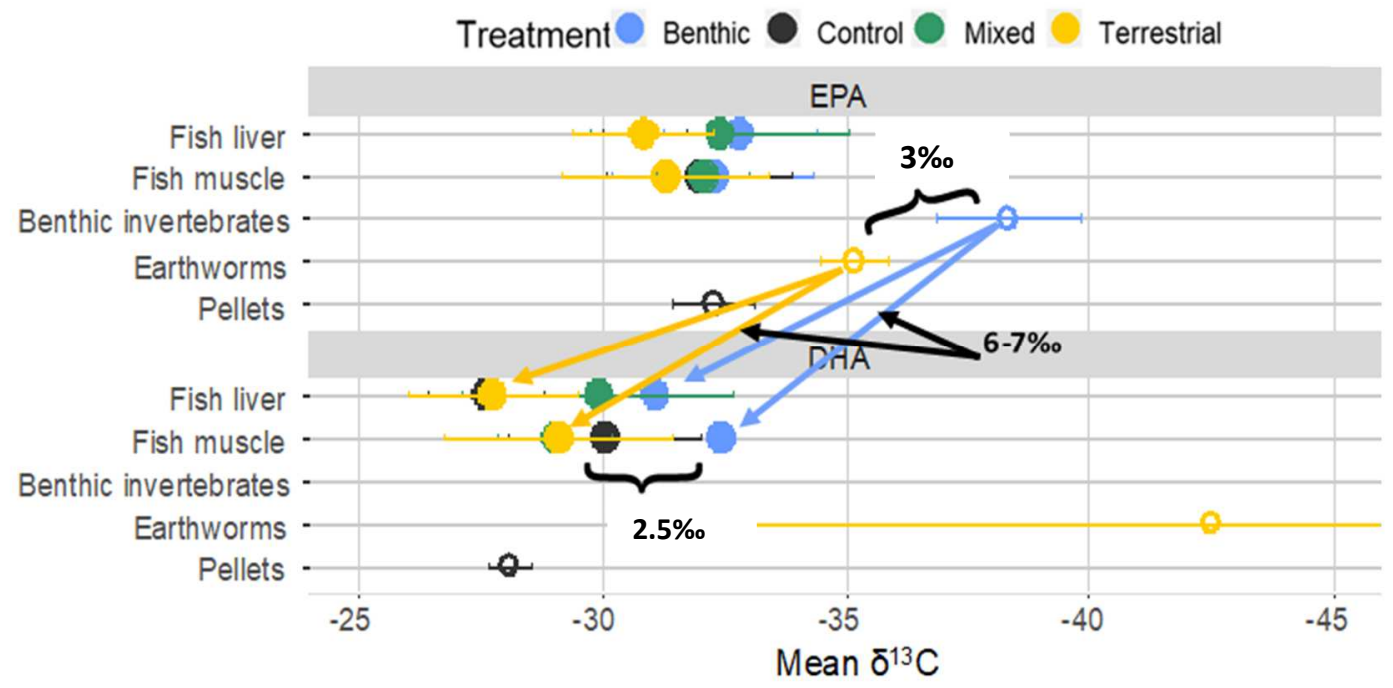

Figure 3.5 Illustration of bioconversion of EPA in diets to DHA in fish tissues, resulting in a $\sim 6-7 \%$ enrichment in fish tissue $\delta^{13} \mathrm{C}_{\mathrm{DHA}}$ for benthic and terrestrial treatments relative to the $\delta^{13} \mathrm{C}_{\mathrm{EPA}}$ in the respective diets (benthic invertebrates and earthworms). The difference in $\delta^{13} \mathrm{C}_{\mathrm{DHA}}$ between fish with benthic and terrestrial diets $(\sim 2.5 \%)$ is similar in magnitude to the differences in $\delta^{13} \mathrm{C}_{\mathrm{EPA}}$ between benthic invertebrates and earthworms ( 3\%), suggesting that fish may be using EPA to synthesize DHA. 


\subsection{References}

Bates, D., Maechler, M., Bolker, B., Walker, S., Bojesen, R.H., Singmann, H., Dai, B., Scheipl, F., Grothendieck, G., Green, P., Fox, J. 2019. Linear Mixed-Effects Models using 'Eigen' and S4. R package version 1.1-21.

Bartoń, K. 2019. MuMInL Multi-Model Inference. R package version 1.43.6.

Bec, A., Desvilettes, C., Véra, A., Fontvieille, D., Bourdier, G., 2003. Nutritional value of different food sources for the benthic Daphnidae Simocephalus vetulus: role of fatty acids. Arch. fur Hydrobiol. 156, 145-163.

Bec, A., Perga, M.E., Koussoroplis, A., Bardoux, G., Desvilettes, C., Bourdier, G., Mariotti, A., 2011. Assessing the reliability of fatty acid-specific stable isotope analysis for trophic studies. Methods Ecol. Evol. 2, 651-659.

Boecklen, W.J., Yarnes, C.T., Cook, B.A., James, A.C., 2011. On the Use of Stable Isotopes in Trophic Ecology. Annu. Rev. Ecol. Evol. Syst. 42, 411-440.

Brett, M.T., Müller-Navarra, D.C., Persson, J., 2009. Crustacen Zooplankton Fatty Acid Composition, in: Kainz, M., Brett, M., Arts, M. (Eds.), Lipids in Aquatic Ecosystems. pp. 115-146.

Budge, S.M., Wooller, M.J., Springer, A.M., Iverson, S.J., McRoy, C.P., Divoky, G.J., 2008. Tracing carbon flow in an arctic marine food web using fatty acid-stable isotope analysis. Oecologia 157, 117-129.

Budge, S.M., Wang, S.W., Hollmen, T.E., Wooller, M.J., 2011. Carbon isotopic fractionation in eider adipose tissue varies with fatty acid structure: implications for trophic studies. J. Exp. Biol. 214, 3790-3800. 
Carpenter, S.R., Cole, J.J., Pace, M.L., Bogert, M. Van De, Bade, D.L., Bastviken, D., Gille, C.M., Hodgson, J.R., Kitchell, J.F., Kritzberg, S., 2005. Ecosystem Subsidies : Terrestrial Support of Aquatic Food Webs from 13 C Addition to Contrasting Lakes. Ecology 86, 2737-2750.

Evershed, R.., Bull, I.D., Corr, L.., Crossman, Z.., Van Dongen, B.E., Evans, C.J., Jim, S., Mottram, H.R., Mukherjee, A.J., Pancost, R.D., 2007. Compound-specific stable isotope analysis in ecology and paleoecology, in: Michener, R., Lajtha, K. (Eds.), Stable Isotopes in Ecology and Environmental Science. Blackwell Publishing, pp. $480-540$.

France, R.L., 1995. Carbon-13 enrichment in benthic compared to planktonic algae : foodweb implications. Mar. Ecol. Prog. Ser.

Galloway, A.W.E., Brett, M.T., Holtgrieve, G.W., Ward, E.J., Ballantyne, A.P., Burns, C.W., Kainz, M.J., Müller-Navarra, D.C., Persson, J., Ravet, J.L., Strandberg, U., Taipale, S.J., Alhgren, G., 2015. A Fatty Acid Based Bayesian Approach for Inferring Diet in Aquatic Consumers. PLoS One 10, e0129723.

Grey, J., 2006. The use of stable isotope analyses in freshwater ecology: current awareness. Polish Jounral Ecol. 54, 563-584.

Grey, J., Kelly, A., Ward, S., Sommerwerk, N., Jones, R.I., 2004. Seasonal changes in the stable isotope values of lake - dwelling chironomid larvae in relation to feeding and life cycle variability. Freshw. Biol. 49, 681-689.

Heissenberger, M., Watzke, J., Kainz, M.J., 2010. Effect of nutrition on fatty acid profiles of riverine, lacustrine, and aquaculture-raised salmonids of pre-alpine habitats. 
Hydrobiologia 650, 243-254.

Hixson, S., Sharma, B., Kainz, M., Wacker, A., Arts, M., 2015. Production, Distribution, and Abundance of Long-Chain Omega-3 Polyunsaturated Fatty Acids: A Fundamental Dichotomy between Freshwater and Terrestrial Ecosystems. Environ. Rev. 23, 414-424.

Kuznetsova, A., Brockhoff, P.B., Christensen, R.H.B. 2019. 1merTest: Tests in Linear Mixed Effects Models. R package version 3.1-0.

Lau, D.C.P., Vrede, T., Pickova, J., Goedkoop, W., 2012. Fatty acid composition of consumers in boreal lakes - variation across species, space and time. Freshw. Biol. 57, $24-38$.

Lenth, R. 2019. Least-Squares Means. R package version 2.30-0.

Milardi, M., Käkelä, R., Weckström, J., Kahilainen, K.K., 2015. Terrestrial prey fuels the fish population of a small, high-latitude lake. Aquat. Sci. 1-12.

Mohan, S.D., Mohan, J.A., Connelly, T.L., Walther, B.D., McClelland, J.W., 2016. Fattyacid biomarkers and tissue-specific turnover: validation from a controlled feeding study in juvenile Atlantic croaker Micropogonias undulatus. J. Fish Biol. 89, 20042023.

Murray, D.S., Hager, H., Tocher, D.R., Kainz, M.J., 2014. Effect of partial replacement of dietary fish meal and oil by pumpkin kernel cake and rapeseed oil on fatty acid composition and metabolism in Arctic charr (Salvelinus alpinus). Aquaculture 431, $85-91$. 
Napolitano, G.E., 1999. Fatty Acids as Trophic and Chemical Markers in Freshwater Ecosystems, in: Arts, M.T., Wainman, B.C. (Eds.), Lipids in Freshwater Ecosystems. Springer New York, New York, NY, pp. 21-44.

Pace, M.L., 2004. Whole lake carbon-13 additions reveal terrestrial support of aquatic food webs. Nature 427, 240-243.

Parrish, C.C., 2009. Essential fatty acids in aquatic food webs, in: Kainz, M., Brett, M., Arts, M. (Eds.), Lipids in Aquatic Ecosystems. Springer, New York, NY, pp. 309326.

Peterson, B.J., Fry, B., 1987. Stable isotopes in ecosystem studies. Annu. Rev. Ecol. Syst. $18,293-320$.

Post, D.M., 2002. Using stable isotopes to estimate trophic position: models, methos, and assumptions. . Ecology 83, 703-718.

Ripley, B., Venables, B., Bates, D.M., Hornik, K., Gebhardt, A., Firth, D., 2019. MASS: Modern applied statistics. R package version 7.3-51.4.

Sayanova, O. V., Napier, J.A., 2004. Eicosapentaenoic acid: Biosynthetic routes and the potential for synthesis in transgenic plants. Phytochemistry 65, 147-158.

Schindler, D.W., 2009. Lakes as sentinels and integrators for the effects of climate change on watersheds, airsheds, and landscapes. Limnol. Oceanogr. 54, 2349-2358.

Solomon, C.T., Carpenter, S.R., Clayton, M.K., Cole, J.J., Coloso, J.J., Pace, M.L., Vander Zanden, M.J., Weidel, B.C., 2011. Terrestrial, benthic, and pelagic resource use in lakes: Results from a three-isotope Bayesian mixing model. Ecology 92, 11151125. 
Taipale, S.J., Kainz, M.J., Brett, M.T., 2011. Diet-switching experiments show rapid accumulation and preferential retention of highly unsaturated fatty acids in Daphnia. Oikos 120, 1674-1682.

Taipale, S.J., Peltomaa, E., Hiltunen, M., Jones, R.I., Hahn, M.W., Biasi, C., Brett, M.T., 2015. Inferring Phytoplankton, Terrestrial Plant and Bacteria Bulk $\delta^{13} \mathrm{C}$ Values from Compound Specific Analyses of Lipids and Fatty Acids. PLoS One 10, e0133974.

Tocher, D.R., 2003. Metabolism and Functions of Lipids and Fatty Acids in Teleost Fish. Rev. Fish. Sci. 11, 107-184.

Vadeboncoeur, Y., Vander Zanden, M.J., Lodge, D.M., 2002. Putting the Lake Back Together: Reintegrating Benthic Pathways into Lake Food Web Models. Bioscience $52,44-54$.

Vander Zanden, J.; Vadeboncoeur, Y., 2002. Fishes as integrators of benthic and pelagic food webs in lakes. Ecology 83, 2152-2161.

Vander Zanden, M.J., Clayton, M.K., Moody, E.K., Solomon, C.T., Weidel, B.C., 2015. Stable Isotope Turnover and Half-Life in Animal Tissues: A Literature Synthesis. PLoS One 10, e0116182. 
Chapter 4

\section{Public perceptions of mountain lake fisheries management in national parks}

This chapter has been published in a peer-reviewed journal, with the following citation:

Chiapella, A. M., Nielsen-Pincus, M., \& Strecker, A. L. (2018). Public perceptions of mountain lake fisheries management in national parks. Journal of Environmental Management, 226, 169-179.

\subsection{Introduction}

Mountain lakes are perceived by many as pristine and untouched ecosystems. In reality, mountain waterbodies across the world have been under direct and indirect human influence for centuries, resulting in complex management challenges. Mountain lakes are typically oligotrophic waterbodies situated in high forest, subalpine, or alpine mountain ecosystems, with geologic barriers to upstream fish passage and hydrological dependence primarily on atmospheric precipitation and/or glaciers. In the American West, humans have introduced fish to mountain lakes since the turn of the $20^{\text {th }}$ century (Pister 2001). State and federal fish and wildlife agencies originally began stocking trout into historically fishless mountain lakes to attract support for public lands conservation (Schoenfeld and Hendee 1978). This practice continued for decades to maintain conservation support, and went largely unquestioned across management and academic communities until recently (Pister 2001). Beginning in the latter half of the $20^{\text {th }}$ century, scientists began to discover the effects of fish in these lake ecosystems (e.g., Bradford et al. 1998, Eby et al. 2006, Finlay and Vredenburg 2007, Knapp and Matthews 2000). 
The introduction of fish in mountain lakes has cascading ecological implications. Most notably, fish prey on aquatic invertebrates and amphibians, and outcompete amphibians and alpine-nesting birds for limited food resources, leading to declines in large-bodied zooplankton, macroinvertebrates, and amphibian species (Carlisle and Hawkins 1998, Epanchin et al. 2010, Finlay and Vredenburg 2007, Knapp and Matthews 2000, Larson and Hoffman 2002, Sarnelle and Knapp 2004, Schindler and Parker 2002). The stocking of non-native trout species in headwater lakes can also have negative downstream effects. In some systems, stocked fish can migrate downstream and compete with native trout species (Adams et al. 2001). In addition to these cascading ecosystem effects, fish stocked in mountain lakes can accumulate relatively high levels of atmospherically-deposited toxins - like polychlorinated biphenyls (PCBs), pesticides, and mercury - which can pose a threat to the health of local wildlife, as well as anglers who consume fish from these lakes (e.g., Landers et al. 2008, Moran et al. 2007).

While the effects of trout introductions on native ecosystems have become increasingly clear, the cultural importance of fish in mountain lakes has made management a complex issue. Many fish-stocked mountain lakes are located in federally protected wilderness areas, defined by the Wilderness Act of 1964 as "an area of undeveloped Federal land retaining its primeval character and influence, without permanent improvements ... which is protected and managed so as to preserve its natural conditions...", and many wilderness areas reside within national park boundaries. Vague policy language in the Wilderness Act has caused conflict and confusion around mountain lake fisheries management, because although the act calls for the preservation of natural and untrammeled land, it also upholds state jurisdiction with respect to fish and 
wildlife management (Landres et al. 2001). These conflicting passages have led to differences in interpretation of how to implement fisheries management practices in mountain lakes across US federal land management and regulatory agencies (e.g., US Forest Service, Bureau of Land Management, National Parks Service, and US Fish and Wildlife Service) (Landres et al. 2001). Trout stocking is still common in many mountain lakes managed by the US Forest Service and Bureau of Land Management, but the practice is at odds with National Park Service policies in the western US (Landres et al. 2001, Pister 2001). At present, the National Parks Service has generally terminated mountain lake stocking programs in the western US (Landres et al. 2001).

Although stocking programs have largely ceased in US national parks, debate remains about how to best manage the remaining fisheries in mountain lake ecosystems. Individual national parks approach this problem differently. For example, Mount Rainier National Park (NP) has mainly used manual methods to remove fish (e.g., gill nets), and only experimentally from a few lakes, while other parks in the western US have used, or are considering, chemical removal techniques. North Cascades NP has used the plantbased piscicide rotenone, in conjunction with gill nets, to remove stocked fish from some mountain lakes. However, in 2016, the Washington Department of Fish and Wildlife began re-stocking select mountain lakes in North Cascades NP with species native to downstream waters. This management shift occurred after federal legislation supported by angling groups - the North Cascades National Park Service Complex Fish Stocking Act of 2014 - reinstated stocking in the park. In California's Sierra Nevada Mountains, fish eradication efforts have been kept confidential by management agencies, as to avoid gill net vandalism and re-stocking of lakes by anglers (Halverson 2011). 
The controversies that led to secretive fish removal efforts and the passing of the North Cascades Fish Stocking Act have illustrated the importance of managing mountain lakes as a socioecological system. The current mismatch in stakeholder priorities indicates that there is a conflict between the ecological and cultural value of mountain lakes, and while the opinions of some stakeholders are clear, the attitudes and perceptions of most park visitors toward the practice of fish stocking and management of fisheries are largely unknown. Watson et al. (2015) demonstrated that lack of public input is a common occurrence in wilderness management. However, there is substantial evidence that people can hold strong attitudes and beliefs that shape how they perceive wildlife management (e.g., Fulton et al. 1996, Hall et al. 2010, Manfredo 2008). In national parks, visitor perspectives are important, as parks strive to maintain management practices that incorporate the needs and desires of visitors for their public lands, as per the National Parks Omnibus Management Act of 1998 (National Parks Service 2006). In addition, addressing non-native species in mountain lakes is an important aspect of tourism management, which is an integral part of the public lands management (Hall et al. 2010). The importance of considering multidimensional socioecological complexity in land management is also illustrated by Papadimitriou (2012), who uses mathematical modeling approaches as a tool for addressing the complexity of land management. Clearly, there is a need to better assess public attitudes and values around mountain lake fisheries management. In addition, many anglers may not know that atmospherically deposited contaminants can accumulate in mountain lake fish. By understanding recreational habits of visitors and the distribution and drivers of their attitudes toward mountain lake fisheries, management agencies may be able to create plans that mitigate 
potential controversy and protect anglers from consuming potentially contaminated fish species.

\subsubsection{Objectives}

The goals of our study were to determine: (1) visitors' attitudes toward a spectrum mountain lake fisheries management approaches; (2) how demographics, recreational habits, knowledge, and value-orientations around mountain lakes drive visitor attitudes towards fisheries management approaches; and (3) an approximation of the risk posed to visitors by consuming mountain lake fish, based on reported angling habits. Attitudes are defined as a negative or positive association toward an object (Ajzen 1991), and are driven by value-orientations, i.e., patterns of beliefs within specific domains (Manfredo et al. 2004, Whittaker et al. 2006). Assessing attitudes can be an important part of management decision making. Attitudes are considered components of a cognitive hierarchy that suggests values and attitudes can be used to anticipate human behavior, and are commonly used to understand human-wildlife interactions (Homer and Kahle 1988, Fulton et al. 1996, Miller 2017). According to attitude theory, values are fundamental cognitions that represent ideal end states or desirable ways of behaving, and they form a foundation for attitudes, social norms, and beliefs, which in turn influence behavior (Fulton et al. 1996). Therefore, incorporating visitor attitudes into management plans could help mitigate against future public controversy around mountain lake fisheries management.

We hypothesize the following. First, visitor attitudes will align around two primary management approaches: one that favors maintaining fish in mountain lakes, and 
one that favors fish eradication. This is based on the theory that the primary wildlife value-orientations are either anthropocentric or biocentric in nature, with underlying drivers of dominance and mutualism, respectively (Manfredo 2008, Vaske and Donnelly 1999). In addition, we also expect to see a "middle" group emerge whose attitudes orient around both a concern for ecosystem health and a desire to maintain fisheries resources, as well as a group for whom the issue is not salient and therefore fails to assign an attitude in either direction. These four expected attitude groups can be explained by the finding from Teel and Manfredo (2010) that public lands visitors in the western US typically have attitudes driven by traditionalist (dominance-driven), mutualist (mutualism-driven), pluralist (both mutualism and dominance-driven), and distanced (neither mutualism or dominance-driven) value-orientations. Second, based on the influence of demographics, value-orientations, recreation participation, and perceived ecosystem threats in determining support for wildlife management interventions, we expect these factors to be important predictors of management attitudes (Daigle et al. 2002, Jacobs et al. 2014, Larson et al. 2011, Manfredo 2008, Scott and Willits 1994, Teel et al., 2010). In line with Manfredo and Dayer's (2004) explanation of the continuum from "wildlife use" to "wildlife protection", we expect respondents in favor of stocking to participate in angling or be members of natural-resource groups, and indicate recreation as an important aspect of park waterbodies. Likewise, we expect those in favor of fish eradication to assign ecological importance to park waterbodies, be members of environmental groups, and list climate change as a threat to park ecosystems. Third, we expect the number of people who consume fish from these systems to be small, but those 
who do consume fish may do so frequently or have the perception that mountain lake fish are pristine.

\subsection{Methods}

In-person intercept surveys were conducted at campgrounds, trailheads, scenic overlooks, and trail crossings at North Cascades and Mount Rainer NP from July to August 2016. We selected these two parks because the National Parks Service was actively considering management options to balance the cultural value of mountain lake fisheries with the ecological value of fish removal (National Parks Service 2007, 2017), providing the opportunity for this study to directly inform management decisions. National parks also generally have easily accessible trailheads, a diverse range of visitors, and higher visitation than, for instance, national forests (331 million versus 148 million visits in 2016, respectively; National Parks Service 2017, U.S. Forest Service 2016), making them appropriate places to study the diverse attitudes of those who visit public lands.

\subsubsection{Survey sites}

North Cascades NP is located along the northern US terminus of the Cascade Range in Washington State. Annual visitation at North Cascades NP is one of the lowest in the country - approximately 23,000 (10-year average) (National Parks Service 2017). There are approximately 40 lakes in the North Cascades NP Service Complex that contain fish populations (National Parks Service 2007). Mount Rainier NP is located about two hours southeast of Seattle, Washington, and encompasses Mount Rainier. 
Annual visitation at Mount Rainier NP is about 1.2 million (10-year average) (National Parks Service 2017). Approximately 35 of the park's lakes have reproducing fish populations (National Parks Service 2017).

\subsubsection{Survey design}

Our study used in-person paper questionnaires to collect information on visitor attitudes towards fish stocking in mountain lakes and possible fisheries management approaches. Informed consent was obtained from all individual participants included in the study (Portland State University Institutional Review Board permit \#163799). Intercept surveys can be an effective means of gathering data on the habits, attitudes, values, and knowledge of a recreational study population, and are commonly used by federal land management agencies like the National Parks Service and US Forest Service (e.g. English et al. 2002, Taylor et al. 2011). In a given year, surveying visitors at trailheads, trail junctions, campgrounds, and other popular sites can provide representative information about a study population and can be a useful tool for informing management decisions. This method does include some bias, particularly against those who are not visiting the aforementioned sites, but may still have strong values with respect to public lands management.

Existing literature indicates that attitudes can be influenced by social norms, beliefs, and value-orientations; therefore we developed our survey to measure these attitude drivers. The questionnaire (Figure C1) included two parts. Part 1 collected demographic information about respondents, including postal code, age, gender, race/ethnicity, education, and income. Demographic information can help to understand 
the cultural context of a respondent, which may influence their value-orientations and attitudes via social norms - or the "expectations of how one... or others should behave" (Manfredo 2008, pp. 113). Part 2 was designed to further understand the social and cultural context of survey respondents by gathering information on respondents' recreational habits, knowledge, waterbody value-orientations, stocking attitudes, and fisheries management attitudes using Likert-scale questions (Likert 1932; see Table 4.1). This section builds off literature showing that recreational behavior, knowledge and awareness of environmental issues, and beliefs around wildlife and the environment can influence attitudes and the nature of those attitudes (Borrie et al. 2002, Fulton et al. 1996, Hall et al. 2010, Larson et al. 2011, Teel and Manfredo 2010, Whittaker et al. 2006). The survey was reviewed by National Parks Service staff, and was tested for clarity on a group of recreationalists prior to formal sampling.

The survey asked respondents to rate their knowledge about park nature and management using a scale that ranged from no knowledge to very knowledgeable. Waterbody value-orientations were then assessed by determining how strongly respondents agreed or disagreed with the importance of national park waterbodies for given uses, e.g., for recreation, for preserving biodiversity. To assess environmental beliefs, we also asked respondents to indicate the extent to which they perceived different threats to national park ecosystems, e.g., climate change, pollution, introduced species. All Likert-type questions were measured on a 5-point scale. Additional questions assessed whether respondents had prior knowledge of fish stocking practices, if they participate in angling on public lands, and if they have ever consumed fish from mountain lakes and if so, how often. Respondents also indicated if they were affiliated 
with any environmental, recreational, or natural resource-focused organizations, and if so, listed any groups they were affiliated with.

The survey asked respondents to rate several statements about the presence of introduced fish in mountain lakes to establish their initial perception of historical fish stocking. Subsequently, an informational excerpt was presented describing the history and current approaches to fish management in mountain lakes. After reading the excerpt, visitors were asked to rate their agreement or disagreement with a series of attitude statements regarding mountain lake fisheries management (Figure 4.1).

\subsubsection{Data collection}

Visitors were approached at popular trailheads and trail crossings, campgrounds, and central parking lots/scenic overlooks, in an effort to sample the diversity of visitor types at national parks $(n=200$ at each park). Surveys were generally administered between 07:00 and 19:00 each day. Contact was attempted with all observed park users at each trailhead, parking lot, and campground to avoid survey bias, and because visitor mobility made stratified sampling techniques difficult. Prospective respondents were approached and asked if they were interested in taking a voluntary survey to document opinions about management issues in the park. Those who were over 18 years of age and who agreed to participate were given a clipboard with the survey, and allowed as long as they needed to complete (typically about 5-10 minutes). If groups were comprised of family members, one eligible group member was randomly selected to fill out the survey. Visitors were counted as non-respondents if they declined to take the survey or ignored or avoided contact with the surveyor when approached. Common reasons for non-response 
included time constraints of mountaineers and parents with young children, avoidance of surveyor, and limited English-speaking skills; it is possible that some of these groups would have had distinctive responses, but further surveying approaches were beyond the scope of this project.

\subsubsection{Data analyses}

The goal of our analyses was to identify common attitudes toward fish stocking and fisheries management in mountain lakes, as well as what influences these attitudes. We used exploratory factor analysis (EFA) for each group of questions to provide a rationale for averaging sets of variables into composite indices. EFA is appropriate because the questions on our survey were tailored to the specific issue of fish stocking and did not have a priori hypothesized relationships. Survey items that factored together were averaged to create indices that could represent important psychological constructs and serve as independent variables in regression models (i.e. existing knowledge of park nature, importance of park waterbodies, perceived ecosystem threats, initial stocking opinions). The same was done for the response variables for each model (i.e., management attitudes). In order to determine which constructs influenced respondents' management attitudes, we then used logistic regression to model how well our independent variables explained differences in fisheries management attitudes. All analyses were completed using R version 3.2.1 (R Core Team 2016). 


\subsubsection{Visitor attitudes toward fisheries management approaches}

To develop a cohesive set of attitude constructs, we created composite indices for different groups of attitude statements based on maximum likelihood EFA with varimax rotation. To ensure data met internal consistency requirements prior to EFA, we calculated Kaiser-Mayer-Olkin measures for each question set (cutoff 0.7). Then, a combination of factor eigenvalues (minimum of 1), variance explained (minimum of $5 \%$ ), parallel analysis, and scree plots were used to determine how many factors to include in each analysis (Figures $\mathrm{C} 2-\mathrm{C} 4)$. Items that loaded on a given factor above a threshold of 0.5 were grouped together. We confirmed item groupings using Cronbach's $\alpha$ (cutoff 0.6 , due to small number of items), assessing sum of squares for loadings of each factor, and by minimizing cross loadings (loading of one item $>0.5$ on one factor and $>0.3$ on one or more other factors) (Osbourne and Costello 2009). Instead of using arbitrary factor scores as a value for each variable in our analyses, we instead averaged the Likert scale values of each item that exceeded the 0.5 factor score threshold for each group (DeAngelo and Nielsen-Pincus 2017, Obeng and Aguilar 2018).

\subsubsection{Drivers of visitor attitudes}

We used logistic regression models to determine which variables were associated with positive attitudes toward each management attitude group. Logistic regression was the most statistically robust option for our data, and allowed for easily interpretable results, since our goal was to determine attitude valence (agreement or disagreement with statements), as opposed to strength. Additionally, response variables were skewed (prostocking attitude was right-skewed, pro-preservation attitude was left-skewed), and 
composed of interval values, and were therefore better represented as binary, since this type of dataset violates certain assumptions of linear regression. We converted factor scores to a binary scale represented by 1 (agreed or strongly agreed with the group of statements) or 0 (disagreed with, strongly disagreed with, or was neutral toward the statements), for use in logistic regression (Brehm et al. 2004, DeAngelo and NielsenPincus 2017, Obeng and Aguilar 2018). This approach allowed us to construct straightforward models that clearly indicated which independent variables were associated with a positive attitude toward each management attitude group. Final models were selected using Akaike Information Criteria (AIC), as well as by assessing model fit with McFadden's pseudo $R^{2}$. Analyses, model comparisons and outputs were completed using the $\mathrm{R}$ packages psych and nFactors for factor analysis (Raiche 2010, Revelle 2017), MASS for logistical model selection (Venables and Ripley 2015), aod for model fitting (Lesnoff and Lancelot 2012), and $\mathrm{pscl}$ for calculating pseudo $R^{2}$ values (Jackman 2015)

\subsubsection{Visitor fish consumption}

We calculated the total percentage of visitors who report consuming mountain lake fish at each park. The total number of survey respondents who consume fish on at least one occasion per year was used to conduct a rough extrapolation to determine approximately how many visitors each year, on average, may be consuming fish from mountain lakes at each park. Extrapolations were based on the 10-year averages of annual recreational visitation to each national park (National Parks Service 2017). 


\subsection{Results}

\subsubsection{Summary of responses}

A total of 400 responses - 200 from each park - were collected between July 21 and August 9, 2016. Of these, 395 responses were usable for analyses. Survey response rate was approximately $60 \%$ - with non-English speakers and visitors with young children representing the primary types of non-respondents. Respondents ranged in age from $18-78$, median income was $\$ 50,000-\$ 74,999$, most respondents were white/Caucasian, and most respondents held a Bachelor's degree at the time of the survey (Table 4.2).

\subsubsection{Visitor attitudes toward fisheries management approaches}

After reading the given excerpt on fish stocking (Figure C1), most survey respondents $(80 \%)$ agreed that the ecological concerns of fish stocking were legitimate, and most agreed $(54 \%)$ that action should be taken - in the form of fish removal - to alleviate the effects of fish on mountain lake ecosystems (Figure 4.1). A minority of respondents agreed that this issue is blown out of proportion, that fish add value to mountain lakes, and that stocking programs should be reinstated, despite ecological concerns (Figure 4.1, Table 4.3). Over $40 \%$ of visitors thought that some lakes should be designated for fishing, while others should be designated for pristine nature, and worried that removing fish from too many lakes would then increase the negative effects of visitors on lakes that still had fish (Figure 4.1). The attitude that fish would be best removed using only manual methods was also a popular one, with over $40 \%$ of 
respondents in agreement. In addition, many respondents (roughly 40\%) did not have an opinion, or felt they did not know enough to comment (Figure 4.1).

The fisheries management attitude statements (Figure 4.1) grouped into four attitude groups in our factor analyses. We refer to these four main EFA factors as management attitudes (Table 4.3). The first factor was influenced by statements that supported fish stocking; we named this the "pro-stocking" management attitude. The second factor represented items that indicated respondents either had no opinion or did not feel informed enough on the issue. This "neutral" management attitude was not included as a response variable in our models, since we were primarily interested in what drives attitude (versus a lack thereof). The third factor represented items expressing concern over fish stocking and beliefs that action should be taken; we named this third factor the "pro-preservation" management attitude. Last, the fourth management attitude was represented by the remaining item with a substantial factor loading - that some lakes should be kept pristine while others should be managed as a fishery. We named this "pro-conservation" management attitude (represented by a single measured item; hence no $\alpha)$.

\subsubsection{Drivers of visitor attitudes}

To capture the effects of visitor ranking of the importance of national park waterbodies and ecological knowledge on visitor attitudes, we created four composite index variables using the EFA results. Three of these indices described the perceived value of waterbodies (Table 4.4), and one represented knowledge of park nature.

Responses to the importance of national park waterbodies grouped into three factors, 
which we named ecological importance, cultural importance, and recreational importance (Table 4.4). The fourth composite variable, i.e., "knowledge", consisted of the average self-ranked knowledge scores for all aspects of park nature and management (Table C1). In our models, we excluded the cultural importance of waterbodies index due to its correlation with the ecological importance index (Pearson's $r=0.72$ ).

Instead of creating a composite variable for perceived ecosystem threats, we chose to average scores for one threat - climate change. We chose this threat because respondents' social norms and value-orientations are likely to influence their perceptions of climate change risk (e.g., van der Linden 2015). We also selected one representative attitude statement - "Stocking mountain lakes in the park with fish is important for recreation" - to characterize stocking attitude (mean index score $=-0.07$ ). Last, we sorted responses about group membership into three types. Ecological groups included those who participate in environmental activism, education, and/or conservation, e.g., The Nature Conservancy or Sierra Club. Recreational groups are those who primarily serve as a resource for outdoor recreation, such as The Mountaineers (a Washington-based mountaineering club), or the American Alpine Club. Resource groups included those organizations primarily focused on managing a specific resource for recreational purposes, such as Trout Unlimited or the Rocky Mountain Elk Foundation (Table 4.2). For each model, final predictor variables included demographic data, self-ranked environmental knowledge, ecological and recreational waterbody importance, attitude toward national park ecosystem health, attitude toward the threat of climate change, prior knowledge of historical fish stocking, group membership type, initial attitude toward fish presence, and participation in angling. All model predictor variables met logistic 
regression assumptions for independence, based on a covariance matrix test and $\chi^{2}$ test of independence for categorical variables.

\subsubsection{Model results}

All three of the logistic regressions capturing management attitudes performed significantly better than a null model $\left(\chi^{2}<0.01\right.$; Table 4.5$)$. A pro-stocking attitude among visitors was best determined by gender, education, recreational value, opinion of ecosystem health, opinion of the threat of climate change, and initial opinion of stocking $\left(\chi^{2}=29.9, p<0.001\right.$, pseudo $\left.R^{2}=0.32\right)$. All of these variables were significant $(\alpha<0.05)$ in our final logistic model, with the exception of recreational value and gender, which showed marginal significance $(\alpha<0.10)$. Respondents with lower levels of education were more likely to hold pro-stocking attitudes. In addition, pro-stocking respondents were more likely to view national park ecosystems as healthy and were less likely to view climate change as a threat. Respondents who initially viewed fish stocking positively, before reading the excerpt, were also more likely to maintain a pro-stocking attitude. A weak relationship with gender suggests that respondents who support fish stocking in mountain lakes were more likely to be male (Table 4.5).

Pro-preservation attitudes were associated with the park at which respondents were visiting, level of education, self-ranked knowledge, recreational importance of lakes, opinion of national park ecosystem health, initial opinion of stocking, and group membership $\left(\chi^{2}=23.6, p=0.001\right.$, pseudo $\left.R^{2}=0.41\right)$. All variables were significant in our final logistic model $(\alpha<0.05)$, with the exception of education, which was marginally significant $(\alpha<0.10)$. Respondents visiting Mount Rainer NP and those with low self- 
ranked knowledge about park ecosystems were more likely to agree with propreservation sentiments. In addition, those who rated lakes as being important for recreation, but did not feel national park ecosystems were healthy, were more likely to support the pro-preservation attitude. Pro-preservation attitudes were also expressed by respondents who had an initially negative view of stocking, prior to reading the excerpt, and by respondents who were not members of natural resource-oriented groups. The model also suggests that those with higher levels of education may be more likely to support a pro-preservation management approach, but this variable was only marginally significant.

Pro-conservation attitudes were associated with respondent age, opinion of the threat of climate change, prior knowledge and initial opinion of stocking practices, and participation in angling $\left(\chi^{2}=41.5, p<0.001\right.$, pseudo $\left.R^{2}=0.32\right)$. All of these variables were significant in our final logistic model $(\alpha<0.05)$, with the exception of age, which was marginally significant $(\alpha<0.10)$. Respondents who agreed with a pro-conservation management approach were unlikely to view climate change as a threat to national park ecosystems. In addition, pro-conservation attitudes were expressed by those who did not have prior knowledge of fish stocking in mountain lakes, but viewed it positively. These respondents were also more likely to participate in angling. The negative relationship with age in our model suggests younger respondents may be more likely to support a conservation approach. 


\subsubsection{Visitor fish consumption}

Our survey found that that $43.5 \%$ of respondents who participate in angling report consuming mountain lake fish on at least one occasion annually, which equates to $12.7 \%$ of survey respondents (Figure 4.2). Extrapolating these results to 2017 annual park recreation visitation indicates that roughly 153,300 visitors at Mount Rainier and 4,400 visitors at North Cascades NP (113,900 if including Ross Lake National Recreation Area) may consume mountain lake fish on at least one occasion each year. However, it should be noted that these figures do not take into account that our survey sample may not be entirely representative of the visitor population at each park. For instance, the value at Mount Rainier NP may be inflated because a sizable proportion of visitors to the park are part of large tour bus groups, who were underrepresented in our data collection. However, we tried to alleviate for this by only using total number of visitors who were reported to be recreating by the NPS (National Parks Service 2017).

\subsection{Discussion}

Historical fish stocking on US public lands has created a challenging management predicament. The cultural importance of mountain lake fishing is at odds with scientific and federal land management objectives - especially in wilderness areas (Landres et al. 2001). Mountain lake fisheries management issues have had little public exposure, leaving a major knowledge gap about public perceptions. This lack of data about public perceptions is a common problem in wilderness management (Watson et al. 2015). Our research indicates that visitors' attitudes toward mountain lake fisheries management are 
diverse, and are driven primarily by visitors' knowledge of ecological issues, recreational habits, social norms, and value-orientations.

\subsubsection{Visitor attitudes toward fisheries management approaches}

As we hypothesized, the emergence of the four fisheries management attitudes pro-stocking, pro-conservation, pro-preservation, and neutral - from our data aligns well with Teel and Manfredo's (2010) four major wildlife-value orientation groups traditionalist, pluralist, mutualist, and distant, respectively. On either end of this attitude spectrum, the pro-stocking and pro-preservation attitude groups support two primary theoretical value orientations: anthropocentric and biocentric (e.g., McFarlane and Boxall 2000, Steel et al. 1994, Vaske and Donnelly 1999).

Based on our results, the attitudes of the majority of national park visitors are aligned with those of the scientific community and the National Parks Service, as most respondents agreed that managers should take action to reduce the negative effects of historical fish stocking in mountain lakes. Our observed support for restorative management actions makes sense in the context of a study by Duffus and Dearden (1990), which summarizes a shift from consumptive to non-consumptive wildlife recreation. The shift to non-consumptive uses has grown since the 1990s, with a documented steady decline in hunting and angling licenses while hiking and backpacking is on the rise (Pergams and Zaradic 2008). With the growth of non-consumptive recreation, it seems intuitive that the majority of visitors viewed preservation-oriented management approaches favorably, since, for example, healthy ecosystems are required for wildlife viewing. Watson et al. (2015) demonstrate this phenomenon with their study 
of visitors at Sequoia and Kings NP in California: respondents broadly supported management actions that would restore park ecosystems to natural conditions.

Notably, while taking action was a popular approach, about half of those respondents who supported management actions to remove fish did not agree with the use of chemical removal techniques. This attitude could be due in part to these respondents' lack of knowledge about piscicides and the precautions that agency managers take when using these chemicals - this information was not included in the questionnaire.

Alternatively, the lack of support for this approach may be because attitudes in support of "severe" (i.e. lethal) interventions are typically only driven by strong value-orientations, or only exist for wildlife issues that have a potentially negative implication for humans (Jacobs et al. 2014).

\subsubsection{Drivers of management attitudes}

Contrary to our expectations, pro-preservation attitudes were associated with low self-ranked ecological knowledge. However, this attitude was associated with a higher level of education. That pro-preservation attitudes are associated with higher rankings for the recreational importance of waterbodies is surprising, because this composite variable includes fishing as an important aspect. We also expected perceived climate change threat to be an important predictor of the pro-preservation attitude, but it was not significant. Our results may be explained by Sharp et al. (2011), who found that while knowledge and perceived threat scores influenced invasive species management preferences, environmental attitudes were the best indicator of management action support. However, the influence of group membership, perception of ecological health, 
and initial opinion of stocking on pro-preservation attitudes do support our hypotheses. Mount Rainier NP visitors may have been more likely to support a preservation attitude, because of the interpretive material about the issue of mountain lake fisheries in at least one of their visitor centers. The conflicting findings for this attitude group may indicate that our belief statements may not have effectively captured the types of attitudes held by those who are in favor of restoration. This is perhaps due to the complexity of values that lead to support for lethal wildlife management approaches (e.g., Jacobs et al. 2014).

Respondents with pro-stocking attitudes were more likely to report lower degree levels obtained than those who supported fish removal actions, recreation as an important aspect of waterbodies, perceive park ecosystems as healthy, and were unlikely to perceive climate change as a threat to ecosystems. Similar results regarding education were found in a study on attitudes toward wolf reintroductions - those who were less educated were less likely to view wolves and their reintroduction as favorable, despite their ecological benefit (Williams et al. 2016). Additionally, due to the importance of environmental education in determining one's level of environmentally responsible behavior (Hungerford and Volk 1990), it is not surprising that pro-stocking attitudes were associated with lower education. The importance of positive initial attitudes about stocking in this group indicates that respondents with a pro-stocking management attitude were unlikely to be swayed by the excerpt on the ecological effects of fish.

Based on Teel and Manfredo's (2010) description of pluralist wildlife-value orientations, we expected pro-conservation attitudes to align with both recreational and ecological waterbody importance, but this was not the case. Respondents with proconservation attitudes were likely to have a positive initial view of stocking, and not 
perceive climate change as a threat to ecosystem health. Pro-conservation respondents were also less likely to have prior knowledge of fish stocking in mountain lakes. Perhaps this indicates that pro-conservation respondents were less likely to have pre-determined attitudes about the issue, which could explain why they were more likely to indicate a more moderate, conservation-based attitude after reading the excerpt, despite having an initially positive view of stocking. In addition, angling participation was associated with a pro-conservation attitude. This may be explained by the fact that angling license programs (along with hunting license programs) are founded on the principle of conservation - where fees from licenses allowing for wildlife harvest sustain the funding for wildlife conservation (e.g., Duda et al. 2010, Heffelfinger et al. 2013)

\subsubsection{Contaminant precautions}

Although the percentage of visitors in our study who consume fish from mountain lakes annually is small (4\%), our extrapolation suggests that many thousands of visitors to mountain lakes at national parks, national forests, and other public lands may consume fish every year. These numbers could also be an underestimate if anglers made up a substantial portion of non-respondents. Considering that levels of many industrial compounds can sometimes exceed US EPA consumption thresholds in existing studies of mountain lake fishes (e.g., Ackerman et al. 2008, Blais et al. 2006, Flanagan Pritz et al. 2014, Landers et al. 2008), fish consumption patterns may be an important focus for managers. Current available research can be used to provide visiting anglers with the best-available knowledge to mitigate against contaminant exposure (e.g., Clayden et al. 2013, Drenner et al. 2013, Flanagan Pritz et al. 2014, Ullrich et al. 2001). For example, 
Chiapella and Strecker (2016) found that rainbow trout, as well as fish from large, deep lakes, had the lowest mercury levels across several national parks. Informed anglers should be able to identify factors that increase the risk of contamination when choosing which lakes to consume fish from. By using proper education and outreach, managers could lower the risk of contaminant consumption by anglers.

\subsubsection{A balanced and participatory approach}

Although many respondents agreed with a management approach that prioritizes ecological health, we found that angling is still a popular activity, and many non-anglers have interest in participating. About one-third of respondents indicated that they have fished in national parks or on other lands at some point, and about $15 \%$ who have not fished on public lands would be interested in doing so in the future. Angling is expected to increase in prevalence due to population growth, despite per capita decreases in participation (Bowker et al. 2012, Cordell et al. 2008). This trend could help explain why a pro-conservation attitude was common among respondents.

This interest in angling, paired with the broad support for conservation-based management by our respondents indicates that a management plan that optimizes ecological integrity using fish removal, but still allows for fishing in less sensitive lakes, could be a popular option for both the average visitor and the angling community alike. Such a balanced approach could also help mitigate illegal stocking, which has been observed after fish removals in North Cascades, Mount Rainier, and Yosemite NP, and is an inconvenient yet unavoidable risk (Halverson 2011, National Parks Service 2017 2007, Pister 2001). The combined interest in angling and concern for ecological health 
from visitors could also be leveraged in the fish removal effort. Education and outreach, especially at wilderness permitting stations, could be an effective means of recruiting visitors to help with manual fish removal efforts by encouraging angling (with the requirement of removal) in mountain lakes with fish. However, using visitors to help with removal would have to be used with caution, to avoid creating a long-term incentive for fishing in systems where total fish eradication is the ultimate goal. If implemented with care, the inclusion of citizen anglers in the management of mountain lakes fisheries would be useful not just with fish removal efforts. Citizen science can also be an important component of education, outreach, and engagement of the public in the management and decision-making process (McKinley et al. 2017). Additionally, based on previous success with educational and interpretive programs on public lands (Marion and Reid 2009), parks could likely garner more support for fish removal using these methods, as long as they are targeted to appeal to the diverse value-orientations of visitors (Miller et al. 2017).

Other examples of major food-web restoration efforts on public lands illustrate that social considerations of management actions are crucial to successful implementation. For instance, the reintroduction of beaver populations on public lands in the Pacific Northwest could restore ecological complexity and resilience in aquatic ecosystems, but has suffered roadblocks due to opposing interests between agricultural, management, and scientific groups (Baldwin 2017). The re-introduction of wolves in Yellowstone NP would not have been possible without balancing the values and concerns of stakeholders (Bath 1989, Fritts et al. 1997). Similarly, for successful management and restoration of mountain lakes, it will be crucial for managers to consider mountain lakes as a complex 
socioecological system, which requires not just ecological monitoring, but engagement with stakeholders and the public to optimize decision-making and management best practices (Alessa et al. 2018).

\subsubsection{Bias and caveats}

In line with past visitor surveys (e.g., Floyd 1999, Ghimire et al. 2016, U.S. Forest Service 2016), the majority of visitors were white, leaving the viewpoints of minority groups vastly underrepresented. Although they only make up a small percentage of visitors, the viewpoints of people of color and Native Americans are important to consider, since they likely have distinct opinions about public lands management (Floyd 1999, Johnson et al. 2004, Krymkowski et al. 2014, Washburne 1978). In addition, national parks are putting effort into increasing the visitation of diverse visitor populations (e.g., McGown et al. 2012). Capturing the perceptions of minority groups on the issue of mountain lakes fisheries management could be an important aspect of the decision-making process, especially if parks want to prioritize visitation accessibility to marginalized communities.

In addition to minority groups, families with small children were also underrepresented by this survey. Although the viewpoints of this demographic are unlikely to differ as drastically as those of minority groups, they may be more at-risk of exposure to contaminants relative to the average visitor portrayed by this study. Many of the toxins that have been detected in mountain lake fish are more harmful during early developmental stages, such as mercury, which is a neurotoxin (Agency for Toxic Substances and Disease Registry 2011). The consumption of fish in these lakes by 
families and their children is something that should be considered in management decisions.

\subsection{Conclusions}

While the attitudes of public lands visitors alone should not dictate management decisions, the decision-making process in public lands and wilderness management often fails to effectively capture public viewpoints (Watson et al. 2015). We found that a balanced management plan that implements fish eradication in lakes with sensitivity to fish presence, but leaves populations in lakes that are more resilient, while also engaging visitors in outreach and the fish removal process would be the best approach to creating a balance between stakeholder attitudes. This strategy would provide a compromise for those who value angling in mountain likes, while still promoting the ecological health of mountain ecosystems, which was the most important aspect of lakes according to our survey, and the most important value of wilderness according to other research (Brown and Alessa 2005, Cordell et al. 1998).

We anticipate these findings are relevant not just for national parks, but for many land management agencies in the US and abroad. Trout are the one most ubiquitously stocked

fish in the world, and have been introduced into mountain lakes ranging from the Sierras, Cascades, and Rockies (Knapp et al. 2001, Pister 2001), to the Andes (Vigliano et al. 2009), Alps, and Pyrenees (Tiberti et al. 2014). Bennett et al. (2016) argue that the inclusion of social science and public values is imperative in management and conservation decisions, and this no doubt applies to a conservation issue as large as fish stocking. Our study provides a foundation for how to incorporate views of the public into 
the management and conservation of mountain lakes, and we encourage future studies to build upon this foundation.

All procedures performed in studies involving human participants were in accordance with the ethical standards of the institutional and/or national research committee and with the 1964 Helsinki declaration and its later amendments or comparable ethical standards. 
Table 4.1 Sections from Part 2 of the survey, including the questions asked, list of rankings, and scale used.

\begin{tabular}{|c|c|c|c|}
\hline Question & & Ranking & Scale \\
\hline $\begin{array}{l}\text { Activity } \\
\text { participation }\end{array}$ & $\begin{array}{l}\text { Overnight, day, hiking, site- } \\
\text { seeing, camping, backpacking, } \\
\text { swimming, fishing, picnicking, } \\
\text { cycling, climbing }\end{array}$ & Yes/No & $\begin{array}{l}\text { Binary } \\
(0 \mid 1)\end{array}$ \\
\hline $\begin{array}{l}\text { Knowledge } \\
\text { ranking }\end{array}$ & $\begin{array}{l}\text { Mammals and birds, forests } \\
\text { and plants, streams and lakes, } \\
\text { geology, park management, } \\
\text { aquatic animals, glaciers, } \\
\text { biodiversity, nutrient cycling }\end{array}$ & $\begin{array}{l}\text { Very little knowledge, } \\
\text { Limited knowledge, } \\
\text { Average knowledge, More } \\
\text { than average knowledge, } \\
\text { Very knowledgeable }\end{array}$ & $\begin{array}{l}\text { Likert } \\
(0-4)\end{array}$ \\
\hline $\begin{array}{l}\text { Waterbody } \\
\text { importance }\end{array}$ & $\begin{array}{l}\text { Recreation, clean water, } \\
\text { biodiversity, fishing, intrinsic, } \\
\text { culture }\end{array}$ & $\begin{array}{l}\text { Strongly disagree, } \\
\text { disagree, neutral, agree, } \\
\text { strongly agree }\end{array}$ & $\begin{array}{l}\text { Likert } \\
(-2-+2)\end{array}$ \\
\hline $\begin{array}{l}\text { Park } \\
\text { ecosystem } \\
\text { health }\end{array}$ & & $\begin{array}{l}\text { Strongly disagree, } \\
\text { disagree, neutral, agree, } \\
\text { strongly agree }\end{array}$ & $\begin{array}{l}\text { Likert } \\
(-2-+2)\end{array}$ \\
\hline $\begin{array}{l}\text { Ecosystem } \\
\text { threats }\end{array}$ & $\begin{array}{l}\text { Climate change, biodiversity } \\
\text { loss, air pollution, water } \\
\text { pollution, visitor use, non- } \\
\text { native species, resource } \\
\text { extraction }\end{array}$ & $\begin{array}{l}\text { Not a threat, minor threat, } \\
\text { don't know, moderate } \\
\text { threat, major threat }\end{array}$ & $\begin{array}{l}\text { Likert } \\
(-2-+2)\end{array}$ \\
\hline $\begin{array}{l}\text { Urgency of } \\
\text { addressing } \\
\text { threats }\end{array}$ & $\begin{array}{l}\text { Climate change, biodiversity } \\
\text { loss, air pollution, water } \\
\text { pollution, visitor use, non- } \\
\text { native species, resource } \\
\text { extraction }\end{array}$ & $\begin{array}{l}\text { No action needed, not } \\
\text { very urgent, neutral, } \\
\text { somewhat urgent, very } \\
\text { urgent }\end{array}$ & $\begin{array}{l}\text { Likert } \\
(-2-+2)\end{array}$ \\
\hline $\begin{array}{l}\text { Stocking } \\
\text { knowledge }\end{array}$ & & Yes/No & $\begin{array}{l}\text { Binary } \\
(0 \mid 1)\end{array}$ \\
\hline $\begin{array}{l}\text { Initial } \\
\text { stocking } \\
\text { attitude }\end{array}$ & $\begin{array}{l}\text { Important for recreation, } \\
\text { adds value to lakes, benefits } \\
\text { other species, does not have } \\
\text { an ecological effect, has a } \\
\text { negative ecological effect }\end{array}$ & $\begin{array}{l}\text { Strongly disagree, } \\
\text { disagree, neutral, agree, } \\
\text { strongly agree }\end{array}$ & $\begin{array}{l}\text { Likert } \\
(-2-+2)\end{array}$ \\
\hline $\begin{array}{l}\text { Group } \\
\text { membership }\end{array}$ & $\begin{array}{l}\text { Environmental, recreation, or } \\
\text { resource group }\end{array}$ & Self-report & Open \\
\hline $\begin{array}{l}\text { Angling } \\
\text { participation }\end{array}$ & & Yes/No & $\begin{array}{l}\text { Binary } \\
(0 \mid 1)\end{array}$ \\
\hline $\begin{array}{l}\text { Fish } \\
\text { consumption }\end{array}$ & $\begin{array}{l}\text { Annual consumption of } \\
\text { mountain lake fish }\end{array}$ & $\begin{array}{l}\text { Never, once, 1-5, 5-10, } \\
>10 \text {, don't know }\end{array}$ & $0-10+$ \\
\hline
\end{tabular}


Table 4.2 Demographic, group membership, stocking knowledge, and angling participation data for survey respondents $(\mathrm{N}=395)$, including total and percent of total respondents.

\begin{tabular}{|c|c|c|}
\hline Personal Income & $\mathbf{N}$ & $\%$ \\
\hline$\$ 0-24,999$ & 59 & 15.0 \\
\hline$\$ 25,000-49,999$ & 74 & 18.7 \\
\hline$\$ 50,000-75,999$ & 72 & 18.2 \\
\hline$\$ 75,000-99,999$ & 53 & 13.4 \\
\hline$\$ 100,000-149,999$ & 47 & 11.9 \\
\hline$\$ 150,000+$ & 38 & 9.6 \\
\hline No response & 52 & 13.2 \\
\hline \multicolumn{3}{|l|}{ Education } \\
\hline High school & 20 & 5.1 \\
\hline Some college & 80 & 20.3 \\
\hline Bachelor's degree & 167 & 42.3 \\
\hline Master's or law degree & 94 & 23.8 \\
\hline Doctorate degree & 33 & 8.4 \\
\hline No response & 1 & 0.2 \\
\hline \multicolumn{3}{|l|}{ Gender } \\
\hline Male & 221 & 55.9 \\
\hline Female & 171 & 43.3 \\
\hline No response & 3 & 0.8 \\
\hline \multicolumn{3}{|l|}{ Race/ethnicity } \\
\hline Asian/Pacific Islander & 16 & 4.1 \\
\hline Black/African American & 4 & 1.0 \\
\hline Hispanic & 8 & 2.0 \\
\hline Native American & 6 & 2.0 \\
\hline White/Caucasian & 348 & 88.1 \\
\hline No response & 13 & 3.3 \\
\hline \multicolumn{3}{|l|}{ Group membership } \\
\hline Environmental & 68 & 17.2 \\
\hline Recreational & 50 & 12.7 \\
\hline Resource & 4 & 1 \\
\hline None & 273 & 69.1 \\
\hline Prior stocking knowledge & 171 & 43.3 \\
\hline Participation in angling on public & 115 & 29.1 \\
\hline
\end{tabular}


Table 4.3 Factors and factor loadings of mountain lakes fisheries management attitude statements $(\mathrm{N}=392)$. Bold indicates a strong contribution to the respective factor. Total variance explained $=47 \%$

\begin{tabular}{|c|c|c|c|c|}
\hline $\begin{array}{l}\text { “How much do you } \\
\text { agree/disagree with } \\
\text { each statement?" }\end{array}$ & $\begin{array}{l}\text { Pro- } \\
\text { stocking } \\
\text { Factor } 1\end{array}$ & $\begin{array}{l}\text { Neutral } \\
\text { Factor } 2\end{array}$ & $\begin{array}{c}\text { Pro- } \\
\text { preservatio } \\
\boldsymbol{n} \\
\text { Factor } 3 \\
\end{array}$ & $\begin{array}{c}\text { Pro- } \\
\text { conservation } \\
\text { Factor } 4\end{array}$ \\
\hline $\begin{array}{l}\text { The benefits of stocking } \\
\text { outweigh the ecological } \\
\text { consequences }\end{array}$ & 0.62 & 0.19 & -0.16 & 0.22 \\
\hline $\begin{array}{l}\text { Fish add value to all } \\
\text { mountain lakes, despite } \\
\text { potential concerns }\end{array}$ & 0.69 & 0.23 & -0.23 & 0.21 \\
\hline $\begin{array}{l}\text { People keep blowing } \\
\text { environmental issues out } \\
\text { of proportion; this is } \\
\text { another example }\end{array}$ & 0.64 & 0.26 & -0.16 & 0.21 \\
\hline $\begin{array}{l}\text { Stocking programs } \\
\text { should be reinstated }\end{array}$ & 0.70 & 0.22 & -0.30 & 0.32 \\
\hline I don't have an opinion & 0.33 & 0.63 & 0.00 & 0.00 \\
\hline $\begin{array}{l}\text { I don't feel informed } \\
\text { enough to have an } \\
\text { opinion }\end{array}$ & 0.22 & 0.73 & 0.00 & 0.00 \\
\hline $\begin{array}{l}\text { The concerns of fish } \\
\text { stocking are legitimate }\end{array}$ & -0.32 & -0.26 & 0.64 & 0.00 \\
\hline $\begin{array}{l}\text { Action should be taken } \\
\text { to alleviate the effects of } \\
\text { fish on all mountain } \\
\text { lakes }\end{array}$ & -0.13 & -0.30 & 0.63 & -0.47 \\
\hline $\begin{array}{l}\text { Some lakes should be } \\
\text { designated for fishing, } \\
\text { other for pristine nature }\end{array}$ & 0.26 & 0.20 & 0.00 & 0.70 \\
\hline $\begin{array}{l}\text { Removing fish is an } \\
\text { appropriate restoration } \\
\text { approach }\end{array}$ & -0.32 & -0.43 & 0.29 & -0.27 \\
\hline $\begin{array}{l}\text { Removing fish from } \\
\text { some will increase }\end{array}$ & 0.00 & 0.00 & 0.00 & 0.20 \\
\hline
\end{tabular}


pressure on those that

still have fish

Removing fish will be just

as harmful as keeping

fish in the lakes

$\begin{array}{llll}0.50 & 0.30 & -0.15 & 0.30\end{array}$

Fish should be removed,

$\begin{array}{lllll}\text { but only using manual } & - & 0.17 & 0.35 & 0.00\end{array}$

methods (no chemicals)

\begin{tabular}{lcccc}
\hline Eigenvalue & 2.53 & 1.63 & 1.23 & 1.16 \\
Percent Variance & 0.20 & 0.13 & 0.09 & 0.09 \\
Explained & 0.85 & 0.70 & 0.72 & $\mathrm{n} / \mathrm{a}$ \\
Cronbach's $\alpha^{1}$ & -0.59 & -0.17 & 0.86 & 0.29 \\
Mean index score &
\end{tabular}

'Cronbach's $\alpha$ was computed for items with substantial (bold) factor loadings

$($ threshold $=0.5)$. 
Table 4.4 Factors and factor loadings for beliefs related to NP waterbody importance $(\mathrm{N}=361)$. Bold indicates a strong contribution to the respective factor. Total variance explained $=61 \%$

\begin{tabular}{|c|c|c|c|}
\hline $\begin{array}{l}\text { "NP waterbodies are } \\
\text { important for..." }\end{array}$ & $\begin{array}{c}\text { Ecological } \\
\text { importance } \\
\text { Factor } 1\end{array}$ & $\begin{array}{c}\text { Cultural } \\
\text { importance } \\
\text { Factor } 2\end{array}$ & $\begin{array}{c}\text { Recreational } \\
\text { importance } \\
\text { Factor } 3\end{array}$ \\
\hline Recreation & 0.22 & 0.13 & 0.69 \\
\hline Clean water & 0.57 & 0.24 & 0.23 \\
\hline Preserving biodiversity & 0.98 & 0.19 & 0.00 \\
\hline Fishing & 0.00 & 0.16 & 0.62 \\
\hline Intrinsic/existence value & 0.37 & 0.51 & 0.15 \\
\hline Culture & 0.18 & 0.86 & 0.23 \\
\hline Eigenvalue & 1.50 & 1.14 & 1.00 \\
\hline $\begin{array}{l}\text { Percent Variance } \\
\text { Explained }\end{array}$ & 0.25 & 0.19 & 0.17 \\
\hline Cronbach's $\alpha^{1}$ & 0.76 & 0.70 & 0.63 \\
\hline Mean index score & 1.75 & 1.47 & 1.34 \\
\hline
\end{tabular}


Table 4.5 Logistic regression model results for predicting positive attitudes toward three mountain lake fisheries management approaches: pro-stocking $(n=303)$, pro-conservation $(n=220)$, and pro-preservation $(n=291)$. Management attitudes were coded as binary $(1 \mid 0)$

\begin{tabular}{|c|c|c|c|c|c|c|c|c|c|}
\hline \multirow[b]{2}{*}{ Variables } & \multicolumn{3}{|c|}{$\begin{array}{l}\text { Pro-stocking model } \\
\text { Pseudo } R^{2}=0.32 \\
\chi^{2}<0.01\end{array}$} & \multicolumn{3}{|c|}{$\begin{array}{l}\text { Pro-preservation model } \\
\text { Pseudo } R^{2}=0.41 \\
\chi^{2}<0.01\end{array}$} & \multicolumn{3}{|c|}{$\begin{array}{l}\text { Pro-conservation model } \\
\text { Pseudo } R^{2}=0.32 \\
\chi^{2}<0.01\end{array}$} \\
\hline & $ß( \pm S E)$ & $z$ & $p$ & $B( \pm S E)$ & $Z$ & $p$ & $\beta( \pm S E)$ & $Z$ & $p$ \\
\hline $\begin{array}{l}\text { Mount } \\
\text { Rainier NP }\end{array}$ & --- & --- & --- & $\begin{array}{l}2.16 \\
( \pm 0.87)\end{array}$ & 2.49 & $0.01^{*}$ & --- & --- & --- \\
\hline Age & --- & --- & --- & --- & --- & --- & $\begin{array}{l}-0.02 \\
( \pm 0.01)\end{array}$ & -1.81 & 0.07 \\
\hline Male & $\begin{array}{l}0.77 \\
( \pm 0.43)\end{array}$ & 1.78 & 0.07 & --- & --- & --- & -- & --- & --- \\
\hline Education & $\begin{array}{l}-0.39 \\
( \pm 0.19)\end{array}$ & -2.04 & $0.04 *$ & $\begin{array}{l}0.71 \\
( \pm 0.40)\end{array}$ & 1.78 & 0.07 & -- & --- & --- \\
\hline $\begin{array}{l}\text { Ecological } \\
\text { knowledge }\end{array}$ & --- & --- & --- & $\begin{array}{l}-1.05 \\
( \pm 0.48)\end{array}$ & -2.20 & $0.03 *$ & --- & --- & --- \\
\hline $\begin{array}{l}\text { Recreation } \\
\text { importance }\end{array}$ & $\begin{array}{l}0.54 \\
( \pm 0.35)\end{array}$ & 1.55 & 0.12 & $\begin{array}{l}1.58 \\
( \pm 0.54)\end{array}$ & 2.90 & $<0.01^{* *}$ & --- & --- & --- \\
\hline $\begin{array}{l}\text { Ecological } \\
\text { health }\end{array}$ & $\begin{array}{l}0.58 \\
( \pm 0.24)\end{array}$ & 2.38 & $0.02 *$ & $\begin{array}{l}-1.02 \\
( \pm 0.46)\end{array}$ & -2.23 & $0.03 *$ & --- & --- & --- \\
\hline $\begin{array}{l}\text { Climate } \\
\text { change } \\
\text { opinion }\end{array}$ & $\begin{array}{l}-0.82 \\
( \pm 0.19)\end{array}$ & -4.38 & $\begin{array}{l}<0.01^{* *} \\
*\end{array}$ & --- & --- & --- & $\begin{array}{l}-1.03 \\
( \pm 0.40)\end{array}$ & -2.60 & $0.01 *$ \\
\hline $\begin{array}{l}\text { Stocking } \\
\text { knowledge }\end{array}$ & --- & --- & --- & --- & -- & --- & $\begin{array}{l}-1.05 \\
( \pm 0.45)\end{array}$ & -2.36 & $0.02 *$ \\
\hline $\begin{array}{l}\text { Stocking } \\
\text { opinion }\end{array}$ & $\begin{array}{l}0.94 \\
( \pm 0.23)\end{array}$ & 4.07 & $\begin{array}{l}<0.01^{* *} \\
*\end{array}$ & $\begin{array}{l}-1.59 \\
( \pm 0.45)\end{array}$ & -3.57 & $\begin{array}{l}<0.01^{* *} \\
*\end{array}$ & $\begin{array}{l}1.17 \\
( \pm 0.23)\end{array}$ & 5.03 & $\begin{array}{l}<0.01 * \\
* *\end{array}$ \\
\hline Angler & --- & --- & --- & --- & --- & --- & $\begin{array}{l}1.30 \\
( \pm 0.52)\end{array}$ & 2.53 & $0.01 *$ \\
\hline $\begin{array}{l}\text { Resource } \\
\text { group }\end{array}$ & --- & --- & --- & $\begin{array}{l}-7.95 \\
( \pm 1.97)\end{array}$ & -4.03 & $\begin{array}{l}<0.01^{* *} \\
*\end{array}$ & --- & --- & --- \\
\hline
\end{tabular}




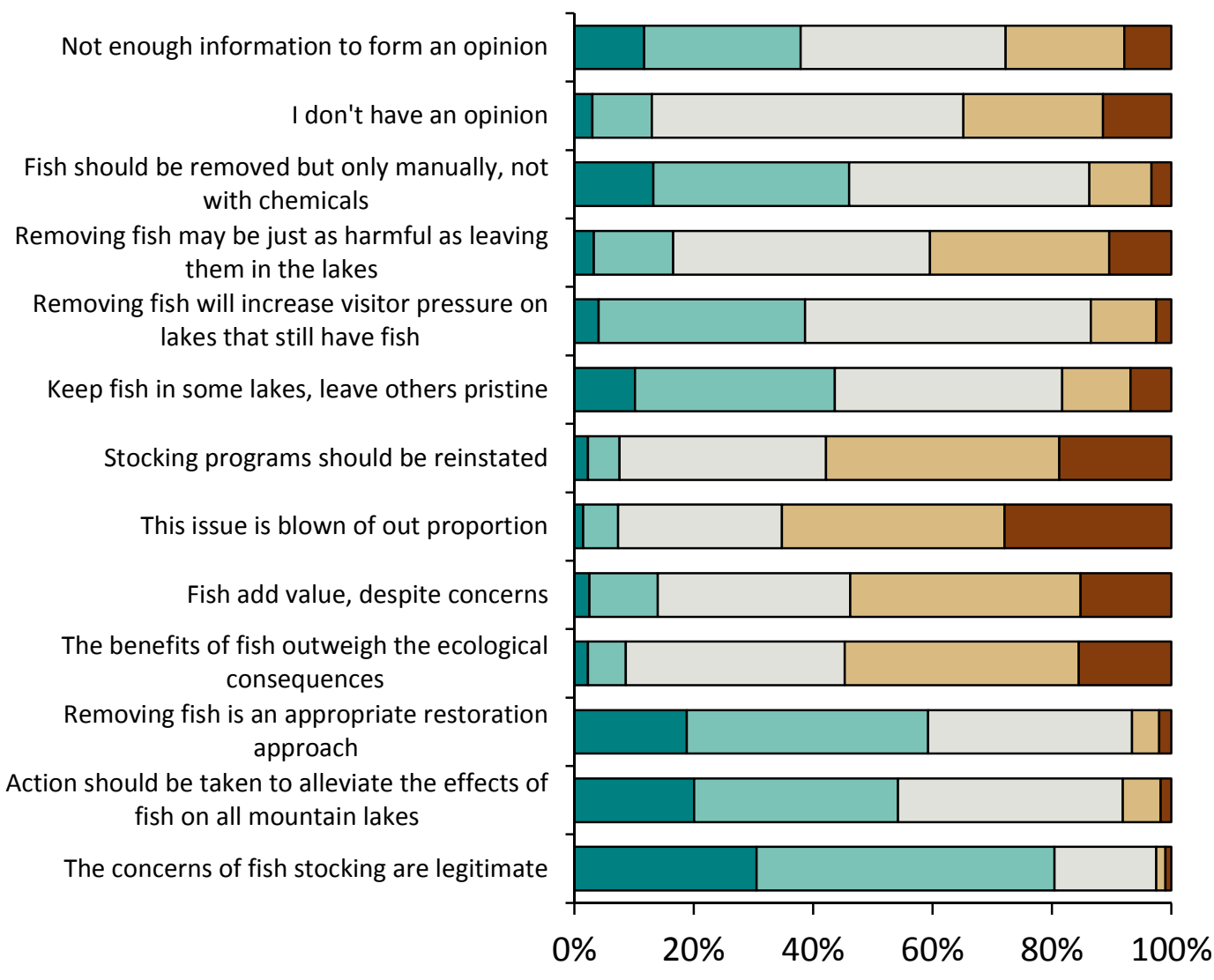

Strongly agree $\square$ Agree $\square$ Neutral $\square$ Disagree $\square$ Strongly disagree

Figure 4.1 Survey responses for each mountain lake fish management statement.

Respondents indicated how strongly the agreed or disagreed (left to right) with each

statement. 


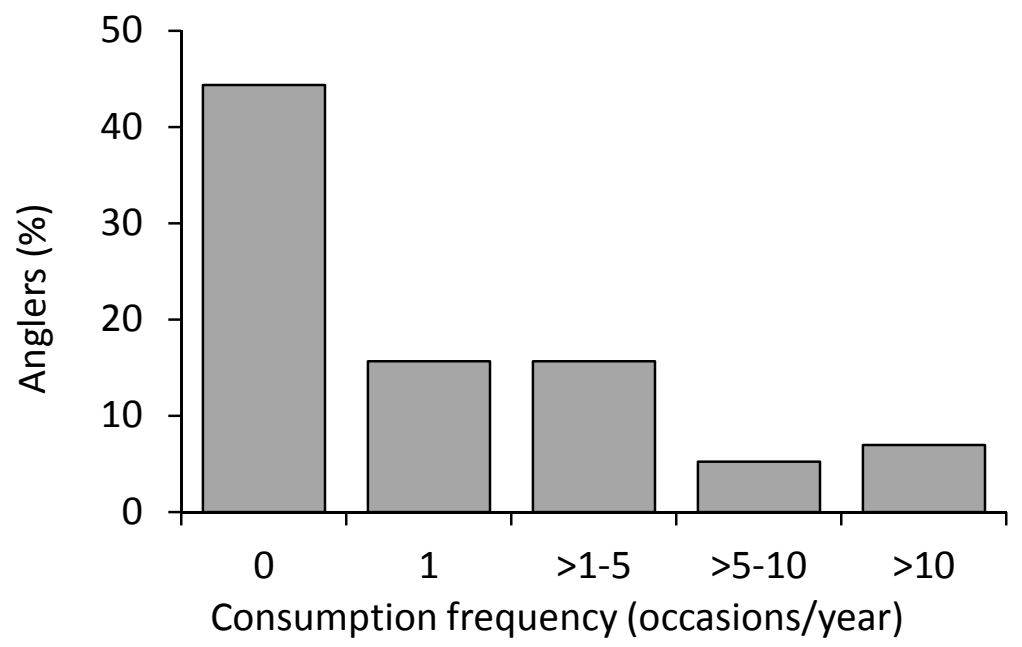

Figure 4.2 Annual fish consumption frequency of angler respondents. 


\subsection{References}

Ackerman, L.K., Schwindt, A.R., Simonich, S.L.M., Koch, D.C., Blett, T.F., Schreck, C.B., Kent, M.L., Landers, D.H., 2008. Atmospherically deposited PBDEs, pesticides, PCBs, and PAHs in western U.S. National Park fish: concentrations and consumption guidelines. Environ. Sci. Technol. 42, 2334-41. https://doi.org/10.1021/es702348j

Adams, S.B., Frissell, C.A., Rieman, B.E., 2001. Geography of invasion in mountain streams: Consequences of headwater lake fish introductions. Ecosystems 4, 296307. https://doi.org/10.1007/s10021-001-0012-5

Agency for Toxic Substances and Disease Registry, 2011. Toxic Substances - Mercury [WWW Document]. Dep. Heal. Hum. Serv. URL https://www.atsdr.cdc.gov/substances/toxsubstance.asp?toxid=24 (accessed 3.19.18).

Alessa, L., Kliskey, A., Gosz, J., Griffith, D., Ziegler, A., 2018. MtnSEON and socialecological systems science in complex mountain landscapes. Front. Ecol. Environ. 16, S4-S10. https://doi.org/10.1002/fee.1753

Baldwin, J., 2017. Institutional Obstacles to Beaver Recolonization and Potential Climate Change Adaptation in Oregon, USA. Assoc. Pacific Coast Geogr. Yearb. 79, 93114. https://doi.org/10.1353/pcg.2017.0005

Bath, A.J., 1989. The public and wolf reintroduction in Yellowstone National Park. Soc. Nat. Resour. 2, 297-306. https://doi.org/10.1080/08941928909380693

Bennett, N.J., Roth, R., Klain, S.C., Chan, K., Christie, P., Clark, D.A., Cullman, G., Curran, D., Durbin, T.J., Epstein, G., Greenberg, A., Nelson, M.P., Sandlos, J., 
Stedman, R., Teel, T.L., Thomas, R., Veríssimo, D., Wyborn, C., 2016.

Conservation social science: Understanding and integrating human dimensions to improve conservation. Biol. Conserv. 205, 93-108.

https://doi.org/10.1016/j.biocon.2016.10.006

Blais, J.M., Charpentié, S., Pick, F., Kimpe, L.E., St Amand, A., Regnault-Roger, C., 2006. Mercury, polybrominated diphenyl ether, organochlorine pesticide, and polychlorinated biphenyl concentrations in fish from lakes along an elevation transect in the French Pyrénées. Ecotoxicol. Environ. Saf. 63, 91-9. https://doi.org/10.1016/j.ecoenv.2005.08.008

Borrie, W.T., Freimund, W.A., Davenport, M.A., 2002. Winter Visitors to Yellowstone National Park : Their Value Orientations and Support for Management Actions. Hum. Ecol. 41-48.

Bowker, J.M., Askew, A.E., Cordell, H.K., Betz, C.J., Zarnoch, S.J., Seymour, L., 2012. Outdoor Recreation Participation in the United States - Projections to 2060.

Bradford, D.F., Cooper, S.D., Jenkins, Jr., T.M., Kratz, K., Sarnelle, O., Brown, A.D., 1998. Influences of natural acidity and introduced fish on faunal assemblages in California alpine lakes. Can. J. Fish. Aquat. Sci. 55, 2478-2491. https://doi.org/10.1139/f98-128

Brehm, J.M., Eisenhauer, B.W., Krannich, R.S., 2004. Dimensions of Community Attachment and Their Relationships to Well-Being in the Amenity Rich Rural West. Rural Sociol. 69, 405-429.

Brown, B.Y.G., Alessa, L., 2005. A GIS - based Inductive Study of Wilderness Values. Int. J. Wilderness 11, 1-5. 
Carlisle, D.M., Hawkins, C.P., 1998. Relationships between Invertebrate Assemblage Structure, 2 Trout Species, and Habitat Structure in Utah Mountain Lakes. J. North Ameican Benthol. Soc. 17, 286-300. https://doi.org/10.2307/1468332

Chiapella, A., Strecker, A., 2016. A stable isotope approach to understanding contaminant distribution in food webs of montane lakes.

Clayden, M.G., Kidd, K. a., Wyn, B., Kirk, J.L., Muir, D.C.G., O’Driscoll, N.J., 2013. Mercury biomagnification through food webs is affected by physical and chemical characteristics of lakes. Environ. Sci. Technol. 47, 12047-12053. https://doi.org/10.1021/es4022975

Cordell, H.., Tarrant, M.A., McDonald, B.., Bergstrom, J.C., 1998. How the public views wilderness. Int. J. Wilderness 4, 28-31.

Cordell, H.K., Betz, C.J., Green, G.T., 2008. Nature-based Outdoor Recreation Trends and Wilderness. Int. J. Wilderness 14, 7-10.

Daigle, J.J., Hrubes, D., Ajzen, I., 2002. A Comparative Study of Beliefs, Attitudes, and Values Among Hunters, Wildlife Viewers, and Other Outdoor Recreationists. Hum. Dimens. Wildl. 7, 1-19. https://doi.org/10.1080/108712002753574756

DeAngelo, M., Nielsen-Pincus, M., 2017. Choosing the Right Policy Tools to Encourage Watershed Stewardship through the Study of Attitude. Soc. Nat. Resour. 30, 13281342. https://doi.org/10.1080/08941920.2017.1347973

Drenner, R.W., Chumchal, M.M., Jones, C.M., Lehmann, C.M.B., Gay, D. a, Donato, D.I., 2013. Effects of mercury deposition and coniferous forests on the mercury contamination of fish in the south central United States. Environ. Sci. Technol. 47, S:1-7. https://doi.org/10.1021/es303734n 
Duda, M., Jones, M., Criscione, A., 2010. The sportsman's voice: Hunting and fishing in America.

Duffus, D.A., Dearden, P., 1990. Non-consumptive wildlife-oriented recreation: A conceptual framework. Biol. Conserv. 53, 213-231. https://doi.org/10.1016/00063207(90)90087-6

Eby, L. a, Roach, W.J., Crowder, L.B., Stanford, J. a, 2006. Effects of stocking-up freshwater food webs. Trends Ecol. Evol. 21, 576-84. https://doi.org/10.1016/j.tree.2006.06.016

English, D.B.K., Kocis, S.M., Zarnoch, S.J., Arnold, J.R., 2002. Forest Service National Visitor Use Monitoring Process: Research Method Documentation.

Epanchin, P.N., Knapp, R. a, Lawler, S.P., 2010. Nonnative trout impact an alpinenesting bird by altering aquatic-insect subsidies. Ecology 91, 2406-15. https://doi.org/https://doi.org/10.1890/09-1974.1

Finlay, J.C., Vredenburg, V.T., 2007. Introduced trout sever trophic connections in watersheds: consequences for a declining amphibian. Ecology 88, 2187-98. https://doi.org/https://doi.org/10.1890/06-0344.1

Flanagan Pritz, C., Eagles-smith, C., Krabbenhoft, D., 2014. Mercury in the National Parks. George Wright Forum 31, 168-180.

Floyd, M.F., 1999. Race, ethnicity and use of the National Park System. Soc. Sci. Res. Rev. 1, 1-24. https://doi.org/10.1111/j.1469-7610.2011.02477.x

Fritts, S.H., Bangs, E.E., Fontaine, J. a, Johnson, M.R., Phillips, M.K., Koch, E.D., Gunson, J.R., 1997. Planning and Implementing a Reintroduction of Wolves to Yellowstone National Park and Central Idaho. Restor. Ecol. 5, 7-27. 
https://doi.org/10.1046/j.1526-100X.1997.09702.x

Fulton, D.C., Manfredo, M.J., Lipscomb, J., 1996. Wildlife value orientations: A conceptual and measurement approach. Hum. Dimens. Wildl. 1, 24-47. https://doi.org/10.1080/10871209609359060

Ghimire, R., Green, G.T., Poudyal, N.C., Cordell, H.K., 2016. Who Recreates Where : Implications from a National Recreation Household Survey. Jounral For. 114, 458465. https://doi.org/https://doi.org/10.5849/jof.14-106

Hall, T.E., Seekamp, E., Cole, D., 2010. Do recreation motivations and wilderness involvement relate to support for wilderness management? A segmentation analysis. Leis. Sci. 32, 109-124. https://doi.org/10.1080/01490400903547096

Halverson, A., 2011. Chasing Rainbows. Conserv. Mag.

Heffelfinger, J.R., Geist, V., Wishart, W., 2013. The role of hunting in North American wildlife conservation. Int. J. Environ. Stud. 70, 399-413. https://doi.org/10.1080/00207233.2013.800383

Hungerford, H.R., Volk, T.L., 1990. Changing learner behavior through environmental education. J. Environ. Educ. https://doi.org/10.1080/00958964.1990.10753743

Jackman, S., 2015. pscl: Classes and methods for R developed in the political science computational laboratory, Stanford University.

Jacobs, M.H., Vaske, J.J., Sijtsma, M.T.J., 2014. Predictive potential of wildlife value orientations for acceptability of management interventions. J. Nat. Conserv. https://doi.org/10.1016/j.jnc.2014.03.005

Johnson, C.Y., Bowker, J.M., Bergstrom, J.C., Cordell, H.K., 2004. Wilderness Values in America: Does Immigrant Status or Ethnicity Matter? Soc. Nat. Resour. 17, 611- 
628. https://doi.org/10.1080/08941920490466585

Knapp, R.A., Corn, P.S., Schindler, D.E., 2001. The Introduction of Nonnative Fish into Wilderness Lakes : Good Intentions, Conflicting Mandates, and Unintended Consequences. Ecosystems 4, 275-278. https://doi.org/10.1007/s10021

Knapp, R.A., Matthews, K.R., 2000. Non-Native Fish Introductions and the Decline of the Mountain Yellow-Legged Frog from within Protected Areas. Conserv. Biol. 14, $428-438$.

Krymkowski, D.H., Manning, R.E., Valliere, W.A., 2014. Race, ethnicity, and visitation to national parks in the United States: Tests of the marginality, discrimination, and subculture hypotheses with national-level survey data. J. Outdoor Recreat. Tour. $7-$ 8, 35-43. https://doi.org/10.1016/j.jort.2014.09.008

Landers, D.H., Simonich, S.M., Jaffe, D., Geiser, L., Campbell, D.H., Schwindt, A., Schreck, C., Kent, M., Hafner, W., Taylor, H.E., Hageman, K., Usenko, S., Ackerman, L., Schrlau, J., Rose, N., Blett, T., Erway, M.M., 2008. The Fate , Transport, and Ecological Impacts of Airborne Contaminants in Western National Parks (USA), EPA/600/R-07/138. U.S. Environmental Protection Agency, Office of Research and Development, NHEERL, Western Ecology Division, Corvallis, Oregon.

Landres, P., Meyer, S., Matthews, S., 2001. The Wilderness Act and Fish Stocking: An Overview of Legislation, Judicial Interpretation, and Agency Implementation. Ecosystems 4, 287-295. https://doi.org/10.1007/s10021

Larson, L.R., Whiting, J.W., Green, G.T., 2011. Exploring the influence of outdoor recreation participation on pro-environmental behaviour in a demographically 
diverse population. Local Environ. 16, 67-86.

https://doi.org/10.1080/13549839.2010.548373

Lesnoff, M., Lancelot, R., 2012. aod: analysis of overdispersed data.

Likert, R., 1932. A technique for the Measurement of Attitudes. Arch. Psychol. 140, 155.

Manfredo, M.J., 2008. Who Cares About Wildlife? Springer, New York, NY.

Manfredo, M.J., Dayer, A.A., 2004. Concepts for Exploring the Social Aspects of Human - Wildlife Conflict in a Global Context 317-328.

https://doi.org/10.1080/10871200490505765

Marion, J.L., Reid, S.E., 2009. Minimising Visitor Impacts to Protected Areas: The Efficacy of Low Impact Education Programmes. J. Sustain. Tour. 15, 5-27. https://doi.org/10.2167/jost593.0

Mccown, R.S., Laven, D., Manning, R., Mitchell, N., 2012. Engaging new and diverse audiences in the national parks: An exploratory study of current knowledge and learning needs. George Wright Forum 29, 272-284.

McFarlane, B.L., Boxall, P.C., 2000. Factors influencing forest values and attitudes of two stakeholder groups: The case of the foothills model forest, alberta, canada. Soc. Nat. Resour. https://doi.org/10.1080/08941920050121927

McKinley, D.C., Miller-Rushing, A.J., Ballard, H.L., Bonney, R., Brown, H., CookPatton, S.C., Evans, D.M., French, R.A., Parrish, J.K., Phillips, T.B., Ryan, S.F., Shanley, L.A., Shirk, J.L., Stepenuck, K.F., Weltzin, J.F., Wiggins, A., Boyle, O.D., Briggs, R.D., Chapin, S.F., Hewitt, D.A., Preuss, P.W., Soukup, M.A., 2017. Citizen science can improve conservation science, natural resource management, and 
environmental protection. Biol. Conserv. 208, 15-28. https://doi.org/10.1016/j.biocon.2016.05.015

Miller, Z.D., Freimund, W., Metcalf, E.C., Nickerson, N., 2017. Targeting your audience: wildlife value orientations and the relevance of messages about bear safety. Hum. Dimens. Wildl. 1209, 1-14. https://doi.org/10.1080/10871209.2017.1409371

Moran, P.W., Aluru, N., Black, R.W., Vijayan, M.M., 2007. Tissue contaminants and associated transcriptional response in trout liver from high elevation lakes of Washington. Environ. Sci. Technol. 41, 6591-7.

National Parks Omnibus Management Act of 1998, 1998. . USA.

National Parks Service, 2017. Annual Visitation Report by Years: 2007 to 2017 [WWW Document]. URL https://irma.nps.gov/Stats/SSRSReports/National Reports/Annual Visitation By Park (1979 - Last Calendar Year)

National Parks Service, 2007. Mountain Lakes Fishery Management Plan Environmental Impact Statement.

National Parks Service, 2006. National Parks Service Management Policies [WWW Document]. URL https://www.nps.gov/policy/MP_2006.pdf (accessed 3.19.18). North Cascades National Park Service Complex Fish Stocking Act. H.R. 1158, 2014. . 113th Congress.

Obeng, E.A., Aguilar, F.X., 2018. Value orientation and payment for ecosystem services: Perceived detrimental consequences lead to willingness-to-pay for ecosystem services. J. Environ. Manage. 206, 458-471. https://doi.org/10.1016/j.jenvman.2017.10.059

Osbourne, J.W., Costello, A.B., 2009. Best Practices in exploratory factor analysis: Four 
recommendations for getting the most from your analysis. Pan-Pacific Manag. Rev. 12, 131-146. https://doi.org/10.1.1.110.9154

Papadimitriou, F., 2012. Modelling landscape complexity for land use management in Rio de Janeiro, Brazil. Land use policy 29, 855-861. https://doi.org/10.1016/j.landusepol.2012.01.004

Pergams, O.R.W., Zaradic, P. a, 2008. Evidence for a fundamental and pervasive shift away from nature-based recreation. Proc. Natl. Acad. Sci. 105, 2295-2300. https://doi.org/10.1073/pnas.0709893105

Pister, E.P., 2001. Wilderness Fish Stocking: History and Perspective. Ecosystems 4, 279-286. https://doi.org/10.1007/s 10021

R Core Team, 2016. R: A language and environment for statistical computing. Raiche, G., 2010. nFactors: an R package for parallel analysis and non-graphical solutions to the Cattell scree test.

Revelle, W., 2017. psych: Procedures for Personality and Psychological Research.

Sarnelle, O., Knapp, R.A., 2004. Zooplankton recovery after fish removal : Limitations of the egg bank. Limnol. Oceanogr. 49, 1382-1392. https://doi.org/https://doi.org/10.4319/1o.2004.49.4_part_2.1382

Schindler, D.W., Parker, B.R., 2002. Biological pollutants: alien fiches in mountain lakes. Water. Air. Soil Pollut. 2, 379-397.

Schoenfeld, C., Hendee, J.C., 1978. Wildlife management in wilderness. Boxwood Press. Scott, D., Willits, F.K., 1994. Environmental Attitudes and Behavior: A Pennsylvania Survey. Environ. Behav. 26, 239-260.

Sharp, R.L., Larson, L.R., Green, G.T., 2011. Factors influencing public preferences for 
invasive alien species management. Biol. Conserv. 144, 2097-2104.

https://doi.org/10.1016/j.biocon.2011.04.032

Steel, B.S., List, P., Shindler, B., 1994. Conflicting values about federal forests: A comparison of national and Oregon publics. Soc. Nat. Resour. 7, 137-153. https://doi.org/10.1080/08941929409380852

Taylor, P.A., Grandjean, B.D., Anatchkova, B., 2011. National Park Service comprehensive survey of the American public, 2008-2009: National Technical Report. Natural Resource Report NPS/NRPC/SSD/NRR—2011/295 295.

Teel, T.L., Manfredo, M.J., 2010. Understanding the Diversity of Public Interests in Wildlife Conservation. Conserv. Biol. 24, 128-139.

Teel, T.L., Manfredo, M.J., Jensen, F.S., Buijs, A.E., Fischer, A., Riepe, C., Arlinghaus, R., Jacbos, M.H., 2010. Understanding the Cognitive Basis for Human - Wildlife Relationships as a Key to Successful Protected-Area Management 40. https://doi.org/1.2753/IJS0020-7659400306

Tiberti, R., von Hardenberg, A., Bogliani, G., 2014. Ecological impact of introduced fish in high altitude lakes: A case of study from the European Alps. Hydrobiologia 724, 1-19. https://doi.org/10.1007/s10750-013-1696-1

U.S. Forest Service, 2016. National Visitor Use Monitoring Results National Summary Report.

Ullrich, S.M., Tanton, T.W., Abdrashitova, S. a., 2001. Mercury in the aquatic environment: a review of factors affecting methylation. Crit. Rev. Environ. Sci. Technol. 31, 241-293. https://doi.org/10.1080/20016491089226 van der Linden, S., 2015. The social-psychological determinants of climate change risk 
perceptions: Towards a comprehensive model. J. Environ. Psychol. 41, 112-124. https://doi.org/10.1016/j.jenvp.2014.11.012

Vaske, J.J., Donnelly, M.P., 1999. A Value - Attitude - Behavior Model Predicting Wildland Preservation Voting Intentions. Soc. Nat. Resour. 12, 523-537. https://doi.org/10.1080/089419299279425

Venables, W., Ripley, B., 2015. MASS: Modern applied statistics with S. Fourth Edition.

Vigliano, P.H., Beauchamp, D.A., Milano, D., Macchi, P.J., Alonso, M.F., Asorey, M.I.G., Denegri, M.A., Ciancio, J.E., Lippolt, G., Rechencq, M., Barriga, J.P., 2009. Quantifying Predation on Galaxiids and Other Native Organisms by Introduced Rainbow Trout in an Ultraoligotrophic Lake in Northern Patagonia, Argentina: A Bioenergetics Modeling Approach. Trans. Am. Fish. Soc. 138, 1405-1419. https://doi.org/10.1577/T08-067.1

Washburne, R.F., 1978. Black Under-Participation in Wildland Recreation: Alternative Explanations. Leis. Sci. 1, 175-189.

Watson, A., Martin, S., Christensen, N., Fauth, G., Williams, D., 2015. The Relationship Between Perceptions of Wilderness Character and Attitudes Toward Management Intervention to Adapt Biophysical Resources to a Changing Climate and Nature Restoration at Sequoia and Kings Canyon National Parks. Environ. Manage. 56, 653-663. https://doi.org/10.1007/s00267-015-0519-8

Whittaker, D., Vaske, J.J., Manfredo, M.J., 2006. Specificity and the cognitive hierarchy: Value orientations and the acceptability of urban wildlife management actions. Soc. Nat. Resour. 19, 515-530. https://doi.org/10.1080/08941920600663912 Williams, C.K., Ericsson, G., Heberlein, T.A., Williams, C.K., Ericsson, G., Heberlein, 
T.A., 2016. A Quantitative Summary of Attitudes toward Wolves and Their Reintroduction (1972-2000). Wildl. Soc. Bull. 30, 575-584. 


\section{Chapter 5}

\section{Conclusions}

Mountain lakes are culturally and ecologically valuable ecosystems, and are important sentinels of environmental change. Although there has recently been an emergence of research about mountain lake food webs (Knapp et al. 2001a, Epanchin et al. 2010, Sánchez-Hernández et al. 2015), we still know very little about them relative to downstream waterbodies because they exist across strong environmental gradients and are difficult to access. Yet, understanding how mountain lakes respond to anthropogenic stressors and how people value and interact with these ecosystems is critically important for protecting the health of these lakes. The overall objective of my dissertation was to understand the interaction between fish stocking and atmospheric mercury deposition from a socioecological lens, and provide insights for the management of mountain lakes. My specific goals were to: (1) identify ecological, limnological, and landscape-level indicators of mercury bioaccumulation in mountain lake food webs in order to inform better ecosystem management; (2) test if fatty acid stable isotopes can partition littoral and terrestrial prey sources in fish in a simplified mountain lake food web, and; (3) determine public perceptions of mountain lake fisheries management, and assess the risk mercury poses to mountain lake anglers.

Using an approach informed by concepts of mercury biogeochemical cycling and ecological theory, I conducted a field study and identified indicators of mercury bioaccumulation in mountain lake fish at multiple scales. Through this field study, I identified a gap in our understanding of trophic dynamics in mountain lake food webs, and designed an experiment to test a novel analytical approach that could help close that knowledge gap in the future. Because of the cultural importance of mountain lakes, and 
the risk mercury bioaccumulation may pose to anglers, I also determined the angling habits of visitors, and identified the values that drive support or opposition to conservation-based fisheries management practices. Together, these studies help to advance the field of trophic ecology, broaden our understanding of mountain lake ecology and mercury bioaccumulation, and provide insight for how to optimize the management of mountain lakes for both human and ecological health.

In Chapter 2, I identified indicator variables that influence mercury bioaccumulation at multiple scales. I found that a lake's nearshore forest cover and fish mean benthic reliance were the best predictors of mountain lake fish mercury concentrations, after correcting for trophic position. These are important findings because individual drivers of mercury bioaccumulation in lakes are often quite complex and difficult to untangle. By identifying single indicators that encompass many of these drivers, I have simplified the process of determining which lakes have the most risk of high mercury bioaccumulation. This information is useful to managers who are interested in considering mercury risk in their decision-making around fish stocking, and will help inform any outreach efforts geared towards anglers who fish in mountain lakes. Tree cover and fish diet can be measured with relatively little effort using GIS software and food web surveys, respectively, whereas analyzing mercury content in fish is laborious and costly. Additionally, by determining that fish diet is an important driver of mercury bioaccumulation, I also uncovered a critical knowledge gap in our understanding of mountain lake food webs. Distinguishing between benthic and terrestrial diets is difficult with traditional diet tracing methods, and we therefore do not know the role of terrestrial subsidies in mediating mercury bioaccumulation in fish. 
In Chapter 3, I tested a novel analytical method that could help to resolve knowledge gaps about dietary subsidies in mountain lakes, and in other aquatic systems where bulk stable isotope analysis falls short. My results demonstrate that using stable isotopes of fatty acids is a promising approach to distinguishing between fish diet sources that would normally overlap when using bulk stable isotope analysis, but to do so effectively requires an in-depth understanding of physiological context specific to the ecosystem of interest. Precursor essential fatty acids that are sufficiently abundant in a consumer's diet show potential to be a stronger diet tracing tool than bulk stable isotopes. Although these results are preliminary and suggest that more experiments are necessary to validate this method, my study provides important foundational knowledge to the nascent field of compound-specific stable isotope ecology. Additionally, this method could be used for future studies of trophic dynamics of mountain lake food webs, which could help determine the role of terrestrial prey subsidies to mountain lake food webs and also better elucidate the role of food web structure in determining mercury bioaccumulation.

While understanding trophic dynamics and drivers of mercury bioaccumulation is critical for protecting mountain lake ecosystems, understanding how people value mountain lakes and their perceptions of management is equally important. In Chapter 4, I provide a social context for the issues of fish stocking and mercury bioaccumulation by determining public perceptions of fisheries management, as well as the risk mercury might pose to mountain lake anglers. I found that while most national park visitors have concerns for the ecological impacts of fish stocking, almost half believe that management should only remove fish from the most sensitive lakes, while maintaining fisheries for 
angling in more resilient lakes. Unsurprisingly, supporters of this conservation-based approach were likely to be anglers. These findings suggest that many mountain lake visitors understand the need to balance ecological health with recreational opportunity, and that fish removals are less likely to be controversial if managers collaborate with fishing groups when determining which lakes to eradicate fish from and which lakes to leave fish in. However, these types of management decisions are complicated by the fact that nearly half of all surveyed anglers reported that they consume fish from mountain lakes on an annual basis. If managers are concerned about exposure of mercury and other contaminants to anglers, this adds another layer of complexity to fisheries management, although the indicators of mercury bioaccumulation I discovered in Chapter 2 will hopefully provide useful insight to the decision-making process.

Together, these chapters provide a unique set of tools that advance our understanding of food web dynamics and mercury bioaccumulation in mountain lakes, and can be used to optimize management of these valuable ecosystems. Although mercury concentrations in my study lakes were generally well below the criterion that the EPA considers unsafe for recreational consumption (Borum et al. 2001), there is growing evidence that these guidelines are not strict enough to protect human health. Therefore, a consideration of mercury exposure risk should still be a top priority to managers of mountain lakes, especially given my finding that tens of thousands of anglers likely consume mountain lake fish annually, in just Washington's national parks alone (Chapter 4). While the indicators of mercury bioaccumulation I identified in Chapter 2 provide a good first step for prioritizing which lakes to remove fish from, there remains unexplained variability (39-45\%), likely due to our limitations in our understanding of 
lake productivity, food web structure, and the role of terrestrial subsidies in mountain lakes. Hopefully, future studies will build upon my findings in Chapter 3, and continue to test the effectiveness of fatty acid stable isotopes, so this method can be used more reliably to solve the unanswered questions about food web structure in mountain lakes, as well as other freshwater systems around the globe. In the meantime, the most effective way to protect the health of mountain lakes and their visitors will be for managing agencies to collaborate with scientists and angling groups when making fisheries management decisions, and to invest in outreach about both the ecological and toxicological implications of fish stocking and mercury bioaccumulation in mountain lakes. The need for such an approach is starting to catch on in the Mountain West; for example, Mount Rainier National Park has learned from the controversies that occurred around fish removals in the Sierra Nevada mountains (Halverson 2011), and is employing an adaptive and collaborative approach to mountain lake fisheries management (National Parks Service 2017).

This type of adaptive, socioecological approach is becoming increasingly called upon by scientists to solve wicked environmental problems around the globe. In fact, mountain ecosystems in particular have received attention because of their strong humanenvironment connection, and because of their sensitivity to major environmental stressors (Alessa et al. 2018). The issues of fish stocking and atmospheric contaminant deposition are not unique to the Mountain West. Stocking mountain lakes with fish is a practice that has occurred globally, from the Sierras, Cascades, and Rockies (Knapp et al. 2001b, Pister 2001), to the Andes (Vigliano et al. 2009), Alps, and Pyrenees (Tiberti et al. 2014). Mountains ecosystems around the globe tend to be hotspots for atmospheric deposition 
(Fitzgerald et al. 1998, Daly and Wania 2005, Fernández et al. 2005), yet they also provide critical protection for freshwater resources, biodiversity (Isaak et al. 2016; Moser et al. 2019), and cultural and recreational value (Chapter 4). The impacts of fish stocking and contaminant bioaccumulation are likely distinctive across mountain regions due to differences in stocking practices, food web structure, climate, and deposition patterns. Additionally, the way humans interact with and value mountain lake ecosystems is likely to be distinctive due to differences in culture, and in how people rely on mountain resources. These global differences further solidify the need to approach management of mountain ecosystems and mountain lakes with a socioecological lens. Mountain areas will experience climate change more intensely than lowland areas (Beniston and Stoffel 2014), which raises critical management questions that must be tackled with a socioecological approach, such as: How will issues around fish stocking and mercury bioaccumulation change in the future? How will climate change affect the implications of stocking and rates of mercury bioaccumulation? How will political climate influence how mountain regions are managed?

My research suggests that in the Pacific Northwest, climate change could exacerbate mercury bioaccumulation in mountain lake fish, as warmer weather may allow for the upward altitudinal expansion of forest cover (Chapter 4; Theurillat and Guisan 2001). Additionally, a warming climate could diminish the role of mountain waterbodies as climate refugia, as we see a greening and browning of historically clear water in arctic and alpine ecosystems (Hayden et al. 2019). The negative ecological effects of fish may also be exacerbated as warming occurs in mountain regions (Symons and Shurin 2016). Concurrently, the ecological and intrinsic value of mountain lakes is likely to increase, as 
the threat of climate change becomes increasingly apparent and more widely acknowledged among the public. However, in the U.S., recent changes in political climate have led to tumultuous changes in land protections, land management, and available management resources (Hejny 2018). The protection of mountain lake ecosystems will thus hinge upon continued research, collaboration, and outreach efforts among stakeholders using a socioecological approach. 


\subsection{References}

Alessa, L., Kliskey, A., Gosz, J., Griffith, D., Ziegler, A., 2018. MtnSEON and socialecological systems science in complex mountain landscapes. Front. Ecol. Environ. 16, S4-S10. https://doi.org/10.1002/fee.1753

Beniston, M., Stoffel, M. 2014. Assessing the impacts of climatic change on mountain water resources. Sci. Tot. Env. 493, 1129-1137.

Borum, D., Manibusan, M., Schoeny, R., Winchester, E., 2001. Water Quality Criterion for the Protections of Human Health: Methylmercury. US Environmental Protection Agency, Washington D.C.

Daly, G., Wania, F. 2005. Organic Contaminants in Mountains. Environmental Science and Technology, 39(2), 385-398.

Epanchin, P.N., Knapp, R. a, Lawler, S.P., 2010. Nonnative trout impact an alpinenesting bird by altering aquatic-insect subsidies. Ecology 91, 2406-15. https://doi.org/https://doi.org/10.1890/09-1974.1

Fernández, P., Carrera, G. Grimalt, J.O. 2005. Persistent organic pollutants in remote freshwater ecosystems. Aquatic Sciences, 67(3), 263-273.

Fitzgerald, W.F., Engstrom, D.R., Mason, R.P., Nater, E. a., 1998. The Case for Atmospheric Mercury Contamination in Remote Areas. Environ. Sci. Technol. 32, 17. https://doi.org/10.1021/es970284w 
Halverson, A. 2011. Chasing Rainbows. Conservation Magazine. https://www.conservationmagazine.org/2011/11/chasing-rainbows/

Hayden, B., Harrod, C., Thomas, S. M., Eloranta, A. P., Myllykangas, J. P., Siwertsson, A., Praebel, K., Knudsen, R., Amundsen, P.A., Kahilainen, K.K. 2019. From clear lakes to murky waters-tracing the functional response of high $\square$ latitude lake communities to concurrent 'greening' and 'browning'. Ecology letters.

Hejny J. 2018. The Trump Administration and environmental policy: Reagan redux? Journal of Environmental Studies and Sciences 8(2): 197-211.

Isaak, D.J., Young, M.K., Luce, C.H., Hostetler, S.W., Wenger, S.J., Peterson, E.E., Ver Hoef, J.M., Groce, M.C., Horan, D.L., Nagel, D.E., 2016. Slow climate velocities of mountain streams portend their role as refugia for cold-water biodiversity. Proc. Natl. Acad. Sci. 113, 4374-4379. https://doi.org/10.1073/pnas.1522429113

Knapp, R., Matthews, K., \& Sarnelle, O., 2001a. Resistance and Resilience of Alpine Lake Fauna to Fish Introductions. Ecol. Monogr. 71, 401-421.

Knapp, R.A., Corn, P.S., Schindler, D.E., 2001b. The Introduction of Nonnative Fish into Wilderness Lakes : Good Intentions, Conflicting Mandates, and Unintended Consequences. Ecosystems 4, 275-278. https://doi.org/10.1007/s10021

Moser, K.A., Baron, J.S., Brahney, J., Oleksy, I.A., Saros, J.E., Hundey, E.J., Sadro, S.A., Kopáček, J., Sommaruga, R., Kainz, M.J., Strecker, A.L., Chandra, S., Walters, D.M., Preston, D.L., Michelutti, N., Lepori, F., Spaulding, S.A., Christianson, K.R., 
Melack, J.M., Smol, J.P., 2019. Mountain lakes: Eyes on global environmental change. Glob. Planet. Change. https://doi.org/10.1016/j.gloplacha.2019.04.001

National Parks Service, 2017. Annual Visitation Report by Years: 2007 to 2017 [WWW Document]. URL https://irma.nps.gov/Stats/SSRSReports/National Reports/Annual Visitation By Park (1979 - Last Calendar Year)

Pister, E.P., 2001. Wilderness Fish Stocking: History and Perspective. Ecosystems 4, 279-286. https://doi.org/10.1007/s10021

Sánchez-Hernández, J., Cobo, F., Amundsen, P.-A., 2015. Food Web Topology in High Mountain Lakes. PLoS One 10, e0143016. https://doi.org/10.1371/journal.pone.0143016

Symons, C.C., Shurin, J.B. 2016. Climate constrains lake community and ecosystem responses to introduced predators. Proc. R. Soc. B. 283, 20160825.

Tiberti, R., von Hardenberg, A., Bogliani, G., 2014. Ecological impact of introduced fish in high altitude lakes: A case of study from the European Alps. Hydrobiologia 724, 1-19. https://doi.org/10.1007/s10750-013-1696-1

Theurillat, J.P., Guisan, A., 2001. Potential impact of climate change on vegetation in the European alps: A review. Clim. Change 50, 77-109. https://doi.org/10.1023/A:1010632015572

Vigliano, P.H., Beauchamp, D.A., Milano, D., Macchi, P.J., Alonso, M.F., Asorey, M.I.G., Denegri, M.A., Ciancio, J.E., Lippolt, G., Rechencq, M., Barriga, J.P., 2009. 
Quantifying Predation on Galaxiids and Other Native Organisms by Introduced Rainbow Trout in an Ultraoligotrophic Lake in Northern Patagonia, Argentina: A Bioenergetics Modeling Approach. Trans. Am. Fish. Soc. 138, 1405-1419. https://doi.org/10.1577/T08-067.1 


\section{Appendix A}

Supporting tables and figures for Chapter 2

Table A1. Comparison of modeled and measured mean depths for each lake. Modeled estimates include values calculated from models by Heathcote et al. (2015) and Messager et al. (2016). Measured estimates include values from the National Parks Service (NPS) and from bathymetric maps created using a sonar device. Bolded values indicate those selected for use in the benthic primary production models.

\begin{tabular}{llllll}
\hline Lake & $Z_{\text {mean }}-$ & $Z_{\text {mean }}-$ & $Z_{\text {mean }}-$ & $Z_{\text {mean }}-$ & $Z_{\text {max }}$ \\
senar & & \\
\hline Lower Anderson & $\mathbf{1 . 5 7}$ & 3.04 & & & 4.9 \\
Bench & 5.81 & 7.38 & & $\mathbf{0 . 6}$ & 1.2 \\
Lower Deadwood & 2.67 & 3.38 & $\mathbf{1 . 7}$ & & 3.8 \\
Doubtful & $\mathbf{1 1 . 8 5}$ & 12.75 & & & 20 \\
Gladys & 1.20 & 2.38 & $\mathbf{1 . 4}$ & & 4.2 \\
Grand & 4.98 & 6.63 & & $\mathbf{1 . 1}$ & 8.3 \\
Hidden & $\mathbf{1 6 . 4 8}$ & 15.20 & & & 79 \\
Lena & 7.23 & 10.35 & & $\mathbf{1 1 . 1}$ & 29.8 \\
Louise & 4.11 & 7.35 & & & 17.7 \\
LP-19 & 1.58 & 3.17 & $\mathbf{4 . 6}$ & & 12.3 \\
Lunch & 6.26 & 5.35 & & $\mathbf{7 . 0}$ & 18.3 \\
Monogram & 7.69 & 11.77 & & $\mathbf{1 5 . 0}$ & 37 \\
Moose & 3.42 & 5.41 & & $\mathbf{4 . 0}$ & 7.45 \\
Lower Palisades & 2.65 & 4.18 & $\mathbf{1 . 6}$ & 0.6 & 2.8 \\
PJ & 4.89 & 6.45 & & $\mathbf{3 . 0}$ & 7.5 \\
Sauk & 3.69 & 5.77 & & $\mathbf{3 . 0}$ & 5.6 \\
Snow & $\mathbf{4 . 9 2}$ & 6.47 & & & 10.5 \\
Lower Thornton & 27.48 & $\mathbf{1 7 . 6 9}$ & & & 33 \\
West Watson & 7.62 & 10.14 & & $\mathbf{5 . 0}$ & 8.9 \\
East Watson & $\mathbf{1 3 . 7 0}$ & $\mathbf{1 3 . 7 1}$ & & & 17.8 \\
\hline
\end{tabular}


Table A2. Zooplankton and Macroinvertebrate MeHg concentrations, by lake.

\begin{tabular}{lll}
\hline Lake & $\begin{array}{l}\text { Zooplankton MeHg } \\
(\mathrm{ng} / \mathrm{g}-\mathrm{dw})\end{array}$ & $\begin{array}{l}\text { Mean Macroinvertebrate } \\
\mathrm{MeHg}(\mathrm{ng} / \mathrm{g}-\mathrm{dw})\end{array}$ \\
\hline L. Anderson & -- & 37.3 \\
L. Deadwood & 19 & 30.6 \\
Doubtful & -- & -- \\
Gladys & 37 & 46.3 \\
Grand & 55.7 & 74.0 \\
Hidden & -- & -- \\
U. Lena & 89.6 & 39.4 \\
Louise & -- & 20.4 \\
LP-19 & 94.1 & -- \\
Lunch & -- & 46.2 \\
Monogram & 79.2 & 24.8 \\
Moose & 95.7 & 49.4 \\
L. Palisades & -- & 17.6 \\
Pj & 102 & 58.8 \\
Sauk & 106 & 66.5 \\
Snow & -- & 27.5 \\
L. Thornton & -- & -- \\
W. Watson & 56.4 & 37.2 \\
E. Watson & -- & --
\end{tabular}


Table A3. Fish-specific data, grouped by sample area, lake, and species

\begin{tabular}{|c|c|c|c|c|c|c|c|}
\hline Area & Lake & Species & $\begin{array}{l}\begin{array}{l}\text { Length } \\
(\mathrm{mm})\end{array} \\
\end{array}$ & $\begin{array}{l}\text { Weight } \\
\text { (g) }\end{array}$ & $\begin{array}{l}\text { Trophic } \\
\text { position }\end{array}$ & $\begin{array}{l}\text { Benthic } \\
\text { reliance (\%) }\end{array}$ & $\begin{array}{l}\mathrm{Hg} \\
(\mathrm{ng} / \mathrm{g})\end{array}$ \\
\hline \multirow[t]{25}{*}{ Rainier } & \multirow[t]{2}{*}{ L. Deadwood } & \multirow[t]{2}{*}{ Rainbow } & 296 & 210 & 2.6 & 100.0 & 345 \\
\hline & & & 227 & 120 & 2.7 & 0.0 & 539 \\
\hline & \multirow[t]{6}{*}{ Louise } & \multirow[t]{6}{*}{ Brook } & 192 & 78 & 3.4 & 30.8 & 291 \\
\hline & & & 183 & 60 & 3.4 & 50.5 & 208 \\
\hline & & & 190 & 60 & 3.4 & 45.9 & 366 \\
\hline & & & 178 & 58 & 3.3 & 38.4 & 199 \\
\hline & & & 177 & 57 & 3.3 & 0.0 & 268 \\
\hline & & & 196 & 76 & 3.3 & 42.1 & 198 \\
\hline & \multirow[t]{4}{*}{ LP-19 } & \multirow[t]{4}{*}{ Brook } & 225 & 117 & 2.9 & 21.1 & 622 \\
\hline & & & 182 & 84 & 2.5 & 35.3 & 225 \\
\hline & & & 60 & 188 & 3.1 & 95.7 & 1193 \\
\hline & & & 213 & 114 & 2.9 & 80.1 & 409 \\
\hline & \multirow[t]{7}{*}{ L. Palisades } & \multirow[t]{7}{*}{ Brook } & 230 & 120 & 2.9 & 69.1 & 599 \\
\hline & & & 208 & 88 & 2.9 & 68.2 & 394 \\
\hline & & & 138 & 29 & 2.7 & 90.3 & 234 \\
\hline & & & 204 & 86 & 2.9 & 32.8 & 395 \\
\hline & & & 195 & 85 & 3.1 & 0.0 & 460 \\
\hline & & & 158 & 40 & 2.8 & 93.0 & 204 \\
\hline & & & 111 & 14 & 2.8 & 93.0 & 177 \\
\hline & \multirow[t]{5}{*}{ Snow } & \multirow[t]{5}{*}{ Brook } & 250 & 160 & 2.5 & 97.9 & 198 \\
\hline & & & 153 & 41 & 2.3 & 93.3 & 112 \\
\hline & & & 169 & 51 & 2.4 & 100.0 & 115 \\
\hline & & & 154 & 40 & 2.4 & 100.0 & 145 \\
\hline & & & 107 & 12 & 2.3 & 100.0 & 94 \\
\hline & Snow & Rainbow & 242 & 140 & 2.7 & 92.8 & 314 \\
\hline \multirow[t]{11}{*}{ North Cascades } & \multirow[t]{6}{*}{ L. Anderson } & \multirow[t]{6}{*}{ Rainbow } & 333 & 299 & 2.9 & 64.9 & 121 \\
\hline & & & 105 & 210 & 2.7 & 0.0 & 163 \\
\hline & & & 69 & 178 & & 100.0 & 135 \\
\hline & & & 52 & 155 & & 83.6 & 85 \\
\hline & & & 275 & & 2.5 & 100.0 & 66 \\
\hline & & & 149 & 40 & 2.3 & 100.0 & 115 \\
\hline & Doubtful & Cutthroat & 156 & 235 & & & 460 \\
\hline & Hidden & Rainbow & 325 & 335 & & & 172 \\
\hline & \multirow[t]{3}{*}{ Monogram } & \multirow[t]{3}{*}{ Cutthroat } & 165 & 237 & & 58.3 & 350 \\
\hline & & & 119 & 221 & 3.1 & 44.7 & 539 \\
\hline & & & 127 & 224 & 2.9 & 66.1 & 216 \\
\hline
\end{tabular}




\begin{tabular}{|c|c|c|c|c|c|c|c|}
\hline Area & Lake & Species & $\begin{array}{l}\text { Length } \\
\text { (mm) }\end{array}$ & $\begin{array}{l}\text { Weight } \\
\text { (g) }\end{array}$ & $\begin{array}{l}\text { Trophic } \\
\text { position }\end{array}$ & $\begin{array}{l}\text { Benthic } \\
\text { reliance (\%) }\end{array}$ & $\begin{array}{l}\mathrm{Hg} \\
(\mathrm{ng} / \mathrm{g})\end{array}$ \\
\hline \multirow[t]{38}{*}{ North Cascades } & \multirow[t]{8}{*}{ Monogram } & \multirow[t]{6}{*}{ Cutthroat } & 93 & 199 & 3 & 61.8 & 263 \\
\hline & & & 128 & 230 & & 37.5 & 443 \\
\hline & & & 85 & 186 & & 100 & 414 \\
\hline & & & 165 & 42 & 2.7 & 82.3 & 145 \\
\hline & & & 275 & 190 & 3 & 55.3 & 448 \\
\hline & & & 289 & 220 & 3 & 31.9 & 387 \\
\hline & & \multirow[t]{2}{*}{ Rainbow } & 183 & 60 & 2.5 & 77.5 & 123 \\
\hline & & & 177 & 55 & 2.8 & 68.7 & 194 \\
\hline & \multirow[t]{7}{*}{ Sauk } & \multirow[t]{7}{*}{ Rainbow } & 154 & 238 & 3.4 & 86.6 & 249 \\
\hline & & & 54 & 185 & 3.5 & 94.5 & 251 \\
\hline & & & 155 & 248 & & 97.0 & 163 \\
\hline & & & 205 & 269 & & & 398 \\
\hline & & & 140 & 241 & & & 139 \\
\hline & & & 170 & 257 & & & 206 \\
\hline & & & 165 & 60 & 2.6 & 93.0 & 277 \\
\hline & \multirow[t]{6}{*}{ L. Thornton } & \multirow[t]{6}{*}{ Cutthroat } & 87 & 185 & & & 195 \\
\hline & & & 159 & 240 & & & 219 \\
\hline & & & 131 & 229 & & & 586 \\
\hline & & & 136 & 227 & & & 410 \\
\hline & & & 122 & 219 & & & 295 \\
\hline & & & 82 & 181 & & & 200 \\
\hline & \multirow[t]{11}{*}{ W. Watson } & \multirow[t]{11}{*}{ Rainbow } & 310 & 360 & 2.8 & 35.8 & 371 \\
\hline & & & 305 & 355 & & 58.7 & 165 \\
\hline & & & 210 & 274 & & 52.4 & 259 \\
\hline & & & 165 & 237 & & 43.3 & 231 \\
\hline & & & 240 & 279 & 3 & 28.5 & 262 \\
\hline & & & 195 & 259 & 2.5 & 54.8 & 103 \\
\hline & & & 180 & 55 & 2.5 & 63.6 & 71 \\
\hline & & & 339 & & 2.7 & 50.7 & 214 \\
\hline & & & 288 & 325 & 2.6 & 59.5 & 165 \\
\hline & & & 233 & 160 & 2.7 & 58.4 & 244 \\
\hline & & & 168 & 54 & 2.5 & 75.3 & 109 \\
\hline & \multirow[t]{6}{*}{ E. Watson } & \multirow[t]{6}{*}{ Rainbow } & 180 & 249 & & & 211 \\
\hline & & & 119 & 225 & & & 209 \\
\hline & & & 300 & 316 & & & 250 \\
\hline & & & 308 & 324 & & & 214 \\
\hline & & & 308 & 324 & & & 147 \\
\hline & & & 118 & 201 & & & 194 \\
\hline
\end{tabular}




\begin{tabular}{|c|c|c|c|c|c|c|c|}
\hline Area & Lake & Species & $\begin{array}{l}\text { Length } \\
(\mathrm{mm})\end{array}$ & $\begin{array}{l}\text { Weight } \\
\text { (g) }\end{array}$ & $\begin{array}{l}\text { Trophic } \\
\text { position }\end{array}$ & $\begin{array}{l}\text { Benthic } \\
\text { reliance (\%) }\end{array}$ & $\begin{array}{l}\mathrm{Hg} \\
\text { (ng/g) }\end{array}$ \\
\hline North Cascades & E. Watson & Rainbow & 210 & 250 & & & 191 \\
\hline \multirow[t]{25}{*}{ Olympic } & Gladys & Brook & 190 & 74 & 2.7 & 94.5 & 210 \\
\hline & & & 197 & 76 & 2.7 & 85.4 & 275 \\
\hline & & & 144 & 33 & 2.5 & 90.3 & 163 \\
\hline & Grand & Brook & 155 & 43 & 2.8 & 100 & 316 \\
\hline & & & 188 & 70 & 3.1 & 20.9 & 422 \\
\hline & U. Lena & Rainbow & 186 & 56 & 3 & 49.3 & 290 \\
\hline & & & 172 & 36 & 2.9 & 33.8 & 165 \\
\hline & & & 190 & 77 & 3.2 & 34.4 & 151 \\
\hline & & & 20 & 88 & 3 & 55.4 & 201 \\
\hline & & & 177 & 54 & 3 & 25.1 & 355 \\
\hline & & & 198 & 88 & 2.9 & 21.8 & 281 \\
\hline & & & 180 & 54 & 3.1 & 86.9 & 222 \\
\hline & & & 148 & 44 & 3 & 73.0 & 181 \\
\hline & Lunch & Brook & 214 & 118 & 3.5 & 76.0 & 872 \\
\hline & & & 165 & 53 & 3 & 24.6 & 93 \\
\hline & & & 156 & 39 & 2.9 & 100.0 & 227 \\
\hline & & & 197 & 88 & 3.2 & 100.0 & 443 \\
\hline & & & 200 & 92 & 3.4 & 77.0 & 716 \\
\hline & & & 152 & 42 & 3.1 & 86.5 & 167 \\
\hline & & & 155 & 49 & 2.8 & 100.0 & 181 \\
\hline & & & 155 & 41 & 2.9 & 100.0 & 169 \\
\hline & Moose & Brook & 153 & 30 & 2.4 & 82.6 & 352 \\
\hline & PJ & Brook & 223 & 98 & 3 & 31.0 & 610 \\
\hline & & & 203 & 84 & 3.1 & 7.7 & 924 \\
\hline & & Rainbow & 72 & 120 & 3.1 & 38.8 & 294 \\
\hline
\end{tabular}


Table A4. Raw data for sample lakes. Some data supplemented from EPA database (https://archive.epa.gov/emap/archive-emap/web/txt/wlsds4.txt)

\begin{tabular}{|c|c|c|c|c|c|c|c|c|c|c|}
\hline Lake & Park & Year & $\begin{array}{l}\text { Julian } \\
\text { day }\end{array}$ & $\begin{array}{l}\text { Elevat } \\
(\mathrm{m})\end{array}$ & & $\begin{array}{l}\text { Surface } \\
\text { area (ha) }\end{array}$ & $\begin{array}{l}\text { Maximu } \\
\text { depth (n }\end{array}$ & $\begin{array}{l}\text { Mean } \\
\text { um depth } \\
\text { m) (m) }\end{array}$ & $\begin{array}{l}\text { Mean slope } \\
\text { within } 25 \% \\
\text { buffer }\end{array}$ & $\begin{array}{l}\text { Mean elevation } \\
\text { change within } \\
25 \% \text { buffer }(\mathrm{m})\end{array}$ \\
\hline L. Anderson & noca & 2014 & 217 & 1360 & & 1.6 & 4.9 & 1.6 & 5.90 & 1361.45 \\
\hline L. Deadwood & d mora & 2015 & 235 & 1595 & & 3.1 & 3.8 & 1.7 & 5.97 & 1597.99 \\
\hline Doubtful & noca & 2014 & 209 & 1641 & & 12.2 & 20.0 & 11.8 & 61.13 & 1663.23 \\
\hline Gladys & olym & 2015 & 246 & 1642 & & 0.5 & 4.2 & 1.4 & 5.13 & 1643.27 \\
\hline Grand & olym & 2015 & 247 & 1446 & & 5.2 & 8.3 & 4.9 & 20.58 & 1452.89 \\
\hline Hidden & noca & 2014 & 250 & 1747 & & 25.0 & 79.0 & 16.5 & 70.39 & 1780.32 \\
\hline U. Lena & olym & 2015 & 251 & 1387 & & 9.2 & 29.8 & 11.1 & 43.32 & 1398.04 \\
\hline Louise & mora & 2015 & 236 & 1401 & & 7.6 & 17.7 & 7.3 & 22.59 & 1406.48 \\
\hline LP-19 & mora & 2015 & 239 & 1372 & & 1.6 & 12.3 & 4.6 & 6.45 & 1373.06 \\
\hline Lunch & olym & 2015 & 242 & 1357 & & 3.0 & 18.3 & 7.0 & 15.68 & 1366.03 \\
\hline Monogram & noca & 2015 & 224 & 1485 & & 11.8 & 37.0 & 15.0 & 52.34 & 1497.66 \\
\hline Moose & olym & 2015 & 246 & 1541 & & 3.3 & 7.5 & 4.0 & 15.54 & 1545.14 \\
\hline L. Palisades & mora & 2015 & 238 & 1664 & & 1.6 & 2.8 & 1.6 & 11.42 & 1666.86 \\
\hline $\mathrm{PJ}$ & olym & 2015 & 244 & 1379 & & 0.7 & 7.5 & 3.0 & 36.50 & 1385.07 \\
\hline Sauk & noca & 2014 & 233.5 & 1250 & & 4.0 & 5.6 & 3.0 & 16.76 & 1254.62 \\
\hline Snow & mora & 2015 & 237 & 1426 & & 2.4 & 10.5 & 4.9 & 24.95 & 1432.52 \\
\hline L. Thornton & noca & 2014 & 223 & 1367 & & 22.3 & 33.0 & 17.7 & 99.80 & 1435.40 \\
\hline W. Watson & noca & 2014 & 219 & 1347 & & 7.3 & 8.9 & 5.0 & 44.66 & 1359.20 \\
\hline E. Watson & noca & 2014 & 218 & 1343 & & 18.5 & 17.8 & 13.7 & 62.41 & 1370.42 \\
\hline Lake & $\begin{array}{l}\text { Secchi } \\
(\mathrm{m})\end{array}$ & $\begin{array}{l}\text { Dissolve } \\
\text { oxygen } \\
(\mathrm{mg} / \mathrm{l})\end{array}$ & $\begin{array}{r}\text { d Speci } \\
\text { condu } \\
(\mu \mathrm{S} / \mathrm{c}\end{array}$ & $\begin{array}{l}\text { ific } \\
\text { uctance } \\
\mathrm{cm} \text { ) }\end{array}$ & $\mathrm{pH}$ & $\begin{array}{l}\text { Secchi } \\
\text { (m) }\end{array}$ & $\begin{array}{l}\text { Clarity } \\
\text { (\% total } \\
\text { depth) }\end{array}$ & $\begin{array}{l}\text { Epilimnetic } \\
\text { temp }(\mathrm{C})\end{array}$ & $\begin{array}{l}\text { PRISM } \\
\text { ic } 5 \mathrm{yr} \text { air } \\
\text { temp }(\mathrm{C})\end{array}$ & $\begin{array}{l}\text { PRISM 5yr } \\
\text { precipitation } \\
(\mathrm{mm})\end{array}$ \\
\hline L. Anderson & 4.2 & 6.69 & 41.3 & & 6.95 & 4.2 & 85.7 & 14.6 & 5.42 & 3903.8 \\
\hline L. Deadwood & 3.2 & 8.40 & 56.7 & & 7.37 & 3.2 & 84.2 & 16.4 & 4.64 & 2139.9 \\
\hline Doubtful & 9.5 & 6.02 & 11.42 & & 6.50 & 9.5 & 47.5 & 6.4 & 2.03 & 2936.9 \\
\hline Gladys & 4.2 & 10.46 & 129.1 & & 7.83 & 4.2 & 100.0 & 8.3 & 3.79 & 2055.4 \\
\hline Grand & 5.5 & 9.66 & 85.6 & & 7.55 & 5.5 & 66.3 & 10.1 & 4.10 & 2024.8 \\
\hline Hidden & 20 & 6.48 & 5.1 & & 6.74 & 20 & 25.3 & 9.4 & 4.50 & 2608.1 \\
\hline U. Lena & 4.5 & 9.03 & 41.9 & & 6.98 & 4.5 & 15.1 & 13.1 & 5.60 & 3198.4 \\
\hline Louise & 8.0 & 8.60 & 8.8 & & 6.18 & 8.0 & 45.2 & 17.3 & 4.20 & 3400.4 \\
\hline LP-19 & 6.0 & 8.53 & 12.4 & & 6.26 & 6.0 & 48.8 & 17.7 & 6.98 & 2385.6 \\
\hline Lunch & 16.0 & & 37.99 & & 7.64 & 16.0 & 87.4 & & 5.58 & 4326.4 \\
\hline Monogram & 12.3 & 8.43 & 19 & & 6.32 & 12.3 & 33.1 & 14.5 & 6.77 & 2803.5 \\
\hline Moose & 6.0 & 9.22 & 82.9 & & 7.24 & 6.0 & 80.0 & 10.4 & 4.06 & 2024.8 \\
\hline L. Palisades & 2.8 & 9.97 & 56.7 & & 7.23 & 2.8 & 100.0 & 13.8 & 3.91 & 1868.6 \\
\hline $\mathrm{PJ}$ & 3.0 & 9.06 & 138.8 & & 7.80 & 3.0 & 40.0 & 12.9 & 5.73 & 1820.8 \\
\hline Sauk & 5.1 & 10.12 & 97.8 & & 6.79 & 5.1 & 91.1 & 11.9 & 6.94 & 3230.0 \\
\hline Snow & 8.0 & 9.38 & 14.6 & & 6.27 & 8.0 & 76.2 & 14.0 & 4.58 & 3269.6 \\
\hline L. Thornton & 13.0 & 4.37 & 5.5 & & 6.42 & 13.0 & 39.4 & 11.4 & 6.30 & 3114.6 \\
\hline W. Watson & 6.8 & 6.50 & 37.9 & & 6.89 & 6.8 & 75.8 & 17.3 & 5.42 & 3903.8 \\
\hline E. Watson & 16.5 & 4.13 & & & 6.99 & 16.5 & 92.7 & 13.5 & 5.42 & 3903.8 \\
\hline
\end{tabular}




\begin{tabular}{|c|c|c|c|c|c|c|c|}
\hline Lake & $\begin{array}{l}\text { Phosphorus } \\
(\mu \mathrm{g} / \mathrm{L})\end{array}$ & $\begin{array}{l}\text { Total } \\
\text { nitrogen } \\
(\mu \mathrm{g} / \mathrm{L})\end{array}$ & $\begin{array}{l}\text { Edible } \\
\text { chlorophyll } \\
\mathrm{a}(\mu \mathrm{g} / \mathrm{L})\end{array}$ & $\begin{array}{l}\text { Specific UV } \\
\text { labsorbance } \\
(440 \mathrm{~nm})\end{array}$ & $\begin{array}{l}\text { Benthic } \\
\text { primary } \\
\text { production (\%) }\end{array}$ & $\begin{array}{l}\text { Mean } \\
\text { benthic } \\
\text { reliance (\%) }\end{array}$ & $\begin{array}{l}\text { Nearshore } \\
\text { tree cover } \\
(\%)\end{array}$ \\
\hline L. Anderson & 0.003 & & 0.95 & & 0.54 & 73.2 & 15.4 \\
\hline L. Deadwood & 0.005 & 247.8 & 0.32 & 0.247 & 0.42 & 98.2 & 91.3 \\
\hline Doubtful & 0.005 & 0.051 & 0.33 & & 0.23 & & 26.1 \\
\hline Gladys & 0.004 & 168.8 & 0.29 & 0.003 & 0.57 & 88.1 & 17.4 \\
\hline Grand & 0.008 & 179.5 & 0.46 & 0.004 & 0.3 & 60.5 & 67.2 \\
\hline Hidden & 0.003 & 0.032 & 0.18 & & 0.51 & & 7.5 \\
\hline U. Lena & 0.007 & 203.1 & 0.35 & 0.008 & 0.19 & 47.5 & 37.1 \\
\hline Louise & 0.003 & 110.9 & 0.33 & 0.003 & 0.35 & 33.6 & 41.4 \\
\hline LP-19 & 0.006 & 191.9 & 0.30 & 0.037 & 0.41 & 58.0 & 93.0 \\
\hline Lunch & 0.001 & & & 0.018 & & 83.0 & 2.2 \\
\hline Monogram & 0.006 & & 0.28 & & 0.31 & 55.1 & 7.0 \\
\hline Moose & 0.010 & 152.2 & 0.57 & 0.012 & 0.4 & 76.9 & 48.2 \\
\hline L. Palisades & 0.009 & 158.2 & 0.90 & 0.007 & 0.34 & 59.1 & 68.3 \\
\hline PJ & 0.012 & 249.1 & 2.77 & 0.005 & 0.32 & 25.8 & 91.8 \\
\hline Sauk & 0.005 & 160.9 & 0.41 & 0.005 & 0.41 & 73.1 & 12.2 \\
\hline Snow & 0.005 & 130.8 & 0.38 & 0.200 & 0.46 & 97.3 & 34.6 \\
\hline L. Thornton & 0.003 & & 0.14 & & 0.46 & & 21.7 \\
\hline W. Watson & 0.022 & & 1.37 & & 0.37 & 52.8 & 40.8 \\
\hline E. Watson & 0.002 & & 0.03 & & 0.38 & & 12.6 \\
\hline Lake & \multicolumn{7}{|l|}{ Notes } \\
\hline L. Anderson & \multicolumn{7}{|c|}{ phosphorus averaged from database (TDP) \& measured (TP) in 2015} \\
\hline L. Deadwood & \multicolumn{7}{|c|}{ phosphorus averaged from database (TDP) \& measured (TP) in 2015} \\
\hline Doubtful & \multicolumn{7}{|c|}{$\begin{array}{l}\text { phosphorus only includes database measurement (measured was erroneously high); } \\
\text { conductance from EPA data }\end{array}$} \\
\hline Gladys & \multicolumn{7}{|c|}{ phosphorus averaged from database (TDP) \& measured (TP) in 2015} \\
\hline Grand & \multicolumn{7}{|c|}{ phosphorus only includes measurement from 2015 (TP) } \\
\hline Hidden & \multicolumn{7}{|c|}{$\begin{array}{l}\text { phosphorus averaged from database (TP) \& measured (TP) in 2015; conductance from } \\
\text { EPA data }\end{array}$} \\
\hline U. Lena & \multicolumn{7}{|c|}{ phosphorus only includes measurement from 2015 (TP) } \\
\hline Louise & \multicolumn{7}{|c|}{ phosphorus averaged from database (TDP) \& measured (TP) in 2015} \\
\hline LP-19 & \multicolumn{7}{|c|}{ phosphorus only includes measurement from 2015 (TP) } \\
\hline Lunch & \multicolumn{7}{|c|}{ phosphorus, secchi, ph, conductance all from EPA data } \\
\hline Monogram & \multicolumn{7}{|c|}{ phosphorus averaged from database (TDP) \& measured (TP) in 2015} \\
\hline Moose & \multicolumn{7}{|c|}{ phosphorus only includes measurement from 2015 (TP) } \\
\hline L. Palisades & \multicolumn{7}{|c|}{ phosphorus averaged from database (TDP) \& measured (TP) in 2015} \\
\hline PJ & \multicolumn{7}{|c|}{ phosphorus only includes measurement from 2015 (TP) } \\
\hline Sauk & \multicolumn{7}{|c|}{ Phosphorus averaged from database (TP) and measured (TP) in 2015} \\
\hline Snow & \multicolumn{7}{|c|}{ phosphorus averaged from database (TDP) \& measured (TP) in 2015} \\
\hline L. Thornton & \multicolumn{7}{|c|}{ phosphorus averaged from database (TDP) \& measured (TP) in 2015} \\
\hline W. Watson & \multicolumn{7}{|c|}{ phosphorus only includes measurement from 2015 (TP) } \\
\hline E. Watson & \multicolumn{7}{|c|}{ phosphorus averaged from database (TDP) \& measured (TP) in 2015} \\
\hline
\end{tabular}




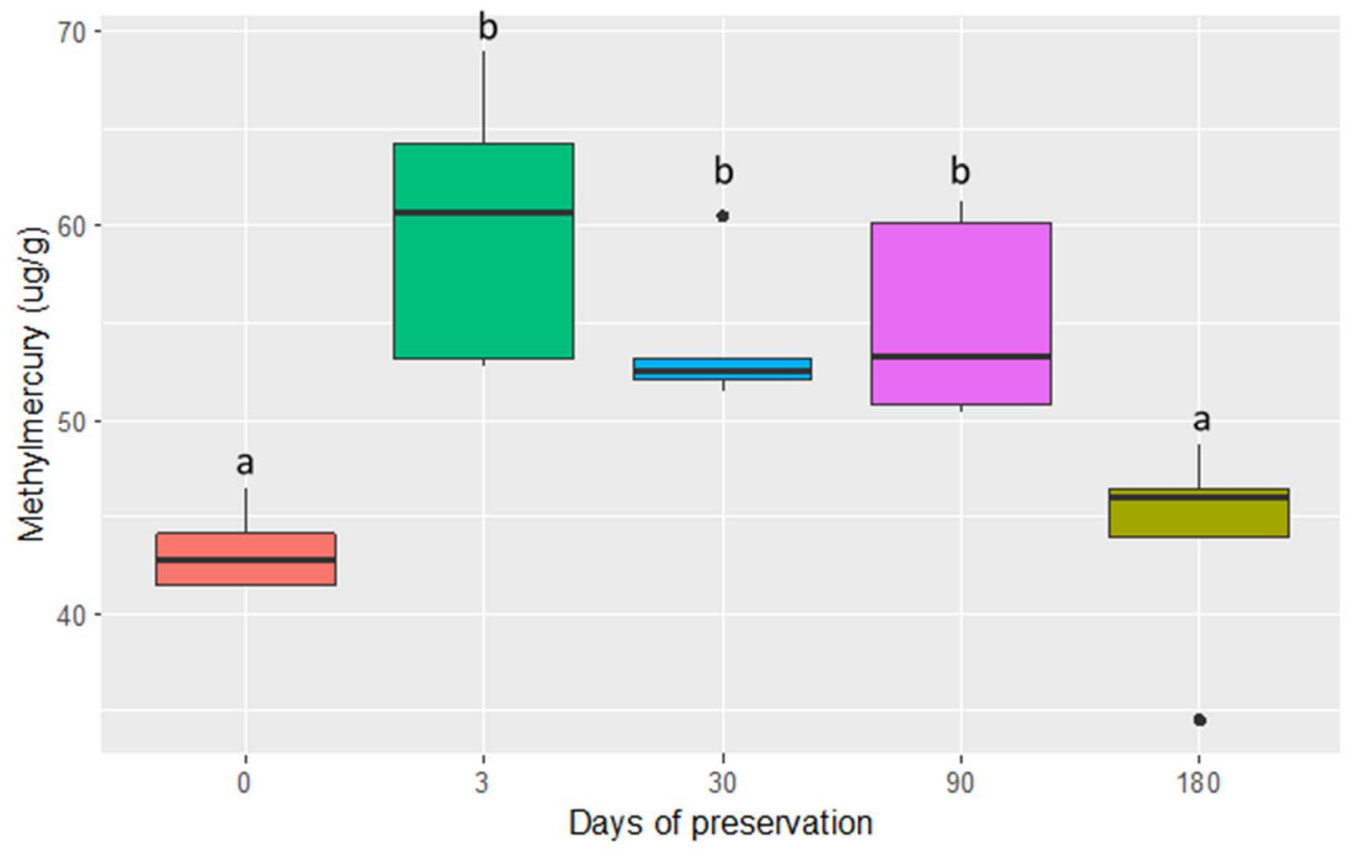

Figure A1. Differences in zooplankton methylmercury concentrations between ethanol preservation after $3(n=5), 30(n=5), 90(n=5)$, and $180(n=5)$ days. Samples from the day zero group $(n=5)$ were frozen until analysis instead of stored in ethanol. While there appears to be significantly higher methylmercury in samples stored in ethanol relative to frozen samples for the first three months after sampling (ANOVA: $\mathrm{F}_{4,20}=10.76, \mathrm{p}<0.01$; Tukey's HSD: 3 days: $\mathrm{p}<0.01 ; 30$ days: $\mathrm{p}=0.02 ; 90$ days: $\mathrm{p}=0.01$ ), the concentrations return to concentrations similar to those in frozen samples after six months ( $\mathrm{p}=0.99$, Tukey's HSD). 
Figure A2. Results from the percent tree cover - precipitation linear regression model $(\beta=-16.50 \pm 4.86, \mathrm{df}=17)$. Percent tree cover was not strongly correlated to precipitation $\left(\mathrm{R}^{2}\right.$ adj $\left.=0.37\right)$, but the relationship was significant $(\mathrm{p}<0.01)$.

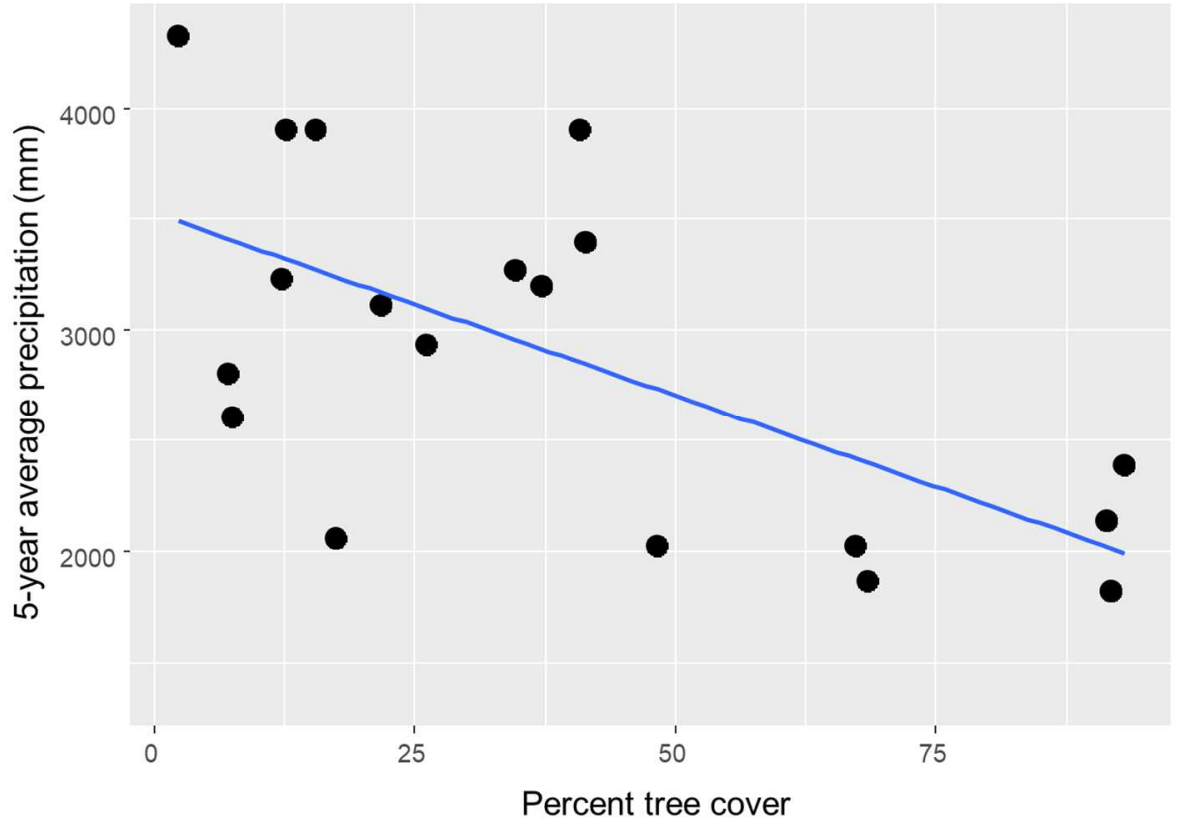




\section{Appendix B}

Supporting tables and figures for Chapter 3

Table B1. Ingredients for Aqua Uni 4mm pellets.

\begin{tabular}{ll} 
Ingredient & Percent composition \\
\hline Poultry meal & 18.5 \\
Sunflower concentrate & 18.0 \\
Fish meal & 14.0 \\
Wheat & 13.7 \\
Swine blood meal & 8.8 \\
Wheat meal & 7.7 \\
Rapeseed cake & 7.5 \\
Fish oil & 5.9 \\
Rapeseed oil & 5.3 \\
Added minerals & 0.6
\end{tabular}

Table B2. Stream benthic invertebrates collected for benthic treatment diets.

\begin{tabular}{|c|c|c|}
\hline Family & Taxa & Feeding strategy \\
\hline \multirow[t]{2}{*}{ Ephemeroptera } & Ecdyonurus venosus & Scrapers, collectors \\
\hline & Ecdyonurus forcipula & Scrapers, collectors \\
\hline \multirow[t]{2}{*}{ Plecoptera } & Perlodes microcephala & Predators \\
\hline & Isoperla similis & Predators \\
\hline \multirow[t]{3}{*}{ Trichoptera } & Sericostoma sp. & Shredders \\
\hline & Drusus trifidus & Shredders \\
\hline & Potamophylax rotundipennis & Shredders, scrapers \\
\hline Oligochaeta & Lumbricidae & Decomposers \\
\hline
\end{tabular}


Table B3. Average concentrations ( \pm standard deviation) of each major fatty acid group and individual EFAs in diets \& treatments.

\begin{tabular}{lllllllll} 
& $\begin{array}{l}\text { SAFA } \\
(\mathrm{mg} / \mathrm{g})\end{array}$ & $\begin{array}{l}\text { MUFA } \\
(\mathrm{mg} / \mathrm{g})\end{array}$ & $\begin{array}{l}\text { PUFA } \\
(\mathrm{mg} / \mathrm{g})\end{array}$ & $\begin{array}{c}\text { ALA } \\
(\mathrm{mg} / \mathrm{g})\end{array}$ & $\begin{array}{c}\text { ARA } \\
(\mathrm{mg} / \mathrm{g})\end{array}$ & $\begin{array}{c}\text { LIN } \\
(\mathrm{mg} / \mathrm{g})\end{array}$ & $\begin{array}{c}\text { EPA } \\
(\mathrm{mg} / \mathrm{g})\end{array}$ & $\begin{array}{c}\text { DHA } \\
(\mathrm{mg} / \mathrm{g})\end{array}$ \\
\hline Earthworms & $18.32 \pm$ & $16.52 \pm$ & $61.01 \pm$ & $2.28 \pm$ & $8.79 \pm$ & $3.99 \pm$ & $28.65 \pm$ & $0.22 \pm$ \\
& 4.41 & 7.38 & 4.21 & 3.33 & 13.53 & 5.77 & 42.85 & 0.10 \\
Benthic & $27.70 \pm$ & $29.49 \pm$ & $40.92 \pm$ & $127.05 \pm$ & $5.70 \pm$ & $35.00 \pm$ & $96.69 \pm$ & $1.22 \pm$ \\
Invertebrates & 2.73 & 4.15 & 2.51 & 130.72 & 5.87 & 34.26 & 101.41 & 0.77 \\
Pellets & $17.65 \pm$ & $46.33 \pm$ & $35.93 \pm$ & $5.09 \pm$ & $0.42 \pm$ & 18.36 & $3.40 \pm$ & $2.53 \pm$ \\
& 0.88 & 1.47 & 0.63 & 0.43 & 0.05 & \pm 1.94 & 0.83 & 1.91 \\
Fish liver & $17.89 \pm$ & $46.92 \pm$ & $34.55 \pm$ & $4.87 \pm$ & $4.71 \pm$ & $20.58 \pm$ & $8.11 \pm$ & $19.95 \pm$ \\
(benthic) & 7.01 & 16.97 & 11.07 & 3.19 & 0.75 & 8.50 & 2.95 & 5.91 \\
Fish liver & $14.41 \pm$ & $64.28 \pm$ & $21.18 \pm$ & $4.13 \pm$ & $4.01 \pm$ & $22.35 \pm$ & $6.54 \pm$ & $16.46 \pm$ \\
(control) & 1.62 & 3.06 & 2.35 & 0.82 & 0.50 & 4.64 & 1.03 & 2.42 \\
Fish liver & $17.74 \pm$ & $46.98 \pm$ & $35.08 \pm$ & $7.60 \pm$ & $6.35 \pm$ & $41.15 \pm$ & $10.55 \pm$ & $25.68 \pm$ \\
(mixed) & 5.11 & 14.86 & 10.74 & 9.48 & 4.12 & 58.84 & 7.30 & 16.98 \\
Fish liver & $16.81 \pm$ & $44.73 \pm$ & $38.17 \pm$ & $2.78 \pm$ & $5.03 \pm$ & $15.37 \pm$ & $6.62 \pm$ & $19.99 \pm$ \\
(terrestrial) & 4.89 & 14.56 & 11.04 & 1.39 & 1.03 & 6.14 & 2.01 & 3.93 \\
Fish muscle & $19.98 \pm$ & $42.15 \pm$ & $37.72 \pm$ & $3.27 \pm$ & $1.36 \pm$ & $15.74 \pm$ & 4.24 & $11.72 \pm$ \\
(benthic) & 4.23 & 9.36 & 5.32 & 1.95 & 0.50 & 11.06 & \pm 1.25 & 2.83 \\
Fish muscle & $17.67 \pm$ & $51.43 \pm$ & $30.78 \pm$ & $6.91 \pm$ & $1.54 \pm$ & $29.45 \pm$ & $5.73 \pm$ & $13.96 \pm$ \\
(control) & 0.48 & 1.51 & 1.64 & 0.95 & 0.30 & 4.87 & 1.30 & 3.07 \\
Fish muscle & $19.83 \pm$ & $42.77 \pm$ & $37.21 \pm$ & $4.62 \pm$ & $1.41 \pm$ & $20.81 \pm$ & $5.12 \pm$ & $14.08 \pm$ \\
(mixed) & 3.88 & 11.51 & 7.74 & 2.52 & 0.37 & 11.25 & 2.19 & 4.37 \\
Fish muscle & $20.61 \pm$ & $40.88 \pm$ & $38.33 \pm$ & $3.50 \pm$ & $1.28 \pm$ & $15.89 \pm$ & $4.08 \pm$ & $11.72 \pm$ \\
(terrestrial) & 4.80 & 13.05 & 8.39 & 1.44 & 0.32 & 6.04 & 1.31 & 2.98 \\
& & & & & & & &
\end{tabular}


Table B4. Full model results for mixed-effects ANOVAs and Tukey's adjusted LSM differences of fatty acid concentrations between treatment groups for (a) diets, (b) fish muscle, and (c) fish liver. Sum $\mathrm{Sq}=$ sum of squares; mean sq= mean square; $\mathrm{SE}=$ standard error; $\mathrm{DF}=$ degrees of freedom.

\section{(a) Diets}

[ALA]

\begin{tabular}{rrrrrrr}
\hline ANOVA: & Sum Sq & Mean Sq & NumDF & DenDF & F & p \\
\cline { 2 - 6 } Random effect: & 59.49 & 29.74 & 2 & 12.99 & 3.77 & 0.05 \\
time & Variance & SD & & & & \\
residual & 0.00 & 0.00 & & & & \\
& 1.68 & 1.30 & & & &
\end{tabular}

LSM differences

\begin{tabular}{lrrrrrrr} 
treatment & \multicolumn{1}{c}{ SE } & DF & & $t$-value & Lower CI & Upper CI & \multicolumn{1}{c}{ p } \\
\hline benthic - control & 122.00 & 49.40 & 13 & 2.47 & 15.21 & 229.00 & 0.03 \\
benthic - terrestrial & 124.80 & 61.30 & 13 & 2.04 & -7.65 & 257.00 & 0.06 \\
control - terrestrial & 2.80 & 62.80 & 13 & 0.04 & -132.88 & 138.00 & 0.97 \\
\hline
\end{tabular}

[LIN]

\begin{tabular}{|c|c|c|c|c|c|c|c|}
\hline \multirow[b]{2}{*}{ ANOVA: } & & Mean & & & & & \\
\hline & Sum Sq & $\mathrm{Sq}$ & NumDF & DenDF & $\mathrm{F}$ & $\mathrm{p}$ & \\
\hline \multirow{6}{*}{$\begin{array}{r}\text { Random effect: } \\
\text { time } \\
\text { residual }\end{array}$} & 321.00 & 160.50 & 2 & 10.72 & 3.46 & 0.07 & \\
\hline & Variance & $\mathrm{SD}$ & & & & & \\
\hline & 212.40 & 14.58 & & & & & \\
\hline & 463.30 & 21.52 & & & & & \\
\hline & \multicolumn{7}{|c|}{ LSM differences } \\
\hline & $B$ & $\mathrm{SE}$ & $\mathrm{DF}$ & $t$-value & Lower CI & Upper CI & $\mathrm{p}$ \\
\hline benthic - control & 33.00 & 16.05 & 8.60 & 2.05 & -3.63 & 69.60 & 0.07 \\
\hline benthic - terrestrial & 34.60 & 15.04 & 10.90 & 2.30 & 1.50 & 67.80 & 0.04 \\
\hline control - terrestrial & 1.70 & 17.34 & 12.80 & 0.10 & -35.87 & 39.20 & 0.93 \\
\hline \multicolumn{8}{|c|}{ [ARA] } \\
\hline \multirow[t]{2}{*}{ ANOVA: } & Sum Sq & $\begin{array}{r}\text { Mean } \\
\mathrm{Sq} \\
\end{array}$ & NumDF & DenDF & $\mathrm{F}$ & $\mathrm{p}$ & \\
\hline & 419.90 & 209.95 & 2 & 11.90 & 8.72 & 0.01 & \\
\hline \multirow[t]{4}{*}{ Random effect: } & Variance & SD & & & & & \\
\hline & 54.84 & 7.41 & & & & & \\
\hline & 24.07 & 4.91 & & & & & \\
\hline & \multicolumn{7}{|c|}{ LSM differences } \\
\hline
\end{tabular}




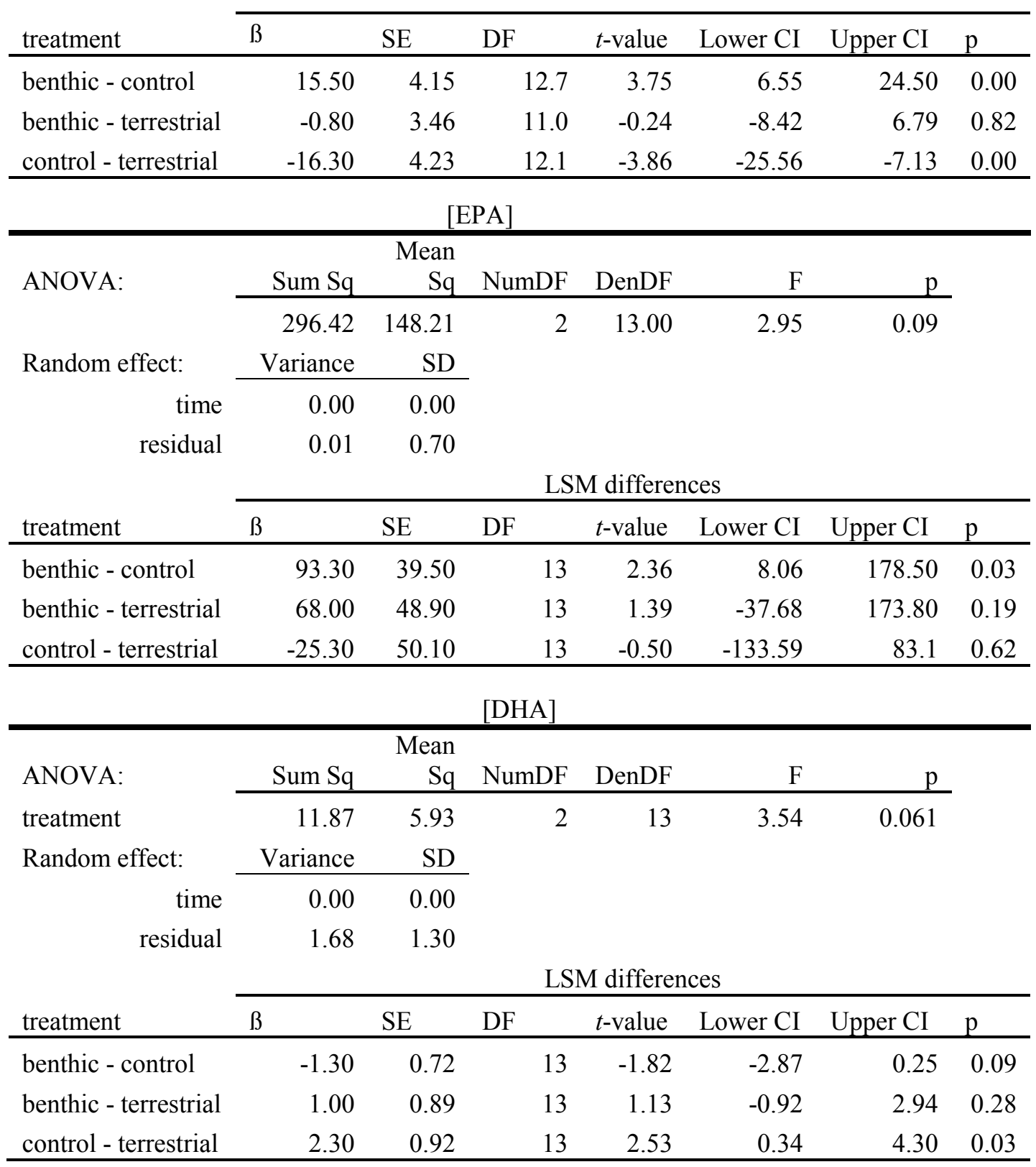

\section{(b) Muscle}

[ALA]

\begin{tabular}{|c|c|c|c|c|c|c|c|}
\hline \multirow[t]{2}{*}{ ANOVA: } & Sum Sq & Mean Sq & NumDF & DenDF & $\mathrm{F}$ & $\mathrm{p}$ & \\
\hline & 20.28 & 6.76 & 3 & 4 & 2.13 & 0.23 & \\
\hline \multirow{4}{*}{$\begin{array}{r}\text { Random effect: } \\
\qquad \begin{array}{r}\text { tank } \\
\text { residual }\end{array}\end{array}$} & Variance & $\mathrm{SD}$ & & & & & \\
\hline & 0.90 & 0.95 & & & & & \\
\hline & 3.18 & 1.78 & & & & & \\
\hline & \multicolumn{7}{|c|}{ LSM Differences } \\
\hline treatment & $B$ & SE & $\mathrm{DF}$ & $t$-value & Lower CI & Upper CI & $\mathrm{p}$ \\
\hline
\end{tabular}




\begin{tabular}{lrrrrrrr}
\hline benthic - control & -4.40 & 1.89 & 5.4 & -2.33 & -9.17 & 0.36 & 0.06 \\
benthic - mixed & -2.30 & 1.61 & 10.1 & -1.44 & -5.90 & 1.27 & 0.18 \\
benthic - terrestrial & -1.30 & 1.74 & 8.2 & -0.74 & -5.27 & 2.70 & 0.48 \\
control - mixed & 2.10 & 1.45 & 2.6 & 1.45 & -2.99 & 7.18 & 0.26 \\
control - terrestrial & 3.10 & 1.59 & 2.6 & 1.97 & -2.38 & 8.63 & 0.16 \\
mixed - terrestrial & 1.00 & 1.24 & 3.9 & 0.83 & -2.46 & 4.52 & 0.45 \\
\hline
\end{tabular}

$[\mathrm{LIN}]$

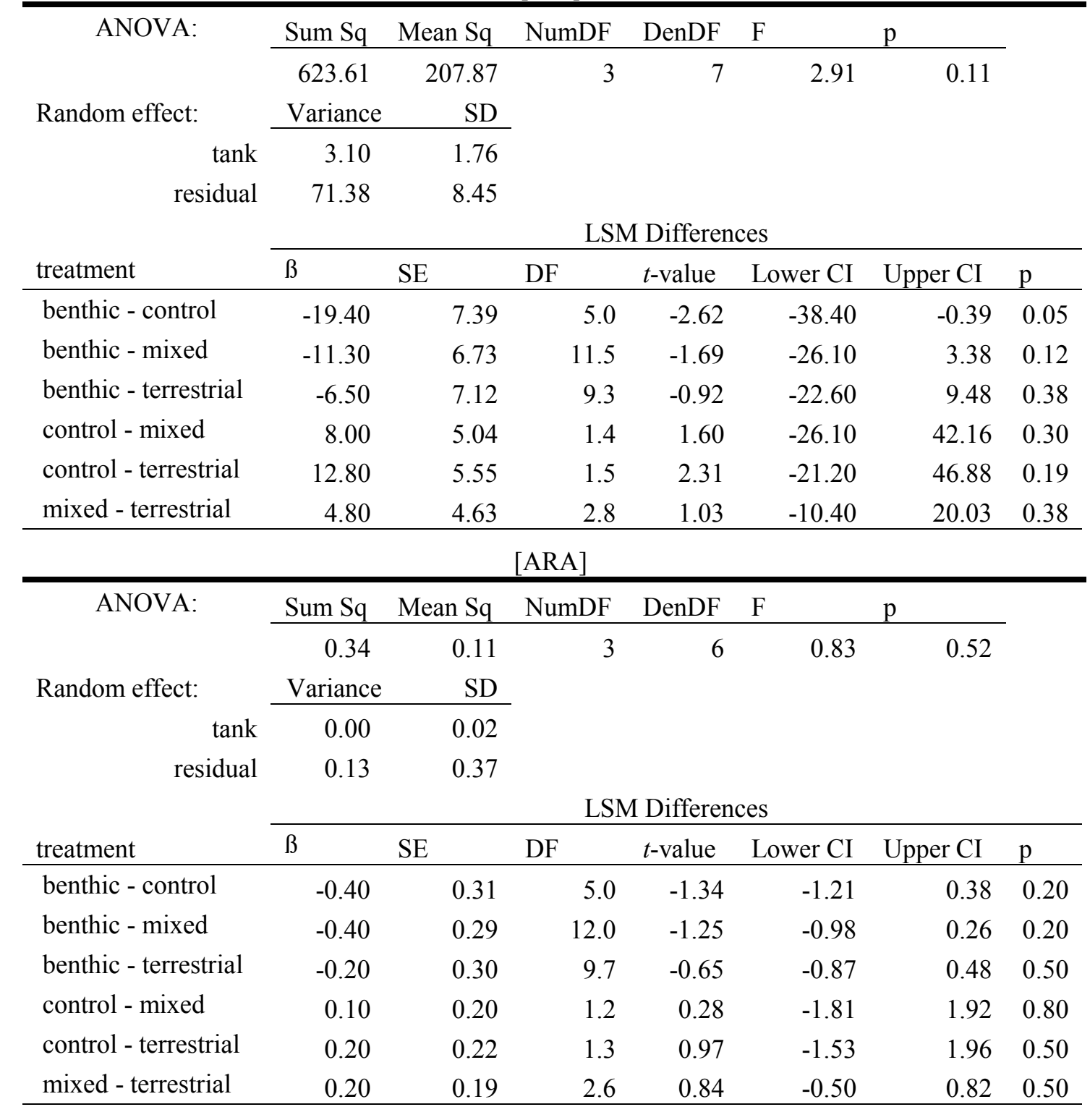

\section{[EPA]}

\begin{tabular}{rrrrrrrr} 
ANOVA: & Sum Sq & Mean Sq & NumDF & DenDF & F & p \\
\cline { 2 - 7 } & 6.24 & 2.08 & 3 & 3 & 0.77 & 0.57
\end{tabular}




\begin{tabular}{rcr} 
Random effect: & Variance & SD \\
\cline { 2 - 3 } tank & 0.28 & 0.53 \\
residual & 2.70 & 1.64
\end{tabular}

\begin{tabular}{lrrrrrrrr} 
& \multicolumn{1}{c}{ LSM Differences } \\
\cline { 2 - 9 } treatment & \multicolumn{1}{c}{ SE } & & DF & & t-value & Lower CI & Upper CI & $\mathrm{p}$ \\
\hline benthic - control & -1.80 & 1.52 & 5.5 & -1.18 & -5.59 & 2.01 & 0.30 \\
benthic - mixed & -1.40 & 1.36 & 11.5 & -1.04 & -4.38 & 1.55 & 0.30 \\
benthic - terrestrial & -0.50 & 1.44 & 9.4 & -0.34 & -3.73 & 2.76 & 0.70 \\
control - mixed & 0.40 & 1.08 & 1.9 & 0.35 & -4.52 & 5.27 & 0.80 \\
control - terrestrial & 1.30 & 1.19 & 2.0 & 1.10 & -3.84 & 6.45 & 0.40 \\
mixed - terrestrial & 0.90 & 0.97 & 3.4 & 0.96 & -1.94 & 3.79 & 0.40 \\
\hline
\end{tabular}

[DHA]

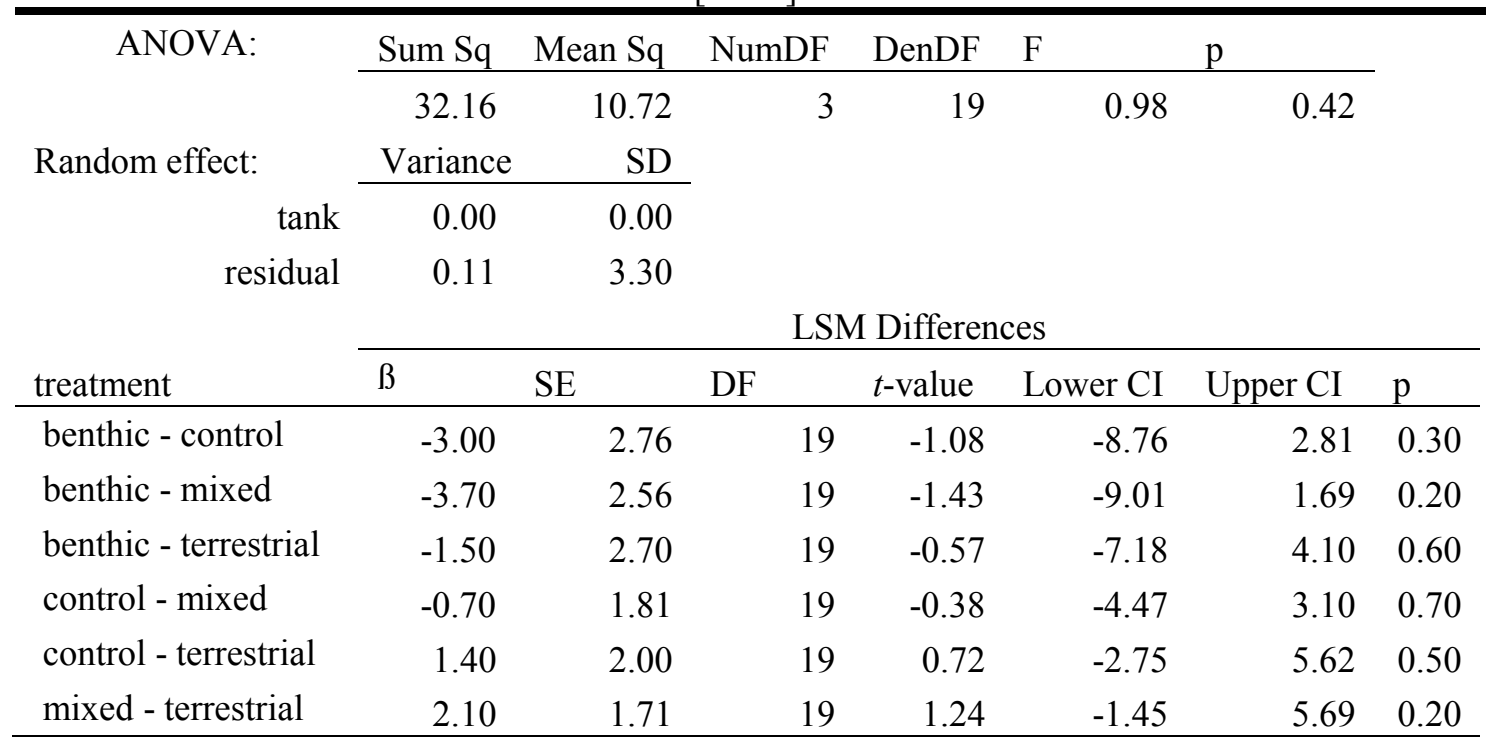

\section{(c) Liver}

[ALA]

\begin{tabular}{|c|c|c|c|c|c|c|c|}
\hline \multirow[t]{2}{*}{ ANOVA: } & Sum Sq & Mean Sq & NumDF & DenDF & $\mathrm{F}$ & $\mathrm{p}$ & \\
\hline & 19.14 & 6.38 & 3.00 & 3.61 & 3.11 & 0.16 & \\
\hline \multirow[t]{4}{*}{ Random effect: } & Variance & SD & & & & & \\
\hline & 1.77 & 1.33 & & & & & \\
\hline & 2.05 & 1.43 & & & & & \\
\hline & \multicolumn{7}{|c|}{ LSM Differences } \\
\hline treatment & ß & SE & DF & $t$-value & Lower CI & Upper CI & $\mathrm{p}$ \\
\hline benthic - control & 4.00 & 2.02 & 3.90 & 1.99 & -1.68 & 9.72 & 0.12 \\
\hline benthic - mixed & 3.70 & 1.61 & 6.20 & 2.28 & -0.24 & 7.56 & 0.06 \\
\hline
\end{tabular}




\begin{tabular}{|c|c|c|c|c|c|c|c|}
\hline benthic - terrestrial & 5.30 & 1.77 & 5.20 & 3.02 & 0.84 & 9.85 & 0.03 \\
\hline control - mixed & -0.40 & 1.69 & 2.60 & -0.21 & -6.24 & 5.52 & 0.85 \\
\hline control - terrestrial & 1.30 & 1.85 & 2.60 & 0.72 & -5.11 & 7.76 & 0.53 \\
\hline mixed - terrestrial & 1.70 & 1.38 & 3.20 & 1.23 & -2.52 & 5.89 & 0.30 \\
\hline \multicolumn{8}{|c|}{$[\mathrm{LIN}]$} \\
\hline \multirow[t]{2}{*}{ ANOVA: } & Sum Sq & Mean Sq & NumDF & DenDF & $\mathrm{F}$ & $\mathrm{p}$ & \\
\hline & 264.51 & 88.17 & 3.00 & 5.46 & 2.96 & 0.13 & \\
\hline \multirow{4}{*}{$\begin{array}{l}\text { Random effect: } \\
\qquad \begin{array}{r}\operatorname{tank} \\
\text { residual }\end{array}\end{array}$} & Variance & $\mathrm{SD}$ & & & & & \\
\hline & 17.38 & 4.17 & & & & & \\
\hline & 29.82 & 5.46 & & & & & \\
\hline & \multicolumn{7}{|c|}{ LSM Differences } \\
\hline treatment & $\beta$ & SE & DF & $t$-value & Lower CI & Upper CI & $\mathrm{p}$ \\
\hline benthic - control & 8.20 & 6.85 & 6.00 & 1.20 & -8.57 & 25.00 & 0.28 \\
\hline benthic - mixed & 12.00 & 5.58 & 9.60 & 2.15 & -0.51 & 24.50 & 0.06 \\
\hline benthic - terrestrial & 17.70 & 6.10 & 8.10 & 2.90 & 3.66 & 31.70 & 0.02 \\
\hline control - mixed & 3.80 & 5.55 & 3.80 & 0.68 & -12.04 & 19.60 & 0.53 \\
\hline control - terrestrial & 9.50 & 6.08 & 3.80 & 1.56 & -7.81 & 26.80 & 0.20 \\
\hline mixed - terrestrial & 5.70 & 4.60 & 4.90 & 1.24 & -6.22 & 17.60 & 0.27 \\
\hline \multicolumn{8}{|c|}{ [ARA] } \\
\hline \multirow[t]{2}{*}{ ANOVA: } & Sum Sq & Mean Sq & NumDF & DenDF & $\mathrm{F}$ & $\mathrm{p}$ & \\
\hline & 3.99 & 1.33 & 3.00 & 4.46 & 1.32 & 0.38 & \\
\hline \multirow{5}{*}{$\begin{array}{r}\text { Random effect: } \\
\text { tank } \\
\text { residual }\end{array}$} & Variance & SD & & & & & \\
\hline & 0.08 & 0.29 & & & & & \\
\hline & 1.01 & 1.01 & & & & & \\
\hline & \multicolumn{7}{|c|}{ LSM Differences } \\
\hline & B & $\mathrm{SE}$ & DF & $t$-value & Lower CI & Upper CI & $\mathrm{p}$ \\
\hline benthic - control & 1.50 & 0.91 & 6.90 & 1.60 & -0.70 & 3.62 & 0.20 \\
\hline benthic - mixed & 0.40 & 0.82 & 13.20 & 0.47 & -1.38 & 2.15 & 0.60 \\
\hline benthic - terrestrial & 0.30 & 0.87 & 11.20 & 0.35 & -1.60 & 2.22 & 0.70 \\
\hline control - mixed & -1.10 & 0.64 & 2.40 & -1.68 & -3.42 & 1.26 & 0.20 \\
\hline control - terrestrial & -1.20 & 0.70 & 2.50 & -1.64 & -3.64 & 1.33 & 0.20 \\
\hline mixed - terrestrial & -0.10 & 0.58 & 4.40 & -0.13 & -1.62 & 1.47 & 0.90 \\
\hline
\end{tabular}

[EPA]

\begin{tabular}{lrrrrrr}
\hline ANOVA: & Sum Sq & Mean Sq & NumDF & DenDF & F & p \\
\hline & 30.55 & 10.18 & 3.00 & 19.00 & 1.87 & 0.17 \\
Random effect: & Variance & SD & & & & \\
\cline { 2 - 4 } & 0.00 & 0.00 & & & &
\end{tabular}


residual $\quad 5.45 \quad 2.33$

LSM Differences

\begin{tabular}{|c|c|c|c|c|c|c|c|}
\hline \multirow[b]{2}{*}{ treatment } & \\
\hline & $\beta$ & SE & DF & $t$-value & Lower CI & Upper CI & $\mathrm{p}$ \\
\hline benthic - control & 3.90 & 1.95 & 19.00 & 2.00 & -0.19 & 7.98 & 0.06 \\
\hline benthic - mixed & 2.10 & 1.81 & 19.00 & 1.15 & -1.71 & 5.86 & 0.27 \\
\hline benthic - terrestrial & 3.60 & 1.91 & 19.00 & 1.89 & -0.38 & 7.59 & 0.07 \\
\hline control - mixed & -1.80 & 1.28 & 19.00 & -1.42 & -4.50 & 0.85 & 0.17 \\
\hline control - terrestrial & -0.30 & 1.41 & 19.00 & -0.21 & -3.25 & 2.67 & 0.84 \\
\hline mixed - terrestrial & 1.50 & 1.21 & 19.00 & 1.27 & -0.99 & 4.05 & 0.22 \\
\hline \multicolumn{8}{|c|}{ [DHA] } \\
\hline \multirow[t]{2}{*}{ ANOVA: } & Sum Sq & Mean Sq & NumDF & DenDF & $\mathrm{F}$ & $\mathrm{p}$ & \\
\hline & 50.63 & 16.88 & 3.00 & 3.80 & 0.94 & 0.50 & \\
\hline \multirow{4}{*}{$\begin{array}{r}\text { Random effect: } \\
\text { tank } \\
\text { residual }\end{array}$} & Variance & SD & & & & & \\
\hline & 1.85 & 1.36 & & & & & \\
\hline & 17.87 & 4.23 & & & & & \\
\hline & \multicolumn{7}{|c|}{ LSM Differences } \\
\hline treatment & $\beta$ & SE & DF & $t$-value & Lower CI & Upper CI & $\mathrm{p}$ \\
\hline benthic - control & 2.90 & 3.91 & 5.90 & 0.74 & -6.70 & 12.50 & 0.50 \\
\hline benthic - mixed & -0.10 & 3.49 & 12.00 & -0.03 & -7.71 & 7.48 & 1.00 \\
\hline benthic - terrestrial & -2.20 & 3.71 & 9.90 & -0.60 & -10.52 & 6.04 & 0.60 \\
\hline control - mixed & -3.00 & 2.78 & 2.10 & -1.08 & -14.54 & 8.52 & 0.40 \\
\hline control - terrestrial & -5.10 & 3.06 & 2.20 & -1.68 & -17.33 & 7.05 & 0.20 \\
\hline mixed - terrestrial & -2.10 & 2.49 & 3.70 & -0.86 & -9.23 & 4.97 & 0.40 \\
\hline
\end{tabular}


Table B5. Full model results for mixed-effects ANOVAs and Tukey's adjusted LSM differences of fatty acid and bulk $\delta^{13} \mathrm{C}$ between treatment groups for (a) diets, (b) fish muscle, and (c) fish liver.

\section{(a) Diets}

\begin{tabular}{|c|c|c|c|c|c|c|c|}
\hline \multicolumn{8}{|c|}{$\delta^{13} \mathrm{C}_{\mathrm{ALA}}$} \\
\hline ANOVA: & Sum Sq & Mean Sq & NumDF & DenDF & $\mathrm{F}$ & $\mathrm{p}$ & \\
\hline \multirow{5}{*}{$\begin{array}{l}\text { Random effect: } \\
\text { time } \\
\text { residual }\end{array}$} & 63.26 & 31.63 & 2 & 10 & 10.66 & 0.003 & \\
\hline & Variance & SD & & & & & \\
\hline & 0.00 & 0.00 & & & & & \\
\hline & 2.97 & 1.72 & & & & & \\
\hline & \multicolumn{7}{|c|}{ LSM differences } \\
\hline treatment & $\beta$ & SE & DF & $t$-value & Lower CI & Upper CI & $\mathrm{p}$ \\
\hline benthic - control & -2.80 & 1.19 & 10 & -2.35 & -5.44 & -0.14 & 0.04 \\
\hline benthic - terrestrial & -5.30 & 1.19 & 10 & -4.50 & -7.99 & -2.70 & 0.00 \\
\hline control - terrestrial & -2.60 & 1.41 & 10 & -1.82 & -5.69 & 0.58 & 0.10 \\
\hline \multicolumn{8}{|c|}{$\delta^{13} C_{\text {LIN }}$} \\
\hline
\end{tabular}

\begin{tabular}{rrrrrrrr}
\hline ANOVA: & Sum Sq & Mean Sq & NumDF & DenDF & F & p \\
\cline { 2 - 7 } & 1.06 & 0.53 & 2 & 10 & 0.32 & 0.73
\end{tabular}

\begin{tabular}{rrr} 
Random effect: & Variance & SD \\
\cline { 2 - 3 } time & 0.00 & 0.00 \\
residual & 1.64 & 1.28
\end{tabular}

LSM differences

\begin{tabular}{|c|c|c|c|c|c|c|c|}
\hline \multirow[b]{2}{*}{ treatment } & \multicolumn{7}{|c|}{ 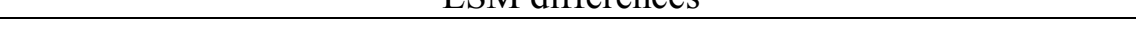 } \\
\hline & $\beta$ & SE & $\mathrm{DF}$ & $t$-value & Lower CI & Upper CI & $\mathrm{p}$ \\
\hline benthic - control & -0.70 & 0.88 & 10 & -0.77 & -2.65 & 1.29 & 0.50 \\
\hline benthic - terrestrial & -0.40 & 0.88 & 10 & -0.44 & -2.36 & 1.58 & 0.70 \\
\hline control - terrestrial & 0.30 & 1.05 & 10 & 0.28 & -2.04 & 2.62 & 0.80 \\
\hline
\end{tabular}

\begin{tabular}{lrrrrrrr}
\multicolumn{8}{c}{$\delta^{13} \mathrm{C}_{\text {ARA }}$} \\
\hline ANOVA: & Sum Sq & Mean Sq & NumDF & DenDF & F & p \\
\cline { 2 - 8 } & 79.80 & 39.9 & 2 & 10 & 19.74 & 0.00
\end{tabular}

\begin{tabular}{rrr} 
Random effect: & Variance & SD \\
\cline { 2 - 3 } time & 0.00 & 0.00 \\
residual & 2.02 & 1.42
\end{tabular}


LSM differences

\begin{tabular}{|c|c|c|c|c|c|c|c|}
\hline \multirow[b]{2}{*}{ treatment } & \multirow[b]{2}{*}{$\beta$} & \multirow[b]{2}{*}{ SE } & \multirow[b]{2}{*}{ DF } & \multirow[b]{2}{*}{$t$-value } & \multirow[b]{2}{*}{ Lower CI } & \multirow[b]{2}{*}{ Upper CI } & \multirow[b]{2}{*}{$\mathrm{p}$} \\
\hline & & & & & & & \\
\hline benthic - control & -1.20 & 0.98 & 10 & -1.27 & -3.44 & 0.94 & 0.23 \\
\hline benthic - terrestrial & -6.10 & 0.98 & 10 & -6.25 & -8.32 & -3.95 & 0.00 \\
\hline control - terrestrial & -4.90 & 1.16 & 10 & -4.21 & -7.47 & -2.30 & 0.00 \\
\hline \multicolumn{8}{|c|}{$\delta^{13} \mathrm{C}_{\mathrm{EPA}}$} \\
\hline \multirow[t]{2}{*}{ ANOVA: } & Sum Sq & Mean Sq & NumDF & DenDF & $\mathrm{F}$ & $\mathrm{p}$ & \\
\hline & 63.83 & 31.92 & 2 & 8.4448 & 22.02 & 0.00 & \\
\hline
\end{tabular}

\begin{tabular}{rrr} 
Random effect: & Variance & SD \\
\cline { 2 - 3 } time & 0.18 & 0.42
\end{tabular}

$\begin{array}{lll}\text { residual } & 1.45 & 1.20\end{array}$

\begin{tabular}{|c|c|c|c|c|c|c|c|}
\hline \multirow[b]{2}{*}{ treatment } & \multicolumn{7}{|c|}{ LSM differences } \\
\hline & $\beta$ & $\mathrm{SE}$ & DF & $t$-value & Lower CI & Upper CI & $\mathrm{p}$ \\
\hline benthic - control & -5.90 & 0.92 & 6.5 & -6.38 & -8.064 & -3.66 & 0.00 \\
\hline benthic - terrestrial & -3.10 & 0.84 & 8.7 & -3.73 & -5.015 & -1.21 & 0.01 \\
\hline control - terrestrial & 2.70 & 1.03 & 9.9 & 2.67 & 0.448 & 5.04 & 0.02 \\
\hline
\end{tabular}

\begin{tabular}{lrrrrrrr}
\multicolumn{8}{c}{$\delta^{13} \mathrm{C}_{\text {DHA }}$} \\
\hline ANOVA: & Sum Sq & Mean Sq & NumDF & DenDF & F & p \\
\cline { 2 - 8 } & 22.20 & 22.20 & 1 & 2.01 & 110.32 & 0.01
\end{tabular}

\begin{tabular}{crr} 
Random effect: & Variance & SD \\
\cline { 2 - 3 } time & 149.37 & 12.22 \\
residual & 0.20 & 0.45
\end{tabular}

\begin{tabular}{|c|c|c|c|c|c|c|c|c|}
\hline \multirow[b]{2}{*}{ treatment } & \multicolumn{8}{|c|}{ LSM differences } \\
\hline & $\beta$ & SE & DF & & $t$-value & Lower CI & Upper CI & $\mathrm{p}$ \\
\hline control - terrestrial & 5.40 & 0.52 & & 2 & 10.50 & 3.23 & 7.65 & 0.01 \\
\hline
\end{tabular}

Bulk $\delta^{13} \mathrm{C}$

\begin{tabular}{lrrrrrr}
\hline ANOVA: & Sum Sq & Mean Sq & NumDF & DenDF & F & p \\
\cline { 2 - 7 } & 104.66 & 52.33 & 2.00 & 6.00 & 9.87 & 0.01
\end{tabular}

\begin{tabular}{rrr} 
Random effect: & Variance & SD \\
\cline { 2 - 3 } time & 0.00 & 0.00
\end{tabular}

$\begin{array}{lll}\text { residual } \quad 5.30 & 2.30\end{array}$

\begin{tabular}{lrrrrrrr} 
& \multicolumn{7}{c}{ LSM differences } \\
\cline { 2 - 8 } treatment & $\beta$ & SE & DF & $t$-value & Lower CI & Upper CI & $\mathrm{p}$ \\
\hline benthic - control & -7.60 & 1.76 & 6 & -4.30 & -11.87 & -3.26 & 0.01 \\
benthic - terrestrial & -5.30 & 1.99 & 6 & -2.65 & -10.18 & -0.41 & 0.04 \\
control - terrestrial & 2.30 & 2.10 & 6 & 1.08 & -2.87 & 7.42 & 0.32 \\
\hline
\end{tabular}

(b) Muscle 


\begin{tabular}{|c|c|c|c|c|c|c|c|}
\hline \multicolumn{8}{|c|}{$\delta^{13} \mathrm{C}_{\mathrm{ALA}}$} \\
\hline \multirow[t]{2}{*}{ ANOVA: } & Sum Sq & Mean Sq & NumDF & DenDF & $\mathrm{F}$ & $\mathrm{p}$ & \\
\hline & 0.07 & 0.02 & 3.00 & 4.32 & 0.01 & 1.00 & \\
\hline Random effect: & Variance & $\mathrm{SD}$ & & & & & \\
\hline $\operatorname{tank}$ & 13.16 & 3.63 & & & & & \\
\hline \multirow[t]{3}{*}{ residual } & 1.88 & 1.37 & & & & & \\
\hline & \multicolumn{7}{|c|}{ LSM differences } \\
\hline & $\beta$ & SE & DF & $t$-value & Lower CI & Upper CI & $\mathrm{p}$ \\
\hline \multirow{2}{*}{$\begin{array}{l}\text { benthic - control } \\
\text { benthic - mixed }\end{array}$} & 0.40 & 4.59 & 4 & 0.08 & -12.01 & 12.75 & 0.90 \\
\hline & -0.20 & 3.32 & 5 & -0.07 & -8.90 & 8.45 & 0.90 \\
\hline benthic - terrestrial & -0.50 & 3.80 & 5 & -0.12 & -10.51 & 9.59 & 0.90 \\
\hline control - mixed & -0.60 & 4.13 & 4 & -0.15 & -12.00 & 10.80 & 0.90 \\
\hline control - terrestrial & -0.80 & 4.52 & 4 & -0.18 & -13.33 & 11.65 & 0.90 \\
\hline mixed - terrestrial & -0.20 & 3.22 & 4 & -0.07 & -9.02 & 8.55 & 0.90 \\
\hline \multicolumn{8}{|c|}{$\delta^{13} \mathrm{C}_{\mathrm{LIN}}$} \\
\hline \multirow[t]{2}{*}{ ANOVA: } & Sum Sq & Mean Sq & NumDF & DenDF & $\mathrm{F}$ & $\mathrm{p}$ & \\
\hline & 0.38 & 0.13 & 3.00 & 19.00 & 0.21 & 0.89 & \\
\hline \multirow{5}{*}{$\begin{array}{r}\text { Random effect: } \\
\qquad \begin{array}{r}\text { tank } \\
\text { residual }\end{array}\end{array}$} & Variance & $\mathrm{SD}$ & & & & & \\
\hline & 0.00 & 0.00 & & & & & \\
\hline & 0.60 & 0.78 & & & & & \\
\hline & \multicolumn{7}{|c|}{ LSM differences } \\
\hline & $\beta$ & SE & $\mathrm{DF}$ & $t$-value & Lower CI & Upper CI & $\mathrm{p}$ \\
\hline \multirow{6}{*}{$\begin{array}{l}\text { benthic - control } \\
\text { benthic - mixed } \\
\text { benthic - terrestrial } \\
\text { control - mixed } \\
\text { control - terrestrial } \\
\text { mixed - terrestrial }\end{array}$} & -0.50 & 0.65 & 19 & -0.72 & -1.83 & 0.89 & 0.50 \\
\hline & -0.50 & 0.60 & 19 & -0.77 & -1.72 & 0.80 & 0.50 \\
\hline & -0.40 & 0.63 & 19 & -0.71 & -1.77 & 0.88 & 0.50 \\
\hline & 0.00 & 0.42 & 19 & 0.01 & -0.88 & 0.90 & 1.00 \\
\hline & 0.00 & 0.47 & 19 & 0.04 & -0.97 & 1.00 & 1.00 \\
\hline & 0.00 & 0.40 & 19 & 0.03 & -0.83 & 0.85 & 1.00 \\
\hline \multicolumn{8}{|c|}{$\delta^{13} \mathrm{C}_{\mathrm{ARA}}$} \\
\hline \multirow[t]{2}{*}{ ANOVA: } & Sum Sq & Mean Sq & NumDF & DenDF & $\mathrm{F}$ & $\mathrm{p}$ & \\
\hline & 28.10 & 9.37 & 3.00 & 19.00 & 2.95 & 0.06 & \\
\hline \multirow[t]{4}{*}{ Random effect: } & Variance & SD & & & & & \\
\hline & 0.00 & 0.00 & & & & & \\
\hline & 3.18 & 1.78 & & & & & \\
\hline & \multicolumn{7}{|c|}{ LSM differences } \\
\hline treatment & $\beta$ & SE & DF & $t$-value & Lower CI & Upper CI & $\mathrm{p}$ \\
\hline
\end{tabular}




\begin{tabular}{lrrrrrrr} 
benthic - control & 4.30 & 1.49 & 19 & 2.87 & 1.16 & 7.40 & 0.01 \\
benthic - mixed & 3.00 & 1.38 & 19 & 2.16 & 0.09 & 5.87 & 0.04 \\
benthic - terrestrial & 2.40 & 1.46 & 19 & 1.62 & -0.69 & 5.40 & 0.12 \\
control - mixed & -1.30 & 0.98 & 19 & -1.33 & -3.35 & 0.74 & 0.20 \\
control - terrestrial & -1.90 & 1.08 & 19 & -1.78 & -4.18 & 0.34 & 0.09 \\
mixed - terrestrial & -0.60 & 0.92 & 19 & -0.67 & -2.55 & 1.31 & 0.51 \\
\hline
\end{tabular}

$\delta^{13} \mathrm{C}_{\mathrm{EPA}}$

\begin{tabular}{rrrrrrr}
\hline ANOVA: & Sum Sq & Mean Sq & NumDF & DenDF & F & p \\
\cline { 2 - 6 } Random effect: & 5.93 & 1.98 & 3.00 & 3.84 & 0.67 & 0.61 \\
tank & Variance & SD & & & & \\
residual & 2.94 & 0.87 & & & & \\
& & 1.71 & & & &
\end{tabular}

LSM differences

\begin{tabular}{|c|c|c|c|c|c|c|c|}
\hline \multirow[b]{2}{*}{ treatment } & \\
\hline & $\beta$ & SE & DF & $t$-value & Lower CI & Upper CI & $\mathrm{p}$ \\
\hline benthic - control & 1.30 & 1.79 & 5 & 0.75 & -3.30 & 5.99 & 0.50 \\
\hline benthic - mixed & 1.50 & 1.53 & 10 & 0.99 & -1.92 & 4.96 & 0.30 \\
\hline benthic - terrestrial & 0.10 & 1.65 & 8 & 0.08 & -3.70 & 3.96 & 0.90 \\
\hline control - mixed & 0.20 & 1.36 & 2 & 0.13 & -5.16 & 5.51 & 0.90 \\
\hline control - terrestrial & -1.20 & 1.49 & 2 & -0.81 & -6.97 & 4.54 & 0.50 \\
\hline mixed - terrestrial & -1.40 & 1.17 & 3 & -1.19 & -4.86 & 2.08 & 0.30 \\
\hline
\end{tabular}

$\delta^{13} \mathrm{C}_{\mathrm{DHA}}$

\begin{tabular}{rrrrrrr}
\hline ANOVA: & Sum Sq & Mean Sq & NumDF & DenDF & F & p \\
\cline { 2 - 7 } & 14.73 & 4.91 & 3.00 & 4.81 & 1.26 & 0.39
\end{tabular}

\begin{tabular}{rrr} 
Random effect: & Variance & SD \\
\cline { 2 - 3 } tank & 105.42 & 10.27 \\
residual & 3.91 & 1.98
\end{tabular} $\begin{array}{lll}\text { residual } & 3.91 & 1.98\end{array}$

\begin{tabular}{lrrrrrrr} 
& \multicolumn{7}{c}{ LSM differences } \\
\cline { 2 - 9 } treatment & \multicolumn{1}{l}{ SE } & DF & t & Lower CI & Upper CI & $\mathrm{p}$ \\
\hline benthic - control & -15.30 & 12.68 & 5 & -1.21 & -48.30 & 17.68 & 0.30 \\
benthic - mixed & -16.30 & 9.03 & 5 & -1.81 & -39.60 & 6.98 & 0.10 \\
benthic - terrestrial & -16.50 & 10.39 & 5 & -1.59 & -43.40 & 10.44 & 0.20 \\
control - mixed & -1.00 & 11.53 & 5 & -0.09 & -31.20 & 29.16 & 0.90 \\
control - terrestrial & -1.20 & 12.63 & 5 & -0.09 & -34.20 & 31.88 & 0.90 \\
mixed - terrestrial & -0.20 & 8.95 & 5 & -0.02 & -23.50 & 23.18 & 1.00 \\
\hline
\end{tabular}

Bulk $\delta^{13} \mathrm{C}$

\begin{tabular}{lrrrrrr}
\hline ANOVA: & Sum Sq & Mean Sq & NumDF & DenDF & F & p \\
\cline { 2 - 7 } & 4.71 & 1.57 & 3.00 & 16.00 & 2.53 & 0.09
\end{tabular}




\begin{tabular}{rrr} 
Random effect: & Variance & SD \\
\cline { 2 - 3 } tank & 0.00 & 0.00 \\
residual & 0.62 & 0.79
\end{tabular}

LSM differences

\begin{tabular}{lrrrrrrr} 
treatment & $\beta$ & $\mathrm{SE}$ & $\mathrm{DF}$ & $t$-value & Lower CI & Upper CI & $\mathrm{p}$ \\
\hline benthic - control & 1.80 & 0.79 & 16.00 & 2.35 & 0.18 & 3.52 & 0.03 \\
benthic - mixed & 0.90 & 0.61 & 16.00 & 1.42 & -0.43 & 2.16 & 0.17 \\
benthic - terrestrial & 0.30 & 0.64 & 16.00 & 0.52 & -1.03 & 1.70 & 0.61 \\
control - mixed & -1.00 & 0.61 & 16.00 & -1.61 & -2.28 & 0.31 & 0.13 \\
control - terrestrial & -1.50 & 0.64 & 16.00 & -2.36 & -2.88 & -0.16 & 0.03 \\
mixed - terrestrial & -0.50 & 0.41 & 16.00 & -1.32 & -1.40 & 0.33 & 0.21 \\
\hline
\end{tabular}

\section{(c) Liver}

\begin{tabular}{lrrrrrr}
\hline \multicolumn{7}{c}{$\delta^{13} \mathrm{C}_{\mathrm{ALA}}$} \\
& $\mathrm{Sum} \mathrm{Sq}$ & Mean Sq & NumDF & DenDF & $\mathrm{F}$ & $\mathrm{p}$ \\
\cline { 2 - 7 } Random effect: & 52.24 & 17.41 & 3.00 & 19.00 & 1.12 & 0.37 \\
tank & 0.00 & 0.00 & & & & \\
residual & 15.54 & 3.94 & & & &
\end{tabular}

LSM differences

\begin{tabular}{|c|c|c|c|c|c|c|c|}
\hline \multirow[b]{2}{*}{ treatment } & \\
\hline & B & SE & DF & $t$-value & Lower CI & Upper CI & $\mathrm{p}$ \\
\hline benthic - control & 5.70 & 3.30 & 19 & 1.74 & -1.15 & 12.65 & 0.10 \\
\hline benthic-mixed & 4.80 & 3.05 & 19 & 1.59 & -1.55 & 11.23 & 0.10 \\
\hline benthic - terrestrial & 3.70 & 3.22 & 19 & 1.16 & -2.99 & 10.48 & 0.30 \\
\hline control - mixed & -0.90 & 2.16 & 19 & -0.42 & -5.42 & 3.61 & 0.70 \\
\hline control - terrestrial & -2.00 & 2.39 & 19 & -0.84 & -7.00 & 2.99 & 0.40 \\
\hline mixed - terrestrial & -1.10 & 2.04 & 19 & -0.54 & -5.36 & 3.16 & 0.60 \\
\hline
\end{tabular}

\begin{tabular}{rrrrrrr}
\hline ANOVA: & Sum Sq & Mean Sq & NumDF & DenDF & F & p \\
\cline { 2 - 7 } & 12.55 & 4.18 & 3.00 & 19.00 & 5.01 & 0.01
\end{tabular}

\begin{tabular}{rrr} 
Random effect: & Variance & SD \\
\cline { 2 - 3 } tank & 0.00 & 0.00 \\
residual & 0.84 & 0.91
\end{tabular}

LSM differences

\begin{tabular}{|c|c|c|c|c|c|c|c|}
\hline \multirow[b]{2}{*}{ treatment } & \\
\hline & $\beta$ & SE & DF & $t$-value & Lower CI & Upper CI & $\mathrm{p}$ \\
\hline benthic - control & -0.90 & 0.77 & 19 & -1.13 & -2.46 & 0.74 & 0.27 \\
\hline benthic - mixed & 0.30 & 0.71 & 19 & 0.37 & -1.22 & 1.74 & 0.72 \\
\hline
\end{tabular}




\begin{tabular}{llllllll} 
benthic - terrestrial & 1.30 & 0.75 & 19 & 1.70 & -0.29 & 2.83 & 0.11 \\
control - mixed & 1.10 & 0.50 & 19 & 2.25 & 0.08 & 2.17 & 0.04 \\
control - terrestrial & 2.10 & 0.55 & 19 & 3.85 & 0.97 & 3.29 & 0.00 \\
mixed - terrestrial & 1.00 & 0.47 & 19 & 2.13 & 0.02 & 2.00 & 0.05 \\
\hline
\end{tabular}

\begin{tabular}{lrrrrrr}
\multicolumn{8}{c}{$\delta^{13} \mathrm{C}_{\mathrm{ARA}}$} \\
\hline ANOVA: & Sum Sq & Mean Sq & NumDF & DenDF & $\mathrm{F}$ & $\mathrm{p}$ \\
\cline { 2 - 7 } & 3.24 & 1.08 & 3.00 & 4.23 & 0.56 & 0.67
\end{tabular}

\begin{tabular}{rrr} 
Random effect: & Variance & SD \\
\cline { 2 - 3 } tank & 11.36 & 3.37 \\
residual & 1.91 & 1.38
\end{tabular}

LSM differences

\begin{tabular}{|c|c|c|c|c|c|c|c|}
\hline \multirow[b]{2}{*}{ treatment } & \\
\hline & $\beta$ & SE & DF & $t$-value & Lower CI & Upper CI & $\mathrm{p}$ \\
\hline benthic - control & 2.10 & 4.29 & 4 & 0.50 & -9.53 & 13.78 & 0.60 \\
\hline benthic - mixed & 3.80 & 3.11 & 5 & 1.22 & -4.36 & 11.93 & 0.30 \\
\hline benthic - terrestrial & 3.80 & 3.55 & 5 & 1.06 & -5.69 & 13.20 & 0.30 \\
\hline control - mixed & 1.70 & 3.85 & 4 & 0.43 & -9.10 & 12.42 & 0.70 \\
\hline control - terrestrial & 1.60 & 4.21 & 4 & 0.39 & -10.16 & 13.41 & 0.70 \\
\hline mixed - terrestrial & 0.00 & 3.01 & 4 & -0.01 & -8.31 & 8.25 & 1.00 \\
\hline
\end{tabular}

\begin{tabular}{rrrrrrr}
\hline ANOVA: & Sum Sq & Mean Sq & NumDF & DenDF & F & p \\
\cline { 2 - 7 } & 10.94 & 3.65 & 3.00 & 3.35 & 0.65 & 0.63
\end{tabular}

\begin{tabular}{rrr} 
Random effect: & Variance & SD \\
\cline { 2 - 3 } tank & 1.05 & 1.02 \\
residual & 5.58 & 2.36
\end{tabular}

LSM differences

\begin{tabular}{lrrrrrrr}
\cline { 2 - 8 } treatment & \multicolumn{1}{c}{$\mathrm{SE}$} & $\mathrm{DF}$ & & $t$-value & Lower CI & Upper CI & $\mathrm{p}$ \\
\hline benthic - control & -1.40 & 2.34 & 5 & -0.59 & -7.52 & 4.77 & 0.60 \\
benthic - mixed & 0.80 & 2.04 & 10 & 0.42 & -3.70 & 5.40 & 0.70 \\
benthic - terrestrial & -0.60 & 2.18 & 8 & -0.26 & -5.63 & 4.48 & 0.80 \\
control - mixed & 2.20 & 1.73 & 2 & 1.28 & -5.73 & 10.18 & 0.30 \\
control - terrestrial & 0.80 & 1.90 & 2 & 0.42 & -7.67 & 9.28 & 0.70 \\
mixed - terrestrial & -1.40 & 1.52 & 3 & -0.94 & -6.14 & 3.30 & 0.40 \\
\hline
\end{tabular}

\begin{tabular}{lrrrrrr}
\hline \multicolumn{7}{c}{$\delta^{13} \mathrm{C}_{\text {DHA }}$} \\
\hline \multirow{2}{*}{ ANOVA: } & Sum Sq & Mean Sq & NumDF & DenDF & F & p \\
\cline { 2 - 7 } Random effect: & 19.51 & 6.50 & 3.00 & 4.69 & 1.94 & 0.25 \\
& Variance & SD & & & & \\
\cline { 2 - 4 } & 46.29 & 6.80 & & & &
\end{tabular}


residual $\quad 3.36 \quad 1.83$

LSM differences

\begin{tabular}{|c|c|c|c|c|c|c|c|}
\hline \multirow[b]{2}{*}{ treatment } & \\
\hline & B & SE & DF & $t$-value & Lower CI & Upper CI & $\mathrm{p}$ \\
\hline benthic - control & -15.40 & 8.47 & 5 & -1.81 & -37.60 & 6.87 & 0.10 \\
\hline benthic - mixed & -12.50 & 6.06 & 5 & -2.05 & -28.10 & 3.21 & 0.10 \\
\hline benthic - terrestrial & -14.10 & 6.97 & 5 & -2.02 & -32.20 & 4.05 & 0.10 \\
\hline control - mixed & 2.90 & 7.67 & 5 & 0.38 & -17.40 & 23.26 & 0.70 \\
\hline control - terrestrial & 1.30 & 8.41 & 5 & 0.15 & -21.00 & 23.60 & 0.90 \\
\hline mixed - terrestrial & -1.60 & 5.97 & 5 & -0.27 & -17.40 & 14.13 & 0.80 \\
\hline \multicolumn{8}{|c|}{ Bulk $\delta^{13} \mathrm{C}$} \\
\hline \multirow[t]{2}{*}{ ANOVA: } & Sum Sq & Mean Sq & NumDF & DenDF & $\mathrm{F}$ & $\mathrm{p}$ & \\
\hline & 3.66 & 1.22 & 3.00 & 5.14 & 1.65 & 0.29 & \\
\hline \multirow{4}{*}{$\begin{array}{l}\text { Random effect: } \\
\text { tank } \\
\text { residual }\end{array}$} & Variance & SD & & & & & \\
\hline & 0.34 & 0.58 & & & & & \\
\hline & 0.74 & 0.86 & & & & & \\
\hline & \multicolumn{7}{|c|}{ LSM differences } \\
\hline treatment & $\beta$ & SE & DF & $t$-value & Lower CI & Upper CI & $\mathrm{p}$ \\
\hline benthic - control & -1.20 & 1.02 & 5.80 & -1.19 & -3.71 & 1.30 & 0.28 \\
\hline benthic - mixed & -1.50 & 0.84 & 9.80 & -1.75 & -3.34 & 0.41 & 0.11 \\
\hline benthic - terrestrial & -2.00 & 0.92 & 8.20 & -2.19 & -4.10 & 0.10 & 0.06 \\
\hline control - mixed & -0.30 & 0.81 & 3.40 & -0.32 & -2.69 & 2.16 & 0.76 \\
\hline control - terrestrial & -0.80 & 0.89 & 3.40 & -0.90 & -3.45 & 1.85 & 0.43 \\
\hline mixed - terrestrial & -0.50 & 0.68 & 4.60 & -0.79 & -2.33 & 1.25 & 0.47 \\
\hline
\end{tabular}




\title{
Appendix C \\ Supporting tables and figures for Chapter 4
}

Figure C1. Questionnaire and informed consent form

\author{
Portland State University \\ National Park Ecology Survey
}

\begin{abstract}
We are interested in learning about what motivates you to recreate in the national park, your knowledge about park ecosystems, and your values and beliefs regarding mountain ecosystems and recreational fishing. We think this information is important to help with communication of conservation information and to strengthen management programs focused on the health of mountain ecosystems; specifically, mountain lakes. Please feel free to ask any questions you have while taking this survey.
\end{abstract}

\section{Part 1}

Demographic information

Zip/postal code of current residence:

Country of residence:

Year born:

Gender (circle one):

Male

Female

Prefer not to answer/other

Race/ethnicity (select all that apply):

Caucasian/white

Hispanic/Latino

African American/black

Native American or American Indian

\section{Asian/Pacific Islander}

Other:

Prefer not to answer

Level of education:
Some high school
Some college
Master's degree
High school diploma/ GED
Bachelor's degree
Doctorate degree

Personal income bracket:
$<\$ 25,000$
$\$ 75,000-\$ 99,999$
Prefer not to answer
$\$ 25,000-\$ 49,999$
$\$ 100,000-\$ 149,999$
$\$ 50,000-\$ 74,999$
$\$ 150,000$ or higher 


\section{Part 2}

1. Are any of these activities the reason for your visit?

Check yes or no

- Overnight trip

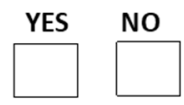

- Day trip

- Hiking

- Sight-seeing/ scenic drives

- Camping

- Backpacking

- Swimming
- Fishing

- Photography and/or art

- Picnicking

- Cycling

- Climbing

- Other:
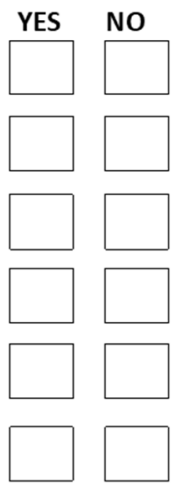

2. How would you rate your knowledge regarding the following aspects of park ecology?

- Forests and alpine plants

- Streams and lakes

- Geologic formations

- Park management policies

- Aquatic animals (fish, amphibians, invertebrates)
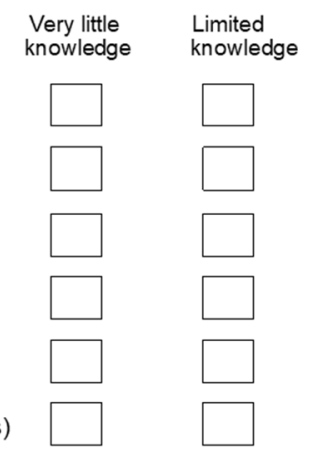

Average
knowledge

More than average Very

$\square$

kery

Glaciers

- Biodiversity

- Nutrient cycling
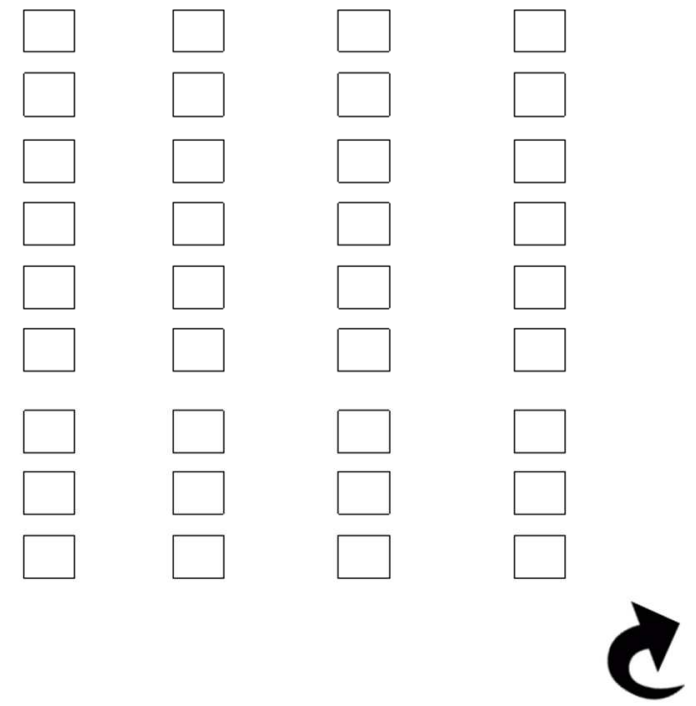
How much do you agree or disagree with the following statements?

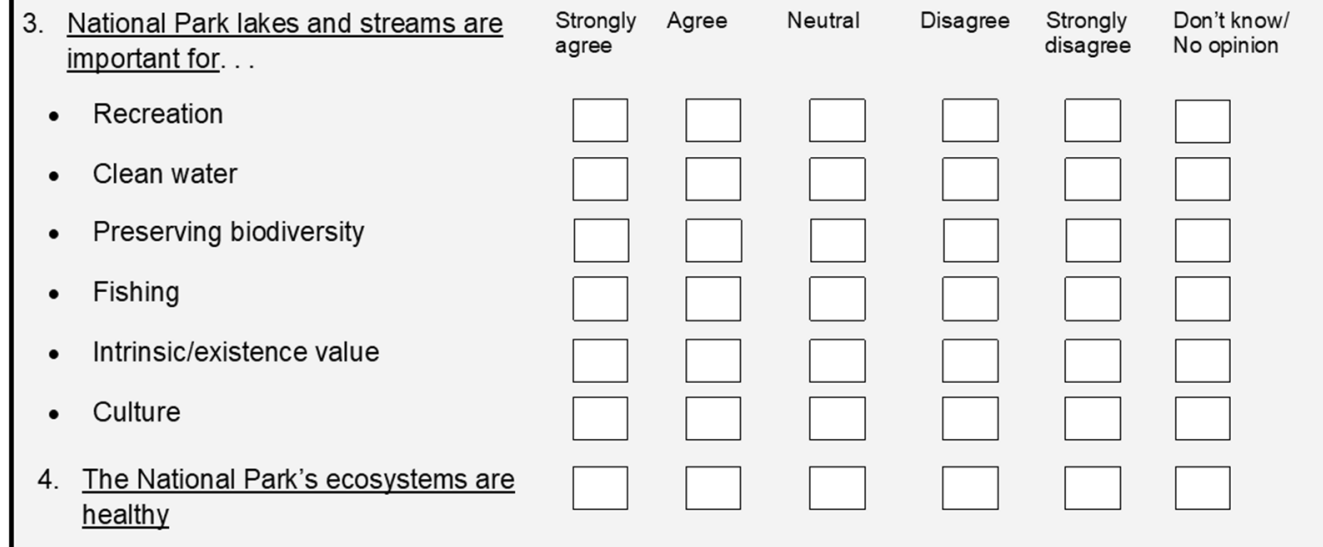

5. Do you feel the following are threats to the health of the park's ecosystems?

- Climate change

- Biodiversity loss

- Air pollution

- Water pollution

- Visitor use

- Non-native/introduced species

- Resource extraction/harvesting

6. Rate the urgency of addressing the above threats:

- Climate change

- Biodiversity loss

- Air pollution

- Water pollution

- Visitor use

- Non-native/introduced species

- Resource extraction/harvesting
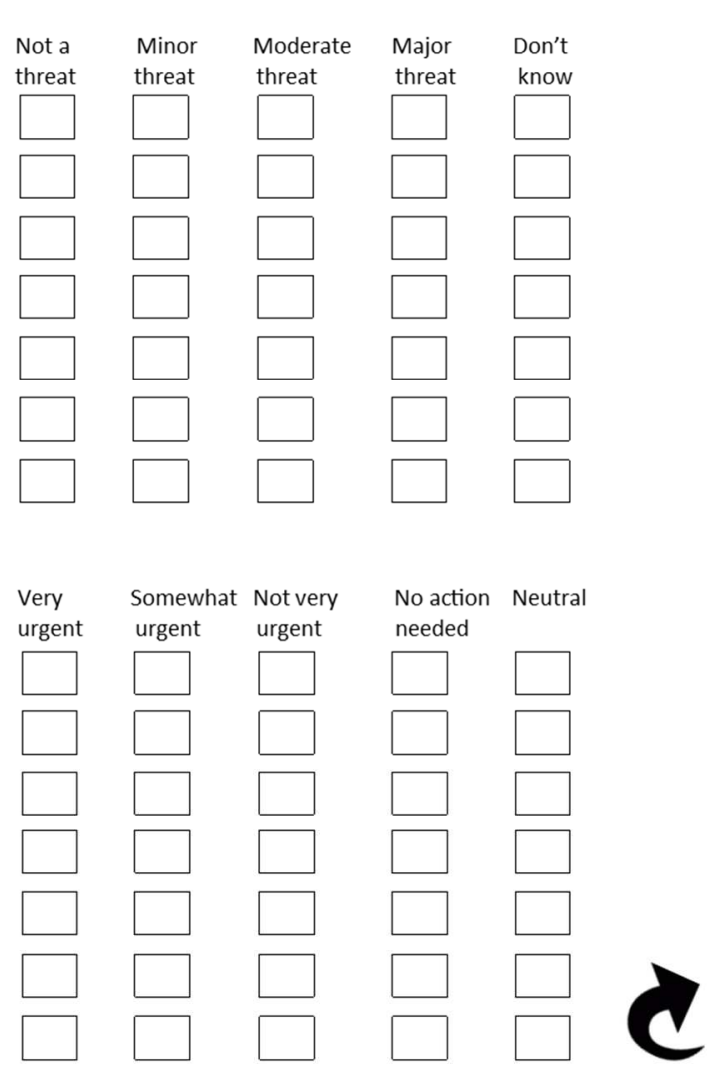
7. Did you know that the mountain lakes in the National Park did not historically have fish in them, but have been stocked with various trout species?

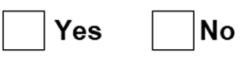

8. How much do you agree or disagree with each statement?

Stocking mountain lakes in the park with fish...

- is important for recreation

- adds value to the lakes

- benefits the other species in the lakes

- doesn't have any effect on the lake ecosystem

- has a negative effect on other species in the lake

9. Do you ever read educational displays in visitor centers or on signs throughout the park?
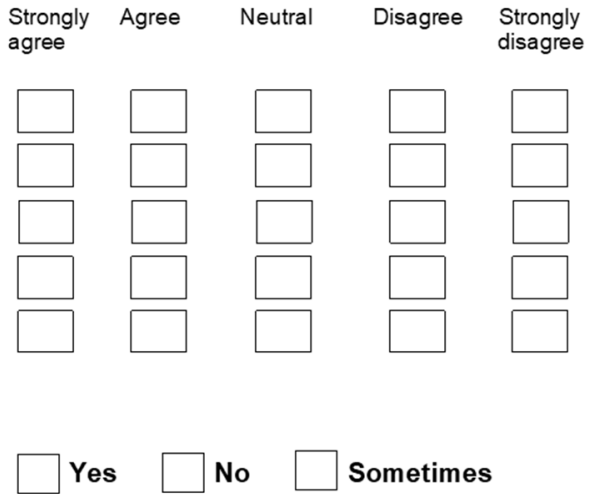

10. Are you a member of, or actively involved with, any environmental, recreational, or natural resourcefocused groups? List any you think apply.

Some examples include:

Mazamas, Hi-Lakers, North Cascades Institute, Washington Wild, Sierra Club, Trout Unlimited.

11. Have you ever fished in this park, or in other National Parks or public lands (e.g. National Forest)?

$$
\square \text { Yes } \square \text { No }
$$

If no, is this an activity that you have interest in for future visits?

$\square$ Yes $\square$ No $\square$ Not sure

12. Would you consider the fish from this National Park to be safer to eat than one (of the same species):

- Purchased at a $\square$ Yes $\square$ No $\square$ Not sure grocery store?

- Caught from a $\square$ Yes $\square$ No $\square$ Not sure lowland water body?

- From the ocean? $\square$ Yes $\square$ No $\square$ Not sure 
Please read the following statement and then answer the questions below:

Mountain lakes were historically fishless. Stocking of mountain lakes began at the turn of the $20^{\text {th }}$ century to encourage public support of conservation. Scientists at the park have begun to understand that stocking fish in mountain lakes can have a detrimental effect on the rest of the mountain lake ecosystem. Research has shown that fish can negatively impact the biodiversity of some of the lakes. Specifically, fish are associated with declines in amphibians (frogs and salamanders), invertebrate animals (insects and zooplankton), and even alpine birds. In response, the park has started to intentionally remove fish from some lakes using gill nets and a piscicide (fish killer) called rotenone, which is plantbased and quickly disintegrates after treatment, meaning it will not harm humans who visit the lake).

13. Please indicate how much you agree or disagree with each statement:

Strongly Agree Neutral Disagree Strongly agree disagree

- The concerns regarding fish stocking are legitimate.

- Action should be taken to alleviate the effects of fish on all mountain lake ecosystems.

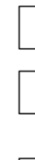

Removing fish is an appropriate approach to restoring mountain lake ecosystems.

- The benefits of stocking fish outweigh the ecological consequences.

- Fish add value to all mountain lake ecosystems, despite any potential concerns.

- People are keep blowing environmental issues out of proportion and fish stocking is just another example.

- Stocking programs should be reinstated.

- Some lakes should be designated for fishing and some for pristine nature.

- Removing fish from some lakes will increase visitor pressure on lakes that still have fish.

- I think removing fish from the lakes may be just as harmful as keeping fish in the lakes.

- I think fish should be removed, but only using manual methods (gill nets, angling), as opposed to chemicals.

- I don't have an opinion about this.

- I still don't know enough about the issue to have an informed opinion

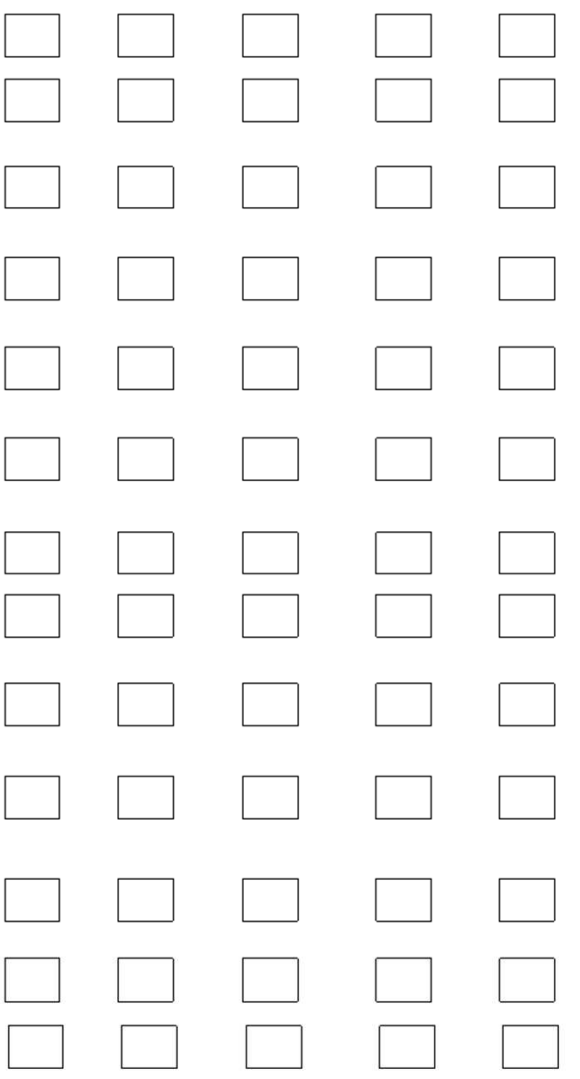

This marks the end of the survey for those who have never fished in National Parks or on other public lands. Please return this survey to the researcher. Otherwise, continue to the next page. 
If you have fished in this park, or on other public lands, please answer the following questions:

14. Have you fished in any of the following places in this park?

- Lowland reservoirs and lakes

- Streams/rivers

- Mountain lakes

(high elevation, usually accessed by trail)

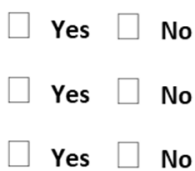

15. How often/how frequently have you visited the park for the purpose of fishing? Select one response.
Just once
$\square$ 10+ times
$1-5$ times
$\square$ More than I can count
5-10 times
$\square$ Don't know/don't remember

16. For how many years have you been fishing here, or at other National Parks or public lands?

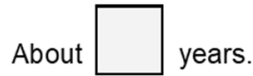

17. How important are the following when you consider where to fish?

- Lakes that are popular for fishing

- Lakes with high fish density/where I think I'll catch the most

- Lakes that are easily accessed

- Reservoirs/large lakes

- Lakes that are far away

- Lakes that are pristine

- Lakes with the least number of people

- Lakes that are most scenic/have the best view

- Other:

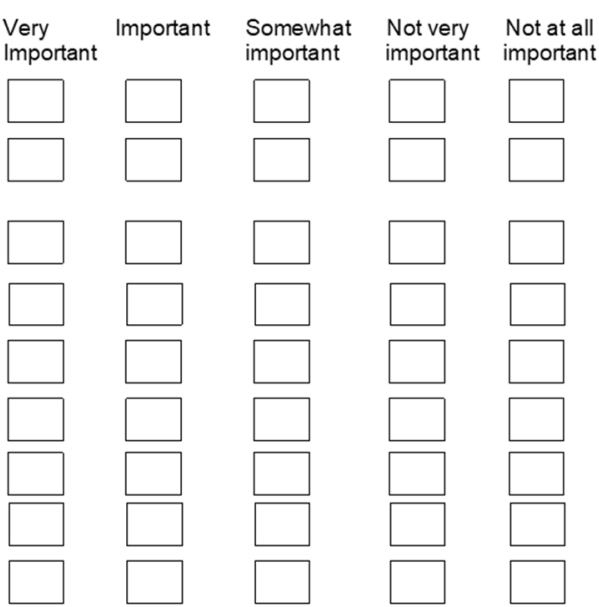

18. Have you ever consumed the fish you catch from mountain lakes in the National Park?

$$
\square \text { Yes } \square \text { No }
$$

19. If so, on how many occasions do you consume fish each year, on average?

$\begin{array}{lll}\text { Just once } & \square \text { 5-10 } & \square \text { Don't know/don't remember } \\ 1-5 \text { times } & \square>10 & \square \text { Never }\end{array}$

This marks the end of the survey, please return the survey to the researcher. 


\section{Informed Consent}

You are invited to participate in a research study conducted by Professors Angela Strecker and PhD student Ariana Chiapella from Portland State University, Department of Environmental Science and Management. These researchers hope to learn about how much you know about park ecosystems, and how you feel about the park's management policies regarding mountain lake management.

You must be at least 18 years of age to participate. If you decide to participate, you will be given a paper survey to fill out, which will take about 5-10 minutes. While participating in this study, it is possible that you will feel some embarrassment or discomfort, at which point you may leave answers blank, return the survey, and/or request that your response not be used. The information gathered from this survey will in no way put you at any legal or civil risk. You may not receive any direct benefit from taking part in this study, but the study may help to increase knowledge which may help others in the future.

Any information that is obtained in connection with this study and that can be linked to you or identify you will be kept private and will not be shared. This information will be kept private by storage at Portland State University in a password-protected computer file. Paper copies will be kept in a locked filing cabinet. Data from this study will be shared with the National Parks Service, and published in a peer-reviewed public journal.

Your participation is voluntary. You do not have to take part in this study and you may withdraw from this study at any time.

If you have questions or concerns about your participation in this study, contact Angela Strecker (strecker@pdx.edu, 503-725-2427) at PO Box 751, Portland State University, Portland OR 97201. If you have concerns about your rights as a research subject, please contact Human Subjects Research Review Committee, Research and Strategic Partnerships, PO Box 751, Portland State University, Portland OR 97201 (hsrrc@lists.pdx.edu, 1-877-480-4400).

Please indicate to the researcher that you have read and understand the above information, that you meet the age requirement (18 years or older), and agree to take part in this study. The researcher will provide you with a copy of this form for your own records. 
Figure C2. Scree plot for group of responses to: "How would you rate your knowledge of..." Parallel analysis suggested using three factors. Based on the scree plot and eigenvalues, we selected to use one.

\section{scree plot}

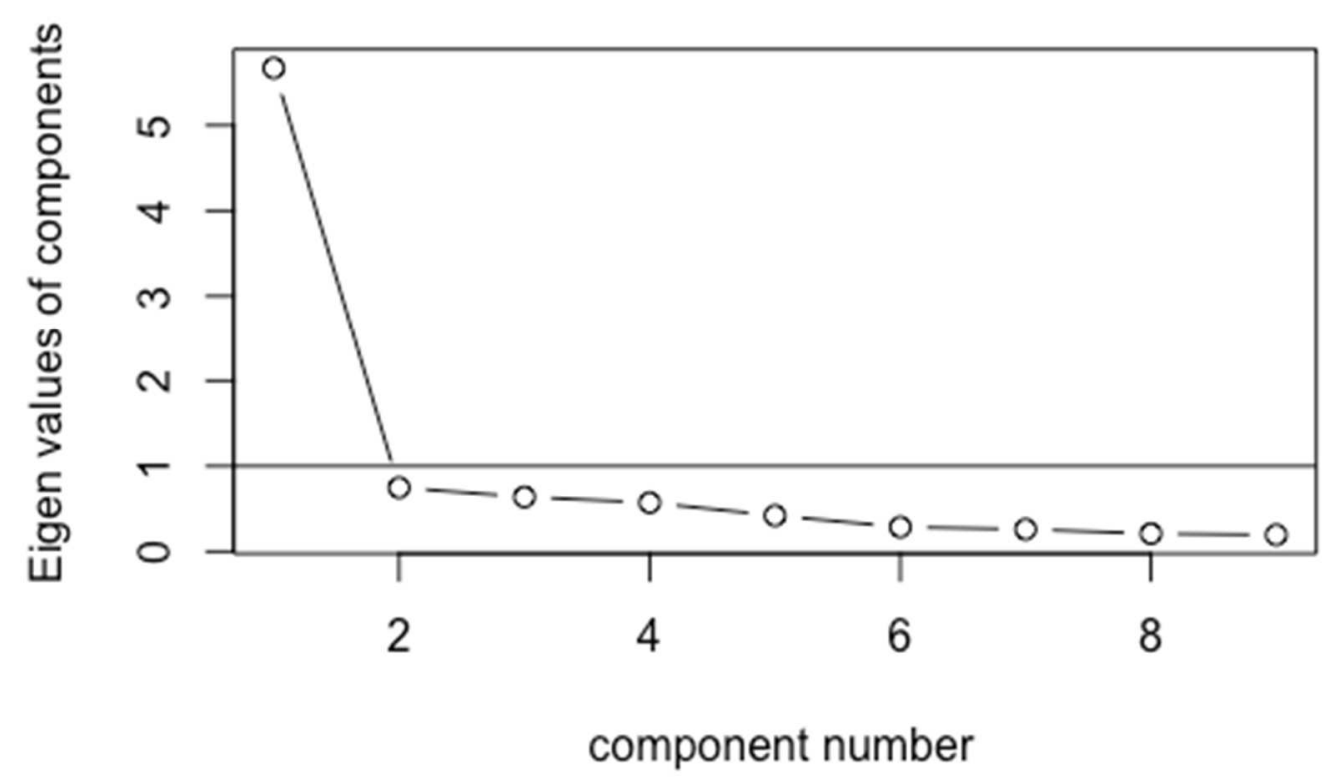


Figure C3. Scree plot for group of responses to: "National park lakes and streams are important for..." Parallel analysis suggested using three factors. We selected to use three factors, as all eigenvalues were $>1$ and percent variance explained by each factors was $>5 \%$.

\section{scree plot}

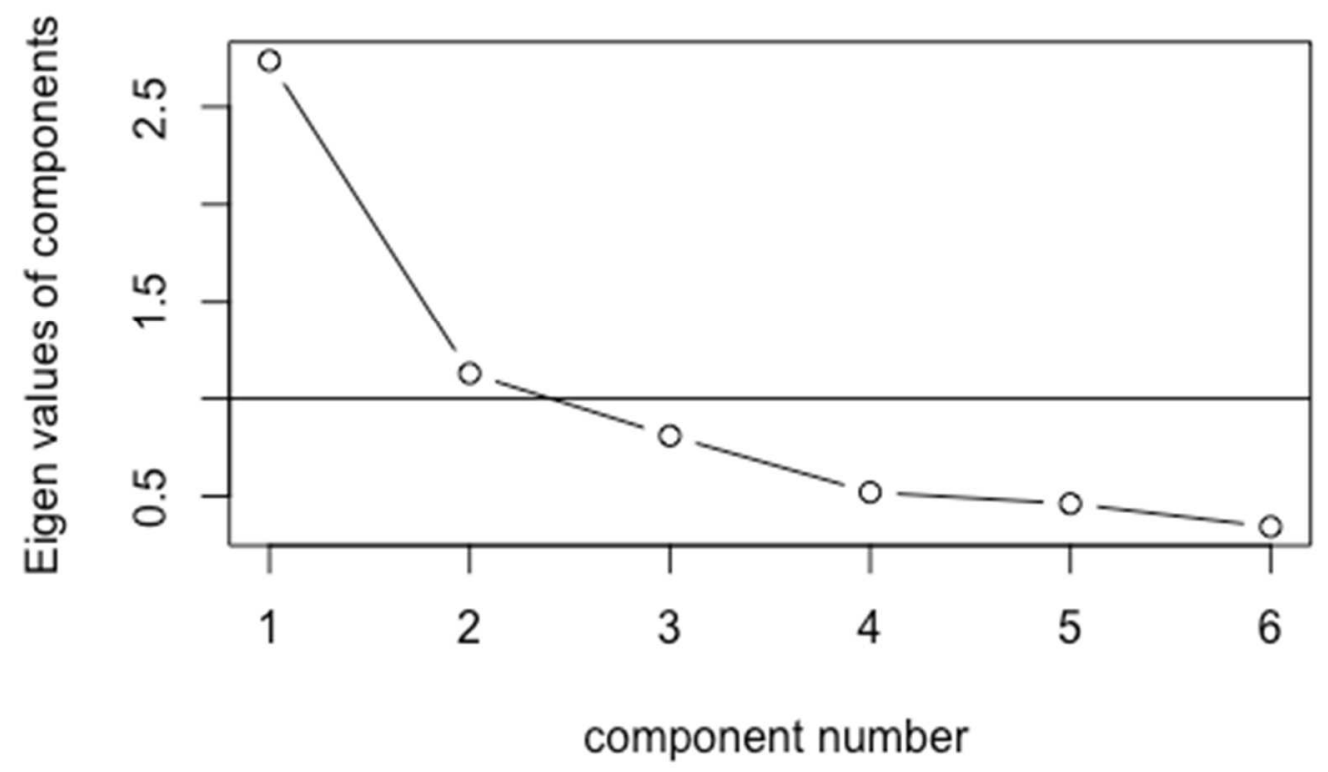


Figure C4. Scree plot for group of responses to mountain lake fisheries management attitude statements. Parallel analysis suggested using four factors. We selected to use four factors, as all eigenvalues were $>1$ and percent variance explained by each factors was $>5 \%$.

\section{scree plot}

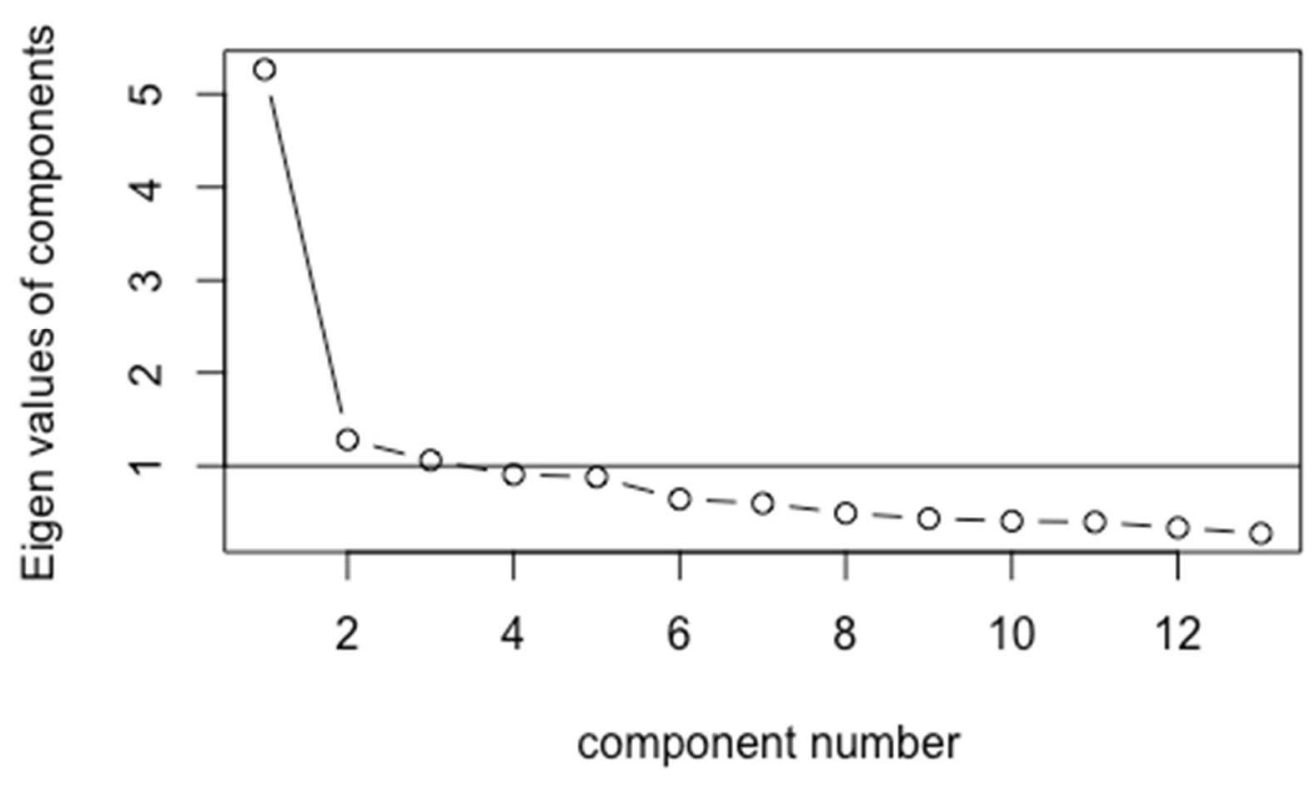


Table C1. Factor and factor loadings from exploratory factor analysis for selfranked knowledge of park ecosystems.

\begin{tabular}{lc}
\hline $\begin{array}{l}\text { "Rank your knowledge } \\
\text { of..." }\end{array}$ & $\begin{array}{c}\text { Ecological } \\
\text { knowledge } \\
\text { Factor } 1\end{array}$ \\
\hline Mammals and birds & 0.81 \\
Forests and alpine plants & 0.87 \\
Streams and lakes & 0.86 \\
Geologic formations & 0.75 \\
Park management & 0.56 \\
Aquatic animals & 0.70 \\
Glaciers & 0.77 \\
Biodiversity & 0.81 \\
Nutrient cycling & 0.70 \\
\hline Eigenvalue & 5.28 \\
Percent Variance & 0.59 \\
Explained & 0.93 \\
Cronbach's $\alpha$ & 1.87 \\
\hline Mean index score &
\end{tabular}




\title{
Appendix D
}

Institutional Review Board approval

\section{舟 Portland State}

\author{
Post Office Box $751 \quad 503-725-2227$ tel \\ Portland, Oregon 97207-0751 503-725-8170 fax \\ Human Subjects Research Review Committee \\ hsrrc@pdx.edu
}

Date: July 28,2016

To: Angela Strecker

From: Karen Cellarius, HSRRC Chair

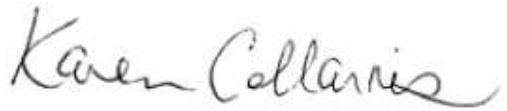

Re: HSRRC approval for your project titled, "Assessment of visitor knowledge, values and opinions regarding stocking and mountain lake management" HSRRC Proposal \# 163799

Review Type: Exempt, Category 2

The amendment submitted on 07/07/2016 to the above protocol has been reviewed by the Portland State University Institutional Review Board and the Office of Research Integrity. This is a minimal risk research protocol that continues to qualify for an exemption from IRB review under 45 CFR 46. 101(b)(2) for research involving the use of educational tests (cognitive, diagnostic, aptitude, achievement), survey procedures, interview procedures or observation of public behavior.

Please note that you will not be required to submit continuing reviews for this protocol, however, you must submit any changes to the protocol to the Office of Research Integrity for assessment to verify that the protocol continues to qualify for exemption.

Your responsibility as a Principal Investigator also includes:

- Obtaining written documentation of the appropriate permissions from public school districts, institutions, agencies, or other organizations, etc., prior to conducting your research

- Notifying the Office of Research Integrity of any change in Principal Investigator

- Notifying the Office of Research Integrity of any changes to or supplemental funding

- Notifying the Office of Research Integrity within 5 days of any unexpected events

- Retaining copies of this determination, any signed consent forms, and related research materials for three years after conclusion of your study or the closure of your sponsored research, whichever comes last.

As with all Human Subject Research, exempt research is subject to periodic Post Approval Monitoring review.

If you have any questions regarding your protocol or the review process, please contact the Office of Research Integrity at HSRRC@pdx.edu or (503)725-2227.

Approved: $\quad$ Survey version 07/07/2016. 


\section{Appendix E}

Institutional Animal Care and Use Committee (IACUC) permit

\section{\& Portland State}

\section{PSU-IACUC}

\section{Protocol Approval}

To: $\quad$ Angela Strecker, Biology

Re: Protocol \#36, entitled, "Ecology of Fish Communities in Waterbodies of the North Cascades, Mount Rainier, and Olympic National Parks, Washington"

Date: August 7, 2015

The protocol entitled, "Ecology of Fish Communities in Waterbodies of the North Cascades, Mount Rainier, and Olympic National Parks, Washington" submitted to the Portland State University IACUC for review on July 20, 2015 has been reviewed by and found to meet all applicable standards for the care and use of vertebrate animals, using the guidelines described in the Guide for the Care and Use of Laboratory Animals and USDA requirements for USDA covered species, as applicable.

Please note: A copy of the approved National Parks Service permit needs to be provided to the Office of Research Integrity once it is obtained.

As per your submitted materials, this project may be conducted for a period of three years. This approval will expire on August 6, 2018.

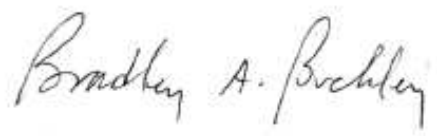

Dr. Brad Buckley

Associate Professor of Biology, PSU

Chair, IACUC

cC: RSPRecords 